\title{
Methodische Untersuchungen zum \\ Einsatz der Nahinfrarot-Spektroskopie (NIRS) zur \\ Qualitätsbeurteilung von High-Oleic-Sonnenblumen
}

\author{
Dissertation \\ zur Erlangung des Doktorgrades \\ der Fakultät für Agrarwissenschaften \\ der Georg-August-Universität Göttingen
}

\author{
vorgelegt von \\ Christian R. Moschner \\ geboren in Braunschweig
}

Göttingen, im Juli 2007 
D 7

1. Referent: Prof. Dr. Heiko C. Becker

2. Korreferentin Prof. Dr. Elke Pawelzik

Tag der mündlichen Prüfung: 12. Juli 2007 
"The very first advice I received when I was learning about statistics, regression analysis, and related topics was "look at the data!" Indeed, when looked at properly, the data itself reveals more about what is going on than any amount of statistics, or computerized number crunching, or anything else you might do to the data. On the other hand, learning how to look at the data properly is a major undertaking in itself."

HOWARD MARK, 1991

"All models are wrong, but some models are very useful."

HARALD MARTENS und TORMOD N/ES, 1989 


\section{INHALTSVERZEICHNIS}

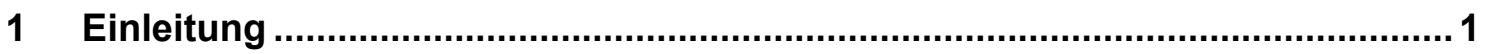

2 Grundlagen der Kalibrationsentwicklung in der Nahinfrarotspektroskopie.... 3

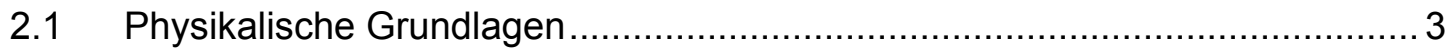

2.2 Übersicht über Gerätetypen und Messprinzipien ....................................... 3

2.3 Multivariate Verfahren in Nahinfrarotspektroskopie ..................................... 4

2.3.1 Regressionsverfahren.................................................................. 4

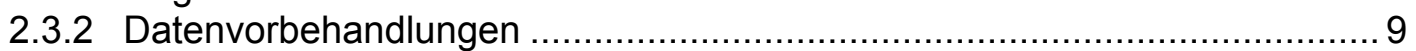

2.3.3 Statistische Parameter zur Methodenbeurteilung ................................. 10

$2.4 \quad$ Ausreißer in der Kalibrationsentwicklung ................................................ 13

3 Material und Methoden ................................................................................. 14

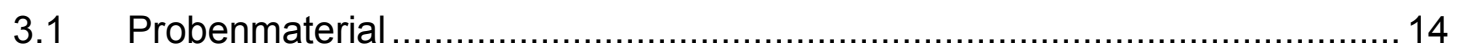

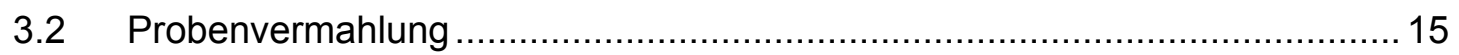

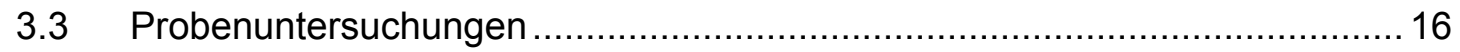

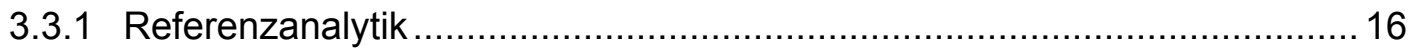

3.3.2 Nahinfrarotspektroskopische Messungen ............................................ 18

3.3.3 Erweiterung der Datenbasis hinsichtlich des Parameters Feuchte ............ 19

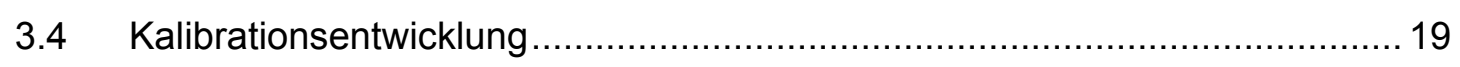

3.4.1 Zusammenstellung der Kalibrations- und Validationssets ......................... 20

3.4.2 Kalibrationsvarianten .............................................................. 23

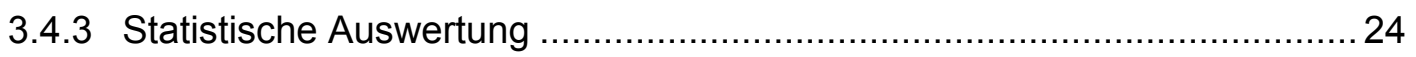

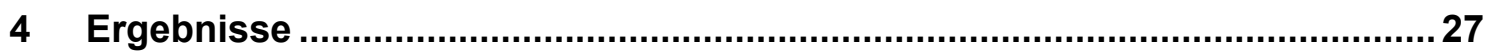

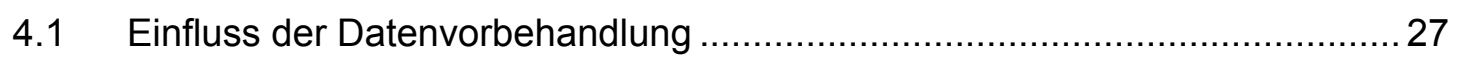

4.2 Vergleich der Vorhersageergebnisse mit den Präzisionsgrenzen amtlicher Methoden ................................................................................................. 34

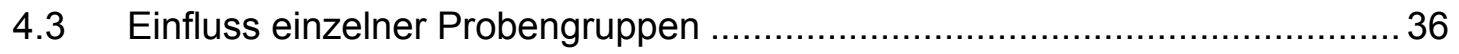

4.3.1 Einbeziehung erntefeuchter Proben ......................................................... 36

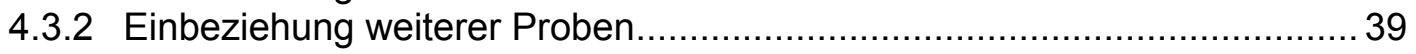

4.4 Populationsbeschreibung mit Hilfe der Faktorwerte .................................... 44 
5 Diskussion

5.1 Beurteilung der entwickelten NIRS-Methoden ..................................... 46

5.1 .1 Beurteilungskriterien .................................................................. 47

5.1.2 Vergleich der Vorhersageergebnisse mit den Präzisionsgrenzen amtlichen

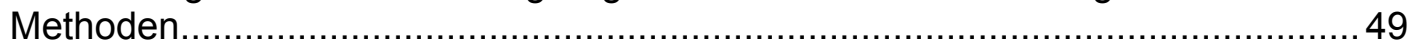

5.1.3 Vergleich der Kalibrationsmodelle mit publizierten Daten .........................50

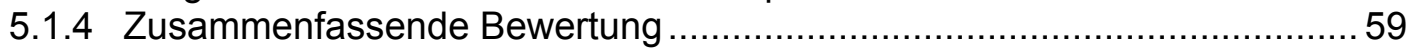

5.2 Chemometrische Verfahren zur Methodenoptimierung.............................. 60

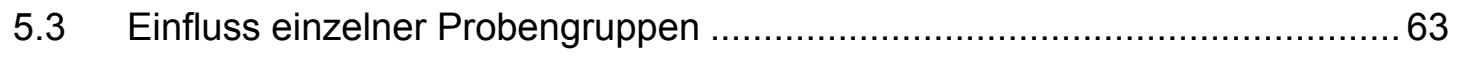

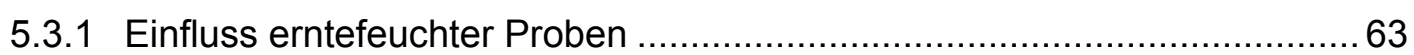

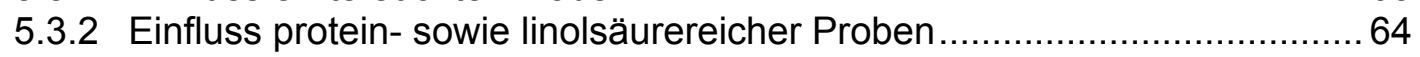

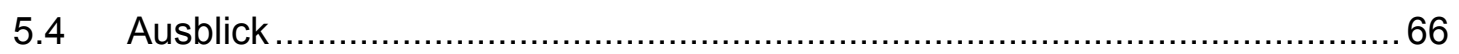

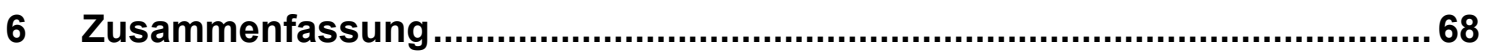

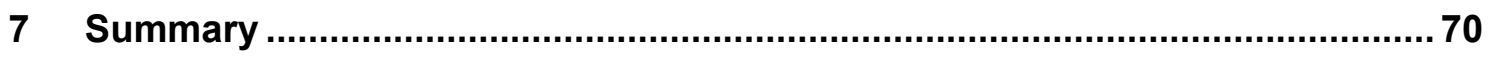

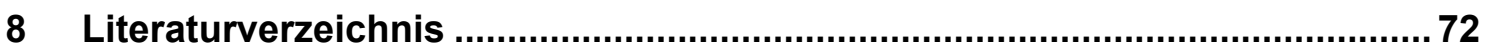

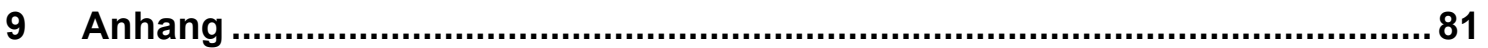




\section{TABELLENVERZEICHNIS}

Tab. 1: Charakterisierung der Leistungsfähigkeit anhand von RPD-Werten .......... 12

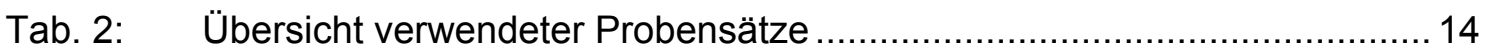

Tab. 3: Wiederholgrenzen $r_{W}$ sowie Vergleichsgrenzen $R_{V}$ amtlicher Methoden zur Qualitätsbestimmung von Sonnenblumensaat...................................... 18

Tab. 4: Zur Kalibrationsentwicklung herangezogene Datensätze ......................... 20

Tab. 5: Zusammensetzung des Kalibrations- und Validationsdatensatz für gemahlene sowie intakte Achänen ................................................. 22

Tab. 6: Zur Kalibrationsentwicklung herangezogene Daten-vorbehandlungen...... 24

Tab. 7: $\quad$ Ergebnisse der Kalibration, Kreuzvalidation und Validation bei Verwendung der Originaldaten (DT(0,0,1), keine SK) bzw. Verwendung der 1. Ableitung (DT $(1,4,4)$, SNVD) für Feuchtegehalt in gemahlenen Achänen

Tab. 8: Ergebnisse der Kalibration, Kreuzvalidation und Validation bei Verwendung der Originaldaten (DT(0,0,1), keine SK) bzw. Verwendung der 1. Ableitung (DT $(1,4,4)$, SNVD) für Linolsäuregehalt $(C 18: 2)$ in gemahlenen Achänen 28

Tab. 9: $\quad$ Ergebnisse der Kalibration, Kreuzvalidation und Validation für die Modelle mit der höchsten Vorhersageleistung (RPD) je Parameter für gemahlene (gm) und intakte Achänen (GK) bei Verwendung verschiedener Ableitungen (DT) sowie Streulichtkorrekturen (SK)

Tab. 10: Erzielte RPD-Werte unter Verwendung verschiedener Ableitungen $(n=8)$ und Streulichtkorrekturen $(n=5)$.

Tab. 11: Übersicht der varianzanalytischen Auswertung mit dem Friedman-Test sowie mit dem multiplen Anschlusstest nach Wilcoxon und Wilcox zum Einfluss verschiedener Datenvorbehandlungen auf die RPD-Werte 32

Tab. 12: Vergleich der absoluten Vorhersagedifferenzen vom Referenzwert mit den Wiederhol- sowie Vergleichgrenzen der amtlichen Methoden 34

Tab. 13: Vergleich der Vorhersageleistungen beim Vorhandensein bzw. Fehlen von erntefeuchten Proben in der Kalibrationsgleichung bzw. im Validationsset am Beispiel des Parameters Öl .

Tab. 14: Vergleich der Vorhersageleistungen beim Vorhandensein bzw. Fehlen von erntefeuchten Proben in der Kalibrationsgleichung bzw. im Validationsset am Beispiel des Parameters Ölsäure

Tab. 15: Spearman-Rangkorrelationskoeffizienten $r_{S}$ zwischen Feuchte- und Öl- bzw. Ölsauregehalt in Datensätzen mit und ohne Einbeziehung erntefeuchter Proben 
Tab. 16: Vergleich der Vorhersageleistungen beim Vorhandensein bzw. Fehlen von Proben aus den Datensätze B1 und B2 in der Kalibrationsgleichung bzw. im Validationsset am Beispiel des Parameters Protein 40

Tab. 17: Vergleich der Vorhersageleistungen beim Vorhandensein bzw. Fehlen von Proben aus den Datensätze B1 und B2 in der Kalibrationsgleichung bzw. im Validationsset am Beispiel des Parameters Ölsäure.

Tab. 18: Übersicht über publizierte Kalibrationen zur Erfassung wertgebender Inhaltsstoffe in verschiedenen Ölsaaten (NIRSystems 6500, $\lambda=1100-2500$ nm, MPLS, 2. Abl./SNV detrend). 51

Tab. 19: Übersicht über die verschiedenen Beurteilungen der entwickelten Kalibrationen anhand des RPD-Wertes, der Vergleichpräzision sowie des Literaturvergleichs 60

Tab. 20: Ergebnisse der Kalibration, Kreuzvalidation und Validation bei Verwendung verschiedener Ableitungen (DT) und Streulicht-korrekturen (SK) für die Parameter Feuchte, FFA, Öl, Protein, C16:0, C18:0, C18:1 sowie C18:2 in gemahlenen bzw. intakten HO-Achänen

Tab. 21: Ergebnisse der Kalibration, Kreuzvalidation und Validation bei Verwendung verschiedener Ableitungen (DT) und Streulichtkorrekturen (SK) für die Parameter Öl $\mathrm{LT}_{\mathrm{LT}}, \mathrm{C} 18: 1_{\mathrm{LT}}$, Protein ${ }_{\mathrm{GES}}$ sowie $18: 1_{\mathrm{GES}}$ in gemahlenen bzW. intakten Achänen 100

Tab. 22: Ergebnisse der Rangvarianzanalyse nach Friedman und multiple Vergleiche nach Wilcoxon und Wilcox zum Einfluss verschiedener Datenvorbehandlungen 108 


\section{ABBILDUNGSVERZEICHNIS}

Abb. 1: Unterschiedliche Varianten hoher und niedriger Richtigkeit sowie Präzision (nach Lohninger, 2007)

Abb. 2: Mittelwertsspektren sowie obere und untere Ausbreitung aller Spektren gemahlener HO-Achänen bei Verwendung der Originaldaten (DT(0,0,1), keine SK) bzw. Verwendung der 1. Ableitung (DT(1,4,4), SNVD) .....

Abb. 3: Validationsdiagramme und Regressionsgeraden für die Erfassung der Linolsäuregehalte (C18:2) in gemahlenen HO-Achänen unter Verwendung der Originaldaten (DT(0,0,1), keine SK) bzw. Verwendung der 1. Ableitung (DT $(1,4,4)$, SNVD)..... 29

Abb. 4: Darstellung der erzielten RPD-Werte für den Parameter Protein in gemahlenen HO-Achänen unter Verwendung verschiedener Ableitungen $(n=8)$ und Streulichtkorrekturen $(n=5)$

Abb. 5: Vergleich der Vorhersage des Ölsäuregehaltes in gemahlenen Proben mit hoher Restfeuchte beim Vorhandensein bzw. Fehlen von erntefeuchten Proben in der Kalibrationsgleichung 38

Abb. 6: Validationsdiagramme und Regressionsgeraden für die Erfassung der Ölsäuregehalte (C18:1) in gemahlenen HO-Achänen (Val bzw. Val ${ }_{\mathrm{GES}}$ ) durch die Kalibrationsgleichungen Kal bzw. Kal ${ }_{\text {GES }}$ (jeweils DT(2,4,4), MSC)

Abb. 7: Validationsdiagramme und Regressionsgeraden für die Erfassung der

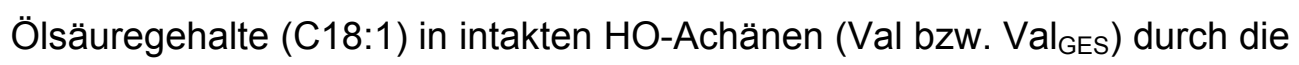
Kalibrationsgleichungen Kal bzw. Kal ${ }_{\text {GES }}$ (jeweils DT(1,4,4), SNV).

Abb. 8: Graphische Darstellung der Faktorwerte der ersten drei Hauptkomponenten spektraler Daten gemahlener Achänen des Gesamtdatensatzes unter Nutzung von SNVD sowie der ersten bzw. dritten Ableitung .... 45

Abb. 9: Fehlerquellen bzw. Einflussfaktoren auf die Güte eines Kalibrationsmodells zur Erfassung der Qualität landwirtschaftlicher Produkte (nach WILLIAMS und NORRIS, 2001)

Abb. 10: Mittelwertsspektren sowie obere und untere Ausbreitung aller Spektren gemahlener bzw. intakter HO-Achänen bei Verwendung der Ableitung DT $(0,0,1)$ sowie verschiedener Streulichtkorrekturen (keine SK, SNV, DET, MSC)

Abb. 11: Mittelwertsspektren sowie obere und untere Ausbreitung aller Spektren gemahlener bzw. intakter HO-Achänen bei Verwendung verschiedener 
Ableitungen (DT(0,0,1), DT(1,4,4), DT(2,4,4), DT(3,4,4)) sowie der Streulichtkorrektur SNVD. 82

Abb. 12: Box-Whisker-Diagramm der aus der Nutzung verschiedener Datenvorbehandlungen (8 Ableitungen; 5 Streulichtkorrekturen) erreichten RPD-Werte für gemahlene sowie intakte Achänen mit Kennzeichnung der Leistungscharakterisierung nach WILLIAMS (2001) 83 


\section{$1 \quad$ Einleitung}

Die Sonnenblume (Helianthus annuus L.) stellt die bedeutendste Ölpflanze aus der Familie der Korbblütler dar (SCHUSTER, 1992). Da gerade in der oleochemischen Industrie züchterisch „maßgeschneiderte“ Öle mit einem möglichst hohen Gehalt einer Fettsäure sehr gefragt sind, sind neben den ursprünglichen Sonnenblumentypen, die in ihrer Fettsäurezusammensetzung einen hohen Linolsäuregehalt (C18:2) aufweisen, heutzutage auch hochölsäurehaltige (HO; high-oleic) Sorten verfügbar (GRAF et al., 2000; FRIEDT und LÜHS, 2001). Pflanzenöle mit einem hohen Anteil der einfach ungesättigte Ölsäure (C18:1) weisen eine sehr gute Oxidations- sowie Temperaturstabilität auf, was wiederum die Ölstabilität positiv beeinflusst (SCHIERHOLT und BECKER, 2000). Insgesamt werden etwa 80\% der HO-Pflanzenöle im Lebensmittelbereich als Salat- bzw. Frittieröle eingesetzt (KÄB, 2001). Für die Oleochemie sind HO-Öle unter anderem auf Grund der geschilderten Stabilität von hohem Interesse und werden z.B. zur Herstellung von Schmierstoffen, Hydraulikölen, Kunststoffen, Tensiden und Kosmetika verwendet (WESTFECHTEL, 2001).

Unter den pflanzlichen Ölsäurequelle nehmen High-Oleic-Sonnenblumen mit ihrem C18:1-Gehalt im Öl von bis zu 92\% eine Spitzenposition ein. Jedoch ist der HOSonnenblumenanbau in Deutschland noch mit einigen Problemen behaftet. So gelingt in Deutschland die Produktion eines HO-Sonnenblumenöls mit mehr als 90\% Ölsäure im Öl nur bei geeigneter Sortenwahl (LÜHS und FRIEDT, 1999). Des Weiteren sind die Erträge stark von den jeweiligen Vegetationsbedingungen des Anbaujahres abhängig. Hierbei haben besonders pilzliche Schaderreger wie Botrytis cinerea (Grauschimmel, Stängel- und Korbfäule) und Sclerotinia sclerotiorum (Weißfäule) aber auch das späte Abreifeverhalten hochölsäurehaltiger Sonnenblumen unter deutschen Anbaubedingungen einen negativen Einfluss auf die Ertragsbildung sowie die Qualität des Erntegutes. (DILCl et al., 2004a). Um diese Probleme zu lösen, sind in der Literatur pflanzenzüchterische sowie pflanzenbauliche Ansätze zum Erhalt von Resistenzen (beispielsweise gegen Sclerotinia durch RÖNICKE et al., 2005), zur verbesserten Keimfähigkeit und Jugendentwicklung bei suboptimalen Temperaturen sowie zur Steigerung der Pflanzengesundheit durch den Einsatz von Flüssiginjektionsdüngungen und Resistenzinduktoren zu finden (DILCl et al., 2004b). 
Neben der Stabilisierung der Ertragssicherheit von High-Oleic-Sonnenblumen in Deutschland ist eine verlässliche Erfassung der verschiedenen Erntequalitäten unumgänglich, um eine optimal Verwertung und Wertschöpfung im food sowie nonfood Bereich zu realisieren. So bestehen in der Praxis bislang Probleme hinsichtlich Vermischung sowie falscher Deklaration von HO-Ware, was für die Erzeuger eine Gewinnreduktion und die Verarbeiter unnötige Schwierigkeiten bedeutet (BISKUPEKKORELL et al., 2003). Der Einsatz eines Refraktometers zur Unterscheidung von HOund konventionellen Sorten beinhaltet zu große Ungenauigkeiten, da sich der Brechungsindex des zu untersuchenden Öls in Abhängigkeit der Umgebungstemperatur sowie der Probenzusammensetzung verändert. Weiterhin wird die Qualität von Sonnenblumenachänen nicht nur durch das Fettsäuremuster sondern z.B. auch durch den Ölgehalt sowie der Feuchte der Saat bestimmt, da diese Faktoren die Ausbeute und die Trocknungskosten beeinflussen. Dabei sollten HOSonnenblumenachänen mindestens $44 \%$ Ölgehalt, auf Grund der Lagerfähigkeit maximal 9\% Feuchte sowie einen Ölsäureanteil von mindestens 83\% im Öl aufweisen (LÜHS und FRIEDT, 1999). Einen weiteren wichtigen Qualitätsparameter in Ölsaaten stellt der Anteil freier Fettsäuren (FFA) dar. Im Hinblick auf die Verwertung wird die Qualitätsanforderung nach Gehalten von maximal 2\% freien Fettsäuren im Rohöl der Saat gestellt, da diese bei der Raffination entfernt werden müssen, was zu einer verringerten Ölausbeute und in der Folge zu Preisabschlägen führt (BOCKISCH 1993; zitiert nach BINGEL und MARQUARD 2001). Untersuchungen durch BINGEL und MARQUARD (2001) sowie durch MOSCHNER und BISKUPEK-KORELL (2006) ergaben, dass hohe Feuchtegehalte und Beschädigungen des Erntegutes zu einem eindeutigen Anstieg des Anteils freier Fettsäuren führen. Ferner ist auch der Rohproteingehalt von Interesse, da der aus der Ölgewinnung zurückbleibende Sonnenblumensaatkuchen ein hochwertiges Eiweißfuttermittel darstellt (HAHN, 2007). Um diese Vielzahl der wertgebenden Inhaltsstoffe von HO-Sonnenblumenachänen (Feuchte-, Öl- und Proteingehalt, Fettsäurespektrum sowie Anteil freier Fettsäuren) simultan zu erfassen, bietet sich der Einsatz der Nahinfrarotspektroskopie (NIRS) an.

Ziel der vorliegenden Arbeit war die Entwicklung, Optimierung sowie die Beurteilung von chemometrischen Methoden auf Basis der Nahinfrarotspektroskopie, um hierdurch eine leistungsfähige sowie robuste Qualitätsanalytik von gemahlenen sowie intakten HO-Sonnenblumenachänen zu realisieren. 


\section{Grundlagen der Kalibrationsentwicklung in der Nahinfrarotspektroskopie}

\subsection{Physikalische Grundlagen}

Unter dem Begriff der Spektroskopie fasst man alle Methoden zusammen, bei denen Wechselwirkungen elektromagnetischer Strahlung mit Materie ausgenutzt werden. Im mittleren Infrarot (MIR; 2500 - $25000 \mathrm{~nm}$ ) kommt es zur Anregung von Molekülschwingungen, wobei im nahen Infrarot (NIR; 800 - 2500 nm) Obertöne und Kombinationsschwingungen der Grundschwingungen aus dem MIR beobachtet werden, welche im wesentlichen den $\mathrm{OH}-, \mathrm{NH}-, \mathrm{CH}-$ und CO-Funktionalitäten zugeordnet werden (RUDZIK, 1993). Diese Schwingungsvorgänge beruhen auf der Änderung des Moleküldipolmomentes im Falle, dass die wellenlängenabhängige Energie des eingestrahlten Lichtes genau der Energiedifferenz zwischen dem Grundzustand und dem jeweiligen Schwingungsniveau entspricht (WÜST und RUDZIK, 1994). Im Grundsatz gilt in der Nahinfrarotspektroskopie das Lambert-Beersche Gesetz, nachdem sich die Absorption an einer bestimmten Wellenlänge proportional zur Konzentration des jeweiligen Inhaltsstoffs verhält. $\mathrm{Da}$ NIR-Spektren von Stoffgemischen wie z.B. Agrarprodukten aus der Überlagerung von Einzelspektren einer Vielzahl meist unbekannter Inhaltsstoffe resultieren, wird in der Nahinfrarotspektroskopie eine erweiterte sowie inverse Form des Gesetzes nach Lambert-Beer angewendet (TILLMANN, 1996).

\section{2 Übersicht über Gerätetypen und Messprinzipien}

Eine Vielzahl an NIR-Spektrometern befindet sich auf dem Markt, die alle dem Grundprinzip folgen, die Wechselwirkungen zwischen der Untersuchungsprobe und dem Licht bestimmter Wellenlänge zu detektieren. MCCLURE und TSUCHIKAWA (2007) geben eine Übersicht über die von insgesamt 58 verschiedenen Herstellerfirmen hauptsächlich vertriebenen Gerätetypen. Diese Spektrometer unterscheiden sich z.B. in der Art der Lichterzeugung bestimmter Wellenlängen und lassen sich im Groben den folgenden Gruppen Dioden-, Filter-, Prisma-, Gitter-, AOTF- (acousto-optic tunable filter) sowie Fourier Transform- (FT) Spektrometer zuordnen. Ein weiterer Unterschied besteht darin, ob die Wellenlängenselektion durch bewegliche oder feste Bauteile erfolgt und ob über einen gewissen Spektralbereich oder nur an einzelnen 
Wellenlängen gemessen wird. Sollen NIR-Daten im Prozessablauf bzw. direkt auf der Erntemaschine erhoben werden, so bieten sich Geräte wie z.B. DiodenzeilenSpektrometer an, da hierbei keine beweglichen Bauteile existieren. Diese Spektrometer sind somit sehr stoßunempfindlich, können staub- und wasserdicht sowie kompakt gebaut werden und verfügen über einen für die Untersuchung von Naturprodukten idealen Wellenlängenbereich (PAUL, 2003). Seit einigen Jahren sind auch tragbare Geräte kommerziell verfügbar, um mobil qualitätsbestimmende Inhaltsstoffe z.B. von Äpfeln (TEMmA et al., 2002), Mangofrüchten (SARANWONG et al., 2003) oder Fenchelsamen (STEUER und SCHULZ, 2003), erfassen zu können.

Bei der Vielzahl an unterschiedlichen Spektrometern sind je nach möglichem Einsatzgebiet neben dem Messprinzip auch die Arten der Probenpräsentation dabei sehr verschieden. So werden Flüssigkeiten häufig in Transmission oder Transflexion vermessen, während bei Feststoffen die Analyse nach dem Reflexionsprinzip überwiegt (STORZ, 2003).

\subsection{Multivariate Verfahren in Nahinfrarotspektroskopie}

In der Nahinfrarotspektroskopie finden eine Vielzahl von Regressionsverfahren und Datentransformationen Anwendung. Diese Methoden werden häufig unter dem Begriff "Chemometrie“ zusammengefasst (GELADI und DABAKK, 1995). Hierbei werden mathematische sowie statistische Verfahren und Methoden der formalen Logik verwendet, um chemische Messverfahren zu optimieren, durchzuführen und auszuwerten sowie die maximale, relevante sowie problembezogene Information aus der Datenanalyse zu erhalten (Wüst et al., 1997; DANZER et al., 2001).

Im Folgenden werden aus der Vielzahl der in der Nahinfrarotspektroskopie eingesetzten chemometrischen Methoden diejenigen vorgestellt, die im Rahmen der vorliegenden Untersuchung oder in der anschließenden Diskussion Verwendung finden bzw. zur Verdeutlichung sowie Erklärung weiterführender Ansätze herangezogen werden.

\subsubsection{Regressionsverfahren}

Das Ziel einer Regressionsanalyse liegt darin, die relevanten Informationen zum Erhalt der resultierenden Variable, hier der quantitativen Abschätzung eines Inhaltsstoffes, herauszufinden und den funktionellen Zusammenhang so zu beschreiben, dass die Differenz zwischen der referenzanalytischen und der durch das Modell errechneten Zielgröße minimal ist (MARK und WORKMANN, 2003). 
Die Gaußsche Methode der kleinsten Fehlerquadratsummen (Least Square Method) ist Grundlage vieler Regressionsverfahren und wird z.B. in der linearen Regressionsanalyse angewendet. $\mathrm{Da}$ NIR-Spektren von landwirtschaftlichen Untersuchungsproben aus der Schwingungsüberlagerung einer Vielzahl von Einzelkomponenten resultieren, wird ein univariates Vorgehen, wie es beispielsweise beim Korrelieren der Absorptionshöhe an einer Wellenlänge zur Konzentration des gesuchten Inhaltsstoffes vorliegt, meist zu keiner optimalen Modellfunktion führen (CONZEN, 2001). Daher werden in der NIR-Spektroskopie multivariate Analysenmethoden, wie z.B. die Multiple Lineare Regression (MLR), verwendet.

Bei der MLR werden hauptsächlich die zwei Verfahren step up und step wise verwendet. Bei der Variante step up werden die Wellenlängen herausgesucht, deren Absorptionswerte mit der Inhaltsstoffkonzentration am höchsten korrelieren. Die hierbei „beste“ Variable wird festgehalten und die nächst beste gesucht, usw. Bei der step wise Variante hingegen wird vor Hinzunahme einer neuen Wellenlänge geprüft, ob eine bislang festgehaltene nicht durch eine neue, nun „bessere“ Variable ersetzt werden kann. Sobald eine zusätzlich aufgenommene Wellenlänge zu keiner signifikanten Verbesserung der Schätzfunktion führt (F-Wert), wird das Verfahren beendet (TILLMANN, 1996). In NIR-Spektren sind die Absorptionshöhen benachbarter Wellenlängen häufig miteinander korreliert. Diese als Multikollinearität bezeichnete Eigenschaft verletzt zum einem die Annahme von unabhängigen, erklärenden Variablen, zum andern sind in der Folge die bei der MLR ermittelten Regressionskoeffizienten mit starken Fehlern behaftet (MARTENS und NAES, 1989). Um Bereiche mit Multikollinearität zu entdecken, sind Methoden zur Berechnung verschiedener Maßzahlen, wie z.B. variance inflation factor und condition number, entwickelt worden (NAES et al., 2002).

Zur Umgehung des Multikollinearitätsproblems wird häufig eine Faktorisierung der Datenmatrix vorgenommen (DANZER et al., 2001). Bei der Zerlegung in Faktoren bzw. Hauptkomponenten (Principal Component, PC) wird zuerst eine Hauptachsentransformation durchgeführt. Bei der anschließenden Hauptkomponentenanalyse (PCA; Principal Component Analysis) charakterisiert der erste Faktor (PC1) den größten Teil der spektralen Varianz und stellt die neue Hauptsachse dar. Die folgenden Faktoren beschreiben den jeweils verbleibenden Anteil der Restvarianz (DANZER et al., 2001). Die Lage der neuen Achsen wird durch die sog. Faktorladungen (loadings) beschrieben (P-Matrix), während die Lage der Datenpunkte durch die sog. Faktorwerte (scores) charakterisiert wird (T-Matrix). Mit 
Hilfe dieser Score-Werte kann z.B. eine graphische Populationsbeschreibung ${ }^{1}$ erfolgen. Des Weiteren wird bei der Faktorzerlegung eine Komprimierung der Spektrendaten auf das Wesentliche erreicht, da hochkorrelierte Wellenlängen zu einem Faktor zusammengefasst werden, wobei die Faktoren Linearkombinationen aus den NIR-Daten darstellen, untereinander unkorreliert und orthogonal ausgerichtet sind (MARTENS und NAES, 1989; TILLMANN, 1996; NAES et al., 2002).

Wird nun die Kalibrationsentwicklung nicht im Wellenlängenraum sondern im Raum der Hauptkomponenten durchgeführt, spricht man von Principal Component Regression (PCR), die analog zur MLR abläuft (DANZER et al., 2001).

Während bei der PCR die Ausrichtung der Koordinaten in Richtung der maximalen spektralen Varianz erfolgt, wird bei der Zerlegung nach PLS-Faktoren (Partial Least Square) auch die Varianz des betreffenden Inhaltsstoffes herangezogen. Somit findet bei der PLS-Regression die Ausrichtung der neuen Achsen in Richtung der maximalen Kovarianz zwischen den spektralen und referenzanalytischen Daten statt (SJÖSTRÖM et al. 1983; NAES et al., 2002). Bei diesem Konzept wird davon ausgegangen, dass eine Veränderung in der Inhaltsstoffkonzentration auch eine Veränderung der zugehörigen Spektren zur Folge hat (CONZEN, 2001). Seit Mitte der 80er Jahre fand die PLSMethode zunehmend Anwendung z.B. in der NIR-Spektroskopie und stell heute in mannigfachen Wissenschaftsbereichen zur Analyse multivariater Datensätze das vorherrschende Regressionsverfahren dar (KESSLER, 2007).

In dieser Arbeit wird zur Kalibrationsentwicklung ein abgewandelter PLS-Algorithmus, nämlich MPLS (Modified Partial Least Square), herangezogen. Die Modifizierung besteht darin, dass im Rahmen der MPLS-Regression die spektralen Daten an jeder Wellenlänge so skaliert werden, dass sie eine Standardabweichung von 1,0 aufweisen (SHENK und WESTERHAUS, 1991a). Innerhalb der Software WinISI II v1.60 (Infrasoft International LLC.) kann bei den MPLS-Verfahren zwischen einer Einzelprobenkalibration (LOCAL) und einer „globalen“ Kalibration unterschieden werden. Bei einer „Iokalen“ Kalibration wird ein zur Probe maßgeschneiderter Teil der Kalibrationsproben verwendet, während bei einer "globalen“ Kalibration der Gesamtdatensatz in die Modellentwicklung einfließt, um durch die Nutzung vielfältigster Eigenschaften und Inhaltsstoffkonzentrationen robuste Kalibrationen zu erhalten (DILLER, 2002).

\footnotetext{
1 "So say 'seven hundred variables' and think three dimensions" (DAVIES und FEARN, 2004)
} 
Durch den Einsatz einer sog. R-Datei (repeatability file) können ungewollte Einflüsse auf die Vorhersageleistung des Kalibrationsmodells wie z.B. Temperaturschwankungen und Geräteunterschiede vermindert werden. Hierfür sind in der R-Datei Spektren mit einem variierenden Anteil der Störgröße enthalten, um die Gewichtung der Faktoren, an denen innerhalb der R-Datei eine hohe Variabilität festzustellen ist, herabzusenken und um somit unempfindlichere Kalibrationsmodelle zu erhalten (TILLMANN, 1997).

Im Rahmen der Kalibrationsentwicklung wird mit zunehmender Anzahl an Faktoren die Beschreibung des Datensatzes immer detaillierter und der Fehler des Regressionsmodells nimmt ab. Da die ersten Faktoren den meisten Informationsgehalt beinhalten, wird mit steigender Anzahl an Faktoren vermehrt Rauschen, also zufällige Schwankungen in den Daten, mitkalibriert. Werden zu viele Faktoren im Modell verwendet, liegt eine Überanpassung (Overfitting) vor, die sich darin äußert, dass modellfremde Daten stark fehlerbehaftet geschätzt werden. Im Falle einer zu geringen Anzahl an Faktoren (Underfitting) nutzt das Modell nicht das gesamte Potenzial, was in der Folge die Vorhersagegüte sowohl für modelleigene wie modellfremde Proben vermindert (KESSLER, 2007). Die optimale Anzahl an Modellfaktoren wird häufig durch eine Kreuzvalidierung (CV; Cross Validation) bestimmt. Hierbei wird ein Teil des Datensatzes von der Modellentwicklung ausgeschlossen und dient der Überprüfung des an den anderen Teilen entwickelten Modells. Dieses Vorgehen erfolgt iterativ bis alle Teile einmal zur Modellbildung wie -testung beigetragen haben. Werden genauso viele Teile wie Proben ausgewählt spricht man von der Leave-One-Out-Methode (DAVIES, 1998). Im Rahmen der Kreuzvalidierung ist es wichtig, dass keine doppelten Proben in den jeweiligen Teilen vorkommen, um eine unabhängige Überprüfung der Kalibrationsfunktion zu ermöglichen. Im Falle kleiner Datenmengen kann es sinnvoll erscheinen, ungemittelte Mehrfachbestimmungen in die Modellbildung einfließen zu lassen, um somit die spektrale Varianz zu erhöhen. Hierbei ist jedoch darauf zu achten, dass sich diese doppelten Proben entweder beide im modellbildenden oder aber im modellüberprüfenden Teil des Gesamtdatensatzes befinden, um eine unabhängige Validation zu ermöglichen. Bei größeren Datensätzen resultiert diese spektrale Varianz aus der Vielzahl der Proben selbst und eine Mittlungen der Mehrfachbestimmungen ist anzuraten (FEARN, 2002).

Zur weiteren Optimierung von Faktor-Modellen wie PCR und PLS kann der sog. Martens Uncertainty Test herangezogen werden. Hierbei wird im Rahmen der LeaveOne-Out-Kreuzvalidierung über alle Einzelkalibrationsmodelle überprüft, inwieweit die verwendeten Faktoren einen signifikanten Einfluss auf die Vorhersageleistung 
aufweisen. In einer erneuten Kalibrationsberechnung werden die Faktoren ausgelassen, die zuvor keinen abgesicherten Einfluss auf die Modellgüte zeigten. Hierdurch kann die Anzahl unbenötigter Variablen reduziert werden, um somit robustere Kalibrationsmodelle zu entwickeln (DAVIES, 2001).

Ein anderes Verfahren zur Faktor-Selektion stellt die Anwendung Genetischer Algorithmen (GAs) dar (LEARDI und NORGAARD, 2005). Die Funktionsweise der GAs soll am zuvor genannten Beispiel der step wise-MLR (Seite 5) verdeutlicht werden: Zwar prüft dieses MLR-Verfahren, ob eine zuvor ins Modell einbezogene Wellenlänge nicht durch eine neuere, nun „bessere“ ersetzt werden kann, jedoch ist das Ergebnis dieser Optimierung vom Startpunkt der Modellbildung abhängig und eine leistungsfähigere Variante bleibt unter Umständen unentdeckt. Der Ansatz, alle möglichen Kombination sukzessiv durchzurechnen, liefert zwar ein optimales Modell, allerdings ist dieses Procedere auf Grund der enormen Rechenzeit kaum praktikabel. Das Prinzip Genetischer Algorithmen ist an die biologische Evolution angelehnt: Aus einer Population an zufällig erzeugten Problemlösungen „überleben“ diejenigen, die der Zielfunktion am besten angepasst sind. Die durch den "Genaustausch" - also Austausch einzelner Lösungsbausteine - zwischen den Lösungen sowie durch die Mutation der verbleibenden Lösungsansätze erhaltene neue Generation wird wieder in Abhängigkeit der Anpassung gegenüber dem Selektionskriterium beurteilt. Lösungsindividuen mit überlegenden Eigenschaften reproduzieren sich somit am häufigsten. Nach einem Abbruchkriterium wird das die Zielfunktion am besten beschreibende Individuum als Lösung verwendet (FROST, 2000; LEARDIE, 2001).

Auch kann die Kalibrationserstellung durch sog. Neuronale Netzwerke (ANN, Artificial Neural Network) erfolgen. Das Netzwerk besteht hierbei aus einzelnen Informationsverarbeitungseinheiten (Neuronen), die untereinander durch gerichtete Verbindungen vernetzt sind. Das Spektrum wird im Rahmen der Modellbildung mit Hilfe eines nichtlinearen Zusammenhangs auf den Zielparameter abgebildet, wobei durch die Veränderung der Verbindungsgewichtung das Netzwerk in der Weise trainiert wird, eine optimale Vorhersage der Zielgröße zu liefern. (WüST und RUDZIK, 1994; DANZER et al., 2001).

Um die Güte entwickelter Modelle zu bestimmen, sollte eine Überprüfung der Kalibrationsgleichungen mit Hilfe unabhängiger Proben stattfinden, welche nicht zur Modellbildung herangezogen wurden und typisch für den zukünftigen 
Anwendungsbereich sind. Dieser Vorgang wird als externe Validation bezeichnet (TILLMANN, 1996; Martens und Naes, 2001).

\subsubsection{Datenvorbehandlungen}

Spektren sind in der Nahinfrarotspektroskopie häufig von Störeffekten überlagert, die z.B. aus einer unterschiedlichen Befüllung der Küvetten oder einer Veränderung hinsichtlich der Korngrößenverteilung resultieren. Um derartige Einflüsse zu minimieren, sind verschiedene Verfahren wie z.B. die Derivativspektroskopie und Algorithmen zur Streulichtkorrektur entwickelt worden.

\section{- Derivativspektroskopie}

Bei der Derivativspektroskopie werden nicht die Originalspektren $(\log 1 / R)$, sondern deren Ableitungen zur weiteren Berechnung herangezogen. Hierdurch werden der Einflüsse von Streulichtkomponenten reduziert, Parallelverschiebungen der Spektren korrigiert sowie systematische Abweichungen von der Basislinie entfernt (NAES et al., 2002). Die Datentransformation zur Bildung der Ableitung wird in dieser Arbeit z.B. durch DT(1,10,5) abgekürzt. Dabei bezeichnet die erste Zahl die Dimension der Ableitung. Die zweite Zahl gibt die Schrittweite in Datenpunkten zur Bildung der Ableitung an, während die dritte Zahl die Anzahl an Datenpunkte festlegt, die zur Glättung mittels gleitender Mittelwerte herangezogen werden (TILLMANN, 1996).

\section{- Streulichtkorrekturen}

Aus der Vielzahl der entwickelten Streulichtkorrekturen werden im Folgenden nur die kurz erläutert, die im weiteren Verlauf dieser Arbeit auch Anwendung finden.

Nahinfrarotspektren weisen die Eigenschaft auf, dass sich mit zunehmender Wellenlänge das Absorptionsniveau erhöht. Hierbei handelt es sich meist um einen linearen Trend, der jedoch auch nichtlinear werden kann, falls beispielsweise unterschiedlich verdichtetes Probenmaterial vermessen wird. Der Algorithmus Detrend (DET) entfernt nun diese Trends, durch den Gebrauch einer Polynomfunktion zweiten Grades (SINNAEVE et al., 1994).

Durch Transformation mittels Standard Normal Variate (SNV) wird jedes Spektrum zentriert und normiert. Dieses geschieht pro Spektrum durch die Subtraktion der 
mittleren Absorption und Division durch die über das gesamte Spektrum berechnete Standardabweichung (NAES et al., 2002).

Häufig werden die Verfahren Standard Normal Variate und Detrend auch kombiniert (SNVD) (TILLMANN, 2000).

Der Algorithmus MSC (Multiplicative Scatter Correction) basiert auf der Idee, dass sich an jeder Wellenlänge eine additive bzw. multiplikative Konstante anwenden lässt, um den Spektrenverlauf zu korrigieren (NAES et al., 2002). Für diese Normierung wird das jeweilige Mittelwertsspektrum des Datensatzes verwendet, wodurch der Einfluss der mittleren Streuung sowie der mittleren Basisliniendrift eliminiert wird (KESSLER, 2007).

Die Verfahren MSC sowie SNV und dementsprechend auch SNVD können nur bei Absorptionsspektren ( $\log 1 / R)$ angewendet werden, da sonst die die Voraussetzung für einen möglichen linearen Zusammenhang zwischen Inhaltsstoffkonzentration sowie Spektrum nicht gegeben ist (KESSLER, 2007).

\subsubsection{Statistische Parameter zur Methodenbeurteilung}

Im Folgenden sind die zur Methodenentwicklung bzw. -beurteilung herangezogenen statistischen Parameter in Anlehnung an TILLMANN (1996) und DILLER (2002) kurz beschrieben.

\section{- SEC}

Der Standardfehler der Kalibrierung (SEC; Standard Error of Calibration) berechnet sich als Standardabweichung aller NIRS-Schätzwerte von den Referenzwerten der Kalibrierproben. Als alleiniger Parameter ist der SEC zur Gütebeurteilung der Kalibration wegen der Overfitting-Problematik nicht geeignet.

$$
S E C=\sqrt{\frac{\sum_{i=1}^{n}\left(y_{R E F_{i}}-y_{N I R S_{i}}\right)^{2}}{n-p-1}}
$$

mit

$\mathrm{y}_{\mathrm{REF}}=$ Referenzwert

$\mathrm{y}_{\text {NIRS }}=$ NIRS-Schätzwert

$\mathrm{n}=$ Anzahl Proben

$p=$ Anzahl im Modell genutzter Faktoren 


\section{- SECV}

Der Standardfehler der Kreuzvalidierung (SECV; Standard Error of Cross Validation) wird häufig als Gütemaß der Kalibration herangezogen, da bei der Berechnung jeweils die Proben einfließen, die nicht an der Modellbildung beteiligt waren und somit als unabhängige Validationsproben angesehen werden können.

$S E C V=\sqrt{\frac{\sum_{i=1}^{n}\left(y_{R E F_{i}}-y_{N I R S_{i}}\right)^{2}}{n-1}}$

- 1-VR

Das Bestimmtheitsmaß der Kreuzvalidierung 1-VR beschreibt den erklärten Anteil der Varianz zur Gesamtvarianz (Quadrat der Standardabweichung SD).

$1-V R=1-\frac{S E C V^{2}}{S D^{2}}$

\section{- SEP}

Der Standardfehler der Vorhersage (SEP; Standard Error of Prediction) berechnet sich als Standardabweichung aller NIRS-Schätzwerte von den Referenzwerten der Validierproben. Sofern kein systematischer Fehler vorliegt, beschreibt der SEP die Güte der extern validierten NIRS-Methode.

$S E P=\sqrt{\frac{\sum_{i=1}^{n}\left(y_{R E F_{i}}-y_{N I R S_{i}}\right)^{2}}{n-1}}$

\section{- Bias}

Das Bias stellt den mittleren systematischen Fehler dar, um den alle Validierproben im Durchschnitt über- bzw. unterschätzt werden.

Bias $=\frac{1}{n} \sum_{i=1}^{n} y_{R E F_{i}}-y_{N I R S_{i}}$

\section{- Slope}

Die Steigung der Regressionsgeraden zwischen den Vorhersagewerten und den Referenzwerten wird als Slope bezeichnet und sollte nahe 1,0 liegen. Weist die Steigung einen von 1,0 bedeutend größeren Slope-Wert auf, so werden besonders Proben mit hohen Inhaltsstoffgehalten überschätzt, während Proben mit niedrigen Werten eher unterschätzt werden. Für Slope-Werte kleiner 1,0 gilt das Umgekehrte. 


\section{- SEPC}

Der SEPC (Standard Error of Prediction corrected for Bias) ist der um den systematischen Fehler (Bias) bereinigte Standardfehler der Vorhersage.

$$
S E P C=\sqrt{\frac{\sum_{i=1}^{n}\left(y_{R E F_{i}}-y_{N I R S_{i}}-B_{i a s}\right)^{2}}{n-1}}
$$

\section{- $\mathbf{R}^{2}$}

Das Bestimmtheitsmaß $\mathrm{R}^{2}$ gibt den Anteil der Varianz der Referenzwerte an, der durch das NIRS-Modell erklärt wird.

$$
R^{2}=\frac{\sum_{i=1}^{n}\left(y_{N I R S_{i}}-\frac{1}{n} \sum_{i=1}^{n} y_{R E F_{i}}\right)^{2}}{\sum_{i=1}^{n}\left(y_{R E F_{i}}-\frac{1}{n} \sum_{i=1}^{n} y_{R E F_{i}}\right)^{2}}
$$

\section{- RPD}

Der RPD (ratio of SEP to the standard deviation of the validation samples) ermöglicht durch die Quotientenbildung aus der Standardabweichung der Referenzwerte der Validationsproben und dem Standardfehler der Vorhersage einen Leistungsvergleich verschiedener Methoden unabhängig von der betreffenden Maßeinheit.

$$
R P D=\frac{S D_{\text {val }}}{S E P}
$$

Die durch WILLIAMS (2001) herangezogene Bewertung der Leistungsfähigkeit entwickelter Kalibrationen für landwirtschaftliche Produkte anhand der RPD-Werte ist in nachfolgender Tabelle (Tab. 1) aufgeführt.

Tab. 1: Charakterisierung der Leistungsfähigkeit anhand von RPD-Werten (WILLIAMS, 2001)

\begin{tabular}{lll} 
RPD & Vorhersageleistung & Anwendungsbereich \\
\hline $0,0-2,3$ & ungenügend & nicht zu empfehlen \\
$2,4-3,0$ & schlecht & grobes Screening \\
$3,1-4,9$ & zufrieden stellend & Screening \\
$5,0-6,4$ & gut & Qualitätskontrolle \\
$6,5-8,0$ & sehr gut & Prozesskontrolle \\
über 8,1 & exzellent & jegliche Anwendung
\end{tabular}




\subsection{Ausreißer in der Kalibrationsentwicklung}

Ausreißer sind Proben, die den von der Gesamtpopulation beschriebenen Zusammenhang durchbrechen. Der Grund für diese Abweichung kann hierbei z.B. ein real existierender Messfehler, das Vertauschen von Proben oder ein Fehler in der Dateneingabe sein. In diesem Falle ist die Ursache bekannt und die Eliminierung dieser „echten“ Ausreißer ist legitim (KESSLER, 2007). Jedoch können ungewöhnliche Proben auch neue, noch nicht im Modell enthaltene Informationen bzw. Eigenschaften aufweisen, deren Einbeziehung in die Kalibrationsentwicklung zu robusteren NIRSMethoden führt (TILLMANN, 1996). Sofern für einen Ausreißer keine eindeutige Ursache festzustellen ist, muss entschieden werden, ob diese Probe entfernt wird oder zur Modellbildung beiträgt. Hierbei wird im Zweifelsfall von NAES et al. (2002) die Eliminierung der Ausreißer empfohlen, da hierdurch das Leistungsvermögen der Kalibrationsgleichung gesteigert werden kann. Im schlimmsten Fall führt dieses Vorgehen zu einer verminderten Robustheit des Kalibrationsmodells (TILLMANN, 1996).

Die in dieser Untersuchung im Rahmen der Kalibrationsentwicklung (Kap. 3.4.1) mit Hilfe der Software WinISI II v1.60 (Infrasoft International LLC.) detektierten AusreißerTypen sind nach stehend in Anlehnung an TILLMANN (1996) kurz erläutert.

Der T-Wert errechnet sich aus der Quotientenbildung der Vorhersagedifferenz einer Probe und dem Standardfehler der Kalibration. Übersteigt der T-Wert eine festgelegte kritische Grenze, so wird die zugehörige Probe als T-Ausreißer bezeichnet.

$T=\frac{\left|y_{N_{I R S}}-y_{R E F_{i}}\right|}{S E C}$

Der H-Wert bzw. die Mahalanobis-Distanz stellt ein mehrdimensionales Maß für die Entfernung eines Spektrums von der spektralen Populationsmitte dar. Übersteigt der $\mathrm{H}$-Wert einer Probe eine zuvor festgesetzte Grenze, so gilt dieses Spektrum als HAusreißer.

Für die Ermittlung von X-Ausreißern wird aus den Faktorwerten (scores) sowie Faktorladungen (loadings) ein rekonstruiertes Spektrum errechnet und mit dem Originalspektrum verglichen, wobei die Differenzen über alle Wellenlängen addiert und mit einer kritischen Grenze verglichen werden. 


\section{Material und Methoden}

\subsection{Probenmaterial}

Die in dieser Arbeit zur Untersuchung herangezogenen Sonnenblumensaatproben. sind in nachstehender Tabelle (Tab. 2) kurz charakterisiert. Weitere Informationen zu dem Material, das meist aus Versuchsprojekten und/oder Voruntersuchungen stammt, sind der angegebenen Literatur zu entnehmen.

\section{Tab. 2: Übersicht verwendeter Probensätze}

\begin{tabular}{|c|c|c|c|c|c|}
\hline Bez. & Erntejahre & Anbauort/-gebiet & Typ* & Beschreibung & Literatur \\
\hline $\mathrm{A} 1$ & $\begin{array}{l}1999- \\
2002\end{array}$ & $\begin{array}{l}\text { Braunschweig, Düllstadt, } \\
\text { Großenstein, } \\
\text { Guthmannshausen, } \\
\text { Niederbayern, } \\
\text { Rheinhessen, } \\
\text { Steinenstadt, Straußfurt, } \\
\text { Triesdorf, Wetterau }\end{array}$ & $\mathrm{HO}$ & $\begin{array}{l}\text { Aurasol, Cadasol, } \\
\text { Capella, Carioca, } \\
\text { Gamasol, Lucil, } \\
\text { Majus, MH 0211, } \\
\text { Olbaril, Olsavil, } \\
\text { Olstaril, PR64A54, } \\
\text { PR64H61, Proleic, } \\
\text { Sunny, XF } 203\end{array}$ & $\begin{array}{l}\text { BISKUPEK- } \\
\text { KORELL et } \\
\text { al., } 2003\end{array}$ \\
\hline $\bar{A} 2$ & $\begin{array}{l}2002- \\
2005\end{array}$ & $\begin{array}{l}\text { Braunschweig, } \\
\text { Eckartsweier }\end{array}$ & $\mathrm{HO}$ & $\begin{array}{l}\text { Aurasol, Olsavil, } \\
\text { PR64H41 }\end{array}$ & $\begin{array}{l}\text { DILCl und } \\
\text { RüHL, } 2006\end{array}$ \\
\hline$\overline{A 3}$ & 2003 & Braunschweig & $\mathrm{HO}$ & $\begin{array}{l}\text { Aurasol, Olsavil, } \\
\text { PR64H41 }\end{array}$ & $\begin{array}{l}\text { MOSCHNER } \\
\text { und } \\
\text { BISKUPEK- } \\
\text { KORELL, } \\
2006\end{array}$ \\
\hline$\overline{A 4}$ & 2006 & Braunschweig & $\mathrm{HO}$ & $\begin{array}{l}\text { Aurasol, Olsavil, } \\
\text { PR64H41 }\end{array}$ & $\begin{array}{l}\text { Siehe } \\
\text { Kap 3.3.3 }\end{array}$ \\
\hline B1 & $\begin{array}{l}1999- \\
2000\end{array}$ & $\begin{array}{l}\text { Bad Lauchstädt, Groß } \\
\text { Gerau, Großenstein, } \\
\text { Güterfelde, Oppenheim, } \\
\text { Salbitz }\end{array}$ & LO & $\begin{array}{l}\text { Alisson, Altesse } \\
\text { RM, Belem, } \\
\text { Candisol, Flavia, } \\
\text { Floyd, Lucil, } \\
\text { Manosol, Salsa } \\
\text { RM, Sanluca }\end{array}$ & $\begin{array}{l}\text { LINDEMANN } \\
\text { und } \\
\text { GRONOW, } \\
2001\end{array}$ \\
\hline $\bar{B} 2$ & $\begin{array}{l}2003- \\
2004\end{array}$ & Eckartsweier, Südafrika & $\mathrm{HO} / \mathrm{LO}$ & $\begin{array}{l}\text { div. Linien und } \\
\text { Hybride }\end{array}$ & HAHN, 2007 \\
\hline
\end{tabular}

${ }^{*}$ HO: high oleic, LO: low oleic

Die Probensätze A1 bis A4 bestehen ausschließlich aus high-oleic-(HO)Sonnenblumenmaterial und stellen mengenmäßig den größten Teil der verwendeten Proben dar. Zusätzlich flossen auch linolsäurereiche, also ölsäurearme (LO) Proben aus dem EU-Sortenversuch 2000 (Datensatz B1) in die Untersuchungen mit ein. Mit 
dem Satz B2 konnte auf Zuchtmaterial zurückgegriffen werden, in dem sowohl ölsäurereiche wie -arme Proben enthalten sind. Während die erstgenannten Probensätze aus Sonnenblumensaaten des Öltyps mit meist schwarzer sowie dünner Samenschale und hohem Ölgehalt bestehen, weist der Datensatz B2 als Ausgangsmaterial zur Züchtung auf hohen Proteingehalt auch Proben auf, die eher dem Speisetypen (Knabberkerne) mit meist braun-weiß oder schwarz-weiß gestreifter Samenschale zuzuordnen sind (HUGGER, 1989).

Die Proben wurden auf einen maximalen Restfeuchtegehalt von 9\% getrocknet sowie von Verunreinigungen wie Besatz und Bruchkörnern befreit und bis zu weiteren Verwendung kühl und trocken gelagert, um qualitätsmindernde Prozesse während der Lagerung zu minimieren.

Zur Erweiterung der Datenbasis hinsichtlich des Parameters freie Fettsäuren (FFA) konnte durch den Datensatz A3 auf Proben zurückgegriffen, bei denen durch ungünstige Bedingungen wie Beschädigungen und warme sowie feuchte Lagerung höhere FFA-Anteile induziert wurden (MOSCHNER und BISKUPEK-KORELL, 2006).

Um die Variabilität der Feuchtegehalte der Datenbasis zu vergrößern, wurden durch den Datensatz A4 auch erntefeuchte HO-Proben (max. 14,6\% Feuchte) in die Versuche mit einbezogen (vgl. Kap 3.3.3).

\subsection{Probenvermahlung}

Ziel der Vermahlung von Sonnenblumensaat ist es, ein feinkörniges, schüttfähiges und weitgehend homogenes Material zu erhalten. Zwar steigt der Vermahlungsgrad mit der Vermahldauer an, jedoch wirkt sich eine zu lange Vermahlung dahin gehend aus, dass die Ölkörper zerschlagen und Agglomerate gebildet werden. Gerade für spektroskopische Messungen ist wichtig, ein standardisiertes Vermahlungsprotokoll anzuwenden. Somit wurde in dieser Untersuchung auf das durch Biskupek-Korell et al. (2003) beschriebene Intervallverfahren zurückgegriffen: Je Probe wurden $20 \mathrm{~g}$ Sonnenblumensaat in einer Haushaltskaffeemühle (petra electric M85.00; Peter Hohlfeldt $\mathrm{GmbH} \&$ Co. KG, Burgau, Deutschland) dreimal für je 5 Sekunden vermahlen, wobei zwischenzeitlich mit einem Löffelstiel gründlich vermischt wurde, so dass kein Material an den Wänden anhaftete. 


\subsection{Probenuntersuchungen}

Alle Untersuchungen wurden als Doppelbestimmung durchgeführt. Bei der Durchführung der Referenzanalytik und der nahinfrarotspektroskopischen Messungen (Kap. 3.3.1 bzw. Kap. 3.3.2) wurde darauf geachtet, dass diese in enger zeitlicher Abfolge erfolgten, um innerhalb der Kalibrationsentwicklung (Kap. 3.4) den Erhalt hoher Korrelationen zwischen referenzanalytischen sowie spektralen Daten zu ermöglichen.

\subsubsection{Referenzanalytik}

Von den Untersuchungsproben wurden der Öl-, Protein- und Feuchtegehalt sowie der Anteil freier Fettsäuren und das Fettsäuremuster ermittelt.

- Ölgehalt: Bestimmung mittels Kernresonanzspektroskopie (NMR) gemäß DIN EN ISO 10565 (1998); Angabe in \% Trockenmasse.

- Proteingehalt: Berechnet als das 6,25 fache des Stickstoffgehaltes bestimmt nach Dumas gemäß DIN EN ISO 16634 (2006); Angabe in \% Trockenmasse.

- Feuchte: Bestimmung mittels Trockenschrankmethode gemäß DIN EN ISO 665 (2001); Angabe in \% Frischmasse.

- Anteil freier Fettsäuren (FFA): Bestimmung mittels Titration in Anlehnung an DIN EN ISO 660 (2005); Angabe in \% Öl (berechnet als Ölsäure).

- Fettsäuremuster: Chromatographische Bestimmung gemäß DGF C-VI 10a (2000); Angabe in \% Öl (Umesterung mit methanolischer NatriummethylatLösung; Normierung der detektierten Fettsäuren (C16:0 bis C24:0) auf 100\%)

Detaillierte Informationen über die Durchführung der referenzanalytischen Methoden, die verwendeten Gerätschaften und Chemikalien sowie zu den methodischen Grundlagen sind der Arbeit von MoschNeR (2003) bzw. im Falle der Analytik freier Fettsäuren der Arbeit von MOSCHNER und BISKUPEK-KORELL (2006) zu entnehmen.

Die Bewertung einer Referenzmethode erfolgt in der Regel nach ihrer Richtigkeit und Präzision, wobei diese Maßzahlen in Ringversuchen bestimmt werden. Nachfolgende Abbildung (

Abb. 1) veranschaulicht die Begriffe Richtigkeit und Präzision. 
Richtigkeit hoch Richtigkeit niedrig

Präzision hoch
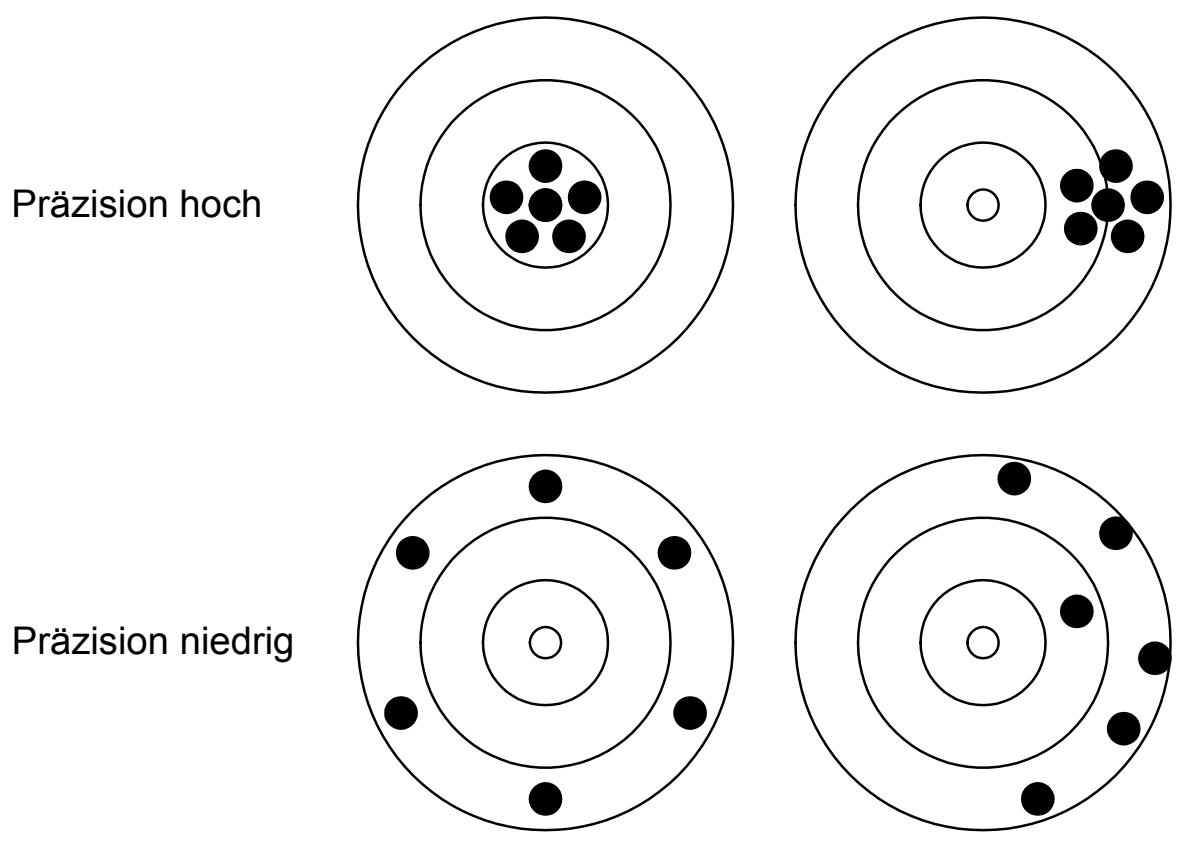

\section{Abb. 1: Unterschiedliche Varianten hoher und niedriger Richtigkeit sowie Präzision (nach BÄRLOCHER, 1999)}

Nach TILLMANN (1997) beschreibt die Richtigkeit einer Methode, ob systematische Abweichungen vom wahren Wert einer Probe vorliegen und ist sichergestellt, sofern kein signifikanter Unterschied zum mittleren Analysenwert der im Ringversuch beteiligten Labore existiert. Wenn der „wahre Wert“ unbekannt ist, wird der gemittelte Analysenwert einer Referenzmethode oder einer amtlichen Methode verwendet. Zur Beschreibung der Präzision werden die Begriffe Wiederholbarkeit und Vergleichbarkeit herangezogen. Dabei berechnen sich die Wiederholgrenzen $r_{W}$ und sowie die Vergleichsgrenzen $R_{V}$ als das 2,8fache der Wiederhol- bzw. Vergleichstandardabweichung. In folgender Tabelle (Tab. 3) sind $r_{W}$ und $R_{V}$ für die in Kapitel 3.3.1 durchgeführten Referenzverfahren aufgelistet. Hierbei wurde auf die im jeweiligen Anhang der Methodenvorschriften aufgeführten Werte für Sonnenblumensaat zurückgegriffen, um die produktspezifischen Präzisionsangaben auch im Vergleich zum Mittelwert der jeweiligen Inhaltsstoffe der in die Ringversuche eingeflossenen Proben verwenden zu können. Da in der amtlichen Methode DGF C-VI 10a zur Analytik der Fettsäuren die Präzisionsangaben nicht speziell für Sonnenblumensaat angegeben sind, wurden die bezüglich der Probenart unspezifischen Präzisionsgrenzen verwendet. In den meisten in Tab. 3 aufgeführten Untersuchungsvorschriften unterscheiden sich die allgemeinen sowie 
produktabhängigen Angaben aus dem Anhang der Methoden nur gering. Da dieses sich jedoch in der amtlichen Methode DIN EN ISO 16634 zur Bestimmung des Gesamtstickstoffs nach Dumas anders verhält, sind in Tab. 3 für die Untersuchung des Proteingehaltes sowohl die allgemeinen Grenzen als auch die für Sonnenblumensaat spezifischen Präzisionsangaben aufgeführt.

Tab. 3: Wiederholgrenzen $r_{\mathrm{w}}$ sowie Vergleichsgrenzen $\mathbf{R}_{\mathrm{V}}$ amtlicher Methoden zur Qualitätsbestimmung von Sonnenblumensaat

\begin{tabular}{|c|c|c|c|c|}
\hline Inhaltsstoff & $r_{W}$ & $\mathrm{R}_{\mathrm{V}}$ & Mittel & Quelle \\
\hline Ölgehalt [\%TM] & 0,94 & 1,13 & 47,89 & DIN EN ISO 10565 \\
\hline Proteingehalt $\left.{ }^{1} \% \mathrm{TM}\right]$ & 1,97 & 1,92 & 18,5 & DIN EN ISO 16634 \\
\hline Proteingehalt ${ }^{1 ; 2}[\% \mathrm{TM}]$ & 0,63 & 1,06 & --- & DIN EN ISO 16634 \\
\hline Feuchte $^{3}[\% \mathrm{FM}]$ & 0,22 & 0,35 & 7,8 & DIN EN ISO 665 \\
\hline FFA $[\%$ \%Öl] & 0,03 & 0,08 & 0,83 & DIN EN ISO 660 \\
\hline Fettsäuren ${ }^{5}[\%$ Ö] $(F S>=5 \%)$ & 0,50 & 2,50 & --- & DGF C-VI 10a \\
\hline Fettsäuren ${ }^{5}[\% O ̈ l](F S<5 \%)$ & 0,20 & 1,00 & -- & DGF C-VI 10a \\
\hline
\end{tabular}

1 Da in der Quelle die Angaben auf Stickstoff- und nicht auf Proteingehalt bezogen sind, erfolgte hier eine Multiplikation mit dem Faktor 6,25

2 Allgemeine, produktunspezifische Präzisionsangaben der Methode

3 Mittelwerte aus drei Ringversuchen

4 Die in der Quelle sowie hier aufgeführten Angaben beziehen sich auf die FFA-Bestimmung im Öl und nicht auf die hier durchgeführte Bestimmung in der Saat

5 Allgemeine, produktunspezifische sowie konzentrationsabhängige Präzisionsangaben der Methode

\subsubsection{Nahinfrarotspektroskopische Messungen}

Die NIRS-Messungen wurden im Institut Pflanzenbau und Grünlandwirtschaft der FAL in Braunschweig-Völkenrode durchgeführt. Hierbei kamen zwei dispersive Spektrometer des Typs NIRSystems 6500 (FOSS A/S, Hillerrod, Dänemark) zum Einsatz, die sich nur im System der Probenzuführung unterschieden. Das NIRSystems 6500 misst in Reflexion in 2 nm-Inkrementen, wobei der Wellenlängenbereich von 400 bis $1100 \mathrm{~nm}$ von einem Silizium-Detektor und der Bereich von 1100-2500 nm von einem Bleisulfid-Detektor erfasst wird. Diese Reflexionsspektren werden in Absorptionsspektren $(A=\log (1 / R))$ umgewandelt, um die Proportionalität zur Konzentration entsprechend dem Lambert-Beerschen Gesetz herzustellen. 
Die Untersuchung gemahlener Proben erfolgte mit dem Autocup Module in den ring cup-Küvetten, während die intakten Achänen über das Sample Transport Module mit Hilfe der Natural Product Cell vermessen wurden.

\subsubsection{Erweiterung der Datenbasis hinsichtlich des Parameters Feuchte}

Um einerseits den möglichen Wertebereich der Kalibrationen für den Inhaltsstoff Feuchte zu vergrößern und um andererseits zu überprüfen, inwieweit Schwankungen im Feuchtigkeitsgehalt die Vorhersageleistungen der Kalibrationen beeinflussen, wurden auch erntefeuchte Proben in die Versuche mit einbezogen (Datensatz A4). Hierfür wurden 20 frisch geerntete Sonnenblumensaatproben zuerst gereinigt und dann dreimal während ihres Trocknungsprozesses spektral an intakten sowie gemahlenen Achänen und referenzanalytisch auf ihre Feuchtegehalte hin untersucht. Somit wurden 60 Spektren erhalten, die sich pro Probe nur im Feuchtegehalt unterscheiden, da die anderen Parameter wie Öl, FFA und Protein als prozentualer Anteil der Trockenmasse bzw. im Falle der unterschiedlichen Fettsäuren als prozentualer Anteil des Öls bestimmt worden sind.

\subsection{Kalibrationsentwicklung}

Die erhobenen referenzanalytischen sowie spektralen Daten (Kap. 3.3.1 bzw. Kap. 3.3.2) wurden zur Kalibrationsentwicklung herangezogen, welche mit Hilfe der Software WinISI II v1.60 (Infrasoft International LLC.) durchgeführt wurde. Alle NIRSchätzgleichungen wurden unter Verwendung des MPLS-Algorithmus als "globale" Kalibration entwickelt. Der Wellenlängenbereich wurde in dieser Arbeit stets auf 1100 bis $2500 \mathrm{~nm}$ eingeschränkt, da einerseits der Gebrauch des Gesamtwellenlängenbereichs von 400 - 2500 nm nach PÉREZ-VICH et al. (1998) bei der Kalibrationsentwicklung für Sonnenblumenachänen zu schlechteren Ergebnissen führt. Folgende weitere Einstellungen innerhalb der WinISI-Software wurden vorgenommen: Maximale Anzahl an Faktoren $=16$; Anzahl an Kreuzvalidierungsgruppen $=4$; Anzahl der Ausreißer-Eliminierungsdurchläufe $=2$ bzw. = 0 (siehe Kap. 3.4.1 bzw. 3.4.2); Kritische Ausreißergrenzen $(T / H / X)=2,5 / 10 / 10$; keine geringere Gewichtung von Ausreißern. 


\subsubsection{Zusammenstellung der Kalibrations- und Validationssets}

Die in Kapitel 3.1 beschriebenen Proben wurden zur Zusammenstellung der Kalibrations- und Validationssets herangezogen. Dabei wurde hauptsächlich auf das HO-Material der Probensätze A1, A2, A3, und A4 zurückgegriffen.

Für die erntefrischen HO-Proben aus dem Datensatz A4 liegen neben den Gehalten an Feuchte auch die Referenzwerte für Ölgehalt und Fettsäuremuster vor. Um zu prüfen, inwieweit der vorherrschende Feuchtegehalt die Vorhersageleistung für andere Inhaltsstoffe beeinflusst, wurden für die Parameter Öl und Ölsäure Sets mit und ohne den Datensatz A4 zusammengestellt, wobei beim Fehlen der erntefeuchten Proben diese Parameter ein „LT“ im Index tragen.

Die Datensätze B1 und B2 wurden herangezogen, um das Verhalten der Kalibrationen beim Vorhandensein von LO-Material zu charakterisieren. Da jedoch nicht alle in Kap. 3.3.1 beschriebenen Referenzverfahren bei jedem Datensatz durchgeführt wurden, beschränken sich die Darstellungen in diesem Vergleich auf die Parameter Protein und Ölsäure als Beispiel aus dem Fettsäuremuster. Hierbei wurden die Sets, die auf die Datensätze B1 und B2 zurückgreifen, mit „GES“ gekennzeichnet.

Folgende Tabelle (Tab. 4) zeigt die zur Kalibrationsentwicklung herangezogene Zusammenstellung der Datensätze für intakte wie gemahlene Achänen auf, wobei die verwendeten Sätze mit „“ markiert wurden. Der Datensatz A3 wurde nur vermahlen vermessen und ist somit bei den Ganzkorn-Kalibrationen nicht vorhanden.

Tab. 4: Zur Kalibrationsentwicklung herangezogene Datensätze

\begin{tabular}{|c|c|c|c|c|c|c|}
\hline & $\mathrm{A} 1$ & $\mathrm{~A} 2$ & A3 & A4 & $\mathrm{B} 1$ & B2 \\
\hline Feuchte & $\bullet$ & $\bullet$ & $\bullet$ & $\bullet$ & & \\
\hline FFA & & $\bullet$ & $\bullet$ & & & \\
\hline Protein & $\bullet$ & $\bullet$ & & & & \\
\hline Protein $_{\mathrm{GES}}$ & - & $\bullet$ & & & $\bullet$ & $\bullet$ \\
\hline Öl & $\bullet$ & $\bullet$ & & $\bullet$ & & \\
\hline Öl ${ }_{L T}$ & $\bullet$ & $\bullet$ & & & & \\
\hline C16:0 & $\bullet$ & $\bullet$ & & $\bullet$ & & \\
\hline C18:0 & $\bullet$ & $\bullet$ & & $\bullet$ & & \\
\hline C18:1 & $\bullet$ & - & & $\bullet$ & & \\
\hline C18:1 $1_{\mathrm{LT}}$ & • & • & & & & \\
\hline C18:1 $1_{\mathrm{GES}}$ & $\bullet$ & $\bullet$ & & $\bullet$ & $\bullet$ & $\bullet$ \\
\hline C18:2 & $\bullet$ & $\bullet$ & & $\bullet$ & & \\
\hline
\end{tabular}


Durch eine erste Kalibrationserstellung (DT(1,4,4); SNVD) mit zwei AusreißerEliminationsdurchläufen erfolgte die Ermittlung von zu stark abweichenden Proben $((T / H / X)=2,5 / 10 / 10)$, welche im Anschluss entfernt wurden. In Abhängigkeit des jeweiligen Parameters sowie der Probenpräsentation lag der Ausreißer-Anteil zwischen 2,6 und 5,5\% (A-Datensätze) bzw. zwischen 4,8 und 8,3 \% (A+B-Datensätze). Diese somit bereinigten Datensätze wurden zur Aufteilung in Kalibrations- und Validationsset herangezogen. Hierbei wurden zuerst unter zur Hilfenahme der Sätze A1, A2 und A3 die Referenzwerte des jeweiligen Inhaltsstoffes aufsteigend sortiert und jede siebte Probe ab der vierten beginnend dem Validationsset zugeführt, während die übrigen Proben das Kalibrationssets bildeten. Bei Hinzufügen des Datensatzes A4 (erntefeuchte Proben) wurde darauf geachtet, dass jeweils die Spektren, die aus der Mehrfachuntersuchung einer Probe hervorgegangen waren, dem gleichen Set für die Validation bzw. Kalibration zugeordnet wurden. Die Hinzunahme der Daten aus B1 und B2 erfolgte ebenfalls anhand der aufsteigend geordneten Referenzwerte des jeweiligen Inhaltsstoffs, wobei wieder jede siebte Probe ab der vierten beginnend dem Validationsset zugeführt wurde. Somit wurde für jeden Parameter ein eigenes, spezifisches Kalibrations- und Validationsset erstellt. Lediglich bei der Aufteilung der einzelnen Fettsäuren wurde ausschließlich auf die aufsteigend sortierten Ölsäuregehalte zurückgegriffen. Generell wurde bei der Zusammenstellung darauf geachtet, dass Proben mit den höchsten bzw. niedrigsten Gehalten des jeweiligen Inhaltsstoffes im Kalibrationsset verblieben. Nur bei den Datensätzen für die Fettsäuren weisen die Validationssets teilweise eine minimal größere Spannbreite auf, die durch die Sortierung allein nach Ölsäuregehalt zurückzuführen ist.

In der nachfolgenden Tabelle (Tab. 5) sind die zur Kalibration sowie zur Validation herangezogenen Sets beschrieben. 
Tab. 5: Zusammensetzung des Kalibrations- und Validationsdatensatz für gemahlene sowie intakte Achänen

\begin{tabular}{|c|c|c|c|c|c|}
\hline & \multicolumn{2}{|c|}{ Gemahlene Achänen } & \multicolumn{2}{|c|}{ Intakte Achänen } \\
\hline & & Kalibration & Validation & Kalibration & Validation \\
\hline \multirow[t]{4}{*}{ Feuchte } & Bereich & $2,08-12,50$ & $2,15-12,10$ & $2,08-12,50$ & $2,15-10,56$ \\
\hline & Mittel & 5,31 & 5,32 & 5,18 & 5,20 \\
\hline & SD & 1,58 & 1,61 & 1,52 & 1,50 \\
\hline & $\mathrm{n}$ & 970 & 162 & 885 & 149 \\
\hline \multirow[t]{4}{*}{ FFA } & Bereich & $0,00-4,46$ & $0,01-4,04$ & $0,00-4,04$ & $0,01-3,30$ \\
\hline & Mittel & 1,07 & 1,06 & 0,93 & 0,92 \\
\hline & SD & 0,93 & 0,91 & 0,79 & 0,77 \\
\hline & $\mathrm{n}$ & 476 & 79 & 427 & 71 \\
\hline \multirow[t]{4}{*}{ Öl } & Bereich & $42,4-57,67$ & $43,18-56,41$ & $43,18-57,06$ & $45,11-56,41$ \\
\hline & Mittel & 50,85 & 50,84 & 50,85 & 50,87 \\
\hline & SD & 2,51 & 2,45 & 2,45 & 2,38 \\
\hline & $\mathrm{n}$ & 1130 & 190 & 1124 & 188 \\
\hline \multirow[t]{4}{*}{ Öl } & Bereich & $42,4-57,67$ & $43,18-56,41$ & $43,18-57,06$ & $45,11-56,41$ \\
\hline & Mittel & 50,98 & 50,97 & 51,01 & 51,00 \\
\hline & SD & 2,43 & 2,42 & 2,35 & 2,33 \\
\hline & $\mathrm{n}$ & 1088 & 181 & 1075 & 179 \\
\hline \multirow[t]{4}{*}{ Protein } & Bereich & $10,74-27,57$ & $10,99-22,98$ & $10,74-22,13$ & $10,99-20,34$ \\
\hline & Mittel & 15,28 & 15,28 & 15,05 & 15,04 \\
\hline & SD & 2,02 & 2,01 & 1,83 & 1,82 \\
\hline & $\mathrm{n}$ & 791 & 132 & 739 & 123 \\
\hline \multirow[t]{4}{*}{ Protein $_{\mathrm{GES}}$} & Bereich & $10,70-29,94$ & $10,99-28,02$ & $10,74-25,38$ & $10,99-23,04$ \\
\hline & Mittel & 16,51 & 16,56 & 15,48 & 15,45 \\
\hline & SD & 3,25 & 3,28 & 2,30 & 2,24 \\
\hline & $\mathrm{n}$ & 1057 & 177 & 824 & 137 \\
\hline \multirow[t]{4}{*}{ C16:0 } & Bereich & $2,21-4,1$ & $2,27-3,93$ & $2,21-4,1$ & $2,27-4,19$ \\
\hline & Mittel & 2,99 & 3,01 & 3,01 & 3,01 \\
\hline & SD & 0,39 & 0,41 & 0,40 & 0,41 \\
\hline & $\mathrm{n}$ & 617 & 116 & 565 & 104 \\
\hline \multirow[t]{4}{*}{ C18:0 } & Bereich & $1,05-4,00$ & $1,04-3,55$ & $1,04-3,61$ & $1,05-3,47$ \\
\hline & Mittel & 2,16 & 2,18 & 2,18 & 2,14 \\
\hline & SD & 0,64 & 0,61 & 0,62 & 0,60 \\
\hline & $\mathrm{n}$ & 861 & 147 & 811 & 137 \\
\hline \multirow[t]{4}{*}{ C18:1 } & Bereich & $80,21-93,24$ & $81,65-92,99$ & $84,25-93,12$ & $84,39-92,98$ \\
\hline & Mittel & 89,47 & 89,45 & 89,59 & 89,61 \\
\hline & SD & 2,17 & 2,19 & 1,96 & 1,97 \\
\hline & $\mathrm{n}$ & 864 & 147 & 802 & 136 \\
\hline \multirow[t]{4}{*}{ C18:1 $1_{\mathrm{LT}}$} & Bereich & $80,21-93,24$ & $81,65-92,99$ & $84,25-93,12$ & $84,39-92,98$ \\
\hline & Mittel & 89,31 & 89,29 & 89,40 & 89,45 \\
\hline & SD & 2,12 & 2,14 & 1,90 & 1,92 \\
\hline & $\mathrm{n}$ & 816 & 138 & 751 & 127 \\
\hline
\end{tabular}


Fortsetzung Tab. 5

\begin{tabular}{|ll|cc|cc|}
\hline & & \multicolumn{2}{|c|}{ Gemahlene Achänen } & \multicolumn{2}{c|}{ Intakte Achänen } \\
& & Kalibration & Validation & Kalibration & Validation \\
\hline C18:1 $1_{\text {GES }}$ & Bereich & $10,95-93,24$ & $16,14-92,99$ & $17,67-93,12$ & $20,21-92,98$ \\
& Mittel & 76,73 & 76,78 & 85,81 & 85,84 \\
& SD & 24,71 & 24,68 & 14,07 & 14,02 \\
& $\mathrm{n}$ & 1146 & 191 & 865 & 147 \\
\hline C18:2 & Bereich & $1,84-10,27$ & $1,84-10,55$ & $1,84-8,08$ & $1,85-7,91$ \\
& Mittel & 3,72 & 3,71 & 3,58 & 3,53 \\
& SD & 1,43 & 1,53 & 1,21 & 1,24 \\
& $\mathrm{n}$ & 861 & 147 & 796 & 134 \\
\hline
\end{tabular}

\subsubsection{Kalibrationsvarianten}

Um zu prüfen, welche Datenvorbehandlung für eine leistungsfähige Erfassung des jeweiligen Inhaltsstoffs in gemahlenen bzw. intakten Achänen geeignet ist, wurden die Spektren im Rahmen der Kalibrationsentwicklung durch Bildung unterschiedlicher Ableitungen $(n=8)$ und Nutzung verschiedener Streulichtkorrekturen $(n=5)$ transformiert. Dabei kamen die in folgender Tabelle (Tab. 6, Seite 24) aufgeführten Varianten zum Einsatz. Kalibriert wurde ohne erneute Ausreißereliminierung unter Verwendung der in Tab. 5 beschriebenen Kalibrationsdatensätze. Die somit je Inhaltsstoff und Präsentationsform (gemahlen, intakt) entwickelten 40 Kalibrationsgleichungen wurden am jeweiligen Validationsdatensatz überprüft.

Neben der Überprüfung der Schätzgleichungen am jeweiligen Validationsdatensatz erfolgte für die Parameter Ölgehalt und Ölsäure in gemahlener und intakter Saat auch ein Vergleich, inwieweit die Vorhersageleistung durch die Einbeziehung erntefeuchter Proben beeinflusst wird. Hierzu wurden die an ausschließlich lagertrockenem Material erstellten Kalibrationsgleichungen durch Validationssets überprüft, in denen erntefeuchte Proben enthalten waren. Auch erfolgte die Abschätzung lagertrockener Proben durch Kalibrationen, welche mit Hilfe der erntefeuchten Proben erstellt wurden.

Zur Beurteilung der Leistungsfähigkeit der an HO-Material erstellten Modelle, wurden die Datensätze B1 und B2, in denen protein- sowie linolsäurereiche Varianten enthalten sind, in die Validation mit eingeschlossen. Des Weiteren wurden Kalibrationsgleichungen unter Einbeziehung dieser Proben erstellt, um den Kalibrationsbereich für den Parameter Protein sowie für die Anteile der verschiedenen Fettsäuren (hier nur am Beispiel Ölsäure aufgezeigt) zu vergrößern bzw. den Einfluss innerhalb der Kalibrationsentwicklung zu bewerten. 
Tab. 6: Zur Kalibrationsentwicklung herangezogene Datenvorbehandlungen

\begin{tabular}{l|l}
\hline Faktoren & Stufen \\
\hline Ableitung & DT $(0,0,1)$ \\
& DT $(1,2,2)$ \\
& DT $(1,4,4)$ \\
& DT $(1,10,5)$ \\
& DT $(2,4,4)$ \\
& DT $(2,10,5)$ \\
& DT $(2,20,10)$ \\
& DT(3,4,4) \\
\hline Streulichtkorrektur & keine SK \\
& DET \\
& SNV \\
& SNVD \\
& MSC \\
\hline
\end{tabular}

Ebenfalls wurde eine Hauptkomponentenanalyse (PCA) durchgeführt, um eine Populationsbeschreibung anhand der spektralen Daten gemahlener Achänen des Gesamtdatensatzes zu realisieren. Diese Berechnungen wurden unter Nutzung der ersten $(\mathrm{DT}(1,4,4))$ bzw. dritten $(\mathrm{DT}(3,4,4))$ Ableitung in Verbindung mit der Streulichtkorrektur SNVD durchgeführt.

\subsubsection{Statistische Auswertung}

Um festzustellen, ob die in Kapitel 3.4.2 eingesetzten Datenvorbehandlungen zu signifikanten Unterschieden in der Vorhersageleistung führen, wurde dieser Versuch varianzanalytisch ausgewertet. Die zwei Einflussfaktoren „Ableitung“ ( $n=8)$ und "Streulichtkorrektur" $(n=5)$ führen hierbei je Inhaltsstoff und Probenpräsentation zu 40 Kalibrationsgleichungen, welche jeweils an einem Validationsset überprüft wurden. Für diese somit verbundenen mehreren Stichproben wurde zur Auswertung der parameterfreie Friedman-Test (Rangvarianzanalyse) herangezogen (KöHLER et al., 2002).

Beim Friedman-Test sind die Stufen des einen Faktors spaltenweise und die des anderen Faktors zeilenweise angeordnet. Hierbei werden die Stufen des Zeilenfaktors als Wiederholung (Wdh.) aufgefasst. Anhand der den Messwerten zugeordneten Ränge wird die Nullhypothese überprüft, dass die Stichproben aller Spalten derselben 
Grundgesamtgesamtheit entstammen. Bei Verwerfung der Nullhypothese weisen mindestens zwei Stufen des Spaltenfaktors eine unterschiedliche Wirkung auf die resultierende Variable auf. Das bislang geschilderte Procedere prüft nur den Einfluss eines Faktors. Um auch die Wirkung des zweiten Faktors zu erfassen, wird nach dem Vertauschen der Spalten und Zeilen eine neue Rangvarianzanalyse durchgeführt. Da hier die einzelnen Faktoren nacheinander Berücksichtigung finden, spricht man vom quasi-zweifaktoriellen Test (KÖHLER et al., 2002).

Ergab die Prüfung mit dem Friedman-Test, dass nicht alle Stichproben einer Grundgesamtheit entstammen, so kann mit einem multiplen Vergleich getestet werden, welche und wie viele der Spaltenfaktoren eine unterschiedliche Wirkung aufweisen. Hierfür wurde in dieser Arbeit der Wilcoxon-Wilcox-Test verwendet. Bei diesem Verfahren werden zuerst die Rangsummen der Größe nach absteigend sortiert und dann aufsteigend indiziert, wobei die größte Rangsumme mit R1 gekennzeichnet ist. Beim Wilcoxon-Wilcox-Test werden die Differenzen der einzelnen Rangsummen mit tabellierten kritischen Werten verglichen. Beim Erreichen oder Überschreiten der kritischen Differenz entstammen die herangezogenen Stichproben nicht derselben Grundgesamtheit (SACHS, 1999).

In dieser Arbeit wurde zur Durchführung des Friedman-Tests die Software WinSTAT für Excel (FITCH, 2003) verwendet, wobei die aus den Einflussfaktoren resultierenden RPD-Werte (vgl. Kap. 2.3.3) zur Rangzuordnung herangezogen wurden. Unterschritt der durch die Software berechnete P-Wert das $5 \%$ Signifikanzniveau $(\alpha=0,05)$, so galt die Nullhypothese, die Behandlungen haben keinen signifikanten Einfluss, als verworfen. Die beim Friedman-Test ausgegebenen Rangmittel wurden für den anschließenden Wilcoxon-Wilcox-Test durch Multiplikation mit der betreffenden Anzahl an Wiederholungen in Rangsummen umgewandelt, um die jeweiligen Rangsummendifferenzen zu berechnen. Nach WILCOXON und WILCOX (1964) ergeben sich bei zweiseitiger Fragestellung folgende Werte: Die kritische Differenz beim Vergleich der unterschiedlichen Ableitungen (8 Stufen, 5 Wdh.) beträgt 23,5 auf dem $5 \%(\alpha=0,05)$ Signifikanzniveau bzw. 27,3 auf dem 1\% ( $\alpha=0,01)$ Signifikanzniveau. Beim Vergleich der verschiedenen Streulichtkorrekturen (5 Stufen, 8 Wdh.) ergibt sich eine kritische Differenz von 17,3 ( $\alpha=0,05)$ bzw. 20,6 ( $\alpha=0,01)$ auf dem jeweiligen Signifikanzniveau. Signifikante Unterschiede werden in der Arbeit mit einem Stern $\left({ }^{*}\right)$ $(\alpha=0,05)$ bzw. mit zwei Sternen $\left.{ }^{* *}\right)(\alpha=0,01)$ gekennzeichnet.

Um eventuelle Einflüsse größerer Variationen im Feuchtegehalt auf die Vorhersageleistung der Kalibrationen für Öl bzw. Ölsäure besser erklären zu können, wurden weiterhin mit Hilfe der Software WinSTAT für Excel (FITCH, 2003) die 
Rangkorrelationskoeffizienten nach Spearman $\left(r_{s}\right)$ zwischen den Laborwerten für Feuchte und jeweiligen Parametern Öl, ÖI $\mathrm{LT}_{\mathrm{L}}$ C18:1 sowie C18:1 $1_{\mathrm{LT}}$ berechnet. Analog hierzu wurden auch die Korrelationen zwischen Ölsäure und Linolsäure innerhalb der HO-Proben sowie innerhalb des Gesamtdatensatzes ermittelt. Die Angabe der Signifikanzniveaus erfolgt auch hier mit einem Stern $\left(^{*}\right)(\alpha=0,05)$ bzw. mit zwei Sternen $\left({ }^{* *}\right)(\alpha=0,01)$. 


\section{$4 \quad$ Ergebnisse}

\subsection{Einfluss der Datenvorbehandlung}

Mit Hilfe der Daten aus der Referenzanalytik (Kap. 3.3.1) sowie aus der nahinfrarotspektroskopischen Untersuchung (Kap. 3.3.2) wurden unter Verwendung verschiedener Ableitungen und Streulichtkorrekturen Kalibrationsgleichungen erstellt (Kap. 3.4.2), die anhand der jeweiligen modellfremden Validationsproben auf ihre Gültigkeit hin überprüft wurden.

Nachfolgende Abbildung (Abb. 2) zeigt die die Mittelwertsspektren gemahlener HOAchänen bei Verwendung der Originaldaten (DT $(0,0,1)$, keine Streulichtkorrektur) bzw. Verwendung der 1. Ableitung (DT $(1,4,4)$, SNVD). Des Weiteren sind die obere und untere Ausbreitung aller zur Berechnung der Mittelspektren herangezogenen Einzelspektren aufgeführt, um die spektrale Variabilität zu verdeutlichen. Weitere Darstellungen transformierter Spektren sind im Anhang (Abb. 10 und Abb. 11) abgebildet.
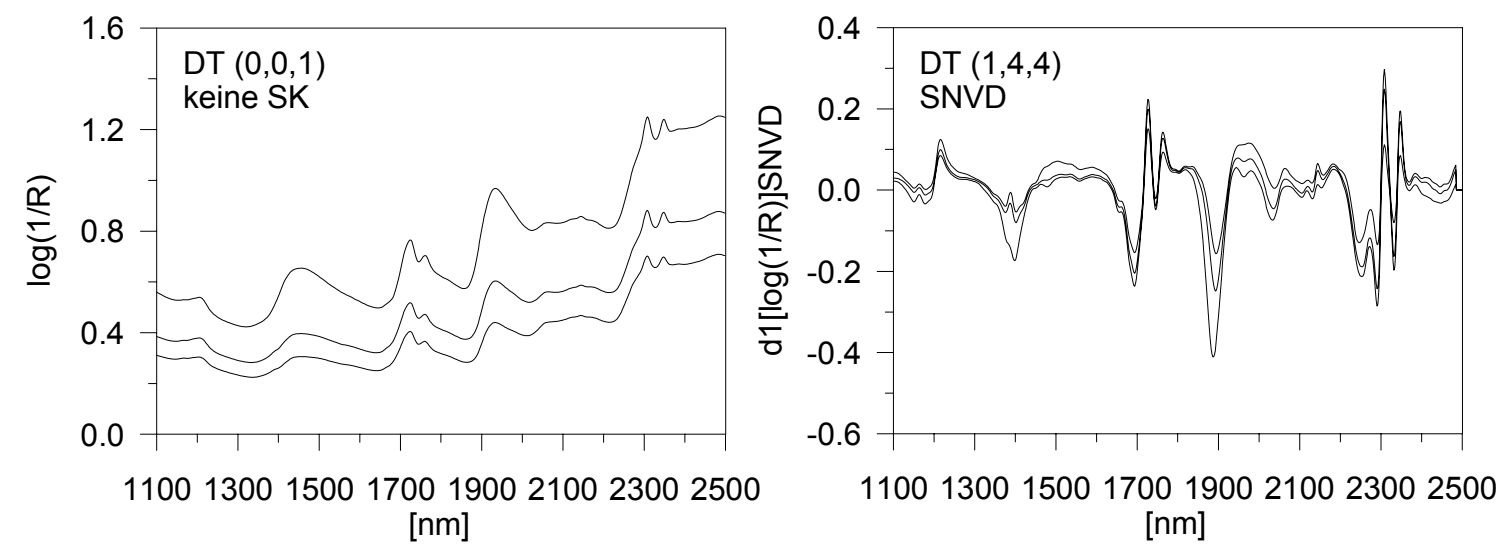

Abb. 2: Mittelwertsspektren sowie obere und untere Ausbreitung aller Spektren gemahlener HO-Achänen bei Verwendung der Originaldaten (DT(0,0,1), keine SK) bzw. Verwendung der 1. Ableitung (DT $(1,4,4)$, SNVD)

Die Auswirkung der in Abb. 2 aufgezeigten Spektrentransformation auf die Güte der Kalibrationsgleichung wird in folgender Tabelle (Tab. 7) für die Schätzung des Parameters Feuchte in gemahlener Saat anhand der Kalibrations- sowie der Validationsstatistik verdeutlicht. Bei gleichem Kalibrations- und Validationsset konnten allein durch die Transformation die Fehler innerhalb der Kalibration (SEC), der Kreuzvalidation (SECV) und der Validation (SEP bzw. SEPC) bei steigendem multiplen Bestimmtheitsmaß ( $R^{2}$ bzw. 1-VR) verringert werden. Die gesteigerte 
Vorhersageleistung wird auch durch den Anstieg des RPD-Wertes von 2,8 auf 3,7 charakterisiert.

Tab. 7: Ergebnisse der Kalibration, Kreuzvalidation und Validation bei Verwendung der Originaldaten (DT(0,0,1), keine SK) bzw. Verwendung der 1. Ableitung (DT $(1,4,4)$, SNVD) für Feuchtegehalt in gemahlenen Achänen

Feuchte, gemahlene Achänen

\begin{tabular}{cc|cc|cc|cccc}
\multicolumn{2}{c|}{ Transformation } & \multicolumn{2}{c|}{ Kalibration } & \multicolumn{2}{c|}{ Kreuzvalidation } & \multicolumn{5}{c}{ Validation } \\
DT & SK & SEC & R $^{2}$ & SECV & 1-VR & SEP & SEPC & $\mathrm{R}^{2}$ & RPD \\
\hline$(0,0,1)$ & keine & 0,51 & 0,89 & 0,51 & 0,89 & 0,57 & 0,57 & 0,87 & 2,8 \\
$(1,4,4)$ & SNVD & 0,40 & 0,94 & 0,43 & 0,93 & 0,43 & 0,43 & 0,93 & 3,7
\end{tabular}

Auch im Folgenden wird am Beispiel der Abschätzung des Parameters Linolsäure (C18:2) an gemahlenen HO-Sonnenblumenachänen der Einfluss der Datentransformation aufgezeigt, wobei wiederum das Verwenden der Originaldaten mit der Verwendung der 1. Ableitung (DT $(1,4,4)$ und Nutzung der Streulichtkorrektur SNVD verglichen wird. Die Kalibrations- sowie Validationsstatistik ist in folgender Tabelle (Tab. 8) aufgeführt.

Tab. 8: Ergebnisse der Kalibration, Kreuzvalidation und Validation bei Verwendung der Originaldaten (DT(0,0,1), keine SK) bzw. Verwendung der 1. Ableitung (DT(1,4,4), SNVD) für Linolsäuregehalt $(C 18: 2)$ in gemahlenen Achänen

C18:2, gemahlene Achänen

\begin{tabular}{cc|cc|cc|cccc}
\multicolumn{2}{c|}{ Transformation } & \multicolumn{2}{|c|}{ Kalibration } & \multicolumn{2}{|c|}{ Kreuzvalidation } & \multicolumn{5}{c}{ Validation } \\
DT & SK & SEC & $\mathrm{R}^{2}$ & SECV & 1-VR & SEP & SEPC & $\mathrm{R}^{2}$ & RPD \\
\hline$(0,0,1)$ & keine & 0,58 & 0,84 & 0,60 & 0,82 & 0,55 & 0,55 & 0,87 & 2,8 \\
$(1,4,4)$ & SNVD & 0,28 & 0,96 & 0,30 & 0,96 & 0,25 & 0,25 & 0,97 & 6,1
\end{tabular}

In dem in Tab. 8 aufgeführten Falle zur Schätzung des C18:2-Gehaltes konnten durch die Nutzung der 1. Ableitung (DT(1,4,4) sowie der Streulichtkorrektur SNVD die Fehler in Kalibration, Kreuzvalidation und der externen Validation um ungefähr die Hälfte reduziert werden, wodurch in Folge der hohe RPD-Wert von 6,1 erreicht wurde. Der durch die Spektrentransformation verringerte Fehler in der Vorhersage modellfremder 
Proben wird auch durch folgende Validationsdiagramme (Abb. 3) veranschaulicht, in denen die Ergebnisse der nahinfrarotspektroskopischen Schätzfunktionen den Werten der Referenzanalytik gegenübergestellt sind, wobei die gestrichelte Linie die Regressionsgerade darstellt. Die verbesserte Leistungsfähigkeit der Kalibration, die mit Hilfe der Transformation DT $(1,4,4)$ sowie SNVD erstellt wurde, zeigt sich in Abb. 3 durch die geringere Streuung der Messpunkte um die Regressionsgerade. Auch die Steigung der Regressionsgerade (Slope) konnte hier von 1,07 auf 1,02 leicht verbessert werden.
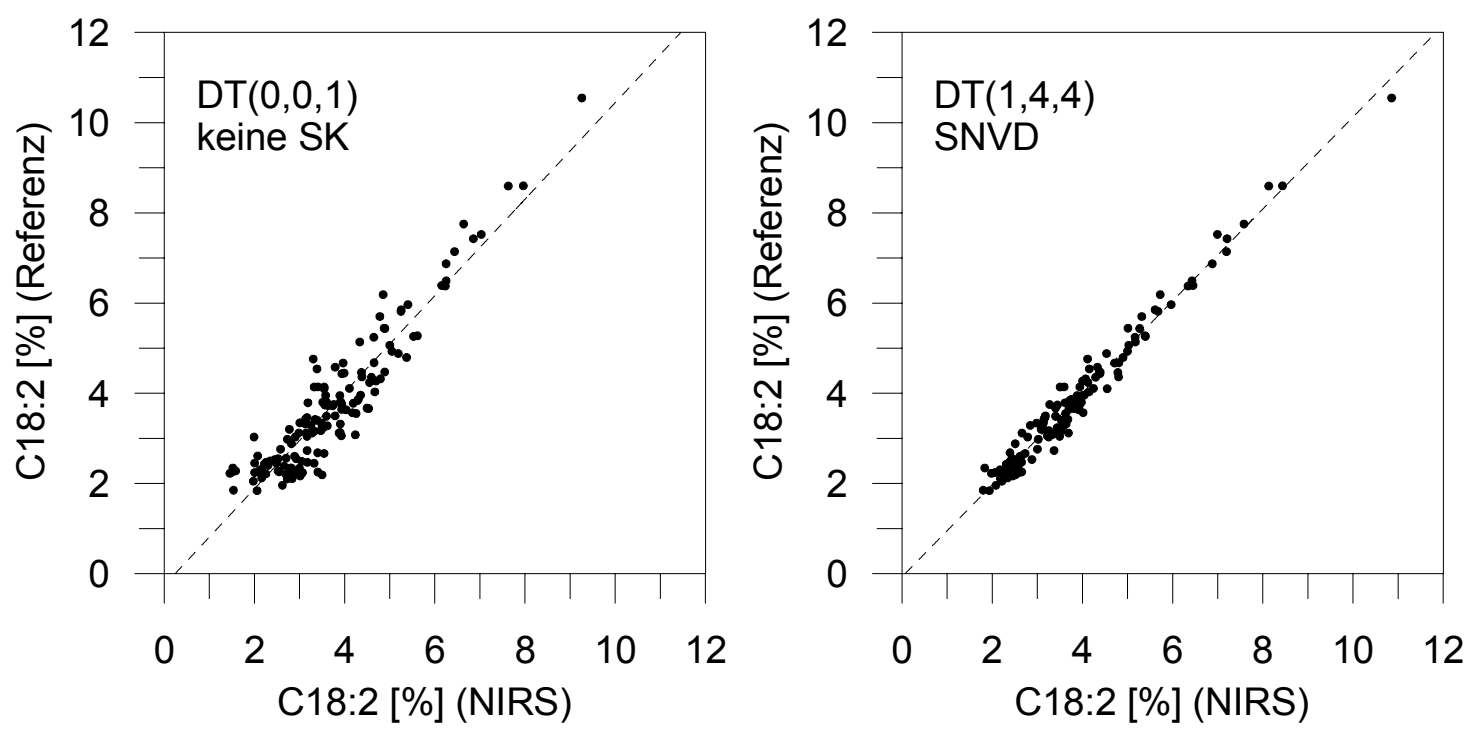

Abb. 3: Validationsdiagramme und Regressionsgeraden für die Erfassung der Linolsäuregehalte (C18:2) in gemahlenen HO-Achänen unter Verwendung der Originaldaten (DT(0,0,1), keine SK) bzw. Verwendung der 1. Ableitung (DT(1,4,4), SNVD)

Bislang wurden die Kalibrationen für die Inhaltsstoffe Feuchte sowie Linolsäure in gemahlener Saat mit einander verglichen, die unter der Verwendung der Originaldaten (DT $(0,0,1)$, keine SK) bzw. und Nutzung der 1. Ableitung (DT(1,4,4),SNVD) erstellt wurden. Wie in Kap. 3.4.2 aufgeführt, wurden auch weitere Spektrentransformationen berechnet. Für die in Tab. 4 gelisteten 12 Parameter wurden somit durch Nutzung 8 verschiedener Ableitungen sowie 5 unterschiedlicher Streulichtkorrekturen insgesamt 960 verschiedene Kalibrationsmodelle erstellt. Diese für gemahlene sowie intakte Achänen entwickelten Schätzgleichungen wurden mit Hilfe der zugehörigen Validationssets überprüft. Die hierbei erzielten Ergebnisse der Kalibration, Kreuzvalidierung sowie der externen Validation sind vollständig im Anhang in Tab. 20 sowie in Tab. 21 gelistet. 
In folgender Tabelle (Tab. 9) sind die Schätzgleichungen aufgeführt, die je Inhaltsstoff und Zustandsform die höchsten RPD-Werte lieferten. Ergebnisse zu den Parametern Öl $\mathrm{LT}_{\mathrm{LT}}, \mathrm{C} 18: 1_{\mathrm{LT}}$, Protein ${ }_{\mathrm{GES}}$ sowie C18:1 $1_{\mathrm{GES}}$ werden hierbei erst in Kap. 4.3 „Einfluss einzelner Probengruppen“ beschrieben.

Tab. 9: Ergebnisse der Kalibration, Kreuzvalidation und Validation für die Modelle mit der höchsten Vorhersageleistung (RPD) je Parameter für gemahlene (gm) und intakte Achänen (GK) bei Verwendung verschiedener Ableitungen (DT) sowie Streulichtkorrekturen (SK)

\begin{tabular}{|c|c|c|c|c|c|c|c|c|c|c|c|}
\hline \multicolumn{2}{|c|}{ Applikation } & \multicolumn{2}{|c|}{ Transformation } & \multicolumn{2}{|c|}{ Kalibration } & \multicolumn{2}{|c|}{ Kreuzvalidation } & \multicolumn{4}{|c|}{ Validation } \\
\hline Para. & $\mathrm{Zu}$. & DT & SK & SEC & $\mathrm{R}^{2}$ & SECV & $1-V R$ & EP & SEPC & $\mathrm{R}^{2}$ & RPD \\
\hline \multirow[t]{2}{*}{ Feuchte } & $\mathrm{gm}$ & $1,4,4)$ & & 0,40 & & 40 & , & 43 & 0,40 & 93 & , \\
\hline & GK & $(1,2,2)$ & $\mathrm{K}$ &, 58 & 0,86 & 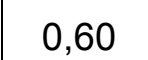 & 0,84 & 55 & 0,55 & 0,87 & 2,0 \\
\hline \multirow[t]{2}{*}{ FFA } & $\mathrm{gm}$ & $(2,4,4)$ & DET & 0,23 & 0,94 & 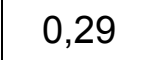 & 0,90 & 21 & 0,21 & 0,95 & 4,3 \\
\hline & GK & , & SNVD & 33 & 0,02 & 0,36 & 0,79 & 34 & 0,34 & 0,80 & $\angle$ \\
\hline \multirow[t]{2}{*}{ Öl } & $\mathrm{gm}$ & $(1,10,5)$ & SNVD & 0,70 & 0,92 & T & 0,91 & 68 & 0,68 & 0,92 & 3,6 \\
\hline & GK & $(<, 4,4)$ & SNVD & ,94 & 0,85 & 1 & 0,83 & 00 & 1,00 & 0,83 & 2,4 \\
\hline \multirow[t]{2}{*}{ Protein } & $\mathrm{gm}$ & $(3,4,4)$ & $\mathrm{S}$ & 6 & 08 & 0,51 & 0,94 & 6 & 5 & 95 & 11 \\
\hline & GK & $(2,4$ & Keine & 0,69 & 0,86 & 0,15 & 0,83 & 0,73 & 0,74 & 0,84 & 2,5 \\
\hline \multirow[t]{2}{*}{ C16:0 } & $\mathrm{gm}$ & $(1,4,4)$ & S & 0,09 & 0,95 & 0,10 & 0,94 & 99 & 0,09 & 95 & 4,5 \\
\hline & GK & $(2,4$ & SNVD & 0,10 & 0,94 & 12 & 0,92 & 0,11 & 0,11 & 0,93 & 3,6 \\
\hline \multirow[t]{2}{*}{ C18:0 } & $\mathrm{gm}$ & $(2,4,4)$ & SNVD & 0,12 & 0,96 & 0,14 & 0,95 & 0,13 & 0,13 & 0,96 & 4,8 \\
\hline & GK & 1 & 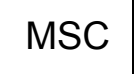 & 8 & 0,91 & 0,20 & 0 & $a$ & $a$ & 11 & 3,3 \\
\hline \multirow[t]{2}{*}{ C18:1 } & $\mathrm{gm}$ & $(2,4,4)$ & MSC & 0,35 & 0,97 & 0,40 & 0,97 & 0,36 & 0,36 & 0,97 & 6,1 \\
\hline & GK & $(1,4,4)$ & SI & 0,82 & 0, & U, & 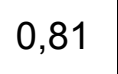 & 0,10 & 0 , & 0,84 & 2,0 \\
\hline \multirow[t]{2}{*}{ C18:2 } & $\mathrm{gm}$ & $(2,4,4$ & MSC & 0,21 & 0,98 & (2) & 0,97 & 0,23 & 0,23 & 0,98 & 6,7 \\
\hline & GK & $(1,4,4)$ & NV & 62 & 0,74 & 0,65 & 0,71 & 0,56 & 6 & 0,80 & 2,2 \\
\hline
\end{tabular}

Die in Tab. 9 charakterisierten Kalibrationsgleichungen weisen stets geringe Standardfehler (SEC, SECV, SEP sowie SEPC) bei hohen Bestimmtheitsmaßen auf. Im Vergleich zu den Kalibrationen für intakte Achänen wird deutlich, dass die an gemahlenem Material erstellten NIRS-Methoden eindeutig zu kleineren Vorhersagefehlern und in der Folge zu höheren RPD-Werten führen. Des Weiteren zeigt Tab. 9, dass zum Erreichen der höchsten Vorhersageleistung (RPD) je Parameter und Präsentationsform eine andere Spektrentransformation von Nöten ist. 
Das Potenzial, durch Verwendung verschiedener Ableitungen sowie Streulichtkorrekturen leistungsfähigere Kalibrationsmodelle zu erhalten, wird durch folgende Tabelle (Tab. 10) anhand der Verteilung der in dieser Arbeit erzielten RPDWerte aufgezeigt (vgl. Tab. 20).

Tab. 10: Erzielte RPD-Werte unter Verwendung verschiedener Ableitungen $(n=8)$ und Streulichtkorrekturen $(n=5)$

\begin{tabular}{c|cccc|cccc}
\hline & \multicolumn{3}{|c|}{ Gemahlene Achänen } & \multicolumn{4}{c}{ Intakte Achänen } \\
& Max & Min & Mittel & SD & Max & Min & Mittel & SD \\
\hline Feuchte & 3,7 & 2,8 & 3,4 & 0,2 & 2,8 & 2,5 & 2,6 & 0,1 \\
FFA & 4,3 & 2,2 & 3,4 & 0,6 & 2,2 & 2,0 & 2,1 & 0,1 \\
Öl & 3,6 & 3,1 & 3,4 & 0,1 & 2,4 & 2,0 & 2,3 & 0,1 \\
Protein & 4,4 & 3,4 & 3,8 & 0,2 & 2,5 & 1,8 & 2,2 & 0,2 \\
C16:0 & 4,5 & 3,2 & 4,0 & 0,4 & 3,6 & 2,5 & 3,1 & 0,3 \\
C18:0 & 4,8 & 2,4 & 3,7 & 0,7 & 3,3 & 2,5 & 3,0 & 0,2 \\
C18:1 & 6,1 & 2,3 & 4,5 & 1,1 & 2,5 & 2,1 & 2,4 & 0,1 \\
C18:2 & 6,7 & 2,6 & 5,0 & 1,3 & 2,2 & 1,8 & 2,0 & 0,1 \\
\hline
\end{tabular}

Die Tabelle (Tab. 10) sowie das Box-Whisker-Diagramm im Anhang (Abb. 12) verdeutlichten, dass aus der Verwendung unterschiedlicher Datenvorbehandlungen Kalibrationsgleichungen mit verschiedener Leistungsfähigkeit resultieren, wobei die größten RPD-Werte sowie Spannbreiten an gemahlenem Material erzielt wurden.

Inwieweit sich die aus der Verwendung verschiedener Spektrentransformationen resultierenden RPD-Werte signifikant unterscheiden, wurde mit der nichtparametrischen Rangvarianzanalyse nach Friedman und dem multiplen Vergleich nach Wilcoxon und Wilcox untersucht. Folgende Tabelle (Tab. 11) gibt eine Übersicht der erzielten Resultate, wobei die vollständigen Ergebnisse der varianzanalytischen Auswertung zum Einfluss verschiedener Datenvorbehandlungen im Anhang (Tab. 20) zu finden sind. 
Tab. 11: Übersicht der varianzanalytischen Auswertung mit dem FriedmanTest sowie mit dem multiplen Anschlusstest nach Wilcoxon und Wilcox zum Einfluss verschiedener Datenvorbehandlungen auf die RPD-Werte

\begin{tabular}{l|cc|cc}
\hline & \multicolumn{2}{|c|}{ Gemahlene Achänen } & \multicolumn{2}{c}{ Intakte Achänen } \\
& Ableitungen & Streulichtkorrekturen. & Ableitungen & Streulichtkorrekturen. \\
\hline Feuchte & $*$ & $*($ n.s. & $*$ & $*$ \\
FFA & $*$ & n.s. & $*$ & n.s. \\
Öl & $*$ & $*$ & $*$ & n.s. \\
Protein & $*$ & $*$ & $*$ & n.s. \\
C16:0 & $*$ & $*$ & $*$ & n.s. \\
C18:0 & $*$ & $*$ & $*$ & $*$ \\
C18:1 & $*$ & $*($ n.s. $)$ & $*$ & $*$ \\
C18:2 & $*$ & $*$ & & \\
\hline
\end{tabular}

*: signifikanter Unterschied mindestens zweier Behandlungen sowohl beim Friedman-Test als auch beim Wilcoxon-Wilcox-Test

n.s.: $\quad$ kein signifikanter Unterschied aller Behandlungen sowohl beim Friedman-Test als auch beim Wilcoxon-Wilcox-Test

*(n.s.): $\quad$ signifikanter Unterschied mindestens zweier Behandlungen beim Friedman-Test, jedoch keine signifikanten Unterschiede beim Wilcoxon-Wilcox-Test

Die Tests nach Friedman sowie die multiplen Vergleiche ergaben, dass die Spektrentransformationen durch Verwendung unterschiedlicher Ableitungen bei allen Parametern und den beiden Probenpräsentationen stets zu mindestens zwei signifikant unterschiedlichen Vorhersageleistungen führen. Dieser Einfluss der Ableitungen wird nach dem Wilcoxon-Wilcox-Test außer für den FFA-Gehalt in intakter Saat für alle anderen Parameter und Probenpräsentationen auf dem 1\% Signifikanzniveau bestätigt. Dahingegen führte in dieser Arbeit das Verwenden verschiedener Streulichtkorrekturen häufig zu keinen signifikanten Unterschieden in der Vorhersageleistung. Bei den Kalibrationen, die an gemahlener Saat entwickelt wurden, ergab sich für die Parameter Feuchte sowie Ölsäure im Friedmann-Test eine Verwerfung der Nullhypothese, während die multiplen Anschlusstests keine signifikanten Unterschiede aufdeckten.

Nachfolgende Abbildung (Abb. 4) veranschaulicht für den Parameter Protein in gemahlener Saat die aus den verschiedenen Spektrentransformationen resultierenden RPD-Werte. Dabei wurden die Ableitungen ihrer im Wilcoxon-Wilcox-Test 
zugeordneten Rangsumme $\left(R_{1}\right.$ bis $\left.R_{8}\right)$ nach aufgeführt. Die Abbildung zeigt, dass sich für den Parameter Protein in gemahlenen HO-Achänen mit der dritten Ableitung (DT $(3,4,4))$ und Nutzung der Streulichtkorrekturen SNV, SNVD und MSC die besten Vorhersageergebnisse erzielen lassen, wobei sich die genannten Streulichtkorrekturen gleich bzw. sehr ähnlich auswirken.

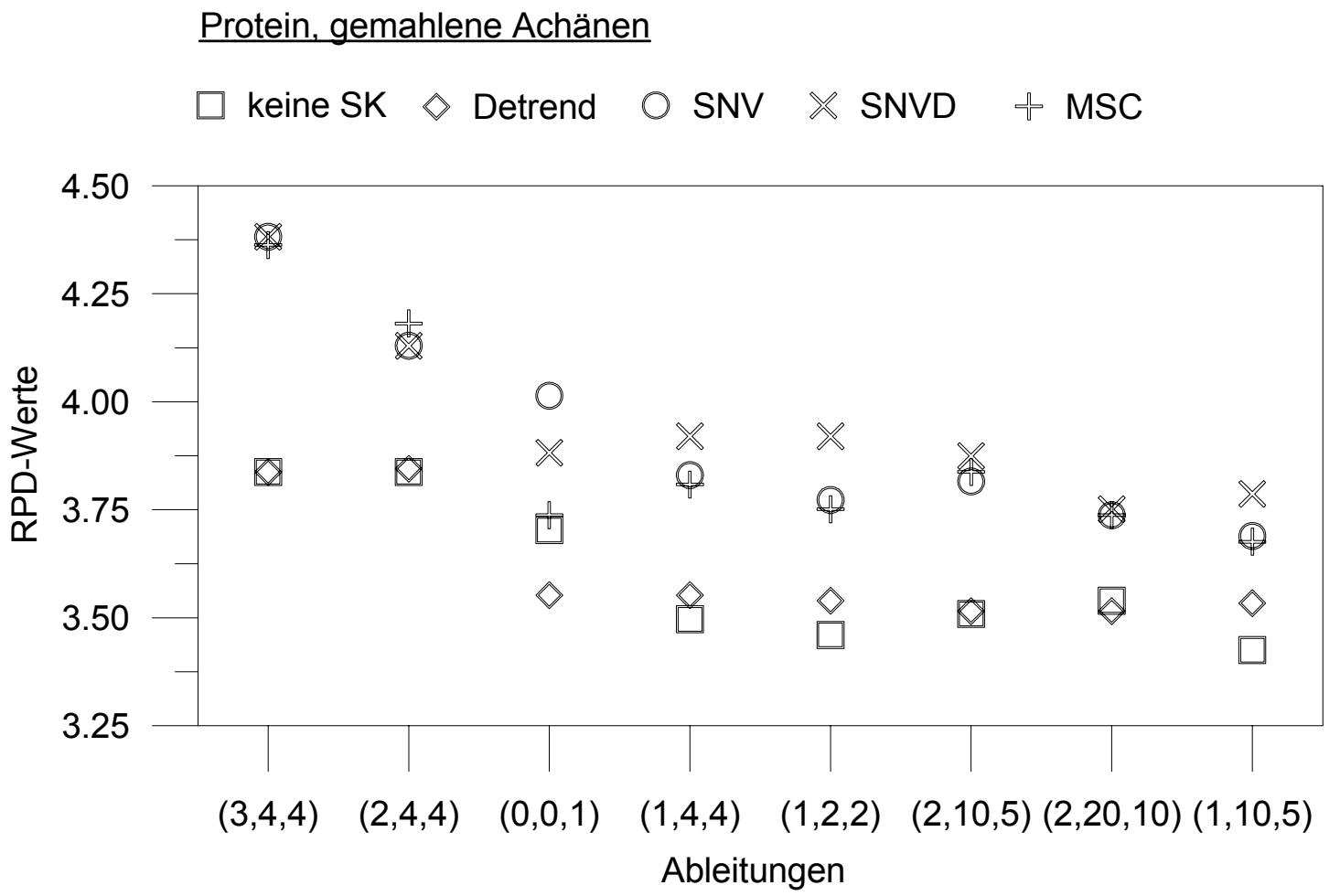

Abb. 4: Darstellung der erzielten RPD-Werte für den Parameter Protein in gemahlenen HO-Achänen unter Verwendung verschiedener Ableitungen $(n=8)$ und Streulichtkorrekturen $(n=5)$

Aber nicht nur die Dimension einer Ableitung hat einen Einfluss auf die Vorhersageleistung, sondern auch die Art der Bildung. So unterscheiden sich in dem in Abb. 4 aufgezeigten Beispiel die Ableitungen DT $(2,4,4)$ und DT(2,20,10) auf dem 5\% Signifikanzniveau (vgl. Tab. 20). Die Ableitung DT(2,20,10) belegt zwar häufig die hinteren Ränge, jedoch ist ihr bei der Vorhersageleistung des Parameters FFA in intakten Achänen die höchste Rangsumme zugeordnet.

Die in diesem Kapitel aufgezeigten Ergebnisse verdeutlichen, dass keine Art der Spektrentransformation bei allen Parametern und Präsentationsformen stets die beste Vorhersageleistung bewirkt. 


\subsection{Vergleich der Vorhersageergebnisse mit den Präzisionsgrenzen amtlicher Methoden}

Resultierend aus den in Tab. 9 gekennzeichneten NIRS-Methoden sind die Vorhersagewerte ( $\mathrm{y}_{\text {NIRS }}$ ) der Validationsproben mit den jeweiligen Werten der Referenzanalyse $\left(\mathrm{y}_{\mathrm{REF}}\right)$ verglichen worden. Die durch die Berechnung $\left|\mathrm{y}_{\mathrm{NIRS}}-\mathrm{y}_{\mathrm{REF}}\right| \mathrm{je}$ Probe ermittelte absolute Differenz $\Delta_{\mathrm{ABS}}$ wurde der betreffenden Wiederholgrenze $r_{\mathrm{W}}$ sowie der Vergleichgrenze $R_{V}$ (vgl. Tab. 3) gegenübergestellt. In nachfolgender Tabelle (Tab. 12) ist der den Präzisionsgrenzen zugeordnete prozentuale Anteil der Validationsproben je Parameter und Probenpräsentation aufgeführt sowie der jeweilige maximal erreichte absolute Fehler (Max $\Delta_{\mathrm{ABs}}$ ) angegeben.

Tab. 12: Vergleich der absoluten Vorhersagedifferenzen vom Referenzwert mit den Wiederhol-sowie Vergleichgrenzen der amtlichen Methoden

\begin{tabular}{l|l|c|c|c|c|c|c}
\hline Parameter & Zu. & $r_{\mathrm{W}}>=\Delta_{\mathrm{ABS}}{ }^{1}$ & $\mathrm{R}_{\mathrm{V}}>=\Delta_{\mathrm{ABS}}>\mathrm{r}_{\mathrm{W}}{ }^{1}$ & $\Delta_{\mathrm{ABS}}>\mathrm{R}_{\mathrm{V}}{ }^{1}$ & $\mathrm{n}_{\mathrm{VAL}}$ & Max $\Delta_{\mathrm{ABS}}{ }^{2}$ & $\mathrm{SD} \Delta_{\mathrm{ABS}}{ }^{2}$ \\
\hline Feuchte & $\mathrm{gm}$ & 45,7 & 16,0 & 38,3 & 162 & 1,31 & 0,28 \\
& $\mathrm{Gk}$ & 30,9 & 18,1 & 51,0 & 149 & 1,51 & 0,33 \\
\hline FFA & $\mathrm{gm}$ & 7,6 & 16,5 & 75,9 & 79 & 0,49 & 0,12 \\
& $\mathrm{Gk}$ & 4,2 & 16,9 & 78,9 & 71 & 0,94 & 0,22 \\
\hline Öl & $\mathrm{gm}$ & 83,7 & 6,3 & 10,0 & 190 & 1,79 & 0,39 \\
& $\mathrm{Gk}$ & 65,4 & 7,4 & 27,1 & 188 & 2,70 & 0,60 \\
\hline Protein & $\mathrm{gm}$ & 100,0 & 0,0 & 0,0 & 132 & 1,76 & 0,29 \\
& $\mathrm{Gk}$ & 99,2 & 0,8 & 0,0 & 123 & 1,96 & 0,44 \\
\hline Protein & gm & 82,6 & 15,9 & 1,5 & 132 & 1,76 & 0,29 \\
& $\mathrm{gm}$ & 61,8 & 22,0 & 16,3 & 123 & 1,96 & 0,44 \\
\hline C16:0 & $\mathrm{gm}$ & 97,4 & 2,6 & 0,0 & 116 & 0,29 & 0,05 \\
& $\mathrm{Gk}$ & 90,4 & 9,6 & 0,0 & 104 & 0,27 & 0,07 \\
\hline C18:0 & $\mathrm{gm}$ & 87,1 & 12,9 & 0,0 & 147 & 0,38 & 0,08 \\
& $\mathrm{Gk}$ & 79,6 & 20,4 & 0,0 & 137 & 0,56 & 0,12 \\
\hline C18:1 & $\mathrm{gm}$ & 83,0 & 17,0 & 0,0 & 147 & 1,04 & 0,23 \\
& $\mathrm{Gk}$ & 52,2 & 47,8 & 0,0 & 136 & 2,35 & 0,48 \\
\hline C18:2 & $\mathrm{gm}$ & 75,5 & 24,5 & 0,0 & 147 & 0,80 & 0,15 \\
& $\mathrm{Gk}$ & 28,4 & 67,9 & 3,7 & 134 & 1,73 & 0,34 \\
\hline
\end{tabular}

$r_{\mathrm{w}}$ : Wiederholgrenze; $R_{\mathrm{V}}$ : Vergleichsgrenze; ${ }^{1}$ : in \% aller Validationsproben; $\Delta_{\mathrm{ABS}}$ : Betrag der Differenz zwischen Vorhersage- und Laborwert; ${ }^{2}$ : in der Einheit des betreffenden Parameters; ${ }^{3}$ : Angaben bezogen auf die produktunspezifischen Präzisionsgrenzen 
Gemessen an der Vergleichsgrenze $R_{V}$ zeigt sich bei dem in Tab. 12 aufgeführtem Vergleich, dass ein Großteil der Validationsproben durch die entwickelten Kalibrationsgleichungen mit der gleichen Präzision wie die amtlichen Methoden vorhergesagt wird. Bei den NIRS-Methoden für die Abschätzung der Anteile der jeweiligen Fettsäure in gemahlenen und intakten Achänen liegen mit Ausnahme der Erfassung der Linolsäure in intakter Saat alle Vorhersagedifferenzen unterhalb der Vergleichsgrenze. Im Falle der Erfassung des Parameters Protein in gemahlenen Achänen werden $100 \%$ bzw. 82,6\% der Validationsproben bei Einhaltung der produktspezifischen bzw. -unspezifischen Wiederholgrenze vorhergesagt. Die Tab. 12 zeigt aber auch auf, dass nicht alle Kalibrationsgleichungen eine Vorhersage der Validationsproben innerhalb der Vergleichgrenze realisieren. So werden bei der Erfassung des Ölgehaltes in gemahlenen Achänen rund 84\% der Proben innerhalb der Wiederholgrenze vorhergesagt, während $10 \%$ der Proben die maximal zulässige Differenz der Vergleichbarkeit überschreiten. Im Falle der Abschätzung des Anteils freier Fettsäuren in gemahlenen sowie intakten Achänen liegen mehr als $75 \%$ aller Validationsproben außerhalb der Präzisionsgrenzen der amtlichen Methode. 


\subsection{Einfluss einzelner Probengruppen}

\subsubsection{Einbeziehung erntefeuchter Proben}

Wie in Kap. 3.4.2 beschrieben, wurde durch Verwenden bzw. Weglassen des Datensatzes A4 (erntefeuchte Proben) überprüft, inwieweit größere Schwankungen im Feuchtegehalt eine veränderte Vorhersageleistung für andere Parameter wie Öl und Ölsäure bewirken. In den folgenden Tabellen (Tab. 13 sowie Tab. 14) ist der Einfluss der erntefrischen Proben für die Parameter Öl bzw. Ölsäure durch die Angabe der jeweils resultierenden SEPC- und RPD-Werte aufgezeigt, wobei der Index „LT“ die ausschließlich auf lagertrockenem Material basierenden Sets kennzeichnet. Des Weiteren ist die Anzahl der in den Sets enthaltenen erntefeuchten Proben $\left(n_{E F}\right)$ aufgeführt. Für den Vergleich wurden die Spektrentransformationen verwendet, welche für die Parameter Öl bzw. Ölsäure je Präsentationsform bei den Kalibrationsmodellen unter Einbeziehung der erntefeuchten Proben die höchsten RPD-Werte lieferten (vgl. Tab. 9).

Tab. 13: Vergleich der Vorhersageleistungen beim Vorhandensein bzw. Fehlen von erntefeuchten Proben in der Kalibrationsgleichung bzw. im Validationsset am Beispiel des Parameters Öl

\begin{tabular}{l|cc|cc} 
Gemahlene Achänen & \multicolumn{2}{|c|}{ Validation $_{\mathrm{LT}}$} & \multicolumn{2}{c}{ Validation $\left(\mathrm{n}_{\mathrm{EF}}=9\right)$} \\
$\mathrm{DT}(1,10,5), \mathrm{SNVD}$ & SEPC & RPD & SEPC & RPD \\
\hline Kalibration $\mathrm{LT}_{\mathrm{N}}$ & 0,69 & 3,5 & 0,74 & 3,3 \\
Kalibration $\left(\mathrm{n}_{\mathrm{EF}}=42\right)$ & 0,67 & 3,6 & 0,68 & 3,6
\end{tabular}

\begin{tabular}{l|cc|cc} 
Intakte Achänen & \multicolumn{2}{|c|}{ Validation $_{\mathrm{LT}}$} & \multicolumn{2}{c}{ Validation $\left(\mathrm{n}_{\mathrm{EF}}=9\right)$} \\
$\mathrm{DT}(2,4,4), \mathrm{SNVD}$ & SEPC & RPD & SEPC & RPD \\
\hline Kalibration & & & & \\
Ka & 0,98 & 2,4 & 1,10 & 2,2 \\
Kalibration $\left(\mathrm{n}_{\mathrm{EF}}=49\right)$ & 1,00 & 2,3 & 1,00 & 2,4
\end{tabular}

$\mathrm{n}_{\mathrm{EF}}$ : Anzahl erntefeuchter Proben; LT: Sets mit ausschließlich lagertrockenem Material

Die oben aufgeführte Tabelle (Tab. 13) zeigt, dass die Kalibrationsmodelle, die mit bzw. ohne Einbeziehung erntefeuchter Proben erstellt wurden, bei der Abschätzung des Parameters Öl in lagertrockenen gemahlenen sowie intakten HO-Achänen vergleichbare Vorhersageergebnisse erzielen. Sofern jedoch im Validationsset auch Proben mit einer höheren Restfeuchte vorhanden sind, bestechen die unter 
Einbeziehung erntefeuchter Proben erstellten Kalibrationen durch eine annährend gleich bleibende Vorhersagegüte, während bei Verwendung der ausschließlich an lagertrockenem Material entwickelten NIRS-Methoden ein Anstieg des Vorhersagefehlers SEPC sowie eine Abnahme des RPD-Wertes zu verzeichnen ist. Dieser Sachverhalt lässt sich auch in folgender Tabelle (Tab. 14) am Beispiel der Abschätzung des Ölsäuregehaltes in gemahlener sowie intakter Saat erkennen.

Tab. 14: Vergleich der Vorhersageleistungen beim Vorhandensein bzw. Fehlen von erntefeuchten Proben in der Kalibrationsgleichung bzw. im Validationsset am Beispiel des Parameters Ölsäure

\begin{tabular}{l|cc|cc} 
Gemahlene Achänen & \multicolumn{2}{|c|}{ Validation $_{\mathrm{LT}}$} & \multicolumn{2}{c}{ Validation $\left(\mathrm{n}_{\mathrm{EF}}=9\right)$} \\
$\mathrm{DT}(2,4,4), \mathrm{MSC}$ & SEPC & RPD & SEPC & RPD \\
\hline Kalibration $\mathrm{LT}_{\mathrm{N}}$ & 0,36 & 5,9 & 0,44 & 4,8 \\
Kalibration $\left(\mathrm{n}_{\mathrm{EF}}=48\right)$ & 0,34 & 6,3 & 0,36 & 6,1
\end{tabular}

\begin{tabular}{l|cc|cc} 
Intakte Achänen & \multicolumn{2}{|c|}{ Validation $n_{\mathrm{LT}}$} & \multicolumn{2}{c}{ Validation $\left(\mathrm{n}_{\mathrm{EF}}=9\right)$} \\
$\mathrm{DT}(1,4,4), \mathrm{SNV}$ & SEPC & RPD & SEPC & RPD \\
\hline Kalibration $\mathrm{LT}$ & 0,77 & 2,5 & 0,80 & 2,5 \\
Kalibration $\left(\mathrm{n}_{\mathrm{EF}}=51\right)$ & 0,77 & 2,5 & 0,78 & 2,5
\end{tabular}

$\mathrm{n}_{\mathrm{EF}}$ : Anzahl erntefeuchter Proben; $\mathrm{LT}$ : Sets mit ausschließlich lagertrockenem Material

Beide Tabellen (Tab. 13 sowie Tab. 14) zeigen, dass Validationsdatensätze, in denen erntefeuchtes Material enthalten ist, am Besten durch Kalibrationen erfasst werden, die auch unter Verwendung erntefrischer Proben entstanden sind. Ebenfalls wird deutlich, dass bei ausschließlich an lagertrockenem Material erstellten Kalibrationen ein Verlust an Vorhersageleistung zu verzeichnen ist, sofern im Validationsset erntefeuchte Proben enthalten sind. Hierbei sind die geschilderten Effekte bei der Verwendung von gemahlenem Material ausgeprägter. So steigt bei den Kalibrationen für gemahlene Achänen der SEPC über alle Validationsproben, unter denen sich auch erntefeuchte Proben befinden, für den Parameter Öl von 0,68 auf 0,74 und für Ölsäure von 0,36 auf 0,44 an, sofern die Schätzgleichungen ohne Einbeziehung dieser zusätzlichen Variabilität an Feuchte entwickelt worden sind. Der Verlust an Vorhersageleistung wird dabei auch durch die sinkenden RPD-Werte der Kalibrationen für Öl von 3,6 auf 3,3 sowie für Ölsäure von 6,1 auf 4,8 verdeutlicht. Werden die unter zur Hilfenahme der erntefrischen Proben erstellten Kalibrationen an lagertrockenem Material angewendet, so ergeben sich für die Schätzung gemahlener Achänen im Vergleich zu den 
Kalibrationsgleichungen, bei denen keine erntefeuchten Proben in Modellbildung mit eingeflossen sind, interessanterweise leicht verbesserte RPD-Werte. Für die hier gezeigten Parameter wird deutlich, dass die Vorhersageleistung für lagertrockene Proben durch die Einbeziehung von erntefrischem Probengut in die Kalibrationsentwicklung annährend unverändert bleibt, während das Vorhersagevermögen für erntefeuchte Proben gesteigert wurde.

Während die bisherigen Betrachtungen zum Einfluss erntefeuchter Proben mit Hilfe des gesamten Validationssets durchgeführt worden sind, wird in der folgenden Abbildung (Abb. 5) am Beispiel der Schätzung der Ölsäuregehalte in gemahlener Saat der Unterschied in der Vorhersageleistung der jeweiligen Kalibrationsgleichung nur an den Validationsproben mit hoher Restfeuchte aufgezeigt. Des Weiteren sind in Abb. 5 die Feuchtegehalte der Proben angegeben.

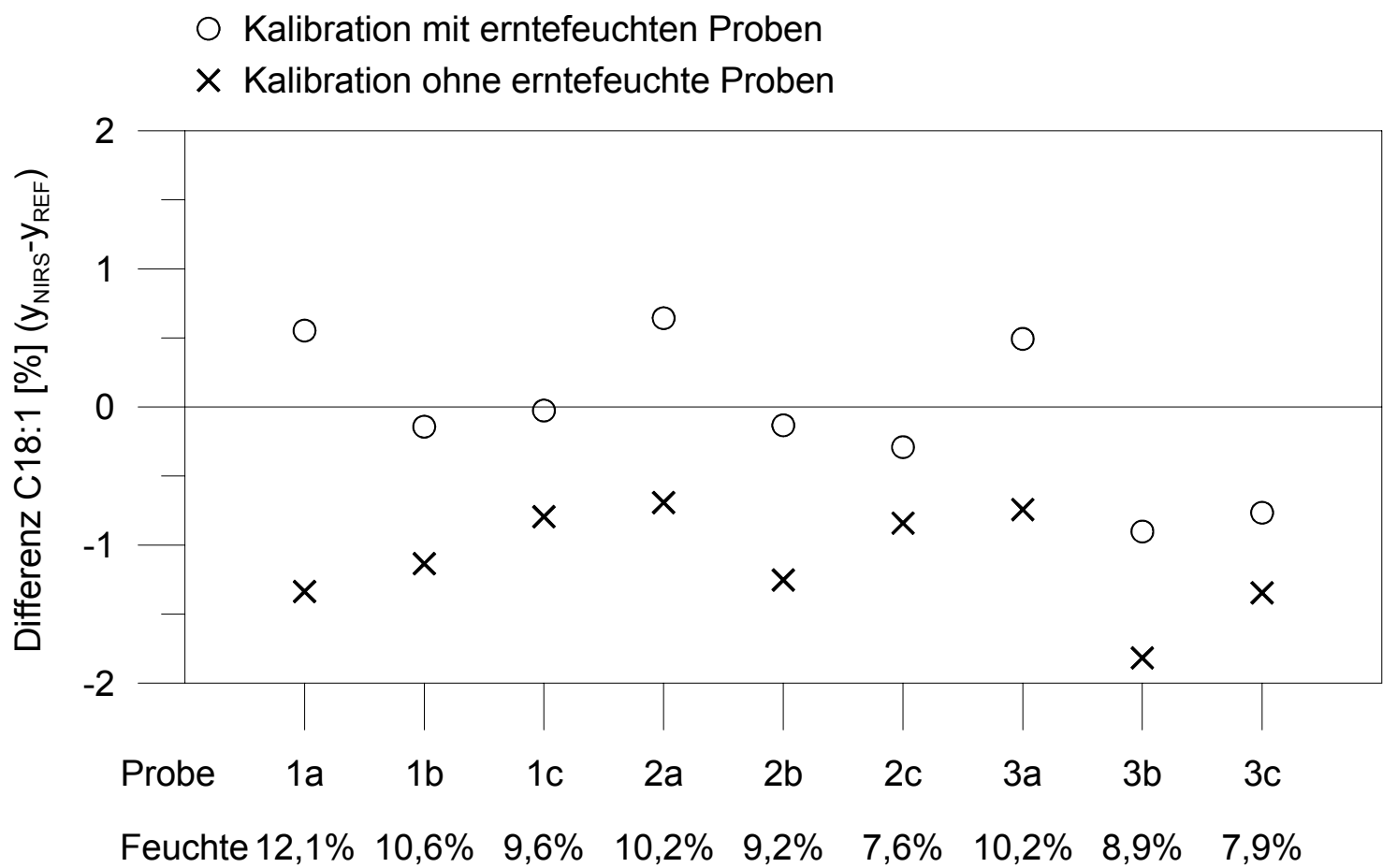

Abb. 5: Vergleich der Vorhersage des Ölsäuregehaltes in gemahlenen Proben
mit hoher Restfeuchte beim Vorhandensein bzw. Fehlen von
erntefeuchten Proben in der Kalibrationsgleichung

Bei der Vorhersage der Ölsäuregehalte der erntefeuchten Proben in Abb. 5 zeigt sich, dass die ausschließlich auf lagertrockenem Material basierende Kalibration den vorherrschenden Gehalt dieser Fettsäure stets unterschätzt. 
Die hier aufgeführten Ergebnisse zeigen, dass Variationen im Feuchtegehalt die Vorhersage anderer Parameter wie Öl und Ölsäure beeinflussen können, während die ermittelten Spearman-Rangkorrelationskoeffizienten $r_{S}$ zwischen Feuchte und dem jeweiligen Parameter (ÖI, Öl $\mathrm{LT}_{\mathrm{T}}, \mathrm{C} 18: 1, \mathrm{C} 18: 1_{\mathrm{LT}}$ ) annährend keine Zusammenhänge beschreiben, wie in nachfolgender Tabelle (Tab. 15) aufgezeigt wird.

Tab. 15: Spearman-Rangkorrelationskoeffizienten $r_{s}$ zwischen Feuchte- und Öl- bzw. Ölsauregehalt in Datensätzen mit und ohne Einbeziehung erntefeuchter Proben

\begin{tabular}{l|cccc} 
Probenmaterial & Öl & Öl & C18:1 & C18:1 $1_{\mathrm{LT}}$ \\
\hline Gemahlene Achänen & $-0,34^{* *}$ &,$- 027^{* *}$ & $0,09^{*}$ & $-0,07^{*}$ \\
Intakte Achänen & $-0,35^{* *}$ &,$- 026^{* *}$ & $0,08^{*}$ & $-0,12^{* *}$
\end{tabular}

LT: Sets mit ausschließlich lagertrockenem Material

\subsubsection{Einbeziehung weiterer Proben}

Die aus dem EU-Sortenversuch 2000 stammenden Proben (Datensatz B1) weisen aufgrund der hohen Gehalte an Linolsäure einen geringeren Anteil an Ölsäure auf. Neben den teilweise hohen Proteingehalten im Datensatz B2 unterscheiden sich diese Proben von den Proben der anderen Datensätze auch in der Beschaffenheit der Samenschale (vgl. Kap. 3.1). Die Einbeziehung der Datensätze B1 und B2 in die Versuche erfolgte, um einerseits den zur Kalibrationsentwicklung zur Verfügung stehenden Wertebereich für den Parameter Protein sowie für die Anteile der verschiedenen Fettsäuren (hier nur am Beispiel Ölsäure aufgezeigt) zu vergrößern und um andererseits die Leistungsfähigkeit der ausschließlich an HO-Material erstellten Kalibrationen zu beurteilen.

In nachfolgender Tabelle (Tab. 16) ist der Einfluss der Proben aus den Datensätzen B1 und B2 auf das Leistungsvermögen und Genauigkeit der Kalibrationsmodelle anhand der resultierenden SEPC- sowie RPD-Werte für den Inhaltsstoff Protein aufgezeigt. Analog zum Verfahren in Kapitel 4.3.1 wurde auch hier für den Vergleich die Spektrentransformation verwendet, welche für den Inhaltsstoff Protein je Zustandsform in Tab. 9 bei den validierten Kalibrationsmodellen unter Verwendung der Datensätze A1 und A2 den höchsten RPD-Wert lieferte. Bei dem in Tab. 16 aufgezeigten Vergleich wurden die Proteingehalte der Proben durch zwei Kalibrationen vorhergesagt, wobei die eine ausschließlich an HO-Material erstellt wurde, während die andere (Kal $\mathrm{KES}_{\text {) }}$ unter Einbeziehung der Datensätze B1 und B2 entwickelt wurde. Zur Validation wurden 
zwei Sets herangezogen, die mit bzw. ohne Einbeziehung von Proben aus den Datensätzen B1 sowie B2 zusammengestellt wurden. Hierbei umfassen die jeweiligen Validations- bzw. Kalibrationssets je Präsentationsform für den Parameter Protein ähnliche Wertebereiche (vgl. Tab. 5).

Tab. 16: Vergleich der Vorhersageleistungen beim Vorhandensein bzw. Fehlen von Proben aus den Datensätze B1 und B2 in der Kalibrationsgleichung bzw. im Validationsset am Beispiel des Parameters Protein

\begin{tabular}{l|cc|cc} 
Gemahlene Achänen & \multicolumn{2}{|c|}{ Validation } & \multicolumn{2}{c}{ Validation $_{\text {GES }}$} \\
DT $(3,4,4)$, SNVD & SEPC & RPD & SEPC & RPD \\
\hline Kalibration & 0,45 & 4,4 & 1,17 & 2,7 \\
Kalibration $_{\text {GES }}$ & 0,51 & 3,9 & 0,64 & 5,1
\end{tabular}

\begin{tabular}{l|cc|cc} 
Intakte Achänen & \multicolumn{2}{|c|}{ Validation } & \multicolumn{2}{c}{ Validation $_{\text {GES }}$} \\
DT $(2,4,4)$, SNVD & SEPC & RPD & SEPC & RPD \\
\hline Kalibration & 0,74 & 2,5 & 1,04 & 2,1 \\
Kalibration $_{\text {GES }}$ & 0,82 & 2,2 & 0,83 & 2,7
\end{tabular}

Kalibration $_{\mathrm{GES}}$ bzW. Validation $\mathrm{GES}_{\mathrm{S}}$ : Sets unter Einbeziehung der Sätze B1 und B2

Beim Parameter Protein führt die Hinzunahme der Datensätze B1 und B2 in die Kalibrationsgleichung bei der Schätzung von Validationssets, die ausschließlich aus HO-Material bestehen, zu einer leichten Erhöhung des Vorhersagefehlers SEPC. Andererseits erhöht dieses Vorgehen besonders bei gemahlenen Achänen die Vorhersageleistung im Falle, dass in den Untersuchungsproben auch von HO-Material abweichende Varianten wie beispielsweise linolsäurereiche Sorten vorhanden sind. Bei der Schätzung des Proteinsgehaltes in gemahlener Saat wird das durch Einbeziehung der Datensätze B1 und B2 gesteigerte Leistungsvermögen durch den sinkenden SEPC-Wert von 1,17 auf 0,64 sowie den steigenden RPD-Wert von 2,7 auf 5,1 angezeigt.

Die Auswirkung der Einbeziehung der Datensätze B1 und B2 in die Kalibrations- bzw. Validationssets für den Parameter Ölsäure ist in nachstehender Tabelle (Tab. 17) sowie den folgenden Abbildungen (Abb. 6 und Abb. 7) aufgezeigt. Auch hier wurde zum Vergleich die Spektrentransformation verwendet, welche für den Inhaltsstoff Ölsäure in gemahlenen bzw. intakten Achänen bei den validierten Kalibrationsmodellen unter Verwendung der Datensätze A1, A2 und A3 den jeweils höchsten RPD-Wert lieferte (vgl. Tab. 9). In Abb. 6, Abb. 7 und Tab. 17 sind die Schätzungen gemahlener sowie intakter Achänen durch zwei unterschiedliche Kalibrationen, die aus derselben 
Spektrentransformation resultieren, aufgezeigt. Hierbei wurde je Präsentationsform die eine Kalibrationsgleichung (Kal) ausschließlich an HO-Material erstellt, während bei der anderen Schätzfunktion ( $\mathrm{Kal}_{\mathrm{GES}}$ ) durch Einbeziehung der Datensätze B1 und B2 auch ölsäurearme Proben in die Modellbildung mit eingeflossen sind. Die Vorhersageleistung dieser Kalibrationsvarianten wurde für gemahlene sowie intakte Achänen mit Hilfe zweier Validationsset überprüft, wobei das eine Set (Val) ausschließlich aus HO-Achänen besteht, während im anderen Set (Val $\mathrm{GES})$ sich durch die Einbeziehung der Datensätze B1 und B2 auch linolsäurereiche, also ölsäurearme Proben befinden. Die im Falle der Kombination Kal vs. Val ${ }_{\text {Ges }}$ vorliegende Validierung mit Extrapolation über den gültigen Wertebereich der Kalibrierung hinaus wurde durchgeführt, um zu prüfen, ob die ausschließlich an HO-Material erstellte Kalibrationsgleichung linolsäurereiche Proben sicher erfasst.

Tab. 17: Vergleich der Vorhersageleistungen beim Vorhandensein bzw. Fehlen von Proben aus den Datensätze B1 und B2 in der Kalibrationsgleichung bzw. im Validationsset am Beispiel des Parameters Ölsäure

\begin{tabular}{l|cc|cc}
\multirow{2}{*}{$\begin{array}{l}\text { Gemahlene Achänen } \\
\text { DT(2,4,4), MSC }\end{array}$} & \multicolumn{2}{|c}{ Validation } & \multicolumn{2}{c}{ Validation $_{\text {GES }}$} \\
\hline Kalibration & SEPC & RPD & SEPC & RPD \\
Kalibration & 0,36 & 6,1 & 6,66 & 3,3 \\
& 0,74 & 2,9 & 0,89 & 27,7 \\
Intakte Achänen & \multicolumn{2}{|c|}{ Validation } & \multicolumn{2}{c}{ Validation } \\
DT $(1,4,4)$, SNV & SEPC & RPD & SEPC & RPD \\
\hline Kalibration & 0,78 & 2,5 & 13,61 & 1,0 \\
Kalibration $_{\text {GES }}$ & 3,27 & 0,6 & 3,42 & 4,1
\end{tabular}

Kalibration $_{\mathrm{GES}}$ bzW. Validation $\mathrm{GES}_{\mathrm{S}}$ : Sets unter Einbeziehung der Sätze B1 und B2

Bei der Vorhersage der Ölsäuregehalte gemahlener Achänen zeigt sich in Tab. 17 sowie in den Validationsdiagrammen in Abb. 6 (Seite 42), dass die ausschließlich an HO-Material erstellte Kalibration (Kal) die HO-Validationsproben (Val) gut erfasst, was neben der geringen Streuung der Messwerte um die Regressionsgerade auch durch den resultierenden SEPC von 0,36 sowie den RPD von 6,1 verdeutlicht wird. Die gleichen Validationsproben werden durch die Kalibration, die unter Einbeziehung der Datensätze B1 und B2 entstanden ist, auffallend schlechter geschätzt, was in Abb. 6 durch eine größere Streuung der Werte um die Regressionsgerade zum Ausdruck kommt. Zusätzlich weist diese Validation einen erhöhten Fehler in der Steigung (Slope $=0,87$ ) auf. Die statistischen Parameter zur Methodenbeurteilung ergaben für 
die Genauigkeit und Leistungsfähigkeit der an den gemahlenen HO-Achänen validierten Kalibrationsgleichung $\mathrm{Kal}_{\mathrm{GES}}$ einen SEPC von 0,74 sowie einen RPD-Wert

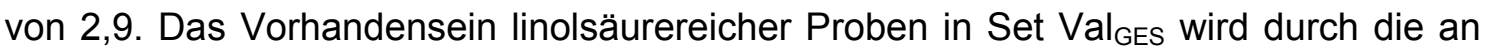
ausschließlich HO-Material erstellte Kalibration sicher erfasst, wenn auch eine große Streuung der Werte um die Regressionsgeraden sowie ein erheblicher Steigungsfehler zu verzeichnen ist. Diese Validierung über den gültigen Wertebereich hinaus liefert einen SEPC von 6,66. Die Kalibration Kal $\mathrm{GES}_{\text {. }}$ hingegen erfasst auch die linolsäurereichen Proben gut, was durch den SEPC von 0,89 sowie die geringe Streuung um die Regressionsgerade verdeutlicht wird.
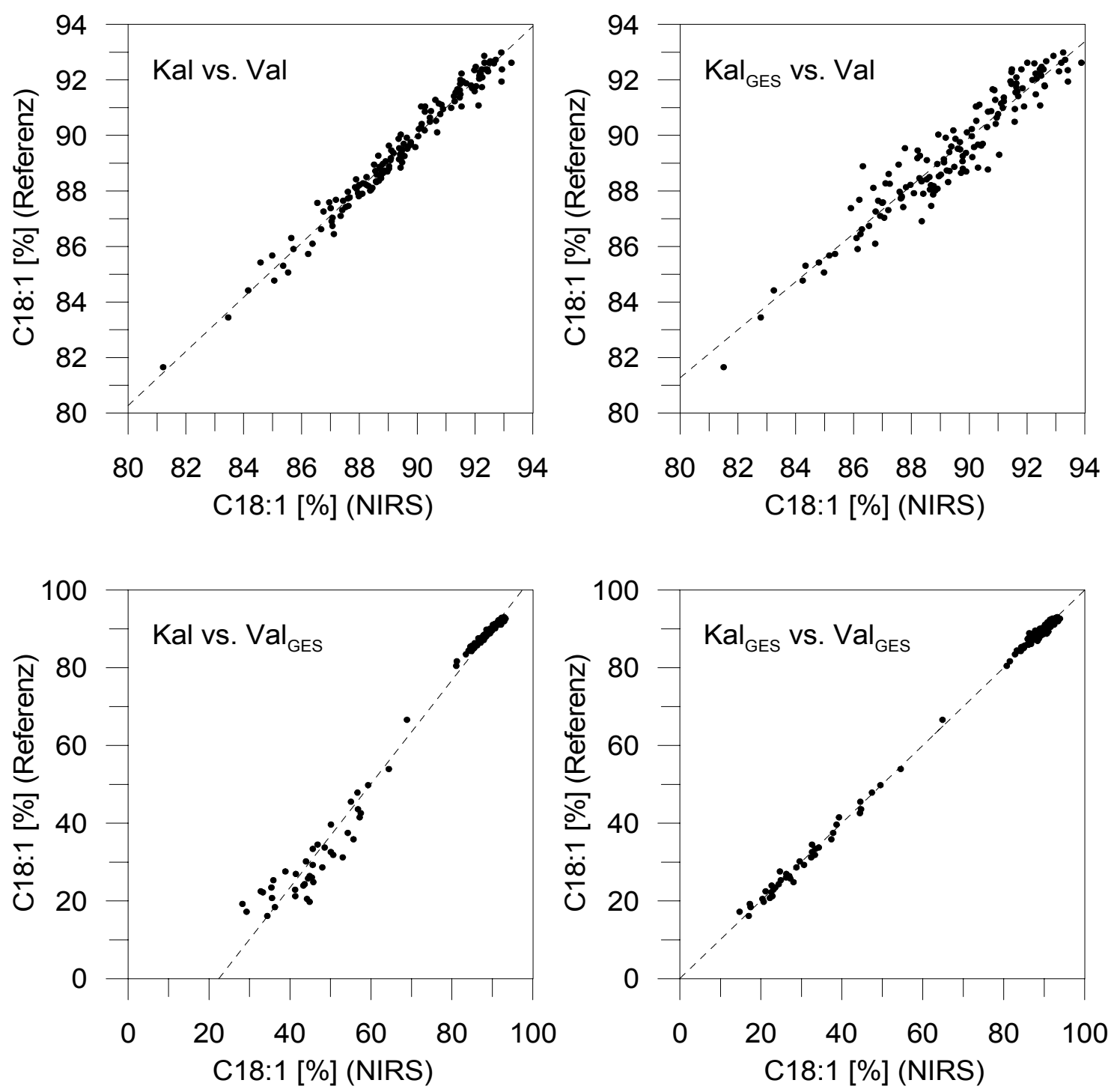

Abb. 6: Validationsdiagramme und Regressionsgeraden für die Erfassung der Ölsäuregehalte (C18:1) in gemahlenen HO-Achänen (Val bzw. Val GES) durch die Kalibrationsgleichungen Kal bzw. Kal ${ }_{\text {GES }}$ (jeweils DT(2,4,4), MSC) 
Bei der Vorhersage der Ölsäuregehalte in intakten Achänen ist in Abb. 7 zu erkennen, dass die an HO-Material erstellte Kalibration die ölsäurereichen Proben bei geringer Streuung um die Regressionsgeraden relativ sicher erfasst, was in Tab. 17 durch den SEPC von 0,78 sowie den RPD von 2,5 zum Ausdruck gebracht wird. Liegen nun jedoch auch linolsäurereiche Proben im Untersuchungsgut vor $\left(\operatorname{Val}_{\mathrm{GES}}\right)$, so werden diese nicht nur nicht richtig geschätzt, sondern hinsichtlich ihrer Ölsäuregehalte auch fälschlicherweise HO-Material zugeordnet.
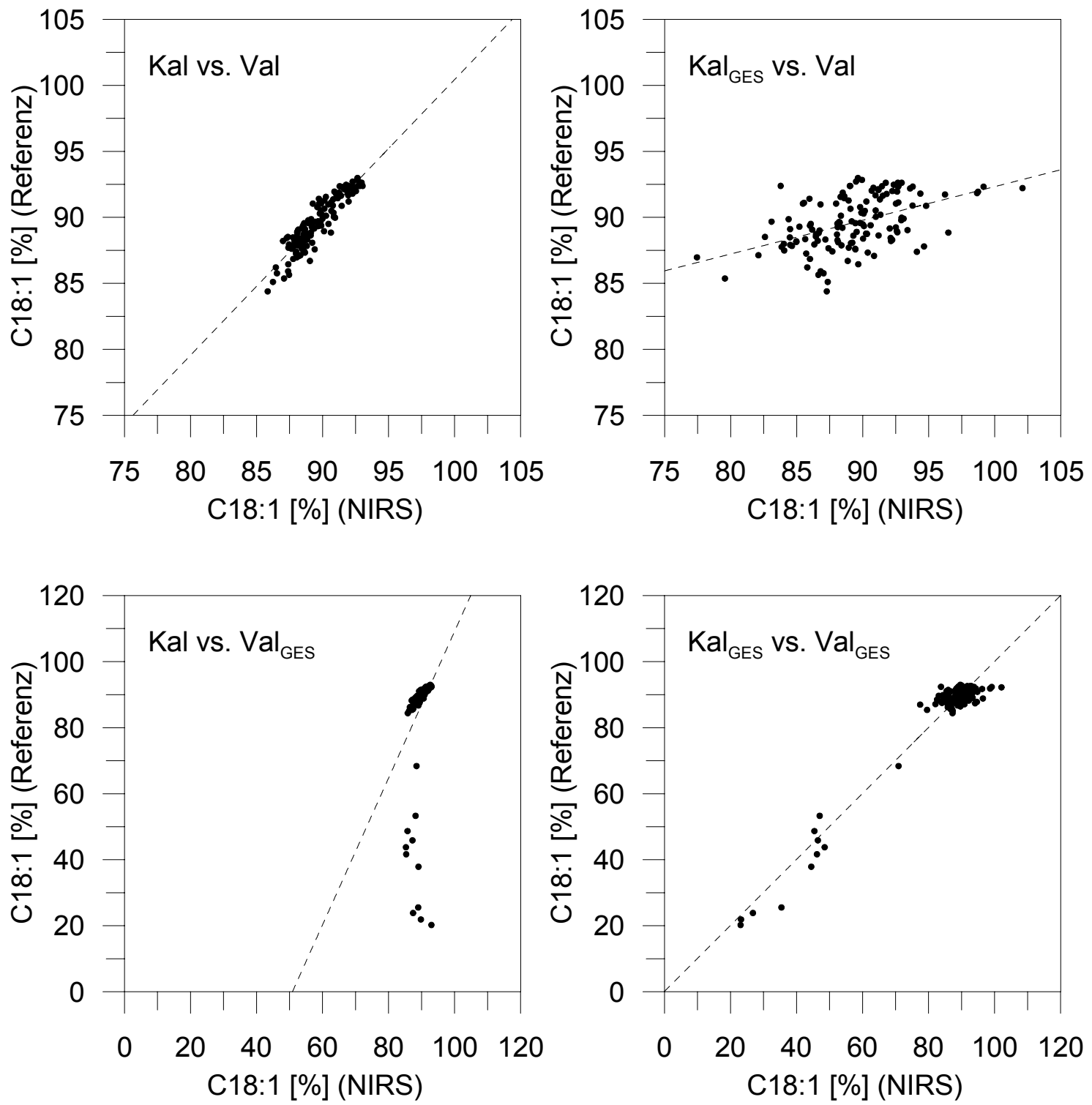

Abb. 7: Validationsdiagramme und Regressionsgeraden für die Erfassung der Ölsäuregehalte (C18:1) in intakten HO-Achänen (Val bzw. Val $\left.\right|_{\text {GES }}$ ) durch die Kalibrationsgleichungen Kal bzw. Kal GES (jeweils DT(1,4,4), SNV) 
Weiterhin zeigt Abb. 7, dass die Kalibrationsgleichung $\mathrm{Kal}_{\mathrm{GES}}$ im Vergleich zu der an HO-Material entwickelten Kalibration die im Set Val ${ }_{\text {GES }}$ enthaltenen linolsäurereichen Proben zwar besser erfasst, jedoch für die Vorhersage von HO-Proben unbrauchbar ist, was auch durch den RPD-Wert von 0,6 aufgezeigt wird.

Die Ermittlung der Spearman-Rangkorrelationskoeffizienten $r_{S}$ zwischen dem Ölsäureund dem Linolsäureanteil zeigte sowohl für gemahlene sowie für intakte Achänen sehr große Korrelationen dieser beiden Fettsäuren untereinander. Die ermittelten Werte für $r_{S}$ lagen je Präsentationsform sowohl innerhalb der HO-Proben sowie im gesamt verwendeten Datensatz zwischen $-0,87^{* *}$ sowie $-0,93^{* *}$ auf dem $1 \% \quad(\alpha=0,01)$ Signifikanzniveau.

\subsection{Populationsbeschreibung mit Hilfe der Faktorwerte}

Wie im Kapitel 3.4.2 beschrieben, erfolgte eine Hauptkomponentenanalyse (PCA) der spektralen Daten gemahlener Achänen des Gesamtdatensatzes unter Nutzung der ersten (DT $(1,4,4))$ bzw. dritten $(\mathrm{DT}(3,4,4))$ Ableitung in Verbindung mit der Streulichtkorrektur SNVD. Zur Populationsbeschreibung sind in folgender Abbildung (Abb. 8) die Faktorwerte (Scores) der ersten drei Hauptkomponenten (PC1, PC2, PC3) aufgeführt, wobei die Zugehörigkeit zum betreffenden Datensatz A1, A2, A3, A4, B1 sowie B2 durch unterschiedliche Symbole verdeutlicht ist. Während die Faktorwerte der PCA, die mit Hilfe der ersten Ableitung erstellt wurde, mit Ausnahme der erntefrischen Proben des Datensatzes A4 noch dicht bei einander liegen, so zerfällt die Population bei der Anwendung der dritten Ableitung in die deutlich erkennbaren Untergruppen A2 (lagertrockene HO-Proben), A4 (erntefrische HO-Proben), B1 (linolsäurereiche Proben) sowie B2 (Zuchtmaterial auf hohen Proteingehalt). Die HODatensätze A1 sowie A3 liegen jedoch vollständig in der Gruppe des Satzes A2 und werden von der Vielzahl dieser Proben überdeckt. Interessant in der Darstellung der Faktorwerte aus der PCA mit der Datentransformation DT $(3,4,4)$ ist die Unterteilung des Datensatzes A2 in zwei Gruppen. Bei der kleineren Teilmenge handelt es sich um Sonnenblumensaatproben, die in Braunschweig 2003 geerntet wurden. Weiterhin wird durch die Darstellung der Score-Werte die große Variabilität des eingesetzten Zuchtmaterials des Datensatzes B2 aufgezeigt. 

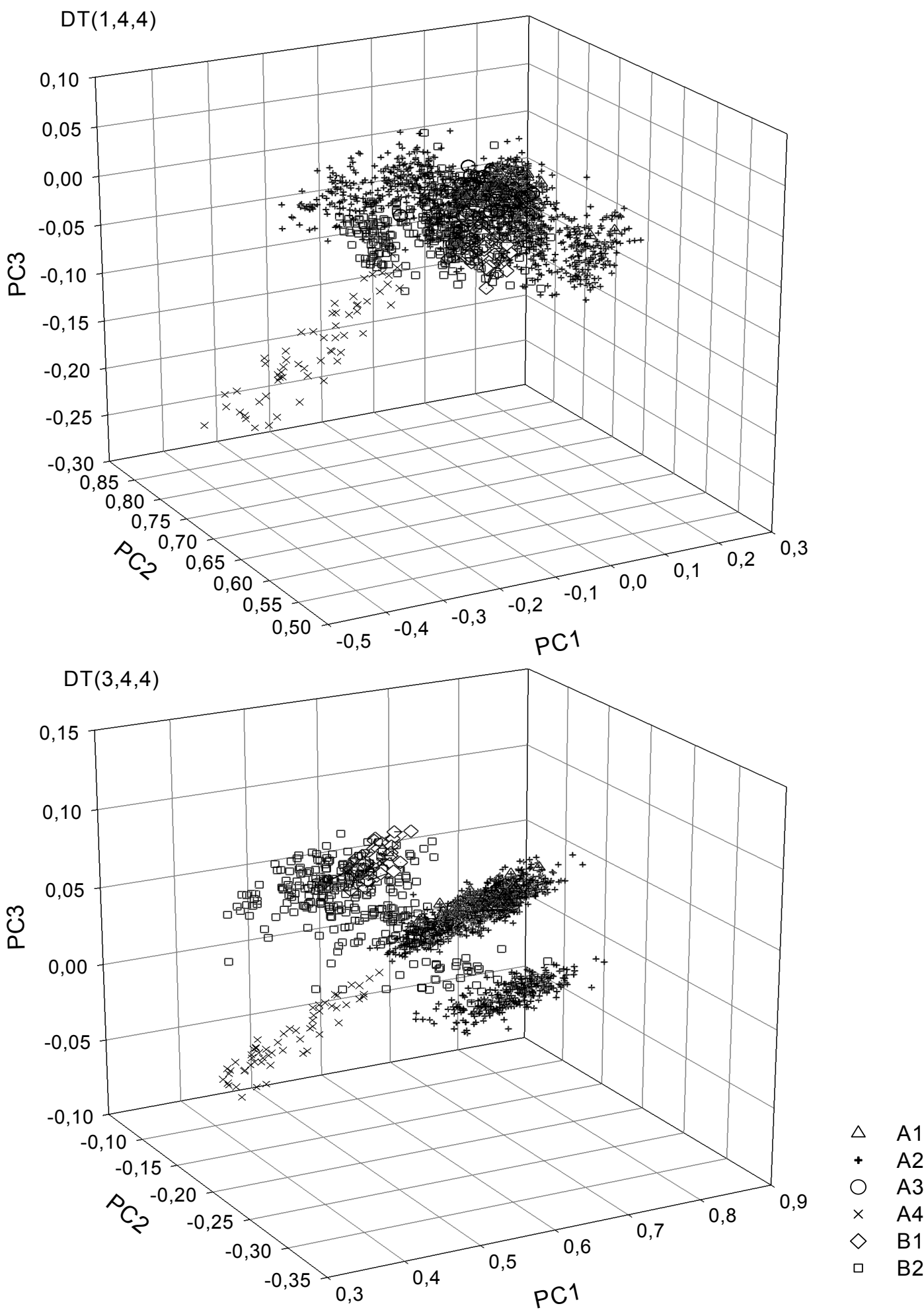

Abb. 8: Graphische Darstellung der Faktorwerte der ersten drei Hauptkomponenten spektraler Daten gemahlener Achänen des Gesamtdatensatzes unter Nutzung von SNVD sowie der ersten bzw. dritten Ableitung 


\section{Diskussion}

\subsection{Beurteilung der entwickelten NIRS-Methoden}

Eine Vielzahl von Einflussfaktoren bestimmt die Güte eines chemometrischen Modells zur Qualitätserfassung landwirtschaftlicher Produkte, was durch die nachfolgende Abbildung (Abb. 9) in Anlehnung an die Ausführungen von WILLIAMS und NORRIS, 2001 verdeutlicht werden soll.

\begin{tabular}{|c|c|}
\hline $\begin{array}{l}\text { Probe } \\
\text { Chemische Zusammensetzung } \\
\text { Korrelationen zwischen den Parametern } \\
\text { Feuchtegehalt } \\
\text { Textur } \\
\text { Probentemperatur } \\
\text { Fremdbestandteile } \\
\text { Vermahlungsart und -bedingungen } \\
\text { Partikelgröße } \\
\text { Schüttdichte } \\
\text { Probenlagerung }\end{array}$ & $\begin{array}{l}\begin{array}{l}\text { Spektrometer } \\
\text { Messprinzip } \\
\text { Lichtquelle } \\
\text { Wellenlängenbereich } \\
\text { Wellenlängengenauigkeit } \\
\text { Detektor } \\
\text { Auflösung } \\
\text { Gerätetemperatur } \\
\text { Messzelle }\end{array} \\
\text { Kalibrationsmodells } \\
\text { Güte des } \\
\text { Kalibrationserstellung } \\
\text { Anzahl der Proben } \\
\text { Auswahl der Proben } \\
\text { Regressionsverfahren } \\
\text { Datenvorbehandlung } \\
\text { Ausreißerbehandlung } \\
\text { Genauigkeit der Referenzanalyse }\end{array}$ \\
\hline
\end{tabular}

Abb. 9: Fehlerquellen bzw. Einflussfaktoren auf die Güte eines Kalibrationsmodells zur Erfassung der Qualität landwirtschaftlicher Produkte (nach WILLIAMS und NORRIS, 2001) 
Die große Anzahl und mögliche Interaktionen der in Abb. 9 aufgezeigten Einflussfaktoren sollten bei der Erstellung sowie der Beurteilung eines Kalibrationsmodells Berücksichtigung finden. So bewirken ursächlich nichtchemische Faktoren wie z.B. Anbaujahr, Sorte, Boden- und Wachstumsbedingen eine Änderung der chemisch-physikalischen Eigenschaften und in der Folge ein verändertes Spektrum, was in der Nahinfrarotspektroskopie häufig mit dem Begriff "Jahrgangseffekt" beschrieben wird (TILLMANN, 2000). Die Forderung innerhalb der Kalibrationsentwicklung, die Kalibrationsproben mögen die gesamte Variabilität der Untersuchungsproben repräsentieren, bezieht sich somit nicht allein auf den zu untersuchenden Inhaltsstoff. Das durch SHENK und WESTERHAUS (1991b) beschriebene Verfahren zur Auswahl der Kalibrationsproben anhand der aus den Spektren berechneten standardisierten Mahalanobis Distanzen (H-Werte) liefert ein Kalibrationsset, welches die vorliegende Gesamtpopulation spektral gut repräsentiert. Diese Vorgehensweise ist z.B. anzuraten, um bei einem teuren oder aufwändigen Referenzverfahren nur die Proben analysieren zu müssen, die für die Vorhersage der Restlichen wichtig sind. Auch für die ständige Weiterentwicklung einer bestehenden NIRS-Methode stellt die Auswahl nach H-Werten eine geeignete Methode dar, um neue spektrale Information in Modellbildung einfließen zu lassen. Für eine Überprüfung der Leistungsfähigkeit einer Kalibration, welche später in der Praxis zur Erfassung unterschiedlicher Qualitäten eingesetzt werden soll, kann dieses Vorgehen jedoch nicht überzeugen, da das Kalibrationsset auf die Validationsproben abgestimmt ist und somit keine unabhängige Kontrolle des Modells erfolgen kann. Daher erfolgte je Parameter die Validierung der in dieser Arbeit erstellten NIRS-Methoden an einem Probenset, welches zum einem durch die Auswahl hinsichtlich der Verteilung der Referenzwerte einen gewissen Wertebereich aufspannt und in dem zum anderen Proben verschiedener Sorten, Erntejahre und Anbaugebiete vertreten sind (vgl. Kap. 3.4.1).

\subsubsection{Beurteilungskriterien}

Die in Kapitel 2.3.3 aufgeführten statistischen Parameter wurden in der vorliegenden Arbeit zur Beurteilung der unterschiedlichen Kalibrationsmodelle herangezogen. Im Hinblick auf die Überprüfung der Leistungsfähigkeit der NIRS-Methoden fand hierbei der aus den Daten der externen Validierung berechnete RPD-Wert besondere Beachtung, um einen Methodenvergleich der für die unterschiedlichen Inhaltsstoffe entwickelten Kalibrationsmodelle realisieren zu können. Zieht man die Charakterisierung der RPD-Werte nach WILLIAMS (2001) (vgl. Tab. 1) heran, so können 
die besten Kalibrationsmodelle (vgl. Tab. 9) für gemahlene Achänen mindestens ein zufrieden stellendes Leistungsvermögen aufweisen, das im Falle der Abschätzung der Fettsäuren Ölsäure sowie Linolsäure mit gut bzw. sehr gut beurteilt wird. Unter den meist als schlecht beurteilten Kalibrationsmodellen für intakte Achänen gibt es aber auch solche, die ein ungenügendes (FFA und C18:2) bzw. ein zufrieden stellendes (C16:0 und C18:0) Leistungsvermögen aufzeigen. Auf Grundlage der durch WILLIAMS (2001) für die jeweiligen RPD-Werte empfohlenen Anwendungsbereiche käme für die NIRS-Modelle für intakte Achänen ein grobes, aber zerstörungsfreies Screening z.B. in der Pflanzenzüchtung in Frage, während die Methoden an gemahlener Saat zu einer viel differenzierteren Erfassung der Parameter bzw. zur Qualitätskontrolle geeignet sind.

Dass jedoch der RPD-Wert als alleiniges Gütekriterium für die Vorhersageleistung eines chemometrischen Modells nicht herangezogen werden kann, zeigt sich in Tab. 17 sowie Abb. 7 auf den Seiten 41 bzw. 43 am Beispiel der Abschätzung des Ölsäuregehaltes in intakten Achänen: Während das unter Einbeziehung der Datensätze B1 und B2 erstellte Kalibrationsmodell (Kalibration ${ }_{\mathrm{GES}}$ ) bei der Schätzung von HO-Material versagt (RPD $=0,6$ ), liefert die selbe Schätzgleichung einen RPDWert von 4,1 für den Fall, dass linolsäurehaltige Proben im Validationsset (Validation ${ }_{\mathrm{GES}}$ ) vorhanden sind und könnte somit als eine NIRS-Methode mit zufrieden stellendem Leistungsvermögen beurteilt werden. Analog hierzu führt die Verwendung gemahlener Achänen bei der Abschätzung des Ölsäuregehaltes (Kalibration ${ }_{\text {GES vs. }}$ Validation $_{\mathrm{GES}}$ ) zu einem RPD-Wert von 27,7 (vgl. Tab. 17), welcher somit weit oberhalb der RPD-Grenze von 8,1 liegt und folglich gemäß WILLIAMS (2001) als eine Methode mit exzellenter Vorhersageleistung charakterisiert werden kann. Als Ursache für die hohen RPD-Werte des Beispiels kann die große Streuung der Referenzwerte in der Validation angesehen werden. So wies das Validationsset bei Vorhandensein der HOProben sowie der linolsäurereichen Varianten aus den Datensätzen B1 und B2 für den Inhaltsstoff Ölsäure eine Standardabweichung von 14,02\% (intakte Achänen) bzw. von 24,68\% (gemahlene Achänen) auf. Auch MoNTES et al. (2006a) ziehen unter anderem den RPD-Wert zur Leistungsbewertung entwickelter NIRS-Methoden heran, verweisen aber darauf, dass dieser stark von der Probenanzahl sowie von der Verteilung der Referenzwerte abhängt. Als weiterer Einflussfaktor auf die Güte eines Kalibrationsmodells wird durch MARK (1991) der verwendete Wertebereich herangezogen, der sich auf viele Parameter wie z.B. SEC, SEP und $\mathrm{R}^{2}$ auswirkt. So erhält man aufgrund des großen Wertebereichs in dem in Abb. 7 gezeigten Beispiel der Abschätzung des Ölsäurehaltes in intakten Achänen (Kal $\left.\right|_{G E S}$ vs. Val ${ }_{G E S}$ ) ein Bestimmtheitsmaß von 0,96 (vgl. Tab. 21), während die gleiche Kalibrationsgleichung 
beim Fehlen der 11 linolsäurereichen Proben (Kal ${ }_{\text {GES }}$ vs. Val) nur noch ein $R^{2}$ von 0,23 liefert. Würden in diesem Beispiel ausschließlich die Werte des Bestimmtheitsmaßes zur Gütebeurteilung herangezogen werden, so wären die konträren Einschätzungen, das Model sei überhaupt nicht geeignet bzw. sehr gut geeignet, die Folge. Einen weiteren Parameter zur Leistungsbeurteilung stellt der RER (ratio error range; RER = Wertebereich/SEP) dar, der sich als Quotient des Wertebereichs der Validationsproben zum SEP berechnet. Auch für erreichte RER-Werte gibt es eine Charakterisierung nach WILLIAMS (2001). Da jedoch der Wertebereich nur durch den Minimal- und Maximalwert bestimmt wird, reagiert der RER viel anfälliger als der RPDWert auf das Vorhandensein von Ausreißern (WILLIAMS 2001; SAEYS et al., 2004) bzW., um beim zuvor genannten Beispiel der Abschätzung des Ölsäuregehaltes in intakten Achänen (Kal $\mathrm{KES}_{\mathrm{Gs}}$ v. $\mathrm{Val}_{\mathrm{GES}}$ ) zu bleiben, auf das Vorhandensein der weit von der Population der HO-Proben entfernten linolsäurereichen Varianten. Den beiden Leistungsparametern RPD sowie RER liegt jedoch der Gedanke zu Grunde, den in der Validation erzielten Vorhersagefehler SEP zu standardisieren und somit einen besseren Vergleich verschiedener NIRS-Methoden zu ermöglichen. Werden neben dem RPD weitere Parameter zur Beurteilung herangezogen, so stellt der Quotient SD/SEP eine hilfreiche Größe dar, die Qualität eines Kalibrationsmodells zu bewerten (MONTES et al., 2006a).

\subsubsection{Vergleich der Vorhersageergebnisse mit den Präzisionsgrenzen amtlichen Methoden}

Zur Beurteilung eines Kalibrationsmodells ist ein Vergleich mit der verwendeten Labormethode anzuraten, da fehlerbehaftete Referenzwerte in die Regressionsanalyse und in der Folge in die Berechnung des Standardfehlers der Vorhersage SEP mit einfließen (TILLMANN, 1996). Aus diesem Grunde sind die absoluten Abweichungen $\Delta_{\text {ABS }}$ zwischen dem Referenzwert und dem Laborwert der Validationsproben je Parameter und Probenpräsentation zu einem Vergleich mit den Präzisionsgrenzen der amtlichen Methoden herangezogen worden (Kap. 4.2). Per Definition beschreiben die Wiederhol- und Vergleichpräzision die jeweilig maximalen Differenzen $r_{W}$ und $R_{V} z w e i e r$ Messungen, die durch eine Person eines Labors bzw. durch verschiedene Personen in unterschiedlichen Laboren jedoch immer durch das gleiche Verfahren ermittelt wurden. Da der hier durchgeführte Vergleich zwischen zwei verschiedenen Methoden erfolgte, wird dieser Unterschied eher durch die Vergleichgrenze $R_{V}$ als durch die Wiederholgrenze $r_{w}$ ausgedrückt. 
Wie in Tab. 12 aufgeführt, wird ein Großteil der Validationsproben innerhalb der maximal zulässigen Differenz der Vergleichbarkeit vorhergesagt. Bei der Abschätzung des Proteingehaltes in gemahlenen Achänen liegen sogar $100 \%$ der Validationsproben unterhalb der für Sonnenblumensaat spezifischen Wiederholgrenze von rund $2 \%$. Zieht man in diesem Falle die allgemeine produktunabhängige Grenze $r_{w}$ von $0,6 \%$ heran, so liegen immer noch mehr als $82 \%$ im Bereich der Wiederholpräzision der amtlichen Methode. Bei der nahinfrarotspektroskopischen Erfassung des FFA-Anteils in gemahlenen sowie intakten Achänen hingegen liegen über $75 \%$ der Validationsproben außerhalb der Präzisionsgrenzen. Hierbei gilt es zu beachten, dass sich die hier herangezogenen maximal zulässigen Differenzen der Wiederholbarkeit und Vergleichbarkeit auf die Bestimmung im Öl und nicht wie in dieser Arbeit durchgeführt in der Saat beziehen.

Sofern kein oder nur ein geringer Bias-Fehler vorliegt, kann zur Ermittlung der Fehlerstreubreite die Faustformel herangezogen werden, dass sich im Bereich von $\pm 2 *$ SEP (bzw. bei größeren Bias-Werten im Bereich von $\pm 2 *$ SEPC) $95 \%$ der Validationsproben befinden (DILLER, 2002; KÖHLER et al., 2002; FIX ,2004). Liegt also das 2 fache des SEP-Wertes unterhalb Vergleichsgrenze $R_{V}$, so würde hinsichtlich der Präzision die NIRS-Methode im Ringversuch den anderen Laborverfahren gleichwertig sein.

\subsubsection{Vergleich der Kalibrationsmodelle mit publizierten Daten}

Um neben der Beurteilung nach RPD-Werten bzw. dem Vergleich mit den Präzisionsgrenzen der amtlichen Methoden eine weitere Einschätzung der in dieser Arbeit erzielten Ergebnisse vornehmen zu können, erfolgt in Tab. 18 eine Übersicht zu bislang publizierten Daten zur nahinfrarotspektroskopischen Erfassung wertbestimmender Inhaltsstoffe von verschiedenen Ölsaaten. Sofern nicht anders gekennzeichnet, wurden die in Tab. 18 aufgeführten Ergebnisse am Spektrometer NIRSystems 6500. Wie auch in dieser Arbeit erfolgte dabei meist die Einschränkung des Wellenlängenbereichs auf 1100 - 2500nm. 
Tab. 18: Übersicht über publizierte Kalibrationen zur Erfassung wertgebender Inhaltsstoffe in verschiedenen Ölsaaten

\begin{tabular}{c|c|c|c|c|c|c|c|c|l|l}
\hline Frucht & Zu. & Param. & SEC & SECV & SEP & SEPC & Bereich & $R^{2} \downarrow$ & Anmerkung & Literaturquelle \\
\hline SB & Öl & C16:0 & 0,81 & 1,26 & & & $3-36$ & & & PÉREZ-VICH et al., 1998 \\
& & C18:0 & 0,79 & 1,22 & & & $1-30$ & & \\
& & C18:1 & 0,67 & 1,09 & & & $8-90$ & & \\
& & C18:2 & 0,56 & 0,78 & & & $2-75$ & & \\
\hline SB & gm & Öl & 1,02 & 1,57 & & & $24-52$ & & Früchte entschält \\
& & C16:0 & 1,63 & 2,73 & & & $3-36$ & & \\
& & C18:0 & 1,44 & 2,36 & & & $1-30$ & & \\
& & C18:1 & 2,10 & 3,12 & & & $8-90$ & & \\
& & C18:2 & 2,21 & 2,78 & & & $2-75$ & & \\
\hline SB & GK & ÖI & 1,19 & 1,69 & & & $24-52$ & Früchte entschält & \\
& & C16:0 & 1,89 & 2,81 & & & $3-36$ & & \\
& & C18:0 & 1,40 & 2,10 & & & $1-30$ & & \\
& & C18:1 & 2,59 & 3,98 & & & $8-90$ & & \\
& & C18:2 & 2,15 & 3,55 & & & $2-75$ & & \\
\hline SB & GK & Öl & 1,86 & 2,18 & 2,07 & & $24-52$ & & \\
& & C16:0 & 2,83 & 3,58 & 3,63 & & $3-36$ & & \\
& & C18:0 & 1,45 & 1,73 & 1,82 & & $1-30$ & & \\
& & C18:1 & 6,75 & 8,94 & 8,75 & & $8-90$ & & \\
& & C18:2 & 5,83 & 7,25 & 7,58 & & $2-75$ & & \\
\hline
\end{tabular}

SB: Sonnenblume; Zu.: Zustand; Param.: Parameter; gm: gemahlen; GK: Ganzkorn

$R^{2} \downarrow$ : Kalibrationen, bei denen mindestens ein Bestimmtheitsmaß unter 0,6 liegt, sind mit "•"gekennzeichnet 


\section{Fortsetzung Tab. 18}

\begin{tabular}{|c|c|c|c|c|c|c|c|c|c|c|}
\hline Frucht & $\mathrm{Zu}$. & Param. & SEC & SECV & SEP & SEPC & Bereich & $R^{2} \downarrow$ & Anmerkung & Literaturquelle \\
\hline \multirow[t]{2}{*}{ SB } & \multirow[t]{2}{*}{ GK } & C18:1 & 7,10 & 8,60 & 9,9 & & \multirow{2}{*}{$\begin{array}{l}10-92 \\
13-77 \\
\end{array}$} & & \multirow[t]{2}{*}{ Einzelkornanalyse } & \multirow[t]{2}{*}{ VELASCO et al., 1999a } \\
\hline & & C18:2 & 6,50 & 7,90 & 9,5 & & & & & \\
\hline \multirow[t]{2}{*}{ SB } & \multirow[t]{2}{*}{ GK } & C18:1 & & & 9,9 & & \multirow[t]{2}{*}{$13-90$} & & Einzelkornanalyse; & \multirow[t]{2}{*}{ ANONYMUS, 2002} \\
\hline & & C18:2 & & & 8,8 & & & & Seed Meister (900-1400 nm) & \\
\hline \multirow[t]{4}{*}{ SB } & \multirow{3}{*}{$\mathrm{gm}$} & C18:1 & 0,59 & 0,67 & 0,58 & 0,57 & \multirow{4}{*}{$\begin{array}{l}66-92 \\
66-92 \\
66-92 \\
66-92\end{array}$} & & & \multirow[t]{4}{*}{ BISKUPEK-KORELL et al., 2003} \\
\hline & & C18:1 & 1,04 & 1,43 & 1,15 & 1,15 & & & InfraAlyzer 500 & \\
\hline & & C18:1 & 2,29 & 2,84 & 3,34 & 3,37 & & & Infratec 1241 & \\
\hline & GK & C18:1 & 4,62 & 5,28 & 4,09 & 3,86 & & - & InfraAlyzer 500 & \\
\hline \multirow[t]{7}{*}{ SB } & \multirow[t]{7}{*}{ gm } & $\mathrm{TM}$ & 0,57 & 0,59 & & & $93-98$ & & Früchte entschält; & \multirow[t]{7}{*}{ FEMENIAS, 2003} \\
\hline & & Öl & 1,17 & 1,22 & & & $30-63$ & & NIRSystems 5000 & \\
\hline & & Protein & 0,51 & 0,54 & & & $9-27$ & & & \\
\hline & & C16:0 & 0,49 & 0,51 & & & $3-9$ & & & \\
\hline & & C18:0 & 0,61 & 0,65 & & & $2-21$ & & & \\
\hline & & C18:1 & 2,84 & 3,00 & & & $14-92$ & & & \\
\hline & & C18:2 & 2,66 & 2,79 & & & $1-75$ & & & \\
\hline
\end{tabular}

SB: Sonnenblume; Zu.: Zustand; Param.: Parameter; gm: gemahlen; GK: Ganzkorn

$R^{2} \downarrow$ : Kalibrationen, bei denen mindestens ein Bestimmtheitsmaß unter 0,6 liegt, sind mit "•"gekennzeichnet 


\section{Fortsetzung Tab. 18}

\begin{tabular}{|c|c|c|c|c|c|c|c|c|c|c|}
\hline Frucht & $\mathrm{Zu}$. & Param. & SEC & SECV & SEP & SEPC & Bereich & $R^{2} \downarrow$ & Anmerkung & Literaturquelle \\
\hline \multirow[t]{6}{*}{ SB } & \multirow[t]{6}{*}{ gm } & Feuchte & 0,54 & 0,60 & 0,56 & 0,55 & $4-8$ & & & \multirow[t]{17}{*}{ MOSCHNER, 2003} \\
\hline & & Öl & 0,64 & 0,69 & 0,63 & 0,63 & $42-58$ & & & \\
\hline & & Protein & 0,33 & 0,36 & 0,37 & 0,35 & $12-24$ & & & \\
\hline & & C18:0 & 0,12 & 0,17 & 0,13 & 0,13 & $1-4$ & & & \\
\hline & & C18:1 & 0,37 & 0,44 & 0,43 & 0,42 & $80-93$ & & & \\
\hline & & C18:2 & 0,22 & 0,27 & 0,26 & 0,25 & $2-11$ & & & \\
\hline \multirow[t]{6}{*}{ SB } & \multirow[t]{6}{*}{ gm } & Feuchte & 0,67 & 0,69 & 0,70 & 0,71 & \multirow{6}{*}{$\begin{array}{c}4-8 \\
42-58 \\
12-24 \\
1-4 \\
80-93 \\
2-11 \\
\end{array}$} & \multirow[t]{6}{*}{ • } & \multirow[t]{6}{*}{ Infratec Grain Analyzer 1241} & \\
\hline & & Öl & 0,77 & 0,81 & 0,92 & 0,93 & & & & \\
\hline & & Protein & 0,49 & 0,53 & 0,49 & 0,48 & & & & \\
\hline & & C18:0 & 0,25 & 0,33 & 0,31 & 0,3 & & & & \\
\hline & & C18:1 & 1,03 & 1,23 & 1,25 & 1,26 & & & & \\
\hline & & C18:2 & 0,81 & 0,94 & 0,95 & 0,96 & & & & \\
\hline \multirow[t]{5}{*}{ SB } & \multirow[t]{5}{*}{ GK } & Öl & 0,84 & 0,97 & 1,09 & 1,06 & $38-56$ & & & \\
\hline & & Protein & 0,79 & 0,99 & 1,09 & 1,08 & $12-28$ & & & \\
\hline & & C18:0 & 0,15 & 0,17 & 0,18 & 0,18 & $1-3$ & & & \\
\hline & & C18:1 & 0,85 & 0,97 & 1,09 & 1,09 & $85-93$ & & & \\
\hline & & C18:2 & 0,70 & 0,79 & 0,86 & 0,86 & $2-8$ & & & \\
\hline
\end{tabular}

SB: Sonnenblume; Zu.: Zustand; Param.: Parameter; gm: gemahlen; GK: Ganzkorn

$R^{2} \downarrow$ : Kalibrationen, bei denen mindestens ein Bestimmtheitsmaß unter 0,6 liegt, sind mit "•"gekennzeichnet 


\section{Fortsetzung Tab. 18}

\begin{tabular}{|c|c|c|c|c|c|c|c|c|c|c|}
\hline Frucht & $\mathrm{Zu}$. & Param. & SEC & SECV & SEP & SEPC & Bereich & $\mathrm{R}^{2} \downarrow$ & Anmerkung & Literaturquelle \\
\hline \multirow[t]{3}{*}{ SB } & \multirow[t]{3}{*}{ GK } & Feuchte & $0,16-0,31$ & $0,30-0,68$ & 0,34 & & $5-9$ & - & \multirow{3}{*}{$\begin{array}{l}\text { 6-10 Achänen pro Küvette; } \\
\text { versch. Wellenlängenbereiche } \\
\text { versch. Spektrentransformationen }\end{array}$} & \multirow[t]{3}{*}{ FASSIO UND COZZOLINO, 2004} \\
\hline & & Öl & $1,54-3,27$ & $2,23-3,83$ & 2,32 & & $35-69$ & $\bullet$ & & \\
\hline & & Protein & $0,66-2,09$ & $1,31-2,33$ & 1,71 & & $9-42$ & & & \\
\hline \multirow[t]{4}{*}{ SB } & \multirow[t]{4}{*}{ GK } & C16:0 & & 2,77 & & & $2-46$ & $\bullet$ & \multirow{4}{*}{$\begin{array}{l}\text { Früchte entschält; } \\
\text { Einzelkornanalyse }\end{array}$} & \multirow[t]{4}{*}{ VELASCO et al., 2004} \\
\hline & & C18:0 & & 4,60 & 4,2 & & $1-54$ & & & \\
\hline & & C18:1 & & 8,43 & 8,29 & & $2-92$ & & & \\
\hline & & C18:2 & & 6,21 & 6,43 & & $1-79$ & & & \\
\hline \multirow[t]{2}{*}{ SB } & \multirow[t]{2}{*}{ gm } & ÖI & & 0,61 & & & $31-56$ & & \multirow[t]{2}{*}{ FT-Spektrometer } & \multirow[t]{2}{*}{ ANONYMUS, 2005} \\
\hline & & C18:1 & & 0,89 & & & $10-90$ & & & \\
\hline SB & gm & FFA & 0,19 & 0,21 & 0,2 & 0,19 & $0-4$ & & & $\begin{array}{l}\text { MOSCHNER und BISKUPEK- } \\
\text { Korell, } 2006\end{array}$ \\
\hline Raps & GK & $\begin{array}{c}\text { Feuchte } \\
\text { Öl } \\
\text { Protein } \\
\text { C18:1 }\end{array}$ & & & $\begin{array}{l}1,0-1,2 \\
0,7-1,1 \\
0,6-1,0 \\
2,5-3,0\end{array}$ & & $\begin{array}{c}3-36 \\
38-53 \\
13-31 \\
39-73 \\
\end{array}$ & & & REINHARDT, 1992 \\
\hline Raps & GK & $\begin{array}{c}\text { Feuchte } \\
\text { Feuchte } \\
\text { Feuchte } \\
\text { C18:1 }\end{array}$ & & & & $\begin{array}{c}0,2 \\
1,0-1,2 \\
0,3 \\
1,9 \\
\end{array}$ & $\begin{array}{c}5-9 \\
3-36 \\
4-14 \\
40-83 \\
\end{array}$ & & & TILLMANN und REINHARDT, 1998 \\
\hline
\end{tabular}

SB: Sonnenblume; Zu.: Zustand; Param.: Parameter; gm: gemahlen; GK: Ganzkorn

$R^{2} \downarrow$ : Kalibrationen, bei denen mindestens ein Bestimmtheitsmaß unter 0,6 liegt, sind mit "•"gekennzeichnet 


\section{Fortsetzung Tab. 18}

\begin{tabular}{|c|c|c|c|c|c|c|c|c|c|c|}
\hline Frucht & Zu. & Param. & SEC & SECV & SEP & SEPC & Bereich & $\mathrm{R}^{2} \downarrow$ & Anmerkung & Literaturquelle \\
\hline Raps & GK & $\begin{array}{l}\text { C16:0 } \\
\text { C18:0 } \\
\text { C18:1 } \\
\text { C18:2 }\end{array}$ & $\begin{array}{l}0,26 \\
0,20 \\
2,36 \\
1,33\end{array}$ & $\begin{array}{l}0,33 \\
0,22 \\
3,21 \\
1,69\end{array}$ & & & $\begin{array}{c}3-6 \\
1-3 \\
10-82 \\
5-45\end{array}$ & & $\begin{array}{l}\text { inkl. Eruca-Raps; } \\
\text { weniger als 3g/Probe } \\
\text { ergab schlechtere Ergebnisse }\end{array}$ & VELASCO und BECKER, 1998 \\
\hline Raps & GK & $\begin{array}{l}\text { C18:1 } \\
\text { C18:2 }\end{array}$ & & $\begin{array}{l}1,50 \\
1,70\end{array}$ & $\begin{array}{l}1,9-2,6 \\
2,0-3,8\end{array}$ & & & & & VELASCO et al., 1998a \\
\hline Raps & GK & $\begin{array}{l}\text { C18:1 } \\
\text { C18:2 } \\
\text { Öl } \\
\text { C18:1 }\end{array}$ & & $\begin{array}{l}8,44 \\
3,38 \\
1,98 \\
3,39\end{array}$ & $\begin{array}{l}8,94 \\
2,99 \\
1,87 \\
2,73\end{array}$ & & $\begin{array}{l}7-85 \\
4-42 \\
29-55 \\
51-85\end{array}$ & & $\begin{array}{l}\text { Einzelkornanalyse; } \\
\text { inkl. Eruca-Raps } \\
\text { Einzelkornanalyse }\end{array}$ & VELASCO ET AL., 1999b \\
\hline Raps & GK & $\begin{array}{c}\text { Protein } \\
\text { Öl }\end{array}$ & & & $\begin{array}{l}0,48-0,53 \\
0,81-0,85\end{array} \mid$ & $\begin{array}{l}0,47-0,52 \\
0,76-0,86\end{array}$ & $\begin{array}{l}18-26 \\
39-49\end{array}$ & & & TILLMANN et al., 2000 \\
\hline Raps & GK & $\begin{array}{c}\text { Öl } \\
\text { C16:0 } \\
\text { C18:0 } \\
\text { C18:1 } \\
\text { C18:2 }\end{array}$ & $\begin{array}{l}0,42 \\
0,08 \\
0,03 \\
0,34 \\
0,24 \\
\end{array}$ & & $\begin{array}{l}0,42 \\
0,09 \\
0,04 \\
0,34 \\
0,38 \\
\end{array}$ & & $59-65$ & & NIRLab 200 & AULRICH und BÖHM, 2007 \\
\hline Raps & GK & $\begin{array}{c}\text { Protein } \\
\text { Öl }\end{array}$ & $\begin{array}{l}0,38 \\
0,98\end{array}$ & $\begin{array}{l}0,74 \\
1,14\end{array}$ & & & $\begin{array}{l}15-32 \\
26-61\end{array}$ & & Einzelkornanalyse & Hom et al., 2007 \\
\hline
\end{tabular}

SB: Sonnenblume; Zu.: Zustand; Param.: Parameter; gm: gemahlen; GK: Ganzkorn

$R^{2} \downarrow$ : Kalibrationen, bei denen mindestens ein Bestimmtheitsmaß unter 0,6 liegt, sind mit "•"gekennzeichnet 


\section{Fortsetzung Tab. 18}

\begin{tabular}{|c|c|c|c|c|c|c|c|c|c|c|}
\hline Frucht & $\mathrm{Zu}$. & Param. & SEC & SECV & SEP & SEPC & Bereich & $R^{2} \downarrow$ & Anmerkung & Literaturquelle \\
\hline \multirow{5}{*}{$\begin{array}{c}\text { Brassica } \\
\text { ssp. }\end{array}$} & \multirow[t]{5}{*}{ GK } & C16:0 & & 0,46 & 0,52 & & & & 17 verschiedene & \multirow[t]{5}{*}{ VELASCO et al., 1998b } \\
\hline & & C18:0 & & 0,21 & 0,27 & & & & Brassica-Spezien & \\
\hline & & C18:1 & & 3,65 & 3,71 & & & & & \\
\hline & & C18:2 & & 2,09 & 2,25 & & & & & \\
\hline & & C20:1 & & 2,68 & 2,83 & & & & & \\
\hline \multirow[t]{4}{*}{ Senf } & \multirow[t]{4}{*}{ GK } & C16:0 & $0,21-0,37$ & $0,24-0,43$ & $0,30-0,34$ & & $2-6$ & & & \multirow[t]{4}{*}{ VELASCO et al., 1997} \\
\hline & & C18:0 & $0,06-0,14$ & $0,08-0,16$ & $0,12-0,17$ & & $0-2$ & & & \\
\hline & & C18:1 & $0,49-1,65$ & $1,12-2,19$ & $1,46-2,58$ & & $7-42$ & & & \\
\hline & & C18:2 & $0,66-1,39$ & $1,03-1,81$ & $1,06-1,72$ & & $7-31$ & & & \\
\hline \multirow[t]{4}{*}{ Soja } & \multirow[t]{4}{*}{ gm } & C16:0 & 0,40 & 0,50 & & 0,9 & $10-13$ & • & & \multirow[t]{8}{*}{ PAZDERNIK et al., 1997} \\
\hline & & C18:0 & 0,20 & 0,20 & & 0,2 & $3-5$ & & & \\
\hline & & C18:1 & 0,50 & 0,60 & & 0,4 & $16-27$ & & & \\
\hline & & C18:2 & 0,80 & 0,90 & & 1,3 & $52-60$ & & & \\
\hline \multirow[t]{4}{*}{ Soja } & \multirow[t]{4}{*}{ GK } & C16:0 & 0,70 & 0,80 & & 1,2 & $10-13$ & - & & \\
\hline & & C18:0 & 0,20 & 0,20 & & 0,3 & $3-5$ & $\bullet$ & & \\
\hline & & C18:1 & 0,60 & 0,80 & & 0,1 & $16-27$ & $\bullet$ & & \\
\hline & & C18:2 & 1,40 & 1,70 & & 0,2 & $52-60$ & & & \\
\hline
\end{tabular}

SB: Sonnenblume; Zu.: Zustand; Param.: Parameter; gm: gemahlen; GK: Ganzkorn

$R^{2} \downarrow$ : Kalibrationen, bei denen mindestens ein Bestimmtheitsmaß unter 0,6 liegt, sind mit "•"gekennzeichnet 


\section{Fortsetzung Tab. 18}

\begin{tabular}{|c|c|c|c|c|c|c|c|c|c|c|}
\hline Frucht & Zu. & Param. & SEC & SECV & SEP & SEPC & Bereich & $\mathrm{R}^{2} \downarrow$ & Anmerkung & Literaturquelle \\
\hline \multirow[t]{4}{*}{ Soja } & \multirow[t]{4}{*}{ GK } & C16:0 & & & 3,16 & & 3-32 & & \multirow{4}{*}{$\begin{array}{l}\text { Infratec Grain Analyzer 1225, } \\
1229 \text { sowie } 1241\end{array}$} & \multirow[t]{4}{*}{ KOVALENKO et al., 2006} \\
\hline & & C18:0 & & & 0,97 & & $2-8$ & $\bullet$ & & \\
\hline & & C18:1 & & & 4,27 & & $12-51$ & & & \\
\hline & & C18:2 & & & 3,77 & & $32-69$ & & & \\
\hline \multirow{5}{*}{$\begin{array}{c}\text { Vernonia } \\
\text { galam. }\end{array}$} & \multirow[t]{5}{*}{ GK } & C16:0 & 0,29 & 0,32 & & & $2-5$ & • & & \multirow[t]{5}{*}{ BAYE und BECKER, 2004} \\
\hline & & C18:0 & 0,32 & 0,40 & & & $2-6$ & • & & \\
\hline & & C18:1 & 1,35 & 1,75 & & & $2-16$ & - & & \\
\hline & & C18:2 & 1,43 & 2,12 & & & $10-27$ & $\bullet$ & & \\
\hline & & Öl & 1,9 & 2,37 & & & $19-44$ & & & \\
\hline \multirow[t]{6}{*}{ Saflor } & \multirow[t]{3}{*}{$\mathrm{gm}$} & \multirow[t]{3}{*}{ Öl } & 0,66 & 0,90 & & & $18-30$ & & Ernte 2003 & \multirow[t]{6}{*}{ RUDOLPHI et al., 2005} \\
\hline & & & 1,01 & 1,09 & & & $10-30$ & & Ernte 2004 & \\
\hline & & & 0,77 & 0,99 & & & $10-30$ & & Ernte $2003+2004$ & \\
\hline & \multirow[t]{3}{*}{ GK } & \multirow[t]{3}{*}{ Öl } & 0,92 & 1,07 & & & $18-30$ & & Ernte 2003 & \\
\hline & & & 1,09 & 1,58 & & & $10-30$ & & Ernte 2004 & \\
\hline & & & 1,16 & 1,53 & & & $10-30$ & & Ernte $2003+2004$ & \\
\hline
\end{tabular}

SB: Sonnenblume; Zu.: Zustand; Param.: Parameter; gm: gemahlen; GK: Ganzkorn

$R^{2} \downarrow$ : Kalibrationen, bei denen mindestens ein Bestimmtheitsmaß unter 0,6 liegt, sind mit "•"gekennzeichnet 
Bei einem Vergleich der in Tab. 18 aufgeführten publizierten Daten untereinander sowie mit den hier erzielten Ergebnissen (Tab. 9) müssen auch die jeweiligen Wertebereiche sowie die herangezogene Probenpräsentationen beachtet werden. Während bei der nahinfrarotspektroskopische Erfassung der wertgebenden Inhaltsstoffe von Rapssaat es mittlerweile üblich ist, diese Messungen am Ganzkorn durchzuführen, rechtfertigt sich der Arbeitsaufwand des Vermahlens ${ }^{2}$ oder Schälens der Sonnenblumenachänen durch die daraus resultierenden erheblich genaueren Schätzungen (PÉREZ-VICH et al., 1998; BISKUPEK-KORELL et al., 2003; MOSCHNER, 2003). Auch bei anderen Ölsaaten führte Vermahlung zu einer verbesserten Schätzgenauigkeit (PAZDERNIK et al., 1997; RUDOLPHI et al., 2005). Die Angaben aus der Literatur sowie die eigenen Ergebnisse zeigen jedoch ebenfalls die Möglichkeit auf, auch von intakten Sonnenblumenachänen die qualitätsrelevanten Inhaltsstoffe mit ausreichender Genauigkeit zu erfassen. Besonders für Züchtungsprogramme bietet die Messung am Ganzkorn den Vorteil, nach der zerstörungsfreien Analyse das Material weiterverwenden zu können.

Die verminderte Vorhersagegenauigkeit nahinfrarotspektroskopischer Untersuchungen beim Verwenden von intakten statt gemahlenen Achänen scheint durch den geringeren Informationsgehalt der Originalspektren begründet zu sein. So weisen z.B. in Abb. 10 die untransformierten Spektren (DT(0,01), keine SK) gemahlener Achänen im Bereich um 1700 sowie um $2300 \mathrm{~nm}$ im Gegensatz zu den Spektren intakter Saat einen weitaus detaillierteren Spektrenverlauf auf. In dieser Spektralregion werden auch in dieser Arbeit beim Einsatz gemahlener Achänen die durch SATO et al. (1995) beschriebenen sowie für Öl charakteristischen Absorptionsmaxima an den Wellenlängen 1722, 1760, 2308 und 2348 nm gefunden.

Die Datensätze, die in den Untersuchungen durch MOSCHNER (2003) sowie durch MOSCHNER und BISKUPEK-KORELL (2006) herangezogen wurden, sind auch in die Kalibrationsentwicklung dieser Arbeit mit eingeflossen. Dieses betrifft zum einen den Probensatz A1 sowie Proben des Erntejahres 2002 vom Standort Braunschweig aus dem Satz A2 und zum anderen den Probensatz A3 (vgl. Tab. 2). Bei einem Vergleich der Ergebnisse dieser früheren Untersuchungen mit den hier entwickelten Kalibrationsmodellen ist festzustellen, dass die Vorhersagegenauigkeiten je Parameter sich nur sehr gering voneinander unterscheiden. Die Kalibrationen dieser Arbeit greifen jedoch auf eine erheblich größere Datenbasis mit Proben verschiedener Herkünfte und

\footnotetext{
2 "It is a very boring job" (WILLIAMS und NORRIS, 2001)
} 
Erntejahre zurück und sind infolgedessen gegenüber derartigen Einflüssen bei annähernd gleichem Vorhersagefehler als robuster zu bezeichnen. Vergleicht man die in der Literatur aufgeführten Leistungsparameter mit den in dieser Arbeit je Parameter und Präsentationsform erzielten Vorhersagegenauigkeiten innerhalb des betreffenden Wertebereichs, so können die hier entwickelten Kalibrationen als überdurchschnittlich gut eingestuft werden.

\subsubsection{Zusammenfassende Bewertung}

In diesem Kapitel 5.1 wurden die entwickelten Kalibrationsmodelle zum einen anhand der Charakterisierung der RPD-Werte nach WILLIAMS (2001) beurteilt. Zum anderen erfolgte ein Vergleich mit den Präzisionsgrenzen der amtlichen Methode sowie mit den Güteparametern verschiedener Kalibrationen, die der Literatur entnommen wurden. Nachfolgende Tabelle (Tab. 19) gibt einen zusammenfassenden Überblick zu den aus den verschiedenen Bewertungskriterien resultierenden Beurteilungen. In Tab. 19 sind dabei erreichten RPD-Werte über 5 mit gut (+), unter 3 als schlecht $(-)$ sowie dazwischen als zufrieden stellend (0) charakterisiert. Die Präzision indes ist mit gut bzw. zufrieden stellend bezeichnet, sofern 95\% bzw. $80 \%$ der Validationsproben die Vergleichsgrenze der amtlichen Methode nicht überschreiten. Hier erstellte Kalibrationen sind im Vergleich zu Literaturdaten mit gut bezeichnet, sofern im Hinblick auf den jeweiligen Wertebereich die erzielten Vorhersagefehler je Präsentationsform dem Spitzenfeld zuzuordnen sind. Aufgrund fehlender publizierter Vergleichsdaten zur nahinfrarotspektroskopischen Erfassung des FFA-Anteils in der Saat statt im Öl entfällt hierfür die Bewertung.

Die Tabelle 19 auf der nächsten Seite zeigt, wie unterschiedlich und derweilen konträr die Beurteilung der Kalibrationsmodelle durch die verschiedenen Bewertungskriterien ausfällt. Wie zuvor in diesem Kapitel ausgeführt, stellt der RPD-Wert eine hilfreiche Größe dar, verschiedene Kalibrationen miteinander zu vergleichen. Jedoch verdeutlicht Tab. 19 aber auch, dass die Charakterisierung der RPD-Werte nach WILLIAMS (2001) gegenüber den beiden anderen Beurteilungskriterien meist zu leicht schlechteren Bewertungen führt. Der Vergleich mit den Präzisionsgrenzen amtlicher Methoden sowie mit bislang publizierten Güteparametern anderer Kalibrationen veranschaulicht allerdings die Eignung der entwickelten Methoden, eine leistungsfähige Qualitätserfassung von hochölsäurereichen Sonnenblumenachänen zu gewährleisten. 
Tab. 19: Übersicht über die verschiedenen Beurteilungen der entwickelten Kalibrationen anhand des RPD-Wertes, der Vergleichpräzision sowie des Literaturvergleichs

\begin{tabular}{l|ccc|ccc}
\hline & \multicolumn{3}{|c|}{ Gemahlene Achänen } & \multicolumn{3}{c}{ Intakte Achänen } \\
& RPD & Präzision & Literatur & RPD & Präzision & Literatur \\
\hline Feuchte & 0 & - & + & - & - & + \\
FFA & 0 & -1 & $\ldots$ & - & -1 & $\ldots$ \\
Öl & 0 & 0 & + & - & - & + \\
Protein & 0 & + & + & - & $+/ 0^{2}$ & + \\
C16:0 & 0 & + & + & 0 & + & + \\
C18:0 & 0 & + & + & 0 & + & + \\
C18:1 & + & + & + & - & + & + \\
C18:2 & + & + & + & - & + & + \\
\hline
\end{tabular}

mit +: gut; 0: zufrieden stellend, -: schlecht

${ }^{1}$ Beurteilung mit der Grenze für die Bestimmung im ÖI

${ }^{2}$ Beurteilung mit der produktabhängigen bzw. -unabhängige Grenze

\subsection{Chemometrische Verfahren zur Methodenoptimierung}

Wie im Kapitel 4.1 aufgezeigt wurde, konnte die Vorhersageleistung der entwickelten Kalibrationsmodelle für gemahlene sowie intakte HO-Sonnenblumenachänen durch den Einsatz verschiedener Ableitungen und Streulichtkorrekturen zum Teil erheblich gesteigert werden. Dabei zeigte sich, dass keine Art der Spektrentransformation bei allen Parametern und Präsentationsformen stets die optimale Datenvorbehandlung darstellt. Das Potenzial, mit Hilfe verschiedener Ableitungen sowie Streulichtkorrekturen die jeweiligen Kalibrationsmodelle verbessern zu können, wird beispielsweise auch durch die Untersuchung von SINNAEVE et al. (1994) anhand der Kalibrationsentwicklung zur Erfassung verschiedener Grünfutterqualitäten aufgezeigt. Wie auch in der vorliegenden Arbeit führte dabei das Verwenden keiner Spektrentransformation in den meisten Fällen zu Kalibrationen mit der geringsten Vorhersagegenauigkeit.

Die hier durchgeführten Tests der nichtparametrischen Rangvarianzanalyse nach Friedman sowie die multiplen Anschlussvergleiche nach Wilcoxon und Wilcox zeigten, dass der Gebrauch der hier eingesetzten Ableitungen bei allen Parametern und Präsentationsformen stets zu mindestens zwei signifikant unterschiedlichen 
Vorhersageleistungen führte, während der Einsatz verschiedener Streulichtkorrekturen häufig keinen signifikanten Unterschied bewirkte (Tab. 11).

In Untersuchungen durch MONTES et al. (2006b) zur Qualitätserfassung von Maiskörnern während des Ernteprozesses wurde bei 2 von 3 Qualitätsparametern ein signifikanter Einfluss auf die Vorhersageleistung durch das Verwenden unterschiedlicher Ableitungen aufgezeigt, während der Einsatz verschiedener Streulichtkorrekturen nur in einem Fall zu signifikanten Unterschieden führte.

Zwischen der Wirkung der sowohl bei MONTES et al. (2006b) als auch in dieser Arbeit herangezogenen Streulichtkorrekturen SNV und MSC zeigen DHANOA et al. (1994) einen linearen Zusammenhang auf. Dieses ist insoweit bemerkenswert, da SNV zur Standardisierung eines Spektrums die Daten desselbigen verwendet, während bei der Normierung durch MSC das Mittelwertsspektrum und somit eine vom gesamten Kalibrationsdatensatz abhängige Größe verwendet wird (NAES et al., 2002). Durch die ähnlichen Transformationsergebnisse beim Verwenden von SNV sowie MSC mag zum einen begründet sein, dass der Einsatz unterschiedlicher Streulichtkorrekturen in dieser sowie der Untersuchung durch MONTES et al. (2006b) häufig zu keinen signifikanten Unterschieden in der Vorhersageleistung führte. Betrachtet man die in verschiedener Weise transformierten Spektren in den Abbildungen Abb. 10 sowie Abb. 11, so ist es zum anderen weiterhin denkbar, dass durch die Bildung von Ableitungen schon ein Großteil der Streulicht- und Basislinieneffekte eliminiert wird. Besonders beim Verwenden der dritten Ableitung ist nur noch ein geringer Unterschied zwischen der oberen sowie unteren Ausbreitung aller Spektren zu beobachten (Abb. 11). Der Gebrauch dieser Ableitungsdimension ist zwar in der Literatur nicht häufig aufgeführt, jedoch konnte diese Variante z.B. bei der Analyse von Rapssaat durch TILLMANN und PAUL (1998) zur Erfassung der Ölsäure sowie durch HOM et al. (2007) zur Abschätzung des Glucosinolatgehaltes (GSL) erfolgreich eingesetzt werden. In der vorliegenden Arbeit führt der Gebrauch der Datentransformation DT(3,4,4) für die Erfassung des Ölgehaltes in gemahlenen Achänen in Tab. 20 zur Belegung des letzten Ranges im Wilcoxon-Wilcox-Test. Dahingegen liefert diese Ableitung bei der Erfassung des Proteingehaltes in gemahlenen Achänen die höchste Vorhersageleistung, was in Abb. 4 durch die hohen RPD-Werte sowie in Tab. 20 durch das Erzielen der höchsten Rangsumme im Wilcoxon-Wilcox-Test verdeutlicht wird. Weiterhin zeigt sich an diesem Beispiel in Tab. 20, dass die Datentransformation DT( $3,4,4)$ zum Erreichen des geringsten Vorhersagefehlers am wenigsten MPLSFaktoren benötigt. Auch bei weiteren Kalibrationsmodellen in dieser Arbeit zeigt sich die Tendenz, dass unabhängig von der eingesetzten Streulichtkorrektur durch 
Verwenden der dritten Ableitung weniger benötigte Regressionsterme in der Schätzgleichung resultieren, was hinsichtlich der Overfitting-Problematik als positiv zu bewerten ist. Indes besteht die Tatsache, dass mit steigender Dimension der Ableitung im Spektrum der Anteil des Signals der Untersuchungsprobe reduziert sowie zeitgleich der Anteil des zufälligen Rauschens erhöht wird (NAES et al., 2002; ADAMS, 2004). Somit wäre bei gleichen Vorhersagefehlern zweier Kalibrationen das Vorziehen eines Modells, welches z.B. durch den Einsatz einer höher dimensionierten Ableitung einen MPLS-Faktor weniger benötigt, kritisch zu hinterfragen.

Die Möglichkeit, mit Hilfe verschiedener Ableitungen die Leistungsfähigkeit eines Kalibrationsmodells zu verbessern, liegt nicht nur in der Dimension der Ableitung sondern auch in der Art der Bildung. Im Kapitel 4.1 konnte am Beispiel der Abschätzung des Proteingehaltes in gemahlenen HO-Achänen gezeigt werden, dass auch die Anzahl verwendeter Datenpunkte im Ableitungs- sowie Glättungsintervall einen signifikanten Einfluss auf die Vorhersageleistung hat. Dieser Sachverhalt wird auch durch WILLIAMS 2001 am Beispiel der Proteinbestimmung in intakten Weizenkörnern durch 25 verschiedene Arten der ersten Ableitung verdeutlicht.

Bei dem in der vorliegenden Untersuchung durchgeführten Versuch zum Einfluss verschiedener Ableitungen und Streulichtkorrekturen auf die Leistungsfähigkeit eines chemometrischen Modells wurde die Standardeinstellung der WinISI II v1.60-Software hinsichtlich der Obergrenze von maximal 16 verwendeten Regressionstermen beibehalten. Wie in Tab. 20 gezeigt, unterscheiden sich die Kalibrationsvarianten auch in der resultierenden Anzahl der benötigten Faktoren. Verwendet man statt der Obergrenze einen fester Wert, um mit einer fixierten Faktorenanzahl die Wirkung der unterschiedlichen Datenvorbehandlungen zu untersuchen, so würden evtl. optimale Modelle mit Kalibrationen verglichen werden, bei denen ein Underfitting vorliegt und die somit nicht das volle Potential des Datensatzes ausschöpfen. Das Abbruchkriterium innerhalb der Kreuzvalidierung gegen eine weitere Zunahme von Regressionstermen ist bei allen Kalibrationsvarianten der Wiederanstieg des SECVs. Daher scheint der Gebrauch einer Obergrenze statt eines Festwertes in dieser Untersuchung gerechtfertigt zu sein, um verschiedene Kalibrationsmodelle mit einer jeweilig optimalen Anzahl an MPLS-Faktoren vergleichen zu können.

Neben dem Einfluss verschiedener Ableitungen sowie Streulichtkorrekturen wurde durch MONTES et al. (2006b) auch die Auswirkung unterschiedlicher Regressionsmethoden auf die Schätzgenauigkeit untersucht. Dabei zeigte sich, dass 
der Gebrauch von PCR, PLS sowie MPLS je Parameter zu signifikant verschiedenen Vorhersageleistungen führte. Des Weiteren kommen die Autoren zu dem Schluss, dass der auch in dieser Arbeit angewendete MPLS-Algorithmus die Methode der ersten Wahl darstellt. Demgegenüber gibt DILLER (2002) zu bedenken, dass durch die Anwendung von MPLS eine sehr starke Anpassung der Schätzfunktion an die Kalibrationsproben erfolgt, wodurch bei der Vorhersage kalibrationsfremder Proben mit größeren Fehlern zu rechnen sei. Es wird aber eingeräumt, dass bei großen Datensätzen gegenüber anderen Regressionsverfahren die Vorteile einer durch MPLS angepassten Kalibrationsfunktion überwiegen könnten.

Die hier diskutierten Möglichkeiten zeigen das enorme Potenzial, durch chemometrische Verfahren die Leistungsfähigkeit einer Kalibrationsfunktion verbessern zu können. Weitere Verfahren wie z.B. der Uncertainty-Test und verschiedene Genetische Regressionsalgorithmen (Kap. 2.3.1) könnten eine zusätzliche Optimierung sowie robustere Modelle liefern. Generell bleibt jedoch zu bedenken, dass die Chemometrie nicht in der Lage ist, mehr Informationen aus den Störgrößen herauszufiltern, als ursprünglich in den Daten enthalten waren, was die Forderung nach einer reproduzierbaren Probenaufbereitung und -präsentation sowie einer genauen Referenzmethode unterstreicht.

\subsection{Einfluss einzelner Probengruppen}

\subsubsection{Einfluss erntefeuchter Proben}

Im Kapitel 4.3.1 konnte aufgezeigt werden, dass größere Schwankungen im Feuchtegehalt die Vorhersageleistung für andere Parameter beeinflussen. So wurden größere Schätzfehler erhalten, wenn die ausschließlich an lagertrockenem Material erstellten Kalibrationsgleichungen die Öl- sowie Ölsäuregehalte erntefeuchter Proben vorhersagten. Durch die Einbeziehung einiger erntefrischer Proben in die Kalibrationsentwicklung resultierte eine für lagertrockene Proben annährend unveränderte Genauigkeit, während das Vorhersagevermögen für erntefeuchte Proben gesteigert wurde (Tab. 13 und Tab. 14). TILLMANN und PAUL (1998) untersuchten verschiedene Varianten, um Kalibrationsgleichungen $\mathrm{zu}$ entwickeln, welche auf variierende Feuchtegehalte der Proben bei der Abschätzung der Öl- sowie GSLGehalte in Rapssaat unempfindlicher reagieren. Hierbei wurden zum einen R-Dateien, in denen Spektren unterschiedlich feuchter Proben enthalten waren, in die Modellbildung mit einbezogen. Zum anderen erfolgte während der 
Kalibrationserstellung der Ausschluss der Wellenlängen, an denen Wasser hauptsächlich absorbiert (1390 - 1426 nm sowie 1846 - $1986 \mathrm{~nm}$ ). Auch die Kombination beider Varianten wurde untersucht. Hierbei resultierte, dass der Einsatz einer R-Datei besonders geeignet war, trotz variabler Feuchtegehalte genaue Vorhersageergebnisse $\mathrm{zu}$ erzielen. TILLMANN und PAUL (1998) zeigten für Rapssaatproben, welche über einen langen Zeitraum gelagert wurden, eine starke negative Korrelation zwischen Feuchte- und Ölgehalt auf. Diese Gleichgewichtseinstellung zwischen den beschriebenen Parametern war der Grund, dass die an abgelagerten Proben erstellte Kalibration bei der Erfassung erntefeuchter Proben stark fehlerbehaftete Vorhersagen lieferte. In dieser Untersuchung hingegen zeigten erntefeuchte Proben einen starken Einfluss auf die Vorhersageleistung der entwickelten Kalibrationsmodelle, wobei zwischen dem Feuchtegehalt und den Parametern ÖI, Öl $\mathrm{LT}_{\mathrm{T}}$ C18:1 sowie C18:1 $1_{\mathrm{LT}}$ keine Korrelationen festgestellt wurden. Daher ist es nahe liegend, dass nicht allein der erhöhte Feuchtegehalt der Proben zur verminderten Vorhersageleistung der an lagertrockenem Material erstellten Kalibration beigetragen hat. BISKUPEK-KORELL et al. (2003) berichten, dass die Vermahlungseignung der Sonnenblumenachänen bei erhöhten Feuchtegehalten stark vermindert ist. Auch in dieser Untersuchung führte trotz Einhaltung des einheitlichen Vermahlungsprotokolls die Vermahlung der erntefeuchten Proben im Gegensatz zu den lagertrockenen zu einem inhomogeneren Probenmaterial und somit zu einer veränderten Partikelgrößenverteilung. Eben diese zwei Faktoren, Feuchtegehalt sowie Partikelgröße, gehören zu den wichtigsten Einflussgrößen auf die Spektren (TILLMANN, 1996). Dieses wird auch durch die Darstellung der Score-Werte aus der PCA mit der Datentransformation DT $(1,4,4)$ sowie DT(3,4,4) in Abb. 8 aufgezeigt, bei der die erntefeuchten Proben (Datensatz A4) stets eine separate Untergruppe bilden. Um die Effekte unterschiedlicher Feuchtegehalte sowie Partikelgrößen zu minimieren, ist die Einbeziehung weiterer Proben, die hinsichtlich dieser Merkmale variieren, anzuraten (OSBORNE und FEARN, 1986).

\subsubsection{Einfluss protein- sowie linolsäurereicher Proben}

Bei der Erfassung des Parameters Protein führte die Einbindung der protein- sowie linolsäurereiche Varianten der Datensätze B1 und B2 in die Modellbildung zwar zu einer leichten Erhöhung der Vorhersagefehler, jedoch auch zu Kalibrationsfunktionen, die deutlich robuster auf von HO-Material abweichende Proben reagieren (Tab. 16). Hierbei waren die Effekte besonders bei gemahlenen Achänen zu verzeichnen. Der geringe Verlust an Vorhersagegenauigkeit bietet den Vorteil weitaus verlässlicherer 
Kalibrationen, die für einen erweiterten Wertebereich sowie für eine größere spektrale Population Gültigkeit besitzen.

Die Hinzunahme der gleichen Proben aus B1 und B2 in die Kalibrationsentwicklung für den Parameter Ölsäure lieferte indes eine erhebliche Verschlechterung der Vorhersagegenauigkeit für HO-Material (Tab. 17). Bei der Abschätzung intakter Ölsäurereicher Achänen versagte die um linolsäurereiche Varianten erweiterte Kalibration, was durch die Punktwolke in Abb. 7 sowie den RPD-Wert von 0,6 aufgezeigt wird. Während die Vorhersage der Ölsäuregehalte in intakten HO-Achänen durch die ausschließlich an high-oleic Proben erstellte Kalibration ausreichende Genauigkeiten ergab, wurden linolsäurereicher Varianten nicht nur mit stark fehlerbehafteten Schätzwerten vorhergesagt, sondern auch auf Grund der scheinbar hohen Ölsäuregehalte fälschlicherweise dem HO-Segment zugeordnet. Die Ursache dieser Fehleinschätzung könnte in der Kombination aus dem schon im Kapitel 5.1 beschriebenen verminderten Informationsgehalt der Spektren intakter Achänen im Bereich der für Öl charakteristischen Absorptionsmaxima und der hohen Korrelation zwischen Ölsäure sowie Linolsäure $\left(r_{S}=-0,87^{* *}\right)$ begründet sein. Um diese Kalibration dennoch nutzen zu können, müssen die Untersuchungsproben durch eine vorgeschaltete, aus linolsäure- sowie ölsäurereichen Proben erstelle Kalibrationsfunktion als HO-Material identifiziert worden sein.

Im Falle gemahlener Achänen zeigt die ausschließlich aus hochölsäurehaltigem Material erstellte Kalibration bei der Erfassung von linolsäurereichen Varianten über den eigentlichen Kalibrationsbereich hinaus trotz der hohen Korrelation der zuvor genannten Fettsäuren eine eindeutige Differenzierung auf und kann somit gesichert eingesetzt werden. Kommen vermehrt linolsäurereiche Varianten im Untersuchungsgut vor, so kann mit Hilfe der in dieser Arbeit am Gesamtdatensatz entwickelten Kalibrationsgleichung eine genauere Vorhersage der Fettsäuren erfolgen. Am Beispiel der Abschätzung des Ölsäuregehaltes in gemahlenen Achänen zeigt sich, dass der Vorhersagefehler mit zunehmendem Wertebereich steigt (Tab. 17). Dieser Sachverhalt wird auch in den durch TILLMANN und REINHARDT (1998) sowie durch VELASCO et al. (1999b) publizierten Kalibrationen (Tab. 18) für den Feuchtegehalt bzw. den Ölsäureanteil aufgezeigt. Nach MARK (1991) gibt es einen optimalen Wertebereich einer Kalibration, der nicht mit dem verfügbaren Bereich identisch sein muss. Hiernach gehen bei einem zu kleinen Wertebereich verstärkt die Fehler der Referenzanalyse in die Modellbildung ein, während bei einem zu großen Bereich Nichtlinearitäten auftreten können. Sollten im gewünschten Wertebereich eines chemometrischen Modells Nichtlinearitäten vorhanden sein, so nennen NAES et al. (2002) verschiedene Methoden zur Problembehebung, welche z.B. durch den Einsatz verschiedener 
Spektrentransformationen, durch das Ausblenden von Wellenlängen oder durch das Verwenden nichtlinearer Regressionsverfahren erfolgen kann. DARDENNE et al. (2000) verglichen in einer Untersuchung die vier unterschiedlichen Regressionsmethoden MLR, PLS, ANN sowie "LOCAL“ zur Kalibrationserstellung für verschiedene Agrarprodukte. Dabei zeigte sich, dass die erzielten Vorhersagegenauigkeiten einander sehr ähnlich waren. Die Autoren verweisen schlussendlich darauf, dass die regelmäßige Einbeziehung neuer Proben in die Kalibrationsfunktion ein sehr großes Optimierungspotenzial darstellt. In dieser Untersuchung zeigt das dreidimensionale Diagramm der Score-Werte (Abb. 8) zum einen die große Variabilität des eingesetzten Zuchtmaterials des Datensatzes B2, dessen Hinzunahme in die Kalibrationserstellung für den Parameter Protein zu einer leistungsfähigen sowie robusten Methode führte. Zum anderen verdeutlicht die Darstellung der Faktorwerte aus der PCA mit der Datentransformation DT(3,4,4) den sog. „Jahrgangseffekt“ (vgl. Kap. 5.1). Während die meisten lagertrockenen HO-Proben des Datensatzes A2 unabhängig vom Erntejahr, Anbauort und von der Sorte eine spektrale Population beschreiben, so bilden die Ernteproben des Jahres 2003 vom Standort Braunschweig eine eigene separate Untergruppe. Die außergewöhnlich trockenen Bedingungen während der Vegetationsperiode mit $244 \mathrm{~mm}$ Niederschlag am Standort zuzüglich zweimaliger Beregnung mit je $30 \mathrm{~mm}$ (DILCI und RÜHL, 2006) sowie die überdurchschnittlich hohen Temperaturen im Jahr 2003 scheinen die besondere Probeneigenschaften zu begründen.

Die hier erläuterten Einflüsse unterstreichen die Forderungen z.B. von DARDENNE und WeLLE (1998), dass die Datenbasis die Gesamtheit an Variationsquellen wie eine Vielzahl an Sorten, Erntejahren, Anbau- sowie Klimabedingungen beinhalten sollte, um leistungsfähige und robuste Kalibrationsmodelle zu erhalten.

\section{$5.4 \quad$ Ausblick}

Die in dieser Untersuchung erzielten Ergebnisse verdeutlichen die Leistungsfähigkeit der entwickelten nahinfrarotspektroskopischen Methoden zur Qualitätserfassung verschiedener Parameter in HO-Sonnenblumenachänen. Während die Abschätzung der Öl- und Proteingehalte sowie des Fettsäuremusters in verschiedenen Agrarprodukten durch den Einsatz der NIRS weit verbreitet ist, so zeigen die im Rahmen dieser Untersuchung entwickelten Kalibrationen zur Bestimmung der Anteile freier Fettsäuren (FFA) direkt in der Saat neue Möglichkeiten der Qualitätsbeurteilung auf. Zum Beispiel stellt gerade bei der Verarbeitung von Ölsaaten in dezentralen Anlagen der FFA-Anteil einen wichtigen Qualitätsparameter dar, da im Gegensatz zur 
industriellen Pflanzenölgewinnung der verfahrenstechnische Schritt der Raffination zur Entfernung der freien Fettsäuren fehlt und somit die Produktqualität durch erhöhte FFA-Gehalte der eingesetzten Saat stark gefährdet ist (SCHUMANN und GRAF, 2005). Aber auch in weiteren Einsatzgebieten ermöglichen die hier entwickelten Methoden eine schnelle, einfache sowie verlässliche Art der Erfassung der qualitätsbestimmenden Inhaltsstoffe von HO-Sonnenblumenachänen. Die simultane Abschätzung des Feuchte-, Öl- und Proteingehaltes, des Fettsäuremusters sowie des FFA-Anteils ermöglichen eine umfassende Qualitätsbeurteilung an gemahlenen aber auch intakten Achänen.

Um diese Kalibrationsgleichungen einem weiten Anwenderkreis zur Verfügung zu stellen, bietet sich ein Transfer der NIRS-Methoden auf weitere Spektrometer an. Hiermit entfallen für den Anwender arbeitsintensive Probenanalysen sowie die Entwicklung einer multivariaten Kalibration. Weiterhin kann als großer Vorteil des Kalibrationstransfers angesehen werden, dass somit auf den unterschiedlichen Spektrometern einheitliche, vergleichbare Ergebnisse erzielt werden können.

Für einen erfolgreichen Transfer der Methoden stehen effiziente Algorithmen wie z.B. Piecewise direct standardisation (PDS) (WANG et al., 1992) oder das Standardisierungsverfahren nach SHENK und WESTERHAUS (1991c) in verschiedenen Softwarepaketen zur Verfügung. Des Weiteren sind verschiedene Arten der Netzwerkbildung detailliert durch z.B. TILLMANN (1997) und FEARN (2001) beschrieben worden, um durch vernetzte NIRS-Methoden eine leistungsfähige Qualitätserfassung zu realisieren.

Die Pflege und Aktualisierung der Methoden sind wichtige Arbeiten, um durch die Einbeziehung neuer Proben stets zuverlässige und aktuelle Kalibrationsmodelle zu gewährleisten, was in der Folge zu einem großen Nutzen für Pflanzenzüchter, Versuchsansteller, Anbauverbände und Ölsaatenverarbeiter führt. 


\section{$6 \quad$ Zusammenfassung}

Eine verlässliche Erfassung der verschiedenen Erntequalitäten von hochölsäurehaltigen ( $\mathrm{HO})$ Sonnenblumen ist unumgänglich, um eine optimal Verwertung und Wertschöpfung im food sowie non-food Bereich zu realisieren. Hierfür bietet sich der Einsatz der Nahinfrarotspektroskopie (NIRS) auf Grund der simultanen sowie Zeit und Kosten sparenden Bestimmung mehrerer Parameter an. Gegenstand der vorliegenden Untersuchung ist die Entwicklung, Optimierung sowie Beurteilung von NIRS-Kalibrationen zur Erfassung der wertgebenden Inhaltsstoffe von HOSonnenblumenachänen (Feuchte-, Öl- und Proteingehalt, Fettsäurespektrum sowie Anteil freier Fettsäuren), um hierdurch eine leistungsfähige sowie robuste Qualitätsanalytik zu gewährleisten.

Um zu prüfen, welche Datenvorbehandlung für eine präzise Vorhersage des jeweiligen Inhaltsstoffs in gemahlenen bzw. intakten Achänen geeignet ist, wurden die Spektren durch die Bildung unterschiedlicher Ableitungen und Nutzung verschiedener Streulichtkorrekturen transformiert. Die aus lagertrockenem HO-Material bestehende Datenbasis wurde mit erntefeuchten Proben ergänzt, um Kalibrationen zu entwickeln, die unabhängig vom vorherrschenden Feuchtegehalt andere Parameter wie den Ölgehalt und das Fettsäuremuster richtig erfassen. Zur Erhöhung der Variabilität innerhalb der Kalibrationssets und zur Beurteilung der Leistungsfähigkeit der erstellten Kalibrationen wurden auch protein- sowie linolsäurereiche Varianten mit in die Untersuchung einbezogen. Somit wurde auf mehr als 1800 Sonnenblumensaatproben aus 8 verschiedenen Erntejahren von 17 Standorten zur Erstellung und Validierung der NIRS-Methoden zurückgegriffen, wobei der Großteil der verwendeten HO-Proben aus 4 Erntejahren von 2 Standorten entstammt.

Es zeigte sich das enorme Potenzial, mit Hilfe verschiedener Spektrentransformationen die Leistungsfähigkeit der Kalibrationsmodelle für HO-Achänen verbessern zu können. Dabei führten die eingesetzten Ableitungen bei allen Parametern und Präsentationsformen stets zu mindestens zwei signifikant unterschiedlichen Vorhersageleistungen, während die Nutzung verschiedener Streulichtkorrekturen häufig keinen signifikanten Unterschied bewirkte. Die Einbeziehung erntefeuchter Proben in die Modellentwicklung lieferte Kalibrationsgleichungen, welche die geprüften Parameter Öl sowie Ölsäure in lagertrockenem Untersuchungsmaterial mit annährend unveränderter Genauigkeit erfassten, während das Vorhersagevermögen für Proben 
mit hoher Restfeuchte gesteigert wurde. Beim Parameter Protein führte die Hinzunahme der protein- sowie linolsäurereichen Proben in die Modellentwicklung zwar zu einer leichten Erhöhung des Vorhersagefehlers bei der Erfassung hochölsäurehaltiger Proben, allerdings resultierte hierdurch eine weitaus robustere Kalibrationsgleichung, welche auch von HO-Material abweichende Varianten sicher erfasst. Die Vorhersage der Ölsäuregehalte in intakten HO-Achänen ergab ausreichende Genauigkeiten. Jedoch wurden linolsäurereiche Proben durch die an HO-Material erstellte Kalibration nicht nur mit großen Fehlern behaftet vorhergesagt, sondern auch fälschlicherweise HO-Material zugeordnet. Dahingegen lieferte die Abschätzung der Ölsäuregehalte in gemahlenen HO-Proben durch eine ausschließlich aus hochölsäurehaltigem Material erstellte Kalibration sehr präzise Vorhersagen und zeigte bei der Erfassung von linolsäurereichen Varianten über den eigentlichen Kalibrationsbereich hinaus eine eindeutige Differenzierung auf.

Neben der Beurteilung der Kalibrationen anhand statistischer Leistungsparameter erfolgte weiterhin ein Vergleich mit den Präzisionsgrenzen amtlicher Methoden sowie mit bislang publizierten Daten zur nahinfrarotspektroskopischen Bestimmung qualitätsrelevanter Inhaltsstoffe in Ölsaaten. Hierbei erwiesen sich die in dieser Untersuchung entwickelten Kalibrationen als zuverlässig, präzise sowie geeignet, eine leistungsfähige sowie robuste Qualitätserfassung von HO-Sonnenblumenachänen zu gewährleisten.

Durch die Weiterentwicklung der Methoden mit Hilfe verschiedener chemometrischer Verfahren aber besonders auch hinsichtlich der Einbeziehung neuer Proben, welche z.B. auf Grund der Sorte, des Erntejahres, der Restfeuchte sowie des Anbaugebietes die Variabilität des bestehenden Datensatzes vergrößern, könnte die Leistungsfähigkeit der hier erarbeiteten Kalibrationen weiter gesteigert werden. Die Einbindung der Kalibrationsfunktionen in ein NIRS-Netzwerk würde zu einem großen Nutzen für den gesamten Personenkreis führen, der sich mit Anbau, Vermarktung sowie Züchtung von High-Oleic-Sonnenblumen befasst. 


\section{$7 \quad$ Summary}

To determine the different quality parameters of high-oleic $(\mathrm{HO})$ sunflower achenes, reliable analytical methods are necessary in order to achieve optimal yield and value for both, the food and non food area. It is therefore recommended to use near-infrared spectroscopy (NIRS), which allows the simultaneous determination of several parameters in a time and cost-saving way. The objective of this investigation is to develop, optimise and assess efficient and robust near-infrared calibrations to estimate the quality parameters (content of moisture, oil, protein, fatty acids and free fatty acids) of ground and intact high oleic sunflower achenes.

In order to examine which data pre-treatment is suitable for the accurate determination of the respective parameters in ground and intact achenes, the spectra were transformed using different derivatives and scatter corrections. The sample population consisting of dry $\mathrm{HO}$-achenes was supplemented with freshly harvested and wet samples in order to reduce the moisture sensitivity of calibration equations for the estimation of other parameters like content of oil and fatty acids. Furthermore, samples with a high content of protein and linoleic acid were also included in this investigation to extend the variability of the calibration set and to verify the calibrations. Altogether, more than 1800 samples of sunflower achenes from 8 different harvest years and 17 origins were used for the development and validation of the NIRS-methods, yet most of the used HO-samples were derived from 4 harvest years and 2 origins.

The investigation shows the enormous potential to improve the prediction accuracy of the calibration equations for $\mathrm{HO}$-achenes using different data pre-treatments. For all parameters and sample presentations the applied derivatives led in all cases to at least two significantly different predictions, while the use of different scatter corrections frequently caused no significant difference. The inclusion of freshly harvested samples into the model development reduced the moisture sensitivity of calibration equations and in consequence the prediction accuracy increased for the estimation of the content of oil and oleic acid in samples with higher moisture content. Through the inclusion of samples with a high content of protein and linoleic acid into the calibration development the prediction error for the protein determination in HO-achenes increased marginally, but this procedure led to a more robust calibration equation for high oleic samples and differing varieties. The calibration equation developed with high oleic sunflower achenes predicted the content of oleic acid in intact HO-achenes with sufficient 
accuracy. However, when using this calibration equation for the determination of samples with a high content of linoleic acid, large prediction errors occurred and furthermore these samples were misleadingly classified as high oleic achenes. By contrast, the estimation of the content of oleic acid in ground high oleic sunflower achenes with a calibration equation solely based on $\mathrm{HO}$-samples led to a precise prediction and showed a clear differentiation between samples with high linoleic and oleic acid content.

In addition to the evaluation of the calibration methods by statistical parameters a comparison of the achieved results with the repeatability and reproducibility of the reference method as well as a comparison with published data of NIRS-methods for the estimation of quality parameter of oilseed was performed. In conclusion the calibration methods developed here are suitable for a precise, reliable and efficient determination of the different quality parameters of high oleic sunflower achenes.

A further development of the these methods by the applying different chemometrics and particularly by including further samples to increase the variability of the sample population in regard to cultivar, harvest year, moisture content and origin, could lead to an increased performance of the calibration equations. The integration of these methods into a network of spectrometers will be of great value for those who are concerned with the cultivation, marketing and breeding of high-oleic-sunflowers. 


\section{Literaturverzeichnis}

AdAMS, M. J., 2004. Chemometrics in analytical spectroscopy. 2. Aufl. Cambridge: Royal Society of Chemistry.

ANONYMUS, 2002. Determination of percent oleic and linoleic acid in sunflower seeds using AOTF-NIR-Spectroscopy. Brimrose Corporation of America, Baltimore, USA. http://www.brimrose.com/seed7.pdf. (geprüft: 29. Mai 2007).

ANONYMUS, 2005. Cognis Corporation, QTA

http://www.qta.com/content/Public_Home/sunflower.asp. (geprüft: 29. Mai 2007).

AULRICH, K. UND BÖHM, H., 2007. Qualitätsbewertung von Raps aus ökologischem Anbau mit Hilfe der Nah-Infrarot-Spektroskopie (NIRS). In: Jahresbericht 2006 Institut für ökologischen Landbau - Bundesforschungsanstalt für Landwirtschaft, S.10-11. http://orgprints.org/10389/01/Jahresbericht_OEL_2006_Langfassung.pdf. (geprüft: 29. Mai 2007).

BÄRLOCHER, F., 1999. Biostatistik. Praktische Einführung in Konzepte und Methoden. Stuttgart: Thieme.

Baye, T. und Becker, H. C., 2004. Analyszing Seed Weight, Fatty Acid Composition, Oil and Protein Contents in Vernonia galamensis Germplasm by Near-Infrared Reflectance Spectroscopy In: J. Am. Oil Chem. Soc., 81, S. 641-645.

BINGEL, S. UND MARQUARD, R., 2001. Untersuchungen zur Bildung freier Fettsäuren bei Sonnenblumen in Abhängigkeit vom Erntetermin, dem Grad der Beschädigung und den Lagerungsbedingungen. In: MAIDL, F.-X. und DIEPENBROCK, W. (Hrsg.) Mitteilungen der Gesellschaft für Pflanzenbauwissenschaften, Band 13: Verlag Freisinger Künstlerpresse, S. 125-126.

BISKUPEK-KoRELL, B.; RAUSCHER, P. UND EIDNER, S., 2003. Entwicklung einer NIRSKalibration zur Bestimmung des Ölsäuregehaltes an vermahlener Sonnenblumensaat als qualitätssichernde Maßnahme bei Vermarktung und Verarbeitung von High-Oleic-Sonnenblumen. In: UFOP-Studien. http://www.ufop.de/downloads/NIRS_Bericht_100507.pdf) (geprüft: 29. Mai 2007).

BoCKISCH, M., 1993. Nahrungsfette und -öle. (Handbuch der Lebensmitteltechnologie). Stuttgart: Ulmer.

CONZEN, J.-P., 2001. Multivariate Kalibration. Ein praktischer Leitfaden zur Methodenentwicklung in der quantitativen Analytik. 3. Aufl.: Bruker Optik GmbH. 
DANZeR, K.; Hobert, H.; Fischbacher, C. Und JagemanN, K.-U., 2001. Chemometrik. Grundlagen und Anwendungen. Berlin: Springer-Verlag.

DARDENNE, P. UND WELLE, R., 1998. New approach for calibration transfer from a local database to a global database In: J. Near Infrared Spectrosc., 6, S. 55-60.

Dardenne, P.; SinnaeVe, G. Und BAeten, V., 2000. Multivariate calibration and chemometrics for near infrared spectroscopy: which method? In: J. Near Infrared Spectrosc., 8, S. 229-237.

DAVIES, A., 1998. Cross-validation: do we love it too much? In: Spectroscopy Europe, 10 (2), S. 24-25.

DAVIES, A., 2001. Uncertainty testing in PLS regression In: Spectroscopy Europe, 13 (2), S. 13-14.

DAVIES, A. UND FEARN, T., 2005. Back to basics: the principles of principal component analysis In: Spectroscopy Europe, 16 (6), S. 20-23.

Deutsche Gesellschaft für Fettwissenschaft. DGF C-VI 10a, 2000. Gaschromatographie - Analyse von Fettsäure.

DhanoA, M.; Lister, S. Und SAnderson, R. BARnes R.J., 1994. The link between Multiplicative Scatter Correction (MSC) and Standard Normal Variate (SNV) transformations of NIR spectra In: J. Near Infrared Spectrosc., 2, S. 43-47.

DILCI, B.; RÜHL, G.; BRAMm, A.; HÖPPNER, F. 2004a. Resistance inducing agent BION® and plant nutrition method CULTAN as alternative agricultural practice for stabilized yield in central Europe in high oleic sunflower (Helianthus annuus L.) In: New directions for a diverse planet: Proceedings of the 4th International Crop Science Congress 2004, Brisbane, Australia.

Dilcl, B.; RÜHL, G.; Hahn, V.; BiskupeK-KoRell, B. Und Moschner, C. R., 2004b. Ertrags- und Qualitätssicherung von High-Oleic-(HO)Sonnenblumen. In: KAUTER, D., KämpF, A., Claupein, W. und DiepenBrock, W. (Hrsg.) Mitteilungen der Gesellschaft für Pflanzenbauwissenschaften, Band 16. Stuttgart: Verlag Günter Heimbach, S. 203-204.

DILCI, B. UND RÜHL, G., 2007. Ertrags- und Qualitätssicherung von HO-Sonnenblumen in Deutschland - Abschlussbericht 2006. (FNR-Förderkennzeichen 22001202). In Vorbereitung. 
DILLER, M., 2002. Untersuchungen zur NIRS-Methodenentwicklung für Kartoffeln aus dem Organischen Landbau unter Berücksichtigung von Jahrgangs- und Sorteneinflüssen. Diss., Universität Bonn.

DIN Deutsches Institut für Normung e.V. DIN EN ISO 10565, 1998. Ö/samen Gleichzeitige Bestimmung des Öl- und Wassergehaltes - Verfahren mit gepulster Kernresonanzspektroskopie.

DIN Deutsches Institut für Normung e.V. DIN EN ISO 665, 2001. Ö/samen Bestimmung des Gehaltes an Feuchtigkeit und flüchtigen Bestandteilen.

DIN Deutsches Institut für Normung e.V. DIN EN ISO 660, 2005. Tierische und pflanzliche Fette und Öle - Bestimmung der Säurezahl und der Azidität.

DIN Deutsches Institut für Normung e.V. DIN EN ISO 16634, 2006. Getreide, Hülsenfrüchte, gemahlene Getreideerzeugnisse, Ölsamen und Futtermittel Bestimmung des Gehaltes an Gesamtstickstoff mit dem Verbrennungsverfahren nach Dumas und Berechnung des Gehaltes an Rohprotein.

FASSIO, A. UND COZZOLINO, D., 2004. Non-destructive prediction of chemical composition in sunflower seeds by near infrared spectroscopy In: Industrial Crops and Products, 20, S. 321-329.

FEARN, T., 2001. Standardisation and calibration transfer for near infrared instruments: a review In: J. Near Infrared Spectrosc., 9, S. 229-244.

FEARN, T., 2002. To average or not to average In: NIR news, 13 (5), S. 13-14.

FEMENIAS, N., 2003. Schriftliche Mitteilung über erstellte Sonnenblumen-NIRSKalibration. Limagrain Genetics, Riom Cedex, Frankreich [Email].

FITCH, 2003. WinSTAT für Excel [Software].

FRIEDT, W. UND LÜHS, W., 2001. Perspektiven der Industriepflanzenzüchtung. In: Nachwachsende Rohstoffe für die Chemie - 7. Symposium 2001: Landwirtschaftsverlag $\mathrm{GmbH}$, S. 47-75.

FROST, V. JÖRG., 2000. Kalibrationsoptimierung mittels Genetischer Algorithmen. Eine Methode zur automatischen Selektion von PCR-Faktoren in der NIR-Spektrometrie. Diss., Universität Duisburg.

GELADI, P. UND DABAKK, E., 1995. An overview of chemometrics applications in near infrared spectroscopy In: J. Near Infrared Spectrosc., 3, S. 119-132. 
Graf, T.; VetTeR, A. Und BIERTüMPfEL, A., 2000. Maßgeschneiderte Fettsäuren aus alternativen Ölpflanzen. In: UFOP-Schriften. Öl- und Faserpflanzen - Neue Wege in die Zukunft, Heft 14, S. 227-232.

HAHN, V., 2007. Die Sonnenblume - eine Eiweißpflanze für den Ökologischen Landbau? In: Beiträge zur 9. Wissenschaftstagung Ökologischer Landbau. Hohenheim 20.-23. März 2007, S. 257-258.

HOM, N.; BECKER, H. C. UND MÖLLERS, C., 2007. Non-destructive analysis of rapeseed quality by NIRS of small seed samples and single seed In: Euphytica, 153, S. 2734.

Hugger, H., 1989. Sonnenblumen. Züchtung, Anbau, Verarbeitung. Stuttgart: Ulmer.

KäB, H., 2001. Marktanalyse industrielle Einsatzmöglichkeiten von High-OleicPflanzenölen. Gülzow: Fachagentur Nachwachsende Rohstoffe e.V. (Gülzower Fachgespräche).

Kessler, W., 2007. Multivariate Datenanalyse für die Pharma, Bio- und Prozessanalytik - Ein Lehrbuch. Weinheim: WILEY-VCH.

KÖHLER, W.; SchACHTEL, G. UND VOlESKE, P., 2002. Biostatistik. Eine Einführung für Biologen und Agrarwissenschaftler. 3. Aufl. Berlin: Springer-Verlag.

KovalenKo, I.; RIPPKe, G. UND HURBURGH, C., 2007. Dimensionality reduction of near infrared spectral data using global and local implementations of principal component analysis for neural network calibrations In: J. Near Infrared Spectrosc., 15, S. 21-28.

LEARDI, R., 2001. Genetic algorithms in chemometrics and chemistry: a review In: Journal of Chemometrics, 15, S. 559-569.

LEARDI, R. UND NORGAARD, L., 2004. Sequential application of backward interval partial least squares and genetic algorithms for the selection of relevant spectral regions In: Journal of Chemometrics, 18, S. 486-497.

LINDEMANN, K. UND GRONOW, J., 2001. EU-Sortenversuch Sonnenblumen 2000 und zweijährige Ergebnisse von EU-Sorten. In: UFOP-Schriften. Sortenversuche 2000 mit Winterraps, Ackerbohnen, Futtererbsen und Sonnenblumen, Heft 16, S. 105125.

LÜHS, W. UND FRIEDT, W., 1999. Anbauempfehlungen für hochölsäurehaltige Sonnenblumen (HO-Sonnenblumen) in Deutschland: Schlüter, B. (Hrsg.) Bundesforschungsanstalt für Landwirtschaft (FAL), Institut für Pflanzenbau und Grünlandwirtschaft. 
MARK, H., 1991. Principles and Practice of Spectroscopic Calibration. New York: Wiley \& Sons. (Chemical analysis ; 118).

MARK, H. UND WORKMAN, J., 2003. Statistics in spectroscopy. 2. Aufl. Amsterdam: Elsevier.

MARTENS, H. UND NAES, T., 1989. Multivariate Calibration. New York: Wiley \& Sons.

MARTENS, H. Und NAES, T., 2001. Multivariate Calibration by Data Compression. In: WILliams, P. und NoRRIS, K. H. (Hrsg.) Near-Infrared Technology in the Agricultural and Food Industries. St. Paul Minn.: American Association of Cereal Chemists, S. 59 - 100.

MCCLURE, W. UND TSUCHIKAWA, S., 2007. Instruments. In: OZAKI, Y., MCCLURE, W. und CHRISTY, A. (Hrsg.) Near-Infrared Spectroscopy in Food Science and Technology: John Wiley \& Sons, S. 75-107.

Montes, J.; UtZ, H.; Schipprack, W.; Kusterer, B.; Muminovic, J. Und PAUL, C., 2006a Near-infrared spectroscopy on combine harvesters to measure maize grain dry matter content and quality parameters In: Plant Breeding, 125, S. 591.

Montes, J.; Paul, C.; Kusterer, B. und Melchinger, A., 2006b Near infrared spectroscopy to measure maize grain composition on plot combine harvesters: evaluation of calibration techniques, mathematical transformations and scatter corrections In: J. Near Infrared Spectrosc., 14, S. 387-394.

MoschNeR, C. R., 2003. Abschätzung des Gehaltes wertgebender Inhaltsstoffe von Sonnenblumensaat mittels Nahinfrarotspektroskopie (NIRS). Diplomarbeit, Fachhochschule Hannover.

MOSCHNER, C. R. UND BISKUPEK-KORELL, B., 2006. Estimating the content of free fatty acids in high-oleic sunflower seeds by near-infrared spectroscopy In: European Journal of Lipid Science and Technology, 108 (7), S. 606-613.

NAes, T.; Isaksson, T.; Fearn, T. Und DaVIES, T., 2002. A user-friendly guide to Multivariate Calibration and Classification. Chichester: NIR Publications.

OsboRne, B. UND FEARN, T., 1986. Near infrared spectroscopy in food analysis. Harlow: Longman Scientific \& Technical.

PAUL, C., 2003. NIR Takes to the Field - NEAR CLIMBS on the HARVESTER and GOES OUT to the FIELD In: The NIR Spectrum, 1 (3). 
PAZDERNIK, D.; KILLAM, A. UND ORF, J., 1997. Analysis of amino and fatty acid composition in Soybean seed, using near-infrared reflectance spectroscopy In: Agronomy, 89, S. 679-685.

Pérez-Vich, B.; Velasco, L. und Fernández-MartíneZ, J. M., 1998. Determination of seed oil content and fatty acid composition in sunflower through the analysis of intact seeds, husked seeds, meals and oil by near-infrared reflectance spectroscopy In: J. Am. Oil Chem. Soc., 75 (5), S. 547-555.

REINHARDT, T.-C., 1992. Entwicklung und Anwendung von Nah-Infrarotspektroskopischen Methoden für die Bestimmung von Öl-, Protein-, Glucosinolat-, Feuchte- und Fettsäure-Gehalten in intakter Rapssaat. Göttingen: Cuvillier-Verlag.

RÖNICKE, S.; HAHN, V. UND FRIEDT, W., 2005. Resistance to Sclerotinia sclerotiorum of 'high oleic' sunflower inbred lines In: Plant Breeding, 124 (4), S. 376-381.

RudolPhI, S.; WiTZKE-EhBRECHT, S. VON UND BECKER, H. C., 2005. Development of Near-Infrared Reflectance Spectroscopy to Estimate Oil Content in Safflower. In: EnVer ESENDAL (Hrsg.) Proceedings of the Sixth international Safflower Conference, 2005, Istanbul, Türkei.

RUDZIK, L., 1993. Infrarotfibel. Infrarotspektroskopie für die Lebensmittel- und Milchindustrie: Hamburg: B. Behrs Verlag.

SACHS, L., 1999. Angewandte Statistik. Anwendung statistischer Methoden. 9. Aufl. Berlin: Springer-Verlag.

Saeys, W.; Darius, P. Und Ramon, H., 2004. Potential for on-site analysis of hog manure using a visual and near infrared diode array reflectance spectrometer In: J. Near Infrared Spectrosc., 12, S. 299-309.

Saranwong, S.; Sornsrivichal, J. Und KaWAno, S., 2003. Performance of a portable near infrared instrument for Brix value determination of intact mango fruit In: J. Near Infrared Spectrosc., 11, S. 175-181.

Sato, T.; TAKahata, Y.; Noda, T.; YANAgISAWA, T. Und MORISHITA, T. UND SAKaI S., 1995. Nondestructive Determination of Fatty Acid Composition of Husked Sunflower (Helianthus annua L.) Seeds by Near-Infrared Spectroscopy In: J. Am. Oil Chem. Soc., 72 (10), S. 1177-1183.

SCHIERHOLT, A. UND BECKER, H. C., 2000. Entwicklung von Hochölsäure Raps. In: UFOP-Schriften. Öl- und Faserpflanzen - Neue Wege in die Zukunft, Heft 14, S. 319-323. 
SCHUMANN, W. UND GRAF, T., 2005. Anforderungen an die Rapssaat im Hinblick auf Qualitätsoptimierung. In: KURATORIUM FÜR TECHNIK UND BAUWESEN IN DER LANDWIRTSCHAFT E.V. (KTBL) (Hrsg.) Dezentrale Ölsaatenverarbeitung, KTBLSchrift 427, S. 21-30.

SCHUSTER, W., 1992. Ölpflanzen in Europa. Frankfurt am Main: DLG-Verl.

ShenK, J. UND Westerhaus, M., 1991a. Population Structuring of Near Infrared Spectra and Modified Partial Least Squares Regression In: Crop Sci., 31, S. 15481555.

Shenk, J. Und Westerhaus, M., 1991b. Population definition, sample selection, and calibration procedures for near infrared spectroscopy In: Crop Sci., 31, S. 469-474.

SHENK, J. UND WesterhaUS, M., 1991c. New standardization and calibration procedures for NIRS analytical systems. In: Crop Sci., 31, S. 1694-1696.

SinnaeVe, G.; Dardenne, P. Und Agneessens, R., 1994. Global or local? A choice for NIR calibrations in analyses of forage quality In: J. Near Infrared Spectrosc., 2, S. 163-175.

Sjöström, M.; Wold, S.; Lindberg, W.; Persson, J.-A. Und MARTens, H., 1983. A multivariate calibration problem in analytical chemistry solved by partial leastsquares models in latent variables In: Analytica Chimica Acta, 150, S. 61-70.

Steuer, B. Und Schulz, H., 2003. Near-infrared Analysis of Fennel on Different Spectrometers - Basis Considerations for a reliable Network In: Phytochem. Anal., 14 , S. $285-289$.

STORZ, E. IRMGARD, 2003. Untersuchung funktioneller Parameter pharmazeutischer Hilfsstoffe mittels Nahinfrarot-Spektroskopie (NIRS). Diss., Universität Bonn.

Temma, T.; Hanamatsu, K. Und ShINOKI, F., 2002. Development of a portable near infrared sugar-measuring instrument In: J. Near Infrared Spectrosc., 10, S. 77-83.

TILLMANN, P., 1996. Kalibrationsentwicklung für NIRS-Geräte. Eine Einführung. Göttingen: Cuvillier.

TILLMANN, P., 1997. Qualitätsuntersuchung von Raps mit der vernetzten Nahinfrarotspektroskopie. (NIRS). Göttingen: Cuvillier.

TILlmann, P. Und PAUL, C., 1998. The repeatability file - a tool for reducing the sensitivity of near infrared spectroscopy calibrations to moisture variation In: J. Near Infrared Spectrosc., 6, S. 61-68. 
TILLMANN, P. UND REINHARDT, T.-C., 1998. Qualitätsbestimmung von Körnerraps mit der vernetzten Nahinfrarotspektroskopie. In: UFOP-Schriften 1998, S. 135-162.

TILLMANN, P., 2000. Kalibrationsentwicklung für NIRS-Geräte. Eine Einführung. Göttingen: Cuvillier.

TillmanN, P.; ReInhardt, T.-C. UND PAUL, C., 2000. Networking of near infrared spectroscopy instruments for rapeseed analysis: a comparison of different procedures In: J. Near Infrared Spectrosc., 8, S. 103-107.

Velasco, L.; Fernández-Martínez, J. M. Und HARO, A. DE, 1997. Determination of fatty acid composition of the oil in intact-seed mustard by near-infrared reflectance spectroscopy In: J. Am. Oil Chem. Soc., 74 (12), S. 1595-1602.

VELAsco, L. UND BECKER, H. C., 1998. Estimating the fatty acid composition of the oil in intact-seed rapeseed (Brassica napus L.) by near-infrared reflectance spectroscopy In: Euphytica, 101, S. 221-230.

Velasco, L.; Schierholt, A. Und BeCKer, H. C., 1998a. Performance of near-infrared reflectance spectroscopy (NIRS) in routine analysis of C18 unsaturated fatty acids in intact rapeseed In: Fett/Lipid, 2, S. 44-48.

Velasco, L.; Goffman, F. UND BeCKer, H. C., 1998b. Variability for the fatty acid composition of the seed oil in a germplasm collection of the genus Brassica In: Genetic Resources and Crop Evolution, 45, S. 371-382.

Velasco, L.; PéRez-Vich, B. und Fernández-Martínez, J. M., 1999a. Nondestructive screening for oleic and linoleic acid in single sunflower achenes by near-infrared reflectance spectroscopy In: Crop Sci., 39, S. 219-222.

Velasco, L.; Möllers, C. UND BeCKer, H. C., 1999b. Estimation of seed weight, oil content and fatty acid composition in intact single seeds of rapeseed (Brassica napus L.) by near- infrared reflectance spectroscopy In: Euphytica, 106, S. 79-85.

Velasco, L.; Pérez-Vich, B. und Fernández-Martínez, J. M., 2004. Use of Nearinfrared Reflectance Spectroscopy for Selecting for High Stearic Acid Concentration in Single Husked Achenes of Sunflower In: Crop Sci., 44, S. 93-97.

WANG, Y.; LYSAGHT, M. UND KOWALSKI, B.R., 1992. Improvement of Multivariate Calibration through Instrument Standardization In: Anal. Chem., 64, S. 562-564.

WestfeCHTEL, A., 2001. Hochölsäurehaltiges Sonnenblumenöl als Rohstoff für die Oleochemie. In: Nachwachsende Rohstoffe für die Chemie - 7. Symposium 2001: Landwirtschaftsverlag $\mathrm{GmbH}$, S. 297-306. 
WILCOXON, F. UND WILCOX, R. A., 1964. Some rapid approximate statistical procedures. Pearl River, New York.: Lederle Laboratories.

WILLIAMS, P. C., 2001. Implementation of Near-Infrared Technology. In: WILLIAMS, P. und NoRRIS, K. H. (Hrsg.) Near-Infrared Technology in the Agricultural and Food Industries. St. Paul Minn.: American Association of Cereal Chemists, S. 145 - 170.

WILliamS, P. C. UND NORRIS, K., 2001. Variables Affecting Near-Infrared Spectroscopic Analysis. In: WILLIAMS, P. und NoRRIS, K. H. (Hrsg.) Near-Infrared Technology in the Agricultural and Food Industries. St. Paul Minn.: American Association of Cereal Chemists, S. 171 - 198.

Wüst, E.; Fehrmann, A.; Hoffmann, A.; Neemann, H. und Rudzik, L., 1997. Chemometrische Methoden zwischen Aberglauben und Wissenschaft In: Deutsche Milchwirtschaft, 48 (3) S. 66-70.

WüST, E. UND RUDZIK, L., 1994. NIR-Spektroskopische Analytik. In: AnalytikerTaschenbuch. (12), S. 241-256. 
$9 \quad$ Anhang
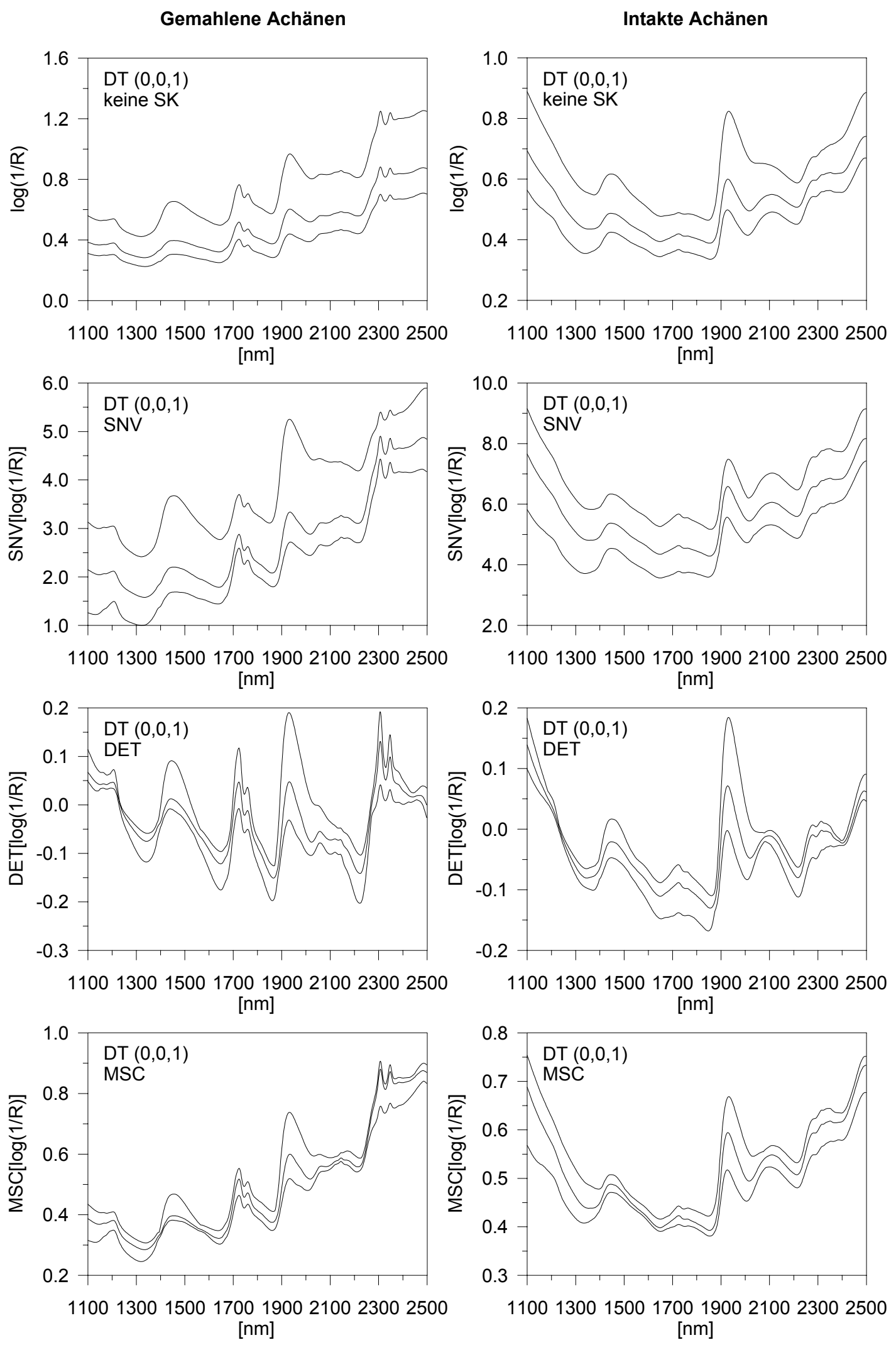

Abb. 10: Mittelwertsspektren sowie obere und untere Ausbreitung aller Spektren gemahlener bzw. intakter HO-Achänen bei Verwendung der Ableitung DT(0,0,1) sowie verschiedener Streulichtkorrekturen (keine SK, SNV, DET, MSC) 
Gemahlene Achänen
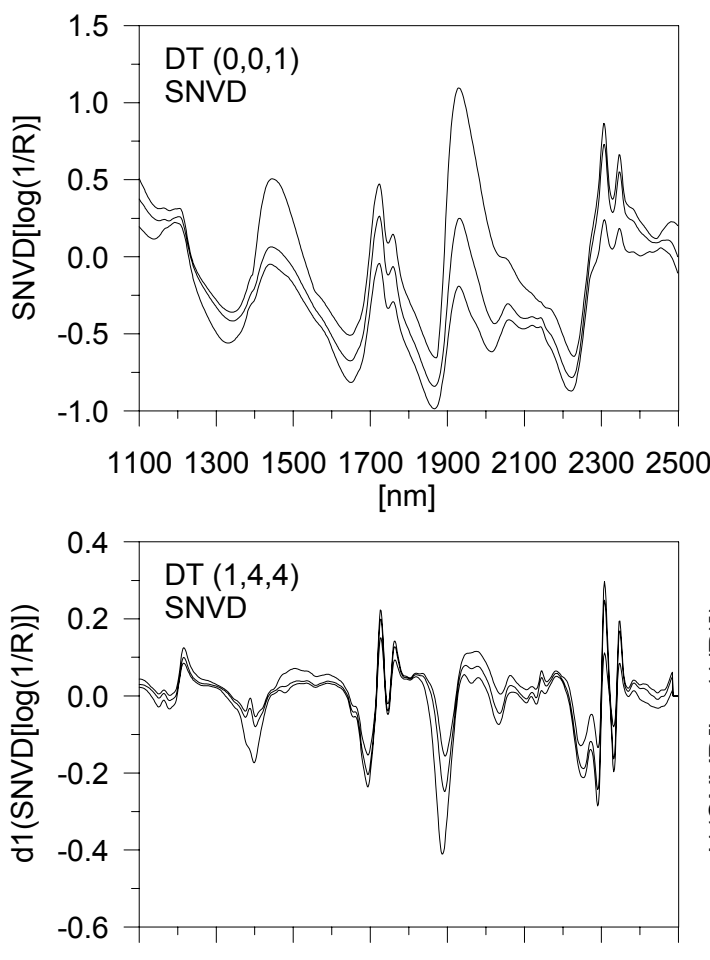

11001300150017001900210023002500 [nm]

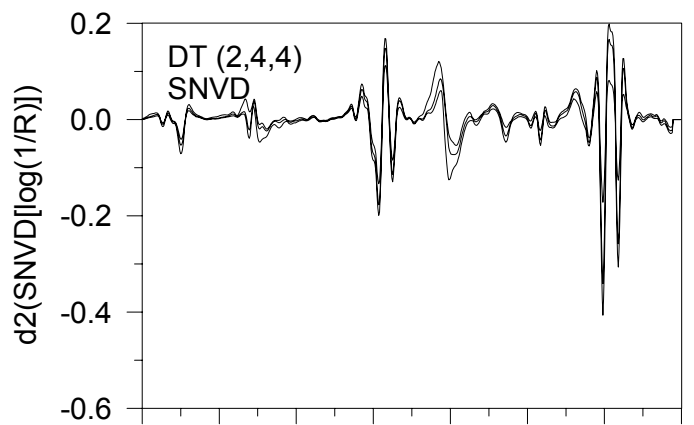

11001300150017001900210023002500 $[\mathrm{nm}]$

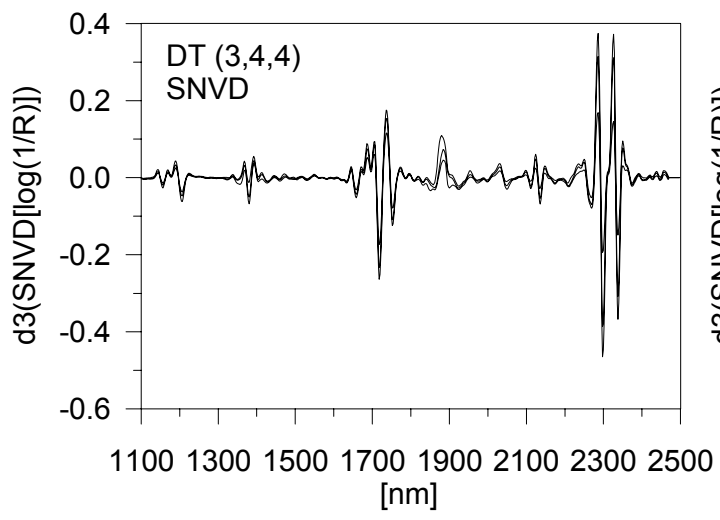

Intakte Achänen
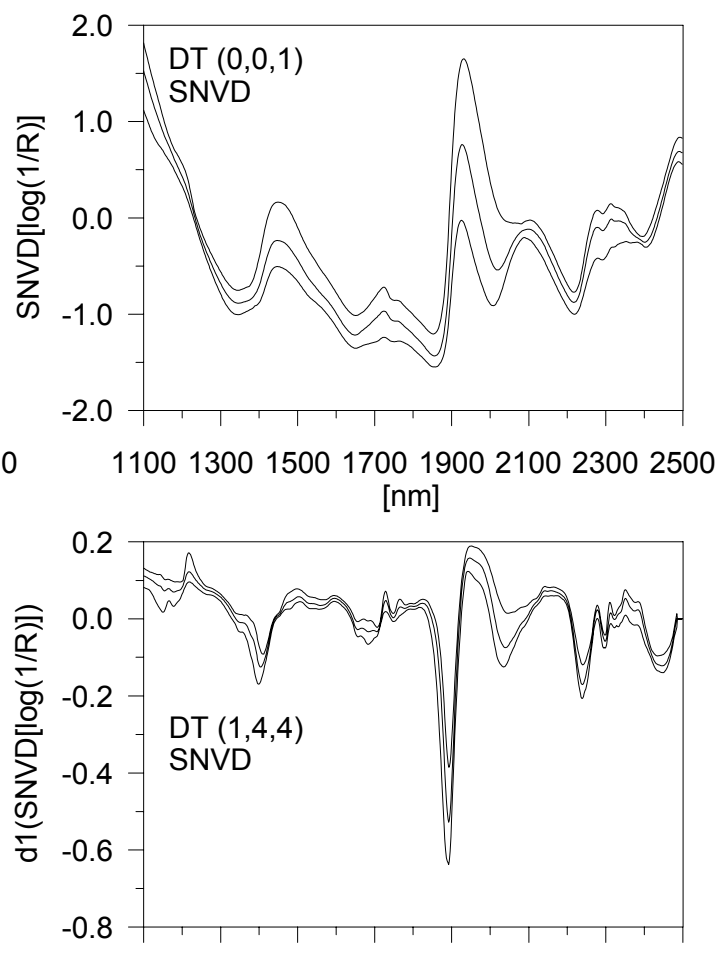

11001300150017001900210023002500 [nm]
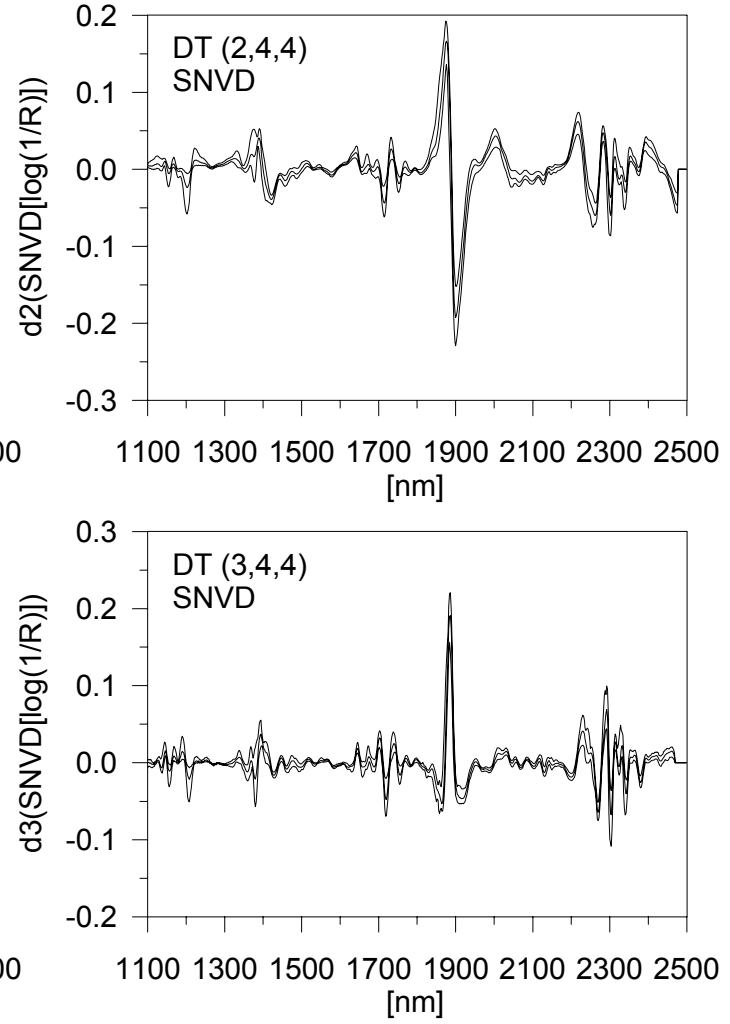

Abb. 11: Mittelwertsspektren sowie obere und untere Ausbreitung aller Spektren gemahlener bzw. intakter HO-Achänen bei Verwendung verschiedener Ableitungen (DT(0,0,1), DT(1,4,4), DT(2,4,4), DT(3,4,4)) sowie der Streulichtkorrektur SNVD 

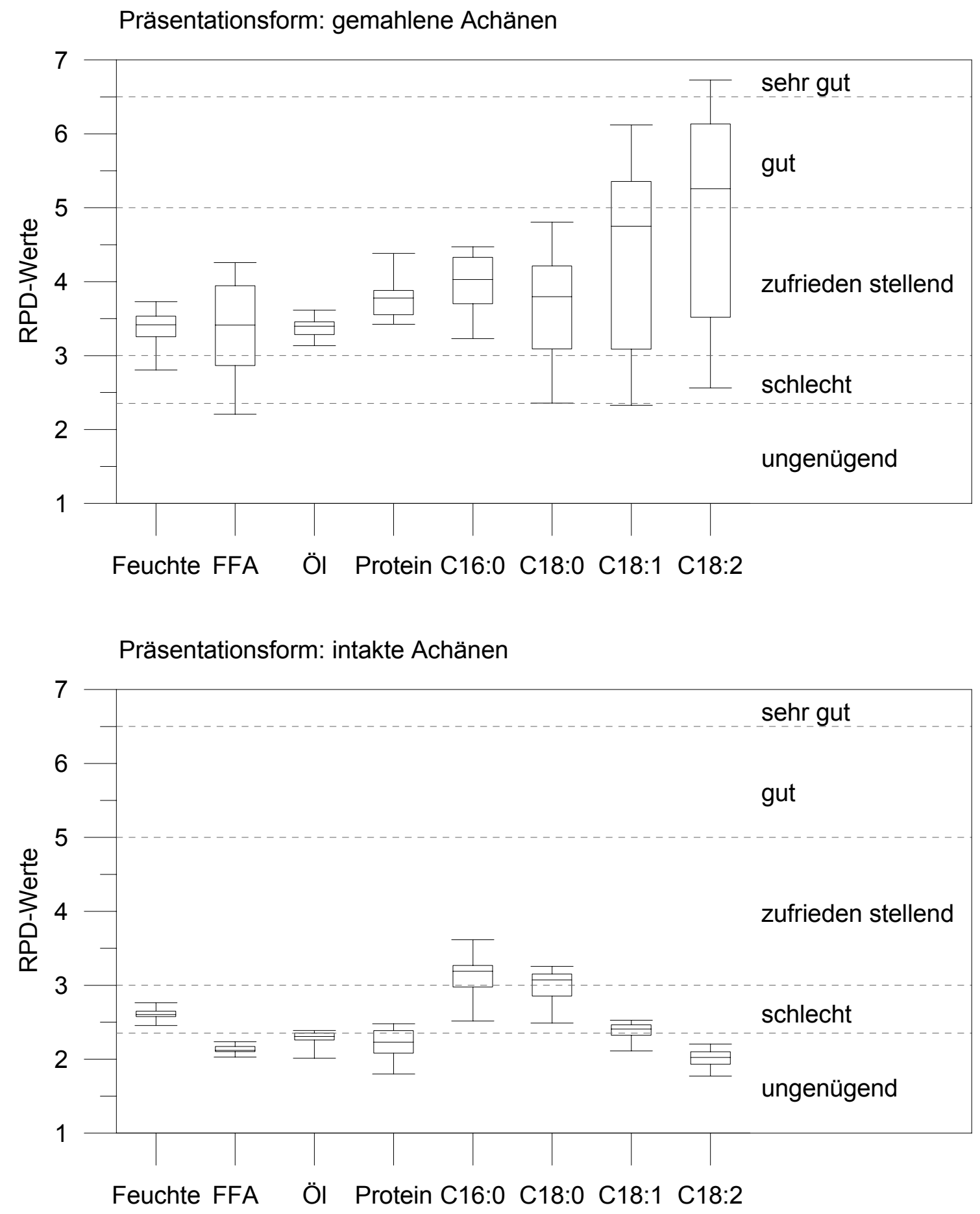

Abb. 12: Box-Whisker-Diagramm der aus der Nutzung verschiedener Datenvorbehandlungen (8 Ableitungen; 5 Streulichtkorrekturen) erreichten RPD-Werte für gemahlene sowie intakte Achänen mit Kennzeichnung der Leistungscharakterisierung nach WILLIAMS (2001) 
Tab. 20: Ergebnisse der Kalibration, Kreuzvalidation und Validation bei

Verwendung verschiedener Ableitungen (DT) und Streulicht-

korrekturen (SK) für die Parameter Feuchte, FFA, Öl, Protein, C16:0,

C18:0, C18:1 sowie C18:2 in gemahlenen bzw. intakten HO-Achänen

Feuchte, gemahlene Achänen

Abl.

SK

SEC $R^{2}$ SECV 1-VR

$(0,0,1)$

$0,51 \quad 0,89 \quad 0,51$

0,89

SEP

$(0,0,1)$

keine

$\begin{array}{lll}0,47 & 0,91\end{array}$

$0,49 \quad 0,90$

0,57

SEPC

RSQ

RPD Terme

$(0,0,1)$

SNV

$\begin{array}{lll}0,48 & 0,91 & 0,50\end{array}$

0,52

0,52

0,87

$2,8 \quad 15$

$(0,0,1)$

SNVD

$\begin{array}{lll}0,48 & 0,91 & 0,49\end{array}$

0,90

0,52

0,52

0,89

$3,1 \quad 16$

$(0,0,1)$

MSC

$\begin{array}{llll}0,48 & 0,91 & 0,50\end{array}$

0,91

0,52

0,52

0,90

$3,1 \quad 15$

$(1,2,2)$

keine

$\begin{array}{lll}0,42 & 0,93 & 0,46\end{array}$

0,90

0,53

0,53

0,89

$3,1 \quad 15$

$(1,2,2)$

Detrend

$\begin{array}{lll}0,42 & 0,93 & 0,46\end{array}$

0,92

0,49

0,49

0,91

$3,1 \quad 15$

$(1,2,2)$

SNV

$\begin{array}{lll}0,41 & 0,93 & 0,44\end{array}$

0,92

0,49

0,49

0,91

$3,3 \quad 15$

$(1,2,2)$

SNVD

$\begin{array}{lll}0,42 & 0,93 & 0,45\end{array}$

0,92

0,47

0,47

0,92

$3,3 \quad 15$

$(1,2,2)$

MSC

$\begin{array}{lll}0,41 & 0,93 & 0,45\end{array}$

0,92

0,47

0,47

0,92

$3,4 \quad 15$

$(1,4,4)$

keine

$\begin{array}{lll}0,42 & 0,93 & 0,45\end{array}$

0,92

0,47

0,47

0,92

$3,4 \quad 15$

$(1,4,4)$

Detrend

$\begin{array}{lll}0,42 & 0,93 & 0,45\end{array}$

0,92

0,46

0,46

0,92

$3,4 \quad 15$

$(1,4,4)$

SNV

$\begin{array}{lll}0,41 & 0,93 & 0,43\end{array}$

0,93

0,47

0,47

0,92

$3,5 \quad 15$

$(1,4,4)$

SNVD

$\begin{array}{lll}0,40 & 0,94 & 0,43\end{array}$

0,93

0,44

0,45

0,92

$3,4 \quad 15$

$(1,4,4)$

MSC

$\begin{array}{llll}0,41 & 0,93 & 0,43\end{array}$

0,93

0,43

0,43

0,93

$3,6 \quad 15$

$(1,10,5)$

keine

$0,45 \quad 0,92$

0,45

0,45

0,92

$3,7 \quad 16$

$(1,10,5)$

Detrend

$0,44 \quad 0,92 \quad 0,46$

0,91

0,49

0,49

0,91

$3,6 \quad 15$

$(1,10,5)$

SNV

$\begin{array}{lll}0,43 & 0,93 & 0,45\end{array}$

0,92

0,47

0,47

0,91

$3,3 \quad 15$

$(1,10,5)$

SNVD

$\begin{array}{lll}0,42 & 0,93 & 0,44\end{array}$

0,92

0,47

0,47

0,92

$3,4 \quad 16$

$(1,10,5)$

MSC

$\begin{array}{lll}0,43 & 0,93 & 0,45\end{array}$

0,92

0,46

0,46

0,92

$3,4 \quad 15$

$(2,4,4)$

keine

$\begin{array}{lll}0,42 & 0,93 & 0,45\end{array}$

0,92

0,47

0,47

0,92

$3,5 \quad 16$

$(2,4,4)$

Detrend

$0,41 \quad 0,93 \quad 0,45$

0,92

0,44

0,45

0,92

$3,4 \quad 15$

$(2,4,4)$

SNV

$\begin{array}{lll}0,41 & 0,93 & 0,44\end{array}$

0,92

0,44

0,44

0,92

$3,6 \quad 12$

$(2,4,4)$

SNVD

$\begin{array}{lll}0,41 & 0,93 & 0,44\end{array}$

0,92

0,45

0,45

0,92

$3,6 \quad 13$

$(2,4,4)$

MSC

$\begin{array}{lll}0,41 & 0,93 & 0,44\end{array}$

0,92

0,45

0,45

0,92

$3,6 \quad 13$

$(2,10,5)$

keine

$\begin{array}{llll}0,42 & 0,93 & 0,45\end{array}$

0,92

0,45

0,45

0,92

$3,6 \quad 13$

$(2,10,5)$

Detrend

$\begin{array}{lll}0,42 & 0,93 & 0,45\end{array}$

0,92

0,46

0,46

0,92

$3,6 \quad 13$

$(2,10,5)$

SNV

$\begin{array}{lll}0,41 & 0,93 & 0,44\end{array}$

0,92

0,46

0,46

0,92

$3,5 \quad 15$

$(2,10,5)$

SNVD

$\begin{array}{llll}0,41 & 0,93 & 0,44\end{array}$

0,92

0,46

0,46

0,92

$3,5 \quad 15$

$(2,10,5)$

MSC

$0,42 \quad 0,93$

0,92

0,45

0,45

0,92

$3,5 \quad 15$

$(2,20,10) \quad$ keine

$\begin{array}{lll}0,45 & 0,92 & 0,48\end{array}$

0,92

0,46

0,46

0,92

$3,6 \quad 15$

$(2,20,10)$

Detrend

$\begin{array}{lll}0,45 & 0,92 & 0,47\end{array}$

0,91

0,48

0,48

0,91

$3,5 \quad 14$

$(2,20,10)$

SNV

$0,44 \quad 0,92$

0,91

0,47

0,47

0,91

$3,4 \quad 15$

$(2,20,10) \quad$ SNVD

$\begin{array}{lll}0,45 & 0,92 & 0,46\end{array}$

0,92

0,47

0,47

0,9

$3,4 \quad 15$

$(2,20,10) \quad$ MSC

$\begin{array}{lll}0,45 & 0,92 \quad 0,46\end{array}$

0,91

0,48

0,48

0,91

$3,4 \quad 15$

$3,4 \quad 14$

$(3,4,4)$

keine

$\begin{array}{lll}0,45 & 0,92 & 0,49\end{array}$

0,47

0,48

0,91

$3,4 \quad 14$

0,91

0,50

0,50

0,91

$3,2 \quad 10$

$(3,4,4)$

Detrend

$\begin{array}{lll}0,45 & 0,92 & 0,49\end{array}$

0,91

0,50 
Fortsetzung Tab. 20

Feuchte, intakte Achänen

\begin{tabular}{|c|c|c|c|c|c|c|c|c|c|c|}
\hline Abl. & SK & SEC & $\mathrm{R}^{2}$ & SECV & 1-VR & SEP & SEPC & $\mathrm{RSQ}$ & RPD & Terme \\
\hline$(0,0,1)$ & keine & 0,65 & 0,82 & 0,66 & 0,81 & 0,59 & 0,59 & 0,85 & 2,6 & 15 \\
\hline$(0,0,1)$ & Detrend & 0,63 & 0,83 & 0,65 & 0,82 & 0,58 & 0,58 & 0,85 & 2,6 & 14 \\
\hline$(0,0,1)$ & SNV & 0,67 & 0,81 & 0,69 & 0,80 & 0,59 & 0,59 & 0,85 & 2,5 & 15 \\
\hline$(0,0,1)$ & SNVD & 0,65 & 0,82 & 0,68 & 0,80 & 0,59 & 0,59 & 0,85 & 2,6 & 15 \\
\hline$(0,0,1)$ & MSC & 0,66 & 0,81 & 0,68 & 0,80 & 0,61 & 0,61 & 0,83 & 2,5 & 15 \\
\hline$(1,2,2)$ & keine & 0,58 & 0,86 & 0,60 & 0,84 & 0,55 & 0,55 & 0,87 & 2,8 & 13 \\
\hline$(1,2,2)$ & Detrend & 0,57 & 0,86 & 0,60 & 0,84 & 0,55 & 0,56 & 0,86 & 2,7 & 13 \\
\hline$(1,2,2)$ & SNV & 0,56 & 0,86 & 0,60 & 0,84 & 0,57 & 0,58 & 0,85 & 2,6 & 13 \\
\hline$(1,2,2)$ & SNVD & 0,57 & 0,86 & 0,60 & 0,84 & 0,55 & 0,55 & 0,87 & 2,7 & 13 \\
\hline$(1,2,2)$ & MSC & 0,56 & 0,86 & 0,61 & 0,84 & 0,57 & 0,57 & 0,86 & 2,6 & 14 \\
\hline$(1,4,4)$ & keine & 0,59 & 0,85 & 0,61 & 0,84 & 0,55 & 0,55 & 0,87 & 2,7 & 13 \\
\hline$(1,4,4)$ & Detrend & 0,57 & 0,86 & 0,60 & 0,84 & 0,55 & 0,55 & 0,87 & 2,7 & 14 \\
\hline$(1,4,4)$ & SNV & 0,56 & 0,86 & 0,61 & 0,84 & 0,58 & 0,58 & 0,85 & 2,6 & 14 \\
\hline$(1,4,4)$ & SNVD & 0,57 & 0,86 & 0,61 & 0,84 & 0,57 & 0,57 & 0,86 & 2,7 & 14 \\
\hline$(1,4,4)$ & MSC & 0,58 & 0,86 & 0,62 & 0,83 & 0,58 & 0,58 & 0,85 & 2,6 & 14 \\
\hline$(1,10,5)$ & keine & 0,58 & 0,85 & 0,61 & 0,84 & 0,56 & 0,56 & 0,86 & 2,7 & 14 \\
\hline$(1,10,5)$ & Detrend & 0,59 & 0,85 & 0,61 & 0,84 & 0,55 & 0,55 & 0,87 & 2,7 & 14 \\
\hline$(1,10,5)$ & SNV & 0,58 & 0,85 & 0,62 & 0,83 & 0,59 & 0,59 & 0,85 & 2,6 & 14 \\
\hline$(1,10,5)$ & SNVD & 0,59 & 0,85 & 0,62 & 0,83 & 0,58 & 0,58 & 0,85 & 2,6 & 14 \\
\hline$(1,10,5)$ & MSC & 0,59 & 0,85 & 0,63 & 0,83 & 0,58 & 0,58 & 0,85 & 2,6 & 14 \\
\hline$(2,4,4)$ & keine & 0,54 & 0,87 & 0,58 & 0,85 & 0,58 & 0,58 & 0,85 & 2,6 & 11 \\
\hline$(2,4,4)$ & Detrend & 0,54 & 0,87 & 0,58 & 0,85 & 0,58 & 0,58 & 0,85 & 2,6 & 11 \\
\hline$(2,4,4)$ & SNV & 0,56 & 0,86 & 0,60 & 0,85 & 0,58 & 0,58 & 0,85 & 2,6 & 10 \\
\hline$(2,4,4)$ & SNVD & 0,56 & 0,86 & 0,60 & 0,85 & 0,58 & 0,58 & 0,85 & 2,6 & 10 \\
\hline$(2,4,4)$ & MSC & 0,55 & 0,87 & 0,60 & 0,84 & 0,58 & 0,58 & 0,85 & 2,6 & 11 \\
\hline$(2,10,5)$ & keine & 0,57 & 0,86 & 0,60 & 0,84 & 0,58 & 0,58 & 0,85 & 2,6 & 11 \\
\hline$(2,10,5)$ & Detrend & 0,57 & 0,86 & 0,60 & 0,84 & 0,58 & 0,57 & 0,85 & 2,6 & 12 \\
\hline$(2,10,5)$ & SNV & 0,58 & 0,85 & 0,61 & 0,84 & 0,58 & 0,58 & 0,85 & 2,6 & 11 \\
\hline$(2,10,5)$ & SNVD & 0,58 & 0,85 & 0,61 & 0,84 & 0,58 & 0,58 & 0,85 & 2,6 & 11 \\
\hline$(2,10,5)$ & MSC & 0,59 & 0,85 & 0,62 & 0,83 & 0,59 & 0,59 & 0,85 & 2,6 & 11 \\
\hline$(2,20,10)$ & keine & 0,60 & 0,84 & 0,63 & 0,83 & 0,58 & 0,59 & 0,85 & 2,6 & 13 \\
\hline$(2,20,10)$ & Detrend & 0,60 & 0,84 & 0,63 & 0,83 & 0,58 & 0,58 & 0,85 & 2,6 & 13 \\
\hline$(2,20,10)$ & SNV & 0,62 & 0,83 & 0,65 & 0,82 & 0,59 & 0,59 & 0,85 & 2,6 & 12 \\
\hline$(2,20,10)$ & SNVD & 0,62 & 0,84 & 0,65 & 0,82 & 0,59 & 0,59 & 0,85 & 2,5 & 12 \\
\hline$(2,20,10)$ & MSC & 0,62 & 0,83 & 0,65 & 0,82 & 0,59 & 0,59 & 0,85 & 2,5 & 13 \\
\hline$(3,4,4)$ & keine & 0,59 & 0,85 & 0,62 & 0,83 & 0,57 & 0,57 & 0,86 & 2,6 & 7 \\
\hline$(3,4,4)$ & Detrend & 0,59 & 0,85 & 0,62 & 0,83 & 0,57 & 0,57 & 0,86 & 2,6 & 7 \\
\hline$(3,4,4)$ & SNV & 0,59 & 0,85 & 0,62 & 0,83 & 0,58 & 0,58 & 0,85 & 2,6 & 7 \\
\hline$(3,4,4)$ & SNVD & 0,59 & 0,85 & 0,62 & 0,83 & 0,58 & 0,58 & 0,85 & 2,6 & 7 \\
\hline$(3,4,4)$ & MSC & 0,58 & 0,86 & 0,62 & 0,83 & 0,58 & 0,57 & 0,86 & 2,6 & 8 \\
\hline
\end{tabular}


Fortsetzung Tab. 20

FFA, gemahlene Achänen

\begin{tabular}{|c|c|c|c|c|c|c|c|c|c|c|}
\hline Abl. & SK & SEC & $\mathrm{R}^{2}$ & SECV & $1-V R$ & SEP & SEPC & $\mathrm{RSQ}$ & RPD & Terme \\
\hline$(0,0,1)$ & keine & 0,38 & 0,83 & 0,41 & 0,80 & 0,40 & 0,41 & 0,81 & 2,3 & 16 \\
\hline$(0,0,1)$ & Detrend & 0,38 & 0,83 & 0,41 & 0,80 & 0,41 & 0,42 & 0,80 & 2,2 & 15 \\
\hline$(0,0,1)$ & SNV & 0,41 & 0,81 & 0,43 & 0,79 & 0,41 & 0,41 & 0,81 & 2,2 & 15 \\
\hline$(0,0,1)$ & SNVD & 0,37 & 0,84 & 0,41 & 0,81 & 0,39 & 0,39 & 0,83 & 2,3 & 16 \\
\hline$(0,0,1)$ & MSC & 0,38 & 0,84 & 0,41 & 0,80 & 0,38 & 0,38 & 0,84 & 2,4 & 16 \\
\hline$(1,2,2)$ & keine & 0,26 & 0,92 & 0,31 & 0,89 & 0,27 & 0,27 & 0,92 & 3,4 & 16 \\
\hline$(1,2,2)$ & Detrend & 0,27 & 0,91 & 0,34 & 0,87 & 0,29 & 0,29 & 0,91 & 3,2 & 15 \\
\hline$(1,2,2)$ & SNV & 0,26 & 0,92 & 0,31 & 0,89 & 0,27 & 0,27 & 0,92 & 3,3 & 16 \\
\hline$(1,2,2)$ & SNVD & 0,26 & 0,92 & 0,31 & 0,89 & 0,28 & 0,27 & 0,92 & 3,3 & 16 \\
\hline$(1,2,2)$ & MSC & 0,26 & 0,92 & 0,31 & 0,89 & 0,27 & 0,27 & 0,92 & 3,4 & 16 \\
\hline$(1,4,4)$ & keine & 0,26 & 0,92 & 0,29 & 0,90 & 0,25 & 0,25 & 0,93 & 3,6 & 16 \\
\hline$(1,4,4)$ & Detrend & 0,27 & 0,92 & 0,31 & 0,89 & 0,26 & 0,26 & 0,92 & 3,5 & 15 \\
\hline$(1,4,4)$ & SNV & 0,26 & 0,92 & 0,29 & 0,90 & 0,26 & 0,26 & 0,93 & 3,5 & 16 \\
\hline$(1,4,4)$ & SNVD & 0,25 & 0,93 & 0,29 & 0,91 & 0,26 & 0,26 & 0,93 & 3,5 & 16 \\
\hline$(1,4,4)$ & MSC & 0,26 & 0,92 & 0,29 & 0,90 & 0,26 & 0,26 & 0,93 & 3,5 & 16 \\
\hline$(1,10,5)$ & keine & 0,30 & 0,90 & 0,32 & 0,89 & 0,29 & 0,29 & 0,90 & 3,1 & 15 \\
\hline$(1,10,5)$ & Detrend & 0,28 & 0,91 & 0,32 & 0,88 & 0,28 & 0,28 & 0,91 & 3,3 & 16 \\
\hline$(1,10,5)$ & SNV & 0,29 & 0,91 & 0,31 & 0,89 & 0,28 & 0,28 & 0,91 & 3,3 & 16 \\
\hline$(1,10,5)$ & SNVD & 0,28 & 0,91 & 0,31 & 0,89 & 0,27 & 0,27 & 0,92 & 3,3 & 16 \\
\hline$(1,10,5)$ & MSC & 0,29 & 0,90 & 0,31 & 0,89 & 0,28 & 0,28 & 0,91 & 3,2 & 16 \\
\hline$(2,4,4)$ & keine & 0,23 & 0,94 & 0,29 & 0,90 & 0,21 & 0 , & 5 & 4,3 & 14 \\
\hline$(2,4,4)$ & Detrend & 0,23 & 0,94 & 0,29 & 0,90 & 0,21 & 0,21 & 0,95 & 4,3 & 14 \\
\hline$(2,4,4)$ & SNV & 0,23 & 0,94 & 0,28 & 0,91 & 0,23 & 0,22 & 0,94 & 4,0 & 14 \\
\hline$(2,4,4)$ & SNVD & 0,23 & 0,94 & 0,28 & 0,91 & 0,23 & 0,22 & 0,94 & 4,0 & 14 \\
\hline$(2,4,4)$ & MSC & 0,23 & 0,94 & 0,28 & 0,91 & 0,23 & 0,22 & 0,94 & 3,9 & 14 \\
\hline$(2,10,5)$ & keine & 0,25 & 0,93 & 0,29 & 0,91 & 0,23 & 0,22 & 0,94 & 4,0 & 14 \\
\hline$(2,10,5)$ & Detren & 0,25 & 0,93 & 0,29 & 0,91 & 0,23 & 0,22 & 0,94 & 4,0 & 14 \\
\hline$(2,10,5)$ & SNV & 0,25 & 0,93 & 0,27 & 0,91 & 0,22 & 0,22 & 0,95 & 4,2 & 14 \\
\hline$(2,10,5)$ & SNVD & 0,24 & 0,93 & 0,27 & 0,91 & 0,23 & 0,22 & 0,95 & 4,0 & 15 \\
\hline$(2,10,5)$ & MSC & 0,24 & 0,93 & 0,27 & 0,91 & 0,23 & 0,22 & 0,94 & 4,0 & 15 \\
\hline$(2,20,10)$ & keine & 0,34 & 0,87 & 0,38 & 0,83 & 0,33 & 0,34 & 0,87 & 2,7 & 14 \\
\hline$(2,20,10)$ & Detrend & 0,34 & 0,87 & 0,38 & 0,83 & 0,35 & 0,35 & 0,86 & 2,6 & 14 \\
\hline$(2,20,10)$ & SNV & 0,32 & 0,88 & 0,36 & 0,85 & 0,32 & 0,32 & 0,88 & 2,9 & 16 \\
\hline$(2,20,10)$ & SNVD & 0,32 & 0,88 & 0,36 & 0,85 & 0,32 & 0,32 & 0,88 & 2,8 & 16 \\
\hline$(2,20,10)$ & MSC & 0,32 & 0,89 & 0,36 & 0,85 & 0,32 & 0,32 & 0,89 & 2,9 & 16 \\
\hline$(3,4,4)$ & keine & 0,23 & 0,94 & 0,30 & 0,90 & 0,26 & 0,25 & 0,92 & 3,6 & 15 \\
\hline$(3,4,4)$ & Detrend & 0,23 & 0,94 & 0,30 & 0,90 & 0,26 & 0,25 & 0,92 & 3,6 & 15 \\
\hline$(3,4,4)$ & SNV & 0,22 & 0,94 & 0,29 & 0,91 & 0,25 & 0,25 & 0,93 & 3,6 & 16 \\
\hline$(3,4,4)$ & SNVD & 0,22 & 0,94 & 0,29 & 0,91 & 0,25 & 0,25 & 0,93 & 3,6 & 16 \\
\hline$(3,4,4)$ & MSC & 0,23 & 0,94 & 0,29 & 0,90 & 0,27 & 0,26 & 0,92 & 3,4 & 14 \\
\hline
\end{tabular}


Fortsetzung Tab. 20

FFA, intakte Achänen

\begin{tabular}{|c|c|c|c|c|c|c|c|c|c|c|}
\hline Abl. & SK & SEC & $\mathrm{R}^{2}$ & SECV & $1-V R$ & SEP & SEPC & $\mathrm{RSQ}$ & RPD & Terme \\
\hline$(0,0,1)$ & keine & 0,36 & 0,79 & 0,39 & 0,76 & 0,38 & 0,38 & 0,76 & 2,0 & 15 \\
\hline$(0,0,1)$ & Detrend & 0,36 & 0,79 & 0,38 & 0,76 & 0,38 & 0,38 & 0,76 & 2,0 & 14 \\
\hline$(0,0,1)$ & SNV & 0,34 & 0,81 & 0,36 & 0,79 & 0,36 & 0,36 & 0,78 & 2,2 & 16 \\
\hline$(0,0,1)$ & SNVD & 0,35 & 0,81 & 0,36 & 0,79 & 0,37 & 0,37 & 0,77 & 2,1 & 14 \\
\hline$(0,0,1)$ & MSC & 0,34 & 0,81 & 0,37 & 0,78 & 0,37 & 0,37 & 0,77 & 2,1 & 15 \\
\hline$(1,2,2)$ & keine & 0,36 & 0,80 & 0,38 & 0,77 & 0,36 & 0,35 & 0,79 & 2,2 & 9 \\
\hline$(1,2,2)$ & Detrend & 0,35 & 0,81 & 0,38 & 0,77 & 0,36 & 0,36 & 0,78 & 2,1 & 10 \\
\hline$(1,2,2)$ & SNV & 0,34 & 0,81 & 0,37 & 0,78 & 0,35 & 0,35 & 0,79 & 2,2 & 9 \\
\hline$(1,2,2)$ & SNVD & 0,35 & 0,80 & 0,37 & 0,78 & 0,36 & 0,36 & 0,78 & 2,1 & 7 \\
\hline$(1,2,2)$ & MSC & 0,35 & 0,80 & 0,37 & 0,78 & 0,36 & 0,36 & 0,79 & 2,2 & 8 \\
\hline$(1,4,4)$ & keine & 0,36 & 0,79 & 0,38 & 0,77 & 0,35 & 0,35 & 0,80 & 2,2 & 9 \\
\hline$(1,4,4)$ & Detrend & 0,33 & 0,82 & 0,37 & 0,78 & 0,37 & 0,37 & 0,77 & 2,1 & 12 \\
\hline$(1,4,4)$ & SNV & 0,33 & 0,83 & 0,36 & 0,79 & 0,35 & 0,35 & 0,79 & 2,2 & 11 \\
\hline$(1,4,4)$ & SNVD & 0,33 & 0,82 & 0,36 & 0,79 & 0,34 & 0,34 & 0,80 & 2,2 & 10 \\
\hline$(1,4,4)$ & MSC & 0,33 & 0,82 & 0,37 & 0,78 & 0,35 & 0,35 & 0,79 & 2,2 & 11 \\
\hline$(1,10,5)$ & keine & 0,34 & 0,81 & 0,37 & 0,78 & 0,36 & 0,36 & 0,79 & 2,2 & 12 \\
\hline$(1,10,5)$ & Detrend & 0,36 & 0,79 & 0,37 & 0,78 & 0,36 & 0,36 & 0,79 & 2,1 & 9 \\
\hline$(1,10,5)$ & SNV & 0,33 & 0,83 & 0,35 & 0,80 & 0,35 & 0,35 & 0,79 & 2,2 & 12 \\
\hline$(1,10,5)$ & SNVD & 0,32 & 0,83 & 0,36 & 0,80 & 0,35 & 0,35 & 0,79 & 2,2 & 13 \\
\hline$(1,10,5)$ & MSC & 0,32 & 0,83 & 0,36 & 0,79 & 0,35 & 0,35 & 0,79 & 2,2 & 13 \\
\hline$(2,4,4)$ & keine & 0,37 & 0,78 & 0,39 & 0,76 & 0,37 & 0,37 & 0,77 & 2,1 & 5 \\
\hline$(2,4,4)$ & Detrend & 0,37 & 0,78 & 0,39 & 0,76 & 0,37 & 0,37 & 0,77 & 2,1 & 5 \\
\hline$(2,4,4)$ & SNV & 0,34 & 0,81 & 0,37 & 0,78 & 0,36 & 0,37 & 0,77 & 2,1 & 5 \\
\hline$(2,4,4)$ & SNVD & 0,35 & 0,81 & 0,37 & 0,78 & 0,37 & 0,37 & 0,77 & 2,1 & 5 \\
\hline$(2,4,4)$ & MSC & 0,35 & 0,81 & 0,37 & 0,78 & 0,36 & 0,37 & 0,77 & 2,1 & 5 \\
\hline$(2,10,5)$ & keine & 0,37 & 0,78 & 0,38 & 0,77 & 0,37 & 0,37 & 0,77 & 2,1 & 6 \\
\hline$(2,10,5)$ & Detren & 0,37 & 0,78 & 0,38 & 0,77 & 0,37 & 0,37 & 0,77 & 2,1 & 6 \\
\hline$(2,10,5)$ & SNV & 0,35 & 0,80 & 0,36 & 0,79 & 0,37 & 0,37 & 0,77 & 2,1 & 5 \\
\hline$(2,10,5)$ & SNVD & 0,35 & 0,80 & 0,36 & 0,79 & 0,37 & 0,37 & 0,77 & 2,1 & 5 \\
\hline$(2,10,5)$ & MSC & 0,35 & 0,81 & 0,36 & 0,79 & 0,36 & 0,36 & 0,78 & 2,1 & 6 \\
\hline$(2,20,10)$ & keine & 0,36 & 0,80 & 0,38 & 0,77 & 0,37 & 0,36 & 0,78 & 2,1 & 10 \\
\hline$(2,20,10)$ & Detrend & 0,35 & 0,80 & 0,37 & 0,77 & 0,36 & 0,36 & 0,78 & 2,1 & 10 \\
\hline$(2,20,10)$ & SNV & 0,33 & 0,82 & 0,35 & 0,80 & 0,34 & 0,35 & 0,80 & 2,2 & 11 \\
\hline$(2,20,10)$ & SNVD & 0,33 & 0,82 & 0,35 & 0,80 & 0,35 & 0,35 & 0,80 & 2,2 & 11 \\
\hline$(2,20,10)$ & MSC & 0,33 & 0,82 & 0,35 & 0,80 & 0,34 & 0,34 & 0,80 & 2,2 & 11 \\
\hline$(3,4,4)$ & keine & 0,38 & 0,76 & 0,41 & 0,73 & 0,38 & 0,38 & 0,76 & 2,1 & 4 \\
\hline$(3,4,4)$ & Detrend & 0,38 & 0,76 & 0,41 & 0,73 & 0,38 & 0,38 & 0,76 & 2,1 & 4 \\
\hline$(3,4,4)$ & SNV & 0,36 & 0,79 & 0,39 & 0,75 & 0,36 & 0,37 & 0,78 & 2,1 & 5 \\
\hline$(3,4,4)$ & SNVD & 0,36 & 0,79 & 0,39 & 0,75 & 0,36 & 0,37 & 0,78 & 2,1 & 5 \\
\hline$(3,4,4)$ & MSC & 0,36 & 0,79 & 0,39 & 0,75 & 0,36 & 0,37 & 0,77 & 2,1 & 5 \\
\hline
\end{tabular}




\section{Fortsetzung Tab.20}

Öl, gemahlene Achänen

\begin{tabular}{|c|c|c|c|c|c|c|c|c|c|c|}
\hline Abl. & SK & SEC & $\mathrm{R}^{2}$ & SECV & 1-VR & SEP & SEPC & $\mathrm{RSQ}$ & RPD & Term \\
\hline$(0,0,1)$ & keine & 0,76 & 0,91 & 0,79 & 0,90 & 0,77 & 0,77 & 0,90 & 3,2 & 15 \\
\hline$(0,0,1)$ & Detrend & 0,76 & 0,91 & 0,78 & 0,90 & 0,77 & 0,77 & 0,90 & 3,2 & 14 \\
\hline$(0,0,1)$ & SNV & 0,75 & 0,91 & 0,76 & 0,91 & 0,74 & 0,74 & 0,91 & 3,3 & 14 \\
\hline$(0,0,1)$ & SNVD & 0,75 & 0,91 & 0,76 & 0,91 & 0,72 & 0,72 & 0,91 & 3,4 & 14 \\
\hline$(0,0,1)$ & MSC & 0,74 & 0,91 & 0,76 & 0,91 & 0,72 & 0,72 & 0,92 & 3,4 & 14 \\
\hline$(1,2,2)$ & keine & 0,72 & 0,92 & 0,75 & 0,91 & 0,75 & 0,75 & 0,91 & 3,3 & 12 \\
\hline$(1,2,2)$ & Detrend & 0,71 & 0,92 & 0,75 & 0,91 & 0,75 & 0,75 & 0,91 & 3,3 & 13 \\
\hline$(1,2,2)$ & SNV & 0,71 & 0,92 & 0,74 & 0,91 & 0,72 & 0,72 & 0,91 & 3,4 & 13 \\
\hline$(1,2,2)$ & SNVD & 0,71 & 0,92 & 0,74 & 0,91 & 0,72 & 0,72 & 0,91 & 3,4 & 12 \\
\hline$(1,2,2)$ & MSC & 0,71 & 0,92 & 0,75 & 0,91 & 0,72 & 0,72 & 0,92 & 3,4 & 12 \\
\hline$(1,4,4)$ & keine & 0,72 & 0,92 & 0,74 & 0,91 & 0,75 & 0,75 & 0,91 & 3,3 & 13 \\
\hline$(1,4,4)$ & Detrend & 0,71 & 0,92 & 0,74 & 0,91 & 0,73 & 0,74 & 0,91 & 3,3 & 14 \\
\hline$(1,4,4)$ & SNV & 0,70 & 0,92 & 0,73 & 0,92 & 0,69 & 0,69 & 0,92 & 3,6 & 14 \\
\hline$(1,4,4)$ & SNVD & 0,71 & 0,92 & 0,73 & 0,92 & 0,70 & 0,70 & 0,92 & 3,5 & 13 \\
\hline$(1,4,4)$ & MSC & 0,69 & 0,92 & 0,72 & 0,92 & 0,69 & 0,69 & 0,92 & 3,6 & 14 \\
\hline$(1,10,5)$ & keine & 0,72 & 0,92 & 0,74 & 0,91 & 0,72 & 0,72 & 0,91 & 3,4 & 15 \\
\hline$(1,10,5)$ & Detrend & 0,71 & 0,92 & 0,74 & 0,91 & 0,73 & 0,73 & 0,91 & 3,4 & 14 \\
\hline$(1,10,5)$ & SNV & 0,71 & 0,92 & 0,73 & 0,91 & 0,69 & 0,69 & 0,92 & 3,6 & 14 \\
\hline$(1,10,5)$ & SNVD & 0,70 & 0,92 & 0,74 & 0,91 & 0,68 & 0,68 & 0,92 & 3,6 & 14 \\
\hline$(1,10,5)$ & MSC & 0,70 & 0,92 & 0,74 & 0,91 & 0,68 & 0,68 & 0,92 & 3,6 & 14 \\
\hline$(2,4,4)$ & keine & 0,72 & 0,92 & 0,78 & & 0,74 & 0,74 & 0,91 & 3,3 & 12 \\
\hline$(2,4,4)$ & Detrer & 0,72 & 0,92 & 0,78 & 0,90 & 0,74 & 0,74 & 0,91 & 3,3 & 12 \\
\hline$(2,4,4)$ & SNV & 0,70 & 0,92 & 0,77 & 0,91 & 0,72 & 0,73 & 0,91 & 3,4 & 12 \\
\hline$(2,4,4)$ & SNVD & 0,70 & 0,92 & 0,77 & 0,91 & 0,73 & 0,73 & 0,91 & 3,4 & 12 \\
\hline$(2,4,4)$ & MSC & 0,70 & 0,92 & 0,77 & 0,91 & 0,72 & 0,73 & 0,91 & 3,4 & 12 \\
\hline$(2,10,5)$ & keine & 0,71 & 0,92 & 0,75 & 0,91 & 0,72 & 0,72 & 0,91 & 3,4 & 14 \\
\hline$(2,10,5)$ & Detrend & 0,71 & 0,92 & 0,75 & 0,91 & 0,72 & 0,72 & 0,91 & 3,4 & 14 \\
\hline$(2,10,5)$ & SNV & 0,70 & 0,92 & 0,74 & 0,91 & 0,71 & 0,71 & 0,92 & 3,5 & 13 \\
\hline$(2,10,5)$ & SNVD & 0,70 & 0,92 & 0,74 & 0,91 & 0,71 & 0,71 & 0,92 & 3,5 & 13 \\
\hline$(2,10,5)$ & MSC & 0,70 & 0,92 & 0,74 & 0,91 & 0,71 & 0,71 & 0,92 & 3,5 & 13 \\
\hline$(2,20,10)$ & keine & 0,73 & 0,92 & 0,76 & 0,91 & 0,74 & 0,74 & 0,91 & 3,3 & 14 \\
\hline$(2,20,10)$ & Detrend & 0,72 & 0,92 & 0,75 & 0,91 & 0,72 & 0,72 & 0,92 & 3,4 & 15 \\
\hline$(2,20,10)$ & SNV & 0,72 & 0,92 & 0,75 & 0,91 & 0,70 & 0,70 & 0,92 & 3,5 & 13 \\
\hline$(2,20,10)$ & SNVD & 0,73 & 0,92 & 0,75 & 0,91 & 0,71 & 0,71 & 0,92 & 3,5 & 13 \\
\hline$(2,20,10)$ & MSC & 0,72 & 0,92 & 0,75 & 0,91 & 0,70 & 0,70 & 0,92 & 3,5 & 13 \\
\hline$(3,4,4)$ & keine & 0,73 & 0,92 & 0,81 & 0,90 & 0,78 & 0,79 & 0,90 & 3,1 & 12 \\
\hline$(3,4,4)$ & Detrend & 0,73 & 0,92 & 0,81 & 0,90 & 0,78 & 0,79 & 0,90 & 3,1 & 12 \\
\hline$(3,4,4)$ & SNV & 0,72 & 0,92 & 0,80 & 0,90 & 0,77 & 0,77 & 0,90 & 3,2 & 12 \\
\hline$(3,4,4)$ & SNVD & 0,72 & 0,92 & 0,80 & 0,90 & 0,77 & 0,77 & 0,90 & 3,2 & 12 \\
\hline$(3,4,4)$ & MSC & 0,72 & 0,92 & 0,80 & 0,90 & 0,77 & 0,77 & 0,90 & 3,2 & 12 \\
\hline
\end{tabular}




\section{Fortsetzung Tab.20}

Öl, intakte Achänen

\begin{tabular}{|c|c|c|c|c|c|c|c|c|c|c|}
\hline Abl. & SK & SEC & $\mathrm{R}^{2}$ & SECV & 1-VR & SEP & SEPC & $\mathrm{RSQ}$ & RPD & Terme \\
\hline$(0,0,1)$ & keine & 1,12 & 0,79 & 1,15 & 0,78 & 1,14 & 1,15 & 0,77 & 2,1 & 16 \\
\hline$(0,0,1)$ & Detrend & 1,10 & 0,80 & 1,14 & 0,78 & 1,10 & 1,11 & 0,79 & 2,2 & 15 \\
\hline$(0,0,1)$ & SNV & 1,17 & 0,77 & 1,18 & 0,77 & 1,17 & 1,17 & 0,76 & 2,0 & 16 \\
\hline$(0,0,1)$ & SNVD & 1,09 & 0,80 & 1,10 & 0,80 & 1,05 & 1,06 & 0,80 & 2,3 & 16 \\
\hline$(0,0,1)$ & MSC & 1,13 & 0,79 & 1,15 & 0,78 & 1,18 & 1,18 & 0,75 & 2,0 & 16 \\
\hline$(1,2,2)$ & keine & 0,97 & 0,84 & 1,00 & 0,83 & 1,02 & 1,03 & 0,82 & 2,3 & 15 \\
\hline$(1,2,2)$ & Detrend & 0,96 & 0,85 & 0,99 & 0,84 & 1,01 & 1,01 & 0,82 & 2,4 & 15 \\
\hline$(1,2,2)$ & SNV & 0,98 & 0,84 & 1,01 & 0,83 & 1,04 & 1,04 & 0,81 & 2,3 & 15 \\
\hline$(1,2,2)$ & SNVD & 0,97 & 0,84 & 1,01 & 0,83 & 1,02 & 1,02 & 0,82 & 2,3 & 15 \\
\hline$(1,2,2)$ & MSC & 0,99 & 0,84 & 1,02 & 0,83 & 1,04 & 1,04 & 0,81 & 2,3 & 14 \\
\hline$(1,4,4)$ & keine & 0,99 & 0,84 & 1,01 & 0,83 & 1,02 & 1,02 & 0,82 & 2,3 & 14 \\
\hline$(1,4,4)$ & Detrend & 0,97 & 0,84 & 1,00 & 0,84 & 1,01 & 1,01 & 0,82 & 2,4 & 15 \\
\hline$(1,4,4)$ & SNV & 0,99 & 0,84 & 1,03 & 0,82 & 1,03 & 1,04 & 0,81 & 2,3 & 14 \\
\hline$(1,4,4)$ & SNVD & 0,98 & 0,84 & 1,01 & 0,83 & 1,02 & 1,02 & 0,82 & 2,3 & 15 \\
\hline$(1,4,4)$ & MSC & 1,00 & 0,83 & 1,02 & 0,83 & 1,03 & 1,04 & 0,81 & 2,3 & 14 \\
\hline$(1,10$ & keine & 0,99 & 0,84 & 1,02 & 0,83 & 1,04 & 1,04 & 0,81 & 2,3 & 15 \\
\hline$(1,10,5)$ & Detren & 0,99 & 0,84 & 1,02 & 0,83 & 1,03 & 1,03 & 0,81 & 2,3 & 15 \\
\hline$(1,10,5)$ & SNV & 1,00 & 0,83 & 1,04 & 0,82 & 1,04 & 1,04 & 0,81 & 2,3 & 15 \\
\hline$(1,10,5)$ & SNVD & 1,01 & 0,83 & 1,03 & 0,82 & 1,03 & 1,03 & 0,81 & 2,3 & 15 \\
\hline$(1,10,5)$ & MSC & 1,02 & 0,83 & 1,05 & 0,82 & 1,06 & 1,06 & 0,80 & 2,2 & 14 \\
\hline$(2,4,4)$ & keine & 0,94 & 0,85 & 1,00 & 0,83 & 1,02 & 1,02 & 0,82 & 2,3 & 12 \\
\hline$(2,4,4)$ & Detrend & 0,94 & 0,85 & 1,00 & 0,83 & 1,01 & 1,02 & 0,82 & 2,3 & 12 \\
\hline$(2,4,4)$ & SNV & 0,95 & 0,85 & 1,01 & 0,83 & 1,00 & 1,00 & 0,83 & 2,4 & 12 \\
\hline$(2,4,4)$ & SNVD & 0,94 & 0,85 & 1,01 & 0,83 & 1,00 & 1,00 & 0,83 & 2,4 & 12 \\
\hline$(2,4,4)$ & MSC & 0,95 & 0,85 & 1,01 & 0,83 & 1,01 & 1,01 & 0,82 & 2,4 & 12 \\
\hline$(2,10,5)$ & keine & 0,95 & 0,85 & 0,99 & 0,84 & 1,03 & 1,04 & 0,81 & 2,3 & 14 \\
\hline$(2,10,5)$ & Detreno & 0,96 & 0,85 & 1,00 & 0,83 & 1,02 & 1,02 & 0,82 & 2,3 & 13 \\
\hline$(2,10,5)$ & SNV & 0,97 & 0,84 & 1,00 & 0,83 & 1,02 & 1,03 & 0,82 & 2,3 & 13 \\
\hline$(2,10,5)$ & SNVD & 0,97 & 0,84 & 1,00 & 0,83 & 1,02 & 1,02 & 0,82 & 2,3 & 13 \\
\hline$(2,10,5)$ & MSC & 0,98 & 0,84 & 1,01 & 0,83 & 1,03 & 1,03 & 0,81 & 2,3 & 13 \\
\hline$(2,20,10)$ & keine & 1,03 & 0,82 & 1,05 & 0,82 & 1,09 & 1,09 & 0,80 & 2,2 & 14 \\
\hline$(2,20,10)$ & Detrend & 1,04 & 0,82 & 1,06 & 0,81 & 1,08 & 1,08 & 0,80 & 2,2 & 13 \\
\hline$(2,20,10)$ & SNV & 1,03 & 0,82 & 1,05 & 0,82 & 1,05 & 1,06 & 0,81 & 2,3 & 14 \\
\hline$(2,20,10)$ & SNVD & 1,03 & 0,82 & 1,05 & 0,82 & 1,05 & 1,06 & 0,81 & 2,3 & 14 \\
\hline$(2,20,10)$ & MSC & 1,02 & 0,83 & 1,05 & 0,82 & 1,03 & 1,04 & 0,81 & 2,3 & 15 \\
\hline$(3,4,4)$ & keine & 0,96 & 0,85 & 1,06 & 0,81 & 1,01 & 1,01 & 0,82 & 2,4 & 12 \\
\hline$(3,4,4)$ & Detrend & 0,96 & 0,85 & 1,06 & 0,81 & 1,01 & 1,01 & 0,82 & 2,4 & 12 \\
\hline$(3,4,4)$ & SNV & 0,97 & 0,84 & 1,07 & 0,81 & 1,01 & 1,01 & 0,82 & 2,4 & 12 \\
\hline$(3,4,4)$ & SNVD & 0,97 & 0,84 & 1,07 & 0,81 & 1,01 & 1,01 & 0,82 & 2,4 & 12 \\
\hline$(3,4,4)$ & MSC & 0,97 & 0,84 & 1,07 & 0,81 & 1,00 & 1,01 & 0,82 & 2,4 & 12 \\
\hline
\end{tabular}


Fortsetzung Tab. 20

Protein, gemahlene Achänen

\begin{tabular}{|c|c|c|c|c|c|c|c|c|c|c|}
\hline Abl. & SK & SEC & $R^{2}$ & SECV & 1-VR & SEP & SEPC & RSQ & RPD & Terme \\
\hline$(0,0,1)$ & keine & 0,55 & 0,93 & 0,56 & 0,92 & 0,54 & 0,54 & 0,93 & 3,7 & 13 \\
\hline$(0,0,1)$ & Detrend & 0,55 & 0,93 & 0,56 & 0,92 & 0,57 & 0,57 & 0,92 & 3,6 & 14 \\
\hline$(0,0,1)$ & SNV & 0,53 & 0,93 & 0,55 & 0,93 & 0,50 & 0,50 & 0,94 & 4,0 & 13 \\
\hline$(0,0,1)$ & SNVD & 0,53 & 0,93 & 0,55 & 0,93 & 0,52 & 0,52 & 0,93 & 3,9 & 13 \\
\hline$(0,0,1)$ & MSC & 0,54 & 0,93 & 0,56 & 0,92 & 0,54 & 0,54 & 0,93 & 3,7 & 13 \\
\hline$(1,2,2)$ & keine & 0,49 & 0,94 & 0,53 & 0,93 & 0,58 & 0,58 & 0,92 & 3,5 & 14 \\
\hline$(1,2,2)$ & Detrend & 0,49 & 0,94 & 0,53 & 0,93 & 0,57 & 0,57 & 0,92 & 3,5 & 13 \\
\hline$(1,2,2)$ & SNV & 0,47 & 0,95 & 0,51 & 0,94 & 0,53 & 0,53 & 0,93 & 3,8 & 13 \\
\hline$(1,2,2)$ & SNVD & 0,46 & 0,95 & 0,49 & 0,94 & 0,51 & 0,51 & 0,94 & 3,9 & 14 \\
\hline$(1,2,2)$ & MSC & 0,47 & 0,95 & 0,51 & 0,94 & 0,54 & 0,53 & 0,93 & 3,8 & 13 \\
\hline$(1,4,4)$ & keine & 0,50 & 0,94 & 0,54 & 0,93 & 0,57 & 0,58 & 0,92 & 3,5 & 14 \\
\hline$(1,4,4)$ & Detrend & 0,51 & 0,94 & 0,54 & 0,93 & 0,57 & 0,57 & 0,92 & 3,6 & 13 \\
\hline$(1,4,4)$ & SNV & 0,46 & 0,95 & 0,50 & 0,94 & 0,52 & 0,53 & 0,93 & 3,8 & 15 \\
\hline$(1,4,4)$ & SNVD & 0,47 & 0,95 & 0,50 & 0,94 & 0,51 & 0,51 & 0,94 & 3,9 & 14 \\
\hline$(1,4,4)$ & MSC & 0,47 & 0,95 & 0,50 & 0,94 & 0,53 & 0,53 & 0,93 & 3,8 & 15 \\
\hline$(1,10,5)$ & keine & 0,51 & 0,94 & 0,55 & 0,93 & 0,59 & 0,59 & 0,92 & 3,4 & 14 \\
\hline$(1,10,5)$ & Detrend & 0,53 & 0,93 & 0,55 & 0,93 & 0,57 & 0,57 & 0,92 & 3,5 & 13 \\
\hline$(1,10,5)$ & SNV & 0,49 & 0,94 & 0,52 & 0,93 & 0,54 & 0,55 & 0,93 & 3,7 & 15 \\
\hline$(1,10,5)$ & SNVD & 0,49 & 0,94 & 0,52 & 0,93 & 0,53 & 0,53 & 0,93 & 3,8 & 14 \\
\hline$(1,10,5)$ & MSC & 0,49 & 0,94 & 0,52 & 0,93 & 0,55 & 0,55 & 0,93 & 3,7 & 15 \\
\hline$(2,4,4)$ & keine & 0,47 & 0,95 & 0,52 & 0,93 & 0,52 & 0,52 & 0,93 & 3,8 & 11 \\
\hline$(2,4,4)$ & Detrend & 0,47 & 0,95 & 0,52 & 0,93 & 0,52 & 0,52 & 0,93 & 3,8 & 11 \\
\hline$(2,4,4)$ & SNV & 0,46 & 0,95 & 0,50 & 0,94 & 0,49 & 0,49 & 0,94 & 4,1 & 10 \\
\hline$(2,4,4)$ & SNVD & 0,46 & 0,95 & 0,50 & 0,94 & 0,49 & 0,49 & 0,94 & 4,1 & 10 \\
\hline$(2,4,4)$ & MSC & 0,44 & 0,95 & 0,49 & 0,94 & 0,48 & 0,48 & 0,94 & 4,2 & 11 \\
\hline$(2,10,5)$ & keine & 0,48 & 0,94 & 0,52 & 0,93 & 0,57 & 0,57 & 0,92 & 3,5 & 14 \\
\hline$(2,10,5)$ & Detrend & 0,48 & 0,94 & 0,52 & 0,93 & 0,57 & 0,57 & 0,92 & 3,5 & 14 \\
\hline$(2,10,5)$ & SNV & 0,46 & 0,95 & 0,50 & 0,94 & 0,53 & 0,53 & 0,93 & 3,8 & 13 \\
\hline$(2,10,5)$ & SNVD & 0,46 & 0,95 & 0,50 & 0,94 & 0,52 & 0,52 & 0,93 & 3,9 & 14 \\
\hline$(2,10,5)$ & MSC & 0,46 & 0,95 & 0,50 & 0,94 & 0,52 & 0,52 & 0,93 & 3,8 & 13 \\
\hline$(2,20,10)$ & keine & 0,52 & 0,93 & 0,55 & 0,93 & 0,57 & 0,57 & 0,92 & 3,5 & 13 \\
\hline$(2,20,10)$ & Detrend & 0,52 & 0,93 & 0,55 & 0,93 & 0,57 & 0,57 & 0,92 & 3,5 & 13 \\
\hline$(2,20,10)$ & SNV & 0,51 & 0,93 & 0,54 & 0,93 & 0,54 & 0,54 & 0,93 & 3,7 & 12 \\
\hline$(2,20,10)$ & SNVD & 0,51 & 0,94 & 0,54 & 0,93 & 0,54 & 0,54 & 0,93 & 3,8 & 12 \\
\hline$(2,20,10)$ & MSC & 0,51 & 0,94 & 0,54 & 0,93 & 0,54 & 0,54 & 0,93 & 3,7 & 12 \\
\hline$(3,4,4)$ & keine & 0,50 & 0,94 & 0,55 & 0,93 & 0,52 & 0,52 & 0,93 & 3,8 & 8 \\
\hline$(3,4,4)$ & Detrend & 0,50 & 0,94 & 0,55 & 0,93 & 0,52 & 0,52 & 0,93 & 3,8 & 8 \\
\hline$(3,4,4)$ & SNV & 0,46 & 0,95 & 0,51 & 0,94 & 0,46 & 0,45 & 0,95 & 4,4 & 9 \\
\hline$(3,4,4)$ & SNVD & 0,46 & 0,95 & 0,51 & 0,94 & 0,46 & 0,45 & 0,95 & 4,4 & 9 \\
\hline$(3,4,4)$ & MSC & 0,46 & 0,95 & 0,51 & 0,94 & 0,46 & 0,46 & 0,95 & 4,4 & 9 \\
\hline
\end{tabular}


Fortsetzung Tab. 20

Protein, intakte Achänen

\begin{tabular}{|c|c|c|c|c|c|c|c|c|c|c|}
\hline Abl. & SK & SEC & $\mathrm{R}^{2}$ & SECV & $1-V R$ & SEP & SEPC & $\mathrm{RSQ}$ & RPD & Terme \\
\hline$(0,0,1)$ & keine & 0,89 & 0,76 & 0,92 & 0,75 & 0,97 & 0,98 & 0,71 & 1,9 & 16 \\
\hline$(0,0,1)$ & Detrend & 0,88 & 0,77 & 0,88 & 0,77 & 0,98 & 0,98 & 0,71 & 1,9 & 16 \\
\hline$(0,0,1)$ & SNV & 0,91 & 0,75 & 0,94 & 0,73 & 1,01 & 1,01 & 0,69 & 1,8 & 15 \\
\hline$(0,0,1)$ & SNVD & 0,83 & 0,79 & 0,87 & 0,77 & 0,94 & 0,94 & 0,73 & 1,9 & 16 \\
\hline$(0,0,1)$ & MSC & 0,86 & 0,78 & 0,90 & 0,76 & 0,99 & 0,99 & 0,71 & 1,8 & 16 \\
\hline$(1,2,2)$ & keine & 0,72 & 0,84 & 0,78 & 0,82 & 0,81 & 0,81 & 0,80 & 2,2 & 15 \\
\hline$(1,2,2)$ & Detrend & 0,72 & 0,84 & 0,77 & 0,82 & 0,78 & 0,79 & 0,81 & 2,3 & 15 \\
\hline$(1,2,2)$ & SNV & 0,72 & 0,84 & 0,78 & 0,82 & 0,83 & 0,83 & 0,80 & 2,2 & 14 \\
\hline$(1,2,2)$ & SNVD & 0,72 & 0,85 & 0,79 & 0,82 & 0,80 & 0,80 & 0,81 & 2,3 & 14 \\
\hline$(1,2,2)$ & MSC & 0,76 & 0,83 & 0,79 & 0,81 & 0,83 & 0,84 & 0,79 & 2,2 & 13 \\
\hline$(1,4,4)$ & keine & 0,72 & 0,85 & 0,76 & 0,82 & 0,80 & 0,81 & 0,81 & 2,3 & 15 \\
\hline$(1,4,4)$ & Detrend & 0,72 & 0,84 & 0,76 & 0,83 & 0,78 & 0,79 & 0,81 & 2,3 & 15 \\
\hline$(1,4,4)$ & SNV & 0,72 & 0,84 & 0,77 & 0,82 & 0,83 & 0,83 & 0,80 & 2,2 & 14 \\
\hline$(1,4,4)$ & SNVD & 0,72 & 0,84 & 0,77 & 0,82 & 0,84 & 0,84 & 0,79 & 2,2 & 14 \\
\hline$(1,4,4)$ & MSC & 0,74 & 0,84 & 0,77 & 0,82 & 0,82 & 0,83 & 0,80 & 2,2 & 14 \\
\hline$(1,10,5)$ & keine & 0,74 & 0,84 & 0,78 & 0,82 & 0,82 & 0,82 & 0,80 & 2,2 & 15 \\
\hline$(1,10,5)$ & Detrend & 0,75 & 0,83 & 0,78 & 0,82 & 0,83 & 0,84 & 0,79 & 2,2 & 15 \\
\hline$(1,10,5)$ & SNV & 0,74 & 0,83 & 0,78 & 0,82 & 0,84 & 0,85 & 0,79 & 2,2 & 14 \\
\hline$(1,10,5)$ & SNVD & 0,74 & 0,83 & 0,78 & 0,82 & 0,85 & 0,85 & 0,78 & 2,1 & 14 \\
\hline$(1,10,5)$ & MSC & 0,74 & 0,84 & 0,78 & 0,82 & 0,84 & 0,84 & 0,79 & 2,2 & 15 \\
\hline$(2,4,4)$ & keine & 0,69 & 0,86 & 0,75 & 0,83 & 0,73 & 0,74 & 0 & 2,5 & 11 \\
\hline$(2,4,4)$ & Detrend & 0,68 & 0,86 & 0,75 & 0,83 & 0,74 & 0,74 & 0,84 & 2,5 & 11 \\
\hline$(2,4,4)$ & SNV & 0,68 & 0,86 & 0,74 & 0,84 & 0,76 & 0,77 & 0,82 & 2,4 & 11 \\
\hline$(2,4,4)$ & SNVD & 0,69 & 0,86 & 0,74 & 0,83 & 0,76 & 0,76 & 0,82 & 2,4 & 10 \\
\hline$(2,4,4)$ & MSC & 0,68 & 0,86 & 0,74 & 0,84 & 0,76 & 0,76 & 0,83 & 2,4 & 11 \\
\hline$(2,10,5)$ & keine & 0,68 & 0,86 & 0,74 & 0,84 & 0,75 & 0,75 & 0,83 & 2,4 & 14 \\
\hline$(2,10,5)$ & Detren & 0,68 & 0,86 & 0,74 & 0,84 & 0,75 & 0,76 & 0,83 & 2,4 & 14 \\
\hline$(2,10,5)$ & SNV & 0,69 & 0,86 & 0,74 & 0,84 & 0,75 & 0,75 & 0,83 & 2,4 & 13 \\
\hline$(2,10,5)$ & SNVD & 0,69 & 0,86 & 0,74 & 0,84 & 0,74 & 0,75 & 0,83 & 2,4 & 13 \\
\hline$(2,10,5)$ & MSC & 0,68 & 0,86 & 0,74 & 0,84 & 0,76 & 0,76 & 0,83 & 2,4 & 14 \\
\hline$(2,20,10)$ & keine & 0,80 & 0,81 & 0,83 & 0,79 & 0,90 & 0,90 & 0,76 & 2,0 & 13 \\
\hline$(2,20,10)$ & Detrend & 0,80 & 0,81 & 0,83 & 0,79 & 0,90 & 0,90 & 0,76 & 2,0 & 13 \\
\hline$(2,20,10)$ & SNV & 0,78 & 0,82 & 0,82 & 0,80 & 0,88 & 0,89 & 0,76 & 2,1 & 14 \\
\hline$(2,20,10)$ & SNVD & 0,78 & 0,82 & 0,82 & 0,80 & 0,87 & 0,88 & 0,77 & 2,1 & 14 \\
\hline$(2,20,10)$ & MSC & 0,79 & 0,81 & 0,83 & 0,79 & 0,89 & 0,89 & 0,76 & 2,0 & 14 \\
\hline$(3,4,4)$ & keine & 0,73 & 0,84 & 0,80 & 0,81 & 0,78 & 0,78 & 0,82 & 2,3 & 8 \\
\hline$(3,4,4)$ & Detrend & 0,73 & 0,84 & 0,80 & 0,81 & 0,78 & 0,78 & 0,82 & 2,3 & 8 \\
\hline$(3,4,4)$ & SNV & 0,73 & 0,84 & 0,79 & 0,81 & 0,79 & 0,79 & 0,81 & 2,3 & 8 \\
\hline$(3,4,4)$ & SNVD & 0,73 & 0,84 & 0,79 & 0,81 & 0,79 & 0,79 & 0,81 & 2,3 & 8 \\
\hline$(3,4,4)$ & MSC & 0,73 & 0,84 & 0,79 & 0,81 & 0,79 & 0,79 & 0,81 & 2,3 & 8 \\
\hline
\end{tabular}


Fortsetzung Tab. 20

C16:0, gemahlene Achänen

\begin{tabular}{|c|c|c|c|c|c|c|c|c|c|c|}
\hline Abl. & SK & SEC & $\mathrm{R}^{2}$ & SECV & 1-VR & SEP & SEPC & $\mathrm{RSQ}$ & RPD & Terme \\
\hline$(0,0,1)$ & keine & 0,12 & 0,91 & 0,13 & 0,90 & 0,13 & 0,13 & 0,90 & 3,2 & 16 \\
\hline$(0,0,1)$ & Detrend & 0,11 & 0,92 & 0,12 & 0,90 & 0,12 & 0,12 & 0,91 & 3,4 & 15 \\
\hline$(0,0,1)$ & SNV & 0,11 & 0,92 & 0,12 & 0,91 & 0,12 & 0,12 & 0,92 & 3,5 & 16 \\
\hline$(0,0,1)$ & SNVD & 0,11 & 0,93 & 0,12 & 0,91 & 0,11 & 0,11 & 0,93 & 3,8 & 16 \\
\hline$(0,0,1)$ & MSC & 0,11 & 0,92 & 0,12 & 0,91 & 0,11 & 0,11 & 0,92 & 3,6 & 16 \\
\hline$(1,2,2)$ & keine & 0,10 & 0,94 & 0,11 & 0,92 & 0,10 & 0,10 & 0,94 & 4,0 & 14 \\
\hline$(1,2,2)$ & Detrend & 0,09 & 0,94 & 0,11 & 0,92 & 0,10 & 0,10 & 0,94 & 4,2 & 15 \\
\hline$(1,2,2)$ & SNV & 0,09 & 0,95 & 0,10 & 0,93 & 0,09 & 0,09 & 0,95 & 4,4 & 16 \\
\hline$(1,2,2)$ & SNVD & 0,09 & 0,95 & 0,10 & 0,93 & 0,09 & 0,09 & 0,95 & 4,4 & 15 \\
\hline$(1,2,2)$ & MSC & 0,09 & 0,94 & 0,10 & 0,93 & 0,09 & 0,09 & 0,95 & 4,3 & 15 \\
\hline$(1,4,4)$ & keine & 0,09 & 0,94 & 0,10 & 0,93 & 0,10 & 0,10 & 0,94 & 4,1 & 15 \\
\hline$(1,4,4)$ & Detrend & 0,09 & 0,94 & 0,10 & 0,93 & 0,10 & 0,10 & 0,94 & 4,2 & 15 \\
\hline$(1,4,4)$ & SNV & 0,09 & 0,95 & 0,10 & 0,94 & 0,09 & 0,09 & 0,95 & 4,4 & 16 \\
\hline$(1,4,4)$ & SNVD & 0,09 & 0,95 & 0,10 & 0,94 & 0,09 & 0,09 & 0,95 & 4,5 & 16 \\
\hline$(1,4,4)$ & MSC & 0,09 & 0,95 & 0,10 & 0,94 & 0,09 & 0,09 & 0,95 & 4,4 & 16 \\
\hline$(1,10,5)$ & keine & 0,10 & 0,94 & 0,11 & 0,92 & 0,11 & 0,11 & 0,93 & 3,8 & 15 \\
\hline$(1,1$ & Detı & 0,10 & 0,93 & 0,11 & 0,92 & 0,11 & 0,11 & 0,93 & 3,8 & - \\
\hline$(1,10,5)$ & SNV & 0,09 & 0,94 & 0,10 & 0,93 & 0,10 & 0,10 & 0,94 & 4,2 & 16 \\
\hline$(1,10,5)$ & SNVD & 0,09 & 0,95 & 0,10 & 0,93 & 0,09 & 0,09 & 0,95 & 4,4 & 16 \\
\hline$(1,10,5)$ & MSC & 0,09 & 0,94 & 0,10 & 0,93 & 0,10 & 0,10 & 0,95 & 4,3 & 16 \\
\hline$(2,4,4)$ & keine & 0,09 & 0,95 & 0,10 & 0,93 & 0,10 & 0,10 & 0,94 & 4,0 & 13 \\
\hline$(2,4,4)$ & Detren & 0,09 & 0,95 & 0,10 & 0,93 & 0,10 & 0,10 & 0,94 & 4,0 & 13 \\
\hline$(2,4,4)$ & SNV & 0,09 & 0,95 & 0,10 & 0,94 & 0,10 & 0,10 & 0,94 & 4,2 & 12 \\
\hline$(2,4,4)$ & SNVD & 0,09 & 0,95 & 0,10 & 0,94 & 0,10 & 0,10 & 0,94 & 4,2 & 12 \\
\hline$(2,4,4)$ & MSC & 0,09 & 0,95 & 0,10 & 0,94 & 0,10 & 0,10 & 0,94 & 4,2 & 12 \\
\hline$(2,10,5)$ & keine & 0,09 & 0,95 & 0,10 & 0,93 & 0,10 & 0,10 & 0,94 & 4,1 & 15 \\
\hline$(2,10,5)$ & Detren & 0,09 & 0,95 & 0,10 & 0,93 & 0,10 & 0,10 & 0,94 & 4,1 & 15 \\
\hline$(2,10,5)$ & SNV & 0,09 & 0,95 & 0,10 & 0,94 & 0,09 & 0,09 & 0,95 & 4,4 & 16 \\
\hline$(2,10,5)$ & SNVD & 0,09 & 0,95 & 0,10 & 0,94 & 0,09 & 0,09 & 0,95 & 4,4 & 16 \\
\hline$(2,10,5)$ & MSC & 0,09 & 0,95 & 0,10 & 0,94 & 0,09 & 0,09 & 0,95 & 4,4 & 15 \\
\hline$(2,20,10)$ & keine & 0,11 & 0,93 & 0,11 & 0,92 & 0,12 & 0,12 & 0,92 & 3,5 & 15 \\
\hline$(2,20,10)$ & Detren & 0,11 & 0,93 & 0,11 & 0,92 & 0,12 & 0,12 & 0,92 & 3,5 & 15 \\
\hline$(2,20,10)$ & SNV & 0,10 & 0,93 & 0,11 & 0,92 & 0,11 & 0,11 & 0,93 & 3,8 & 16 \\
\hline$(2,20,10)$ & SNVD & 0,10 & 0,93 & 0,11 & 0,92 & 0,11 & 0,11 & 0,93 & 3,7 & 15 \\
\hline$(2,20,10)$ & MSC & 0,10 & 0,93 & 0,11 & 0,92 & 0,11 & 0,11 & 0,93 & 3,7 & 15 \\
\hline$(3,4,4)$ & keine & 0,10 & 0,94 & 0,11 & 0,91 & 0,12 & 0,12 & 0,91 & 3,4 & 11 \\
\hline$(3,4,4)$ & Detrend & 0,10 & 0,94 & 0,11 & 0,91 & 0,12 & 0,12 & 0,91 & 3,4 & 11 \\
\hline$(3,4,4)$ & SNV & 0,09 & 0,95 & 0,11 & 0,92 & 0,11 & 0,11 & 0,93 & 3,7 & 13 \\
\hline$(3,4,4)$ & SNVD & 0,09 & 0,95 & 0,11 & 0,92 & 0,11 & 0,11 & 0,93 & 3,7 & 13 \\
\hline$(3,4,4)$ & MSC & 0,09 & 0,95 & 0,11 & 0,92 & 0,11 & 0,11 & 0,93 & 3,7 & 13 \\
\hline
\end{tabular}


Fortsetzung Tab. 20

C16:0, intakte Achänen

\begin{tabular}{|c|c|c|c|c|c|c|c|c|c|c|}
\hline Abl. & SK & SEC & $\mathrm{R}^{2}$ & SECV & 1-VR & SEP & SEPC & $\mathrm{RSQ}$ & RPD & Terme \\
\hline$(0,0,1)$ & keine & 0,15 & 0,87 & 0,15 & 0,86 & 0,16 & 0,16 & 0,86 & 2,6 & 14 \\
\hline$(0,0,1)$ & Detrend & 0,14 & 0,88 & 0,14 & 0,87 & 0,15 & 0,15 & 0,88 & 2,8 & 16 \\
\hline$(0,0,1)$ & SNV & 0,15 & 0,86 & 0,15 & 0,85 & 0,16 & 0,16 & 0,86 & 2,6 & 15 \\
\hline$(0,0,1)$ & SNVD & 0,15 & 0,87 & 0,15 & 0,86 & 0,15 & 0,15 & 0,86 & 2,6 & 15 \\
\hline$(0,0,1)$ & MSC & 0,15 & 0,87 & 0,15 & 0,86 & 0,16 & 0,16 & 0,84 & 2,5 & 15 \\
\hline$(1,2,2)$ & keine & 0,12 & 0,91 & 0,13 & 0,89 & 0,13 & 0,13 & 0,90 & 3,1 & 14 \\
\hline$(1,2,2)$ & Detrend & 0,12 & 0,92 & 0,13 & 0,90 & 0,13 & 0,13 & 0,91 & 3,2 & 14 \\
\hline$(1,2,2)$ & SNV & 0,12 & 0,92 & 0,13 & 0,90 & 0,13 & 0,13 & 0,90 & 3,1 & 14 \\
\hline$(1,2,2)$ & SNVD & 0,11 & 0,92 & 0,13 & 0,90 & 0,12 & 0,12 & 0,91 & 3,3 & 14 \\
\hline$(1,2,2)$ & MSC & 0,12 & 0,92 & 0,13 & 0,90 & 0,13 & 0,13 & 0,90 & 3,1 & 14 \\
\hline$(1,4,4)$ & keine & 0,11 & 0,92 & 0,12 & 0,91 & 0,12 & 0,12 & 0,91 & 3,3 & 15 \\
\hline$(1,4,4)$ & Detrend & 0,11 & 0,92 & 0,12 & 0,91 & 0,13 & 0,13 & 0,91 & 3,2 & 15 \\
\hline$(1,4,4)$ & SNV & 0,11 & 0,92 & 0,12 & 0,91 & 0,13 & 0,13 & 0,91 & 3,2 & 15 \\
\hline$(1,4,4)$ & SNVD & 0,11 & 0,93 & 0,12 & 0,91 & 0,13 & 0,13 & 0,91 & 3,2 & 5 \\
\hline$(1,4,4)$ & MSC & 0,11 & 0,92 & 0,12 & 0,91 & 0,13 & 0,13 & 0,91 & 3,2 & 15 \\
\hline$(1,10,5)$ & keine & 0,12 & 0,91 & 0,13 & 0,90 & 0,13 & 0,13 & 0,90 & 3,1 & 15 \\
\hline$(1,10,5)$ & Detrend & 0,12 & 0,92 & 0,13 & 0,90 & 0,13 & 0,13 & 0,90 & 3,1 & 15 \\
\hline$(1,10,5)$ & SNV & 0,11 & 0,92 & 0,12 & 0,91 & 0,13 & 0,13 & 0,91 & 3,1 & 16 \\
\hline$(1,10,5)$ & SNVD & 0,11 & 0,92 & 0,12 & 0,91 & 0,12 & 0,13 & 0,91 & 3,3 & 16 \\
\hline$(1,10,5)$ & MSC & 0,11 & 0,92 & 0,12 & 0,91 & 0,13 & 0,13 & 0,91 & 3,2 & 16 \\
\hline$(2,4,4)$ & keine & 0,10 & 0,94 & 0,12 & 0,92 & 0,11 & 0,11 & 0,93 & 3,6 & 14 \\
\hline$(2,4,4)$ & Detren & 0,10 & 0,94 & 0,12 & 0,92 & 0,11 & 0,11 & 0,93 & 3,6 & 14 \\
\hline$(2,4,4)$ & SNV & 0,10 & 0,94 & 0,12 & 0,92 & 0,11 & 0,11 & 0,93 & 3,6 & 13 \\
\hline$(2,4,4)$ & SNVD & 0,10 & 0,94 & 0,12 & 0,92 & 0,11 & 0,11 & 0,93 & 3,6 & 13 \\
\hline$(2,4,4)$ & MSC & 0,10 & 0,94 & 0,12 & 0,92 & 0,12 & 0,12 & 0,92 & 3,5 & 12 \\
\hline$(2,10,5)$ & keine & 0,11 & 0,93 & 0,12 & 0,91 & 0,13 & 0,13 & 0,91 & 3,2 & 14 \\
\hline$(2,10,5)$ & Detren & 0,11 & 0,93 & 0,12 & 0,91 & 0,13 & 0,13 & 0,91 & 3,2 & 14 \\
\hline$(2,10,5)$ & SNV & 0,11 & 0,93 & 0,12 & 0,91 & 0,13 & 0,13 & 0,90 & 3,2 & 14 \\
\hline$(2,10,5)$ & SNVD & 0,11 & 0,93 & 0,12 & 0,91 & 0,13 & 0,13 & 0,91 & 3,2 & 14 \\
\hline$(2,10,5)$ & MSC & 0,11 & 0,93 & 0,12 & 0,91 & 0,13 & 0,13 & 0,90 & 3,2 & 14 \\
\hline$(2,20,10)$ & keine & 0,13 & 0,90 & 0,14 & 0,88 & 0,14 & 0,14 & 0,89 & 3,0 & 14 \\
\hline$(2,20,10)$ & Detrend & 0,13 & 0,89 & 0,14 & 0,88 & 0,14 & 0,14 & 0,89 & 2,9 & 13 \\
\hline$(2,20,10)$ & SNV & 0,13 & 0,89 & 0,14 & 0,87 & 0,14 & 0,14 & 0,88 & 2,8 & 14 \\
\hline$(2,20,10)$ & SNVD & 0,13 & 0,89 & 0,14 & 0,87 & 0,14 & 0,14 & 0,88 & 2,8 & 14 \\
\hline$(2,20,10)$ & MSC & 0,13 & 0,89 & 0,14 & 0,88 & 0,14 & 0,15 & 0,88 & 2,8 & 15 \\
\hline$(3,4,4)$ & keine & 0,10 & 0,93 & 0,12 & 0,90 & 0,12 & 0,12 & 0,92 & 3,4 & 11 \\
\hline$(3,4,4)$ & Detrend & 0,10 & 0,93 & 0,12 & 0,90 & 0,12 & 0,12 & 0,92 & 3,4 & 11 \\
\hline$(3,4,4)$ & SNV & 0,10 & 0,93 & 0,12 & 0,90 & 0,12 & 0,12 & 0,91 & 3,3 & 11 \\
\hline$(3,4,4)$ & SNVD & 0,10 & 0,93 & 0,12 & 0,90 & 0,12 & 0,12 & 0,91 & 3,3 & 11 \\
\hline$(3,4,4)$ & MSC & 0,11 & 0,93 & 0,12 & 0,90 & 0,12 & 0,12 & 0,91 & 3,3 & 11 \\
\hline
\end{tabular}


Fortsetzung Tab. 20

C18:0, gemahlene Achänen

\begin{tabular}{|c|c|c|c|c|c|c|c|c|c|c|}
\hline Abl. & SK & SEC & $\mathrm{R}^{2}$ & SECV & 1-VR & SEP & SEPC & $\mathrm{RSQ}$ & RPD & Terme \\
\hline$(0,0,1)$ & keine & 0,25 & 0,84 & 0,28 & 0,81 & 0,26 & 0,26 & 0,82 & 2,4 & 16 \\
\hline$(0,0,1)$ & Detrend & 0,23 & 0,87 & 0,25 & 0,85 & 0,21 & 0,21 & 0,88 & 2,9 & 16 \\
\hline$(0,0,1)$ & SNV & 0,25 & 0,84 & 0,27 & 0,82 & 0,25 & 0,25 & 0,83 & 2,4 & 16 \\
\hline$(0,0,1)$ & SNVD & 0,25 & 0,85 & 0,25 & 0,85 & 0,24 & 0,24 & 0,85 & 2,6 & 16 \\
\hline$(0,0,1)$ & MSC & 0,26 & 0,83 & 0,27 & 0,82 & 0,26 & 0,26 & 0,83 & 2,4 & 16 \\
\hline$(1,2,2)$ & keine & 0,16 & 0,94 & 0,17 & 0,93 & 0,17 & 0,17 & 0,93 & 3,7 & 16 \\
\hline$(1,2,2)$ & Detrend & 0,16 & 0,94 & 0,17 & 0,93 & 0,17 & 0,17 & 0,92 & 3,6 & 16 \\
\hline$(1,2,2)$ & SNV & 0,15 & 0,94 & 0,16 & 0,93 & 0,17 & 0,17 & 0,93 & 3,7 & 16 \\
\hline$(1,2,2)$ & SNVD & 0,16 & 0,94 & 0,17 & 0,93 & 0,16 & 0,16 & 0,93 & 3,8 & 15 \\
\hline$(1,2,2)$ & MSC & 0,15 & 0,94 & 0,17 & 0,93 & 0,17 & 0,17 & 0,93 & 3,7 & 16 \\
\hline$(1,4,4)$ & keine & 0,15 & 0,95 & 0,16 & 0,94 & 0,15 & 0,15 & 0,94 & 4,2 & 16 \\
\hline$(1,4,4)$ & Detrend & 0,15 & 0,94 & 0,16 & 0,94 & 0,15 & 0,15 & 0,94 & 4,0 & 16 \\
\hline$(1,4,4)$ & SNV & 0,14 & 0,95 & 0,15 & 0,94 & 0,14 & 0,15 & 0,95 & 4,3 & 16 \\
\hline$(1,4,4)$ & SNVD & 0,14 & 0,95 & 0,15 & 0,94 & 0,14 & 0,14 & 0,95 & 4,4 & 16 \\
\hline$(1,4,4)$ & MSC & 0,15 & 0,95 & 0,15 & 0,94 & 0,14 & 0,14 & 0,95 & 4,4 & 16 \\
\hline$(1,10,5)$ & keine & 0,18 & 0,92 & 0,19 & 0,92 & 0,17 & 0,17 & 0,92 & 3,6 & 16 \\
\hline$(1,10,5)$ & Detrend & 0,17 & 0,93 & 0,18 & 0,92 & 0,17 & 0,17 & 0,93 & 3,6 & 16 \\
\hline$(1,10,5)$ & SNV & 0,17 & 0,93 & 0,18 & 0,92 & 0,17 & 0,17 & 0,92 & 3,6 & 16 \\
\hline$(1,10,5)$ & SNVD & 0,17 & 0,93 & 0,18 & 0,92 & 0,17 & 0,17 & 0,92 & 3,6 & 16 \\
\hline$(1,10,5)$ & MSC & 0,17 & 0,93 & 0,18 & 0,92 & 0,17 & 0,17 & 0,93 & 3,7 & 16 \\
\hline$(2,4,4)$ & keine & 0,13 & 0,96 & 0,15 & 0,94 & 0,14 & 0,14 & 0,95 & 4,4 & 15 \\
\hline$(2,4,4)$ & Detren & 0,13 & 0,96 & 0,15 & 0,94 & 0,14 & 0,14 & 0,95 & 4,4 & 15 \\
\hline$(2,4,4)$ & SNV & 0,12 & 0,96 & 0,14 & 0,95 & 0,13 & 0,13 & 0,96 & 4,8 & 16 \\
\hline$(2,4,4)$ & SNVD & 0,12 & 0,96 & 0,14 & 0,95 & 0,13 & 0,13 & 0,96 & 4,8 & 16 \\
\hline$(2,4,4)$ & MSC & 0,12 & 0,96 & 0,14 & 0,95 & 0,13 & 0,13 & 0,96 & 4,7 & 15 \\
\hline$(2,10,5)$ & keine & 0,15 & 0,94 & 0,16 & 0,93 & 0,15 & 0,15 & 0,94 & 4,0 & 16 \\
\hline$(2,10,5)$ & Detrer & 0,15 & 0,94 & 0,16 & 0,93 & 0,15 & 0,15 & 0,94 & 4,0 & 16 \\
\hline$(2,10,5)$ & SNV & 0,15 & 0,94 & 0,16 & 0,94 & 0,15 & 0,15 & 0,94 & 4,2 & 16 \\
\hline$(2,10,5)$ & SNVD & 0,15 & 0,94 & 0,16 & 0,94 & 0,15 & 0,15 & 0,94 & 4,2 & 16 \\
\hline$(2,10,5)$ & MSC & 0,15 & 0,94 & 0,16 & 0,94 & 0,15 & 0,14 & 0,95 & 4,2 & 16 \\
\hline$(2,20,10)$ & keine & 0,20 & 0,90 & 0,22 & 0,88 & 0,20 & 0,20 & 0,89 & 3,0 & 16 \\
\hline$(2,20,10)$ & Detrend & 0,20 & 0,90 & 0,22 & 0,88 & 0,20 & 0,20 & 0,89 & 3,0 & 16 \\
\hline$(2,20,10)$ & SNV & 0,21 & 0,89 & 0,22 & 0,88 & 0,20 & 0,20 & 0,90 & 3,1 & 16 \\
\hline$(2,20,10)$ & SNVD & 0,21 & 0,89 & 0,23 & 0,88 & 0,20 & 0,20 & 0,90 & 3,1 & 16 \\
\hline$(2,20,10)$ & MSC & 0,21 & 0,89 & 0,23 & 0,87 & 0,20 & 0,20 & 0,90 & 3,1 & 16 \\
\hline$(3,4,4)$ & keine & 0,13 & 0,96 & 0,16 & 0,94 & 0,16 & 0,16 & 0,93 & 3,8 & 16 \\
\hline$(3,4,4)$ & Detrend & 0,13 & 0,96 & 0,16 & 0,94 & 0,16 & 0,16 & 0,93 & 3,8 & 16 \\
\hline$(3,4,4)$ & SNV & 0,13 & 0,96 & 0,15 & 0,94 & 0,15 & 0,15 & 0,94 & 4,1 & 15 \\
\hline$(3,4,4)$ & SNVD & 0,13 & 0,96 & 0,15 & 0,94 & 0,15 & 0,15 & 0,94 & 4,1 & 15 \\
\hline$(3,4,4)$ & MSC & 0,13 & 0,96 & 0,15 & 0,94 & 0,15 & 0,15 & 0,94 & 4,2 & 16 \\
\hline
\end{tabular}


Fortsetzung Tab. 20

C18:0, intakte Achänen

\begin{tabular}{|c|c|c|c|c|c|c|c|c|c|c|}
\hline Abl. & SK & SEC & $\mathrm{R}^{2}$ & SECV & $1-\mathrm{VR}$ & SEP & SEPC & RSQ & RPD & Terme \\
\hline$(0,0,1)$ & keine & 0,23 & 0,87 & 0,23 & 0,86 & 0,24 & 0,24 & 0,84 & 2,5 & 15 \\
\hline$(0,0,1)$ & Detrend & 0,21 & 0,89 & 0,22 & 0,88 & 0,21 & 0,21 & 0,88 & 2,9 & 16 \\
\hline$(0,0,1)$ & SNV & 0,23 & 0,86 & 0,24 & 0,85 & 0,24 & 0,24 & 0,84 & 2,5 & 15 \\
\hline$(0,0,1)$ & SNVD & 0,22 & 0,87 & 0,23 & 0,87 & 0,22 & 0,22 & 0,86 & 2,7 & 15 \\
\hline$(0,0,1)$ & MSC & 0,22 & 0,87 & 0,23 & 0,86 & 0,22 & 0,22 & 0,87 & 2,7 & 16 \\
\hline$(1,2,2)$ & keine & 0,18 & 0,91 & 0,20 & 0,90 & 0,19 & 0,19 & 0,90 & 3,1 & 15 \\
\hline$(1,2,2)$ & Detrend & 0,18 & 0,91 & 0,20 & 0,90 & 0,20 & 0,20 & 0,89 & 3,1 & 14 \\
\hline$(1,2,2)$ & SNV & 0,18 & 0,91 & 0,20 & 0,90 & 0,19 & 0,19 & 0,90 & 3,2 & 14 \\
\hline$(1,2,2)$ & SNVD & 0,19 & 0,91 & 0,20 & 0,90 & 0,19 & 0,19 & 0,90 & 3,2 & 14 \\
\hline$(1,2,2)$ & MSC & 0,19 & 0,91 & 0,20 & 0,89 & 0,19 & 0,19 & 0,90 & 3,2 & 14 \\
\hline$(1,4,4)$ & keine & 0,18 & 0,91 & 0,20 & 0,90 & 0,19 & 0,19 & 0,90 & 3,2 & 15 \\
\hline$(1,4,4)$ & Detrend & 0,18 & 0,91 & 0,19 & 0,90 & 0,19 & 0,19 & 0,90 & 3,1 & 15 \\
\hline$(1,4,4)$ & SNV & 0,18 & 0,91 & 0,20 & 0,90 & 0,19 & 0,19 & 0,90 & 3,2 & 15 \\
\hline$(1,4,4)$ & SN & 0,18 & 0,91 & 0,20 & 0,90 & 0,19 & 0,19 & 0,90 & 3,2 & 15 \\
\hline$(1,4,4)$ & MSC & 0,18 & 0,91 & 0,20 & 0,90 & 0,19 & 0,19 & 0,91 & 3,3 & 15 \\
\hline$(1,10,5)$ & keine & 0,19 & 0,90 & 0,20 & 0,89 & 0,20 & 0,20 & 0,89 & 3,0 & 14 \\
\hline$(1,10,5)$ & Detrend & 0,19 & 0,90 & 0,20 & 0,89 & 0,20 & 0,20 & 0,89 & 3,0 & 14 \\
\hline$(1,10,5)$ & SNV & 0,19 & 0,90 & 0,20 & 0,89 & 0,19 & 0,19 & 0,90 & 3,1 & 15 \\
\hline$(1,10,5)$ & SNVD & 0,19 & 0,91 & 0,20 & 0,89 & 0,20 & 0,20 & 0,89 & 3,0 & 15 \\
\hline$(1,10,5)$ & MSC & 0,20 & 0,90 & 0,21 & 0,89 & 0,20 & 0,20 & 0,89 & 3,1 & 14 \\
\hline$(2,4,4)$ & kei & 0,18 & 0,92 & 0,19 & 0,90 & 0,20 & 0,20 & 0,89 & 3,1 & 1 \\
\hline$(2,4,4)$ & Detrend & 0,18 & 0,92 & 0,19 & 0,90 & 0,20 & 0,20 & 0,89 & 3,1 & 11 \\
\hline$(2,4,4)$ & SNV & 0,18 & 0,92 & 0,19 & 0,90 & 0,19 & 0,19 & 0,90 & 3,1 & 11 \\
\hline$(2,4,4)$ & SNVD & 0,17 & 0,92 & 0,19 & 0,90 & 0,19 & 0,19 & 0,90 & 3,2 & 11 \\
\hline$(2,4,4)$ & MSC & 0,18 & 0,92 & 0,19 & 0,90 & 0,20 & 0,20 & 0,89 & 3,1 & 11 \\
\hline$(2,10,5)$ & keine & 0,17 & 0,92 & 0,19 & 0,91 & 0,19 & 0,19 & 0,90 & 3,2 & 14 \\
\hline$(2,10,5)$ & Detrend & 0,17 & 0,92 & 0,19 & 0,91 & 0,19 & 0,19 & 0,90 & 3,1 & 14 \\
\hline$(2,10,5)$ & SNV & 0,18 & 0,92 & 0,19 & 0,90 & 0,19 & 0,19 & 0,90 & 3,2 & 14 \\
\hline$(2,10,5)$ & SNVD & 0,18 & 0,92 & 0,19 & 0,90 & 0,19 & 0,19 & 0,90 & 3,2 & 14 \\
\hline$(2,10,5)$ & MSC & 0,17 & 0,92 & 0,19 & 0,91 & 0,19 & 0,19 & 0,90 & 3,2 & 15 \\
\hline$(2,20,10)$ & keine & 0,20 & 0,90 & 0,21 & 0,88 & 0,22 & 0,22 & 0,87 & 2,8 & 14 \\
\hline$(2,20,10)$ & Detrend & 0,20 & 0,90 & 0,21 & 0,88 & 0,22 & 0,22 & 0,87 & 2,8 & 14 \\
\hline$(2,20,10)$ & SNV & 0,20 & 0,89 & 0,21 & 0,88 & 0,22 & 0,22 & 0,86 & 2,7 & 13 \\
\hline$(2,20,10)$ & SNVD & 0,20 & 0,89 & 0,21 & 0,88 & 0,22 & 0,23 & 0,86 & 2,7 & 13 \\
\hline$(2,20,10)$ & MSC & 0,20 & 0,89 & 0,21 & 0,88 & 0,22 & 0,22 & 0,87 & 2,8 & 14 \\
\hline$(3,4,4)$ & keine & 0,18 & 0,92 & 0,20 & 0,90 & 0,20 & 0,20 & 0,89 & 3,1 & 10 \\
\hline$(3,4,4)$ & Detrend & 0,18 & 0,92 & 0,20 & 0,90 & 0,20 & 0,20 & 0,89 & 3,1 & 10 \\
\hline$(3,4,4)$ & SNV & 0,18 & 0,91 & 0,20 & 0,89 & 0,20 & 0,20 & 0,89 & 3,0 & 10 \\
\hline$(3,4,4)$ & SNVD & 0,18 & 0,91 & 0,20 & 0,89 & 0,20 & 0,20 & 0,89 & 3,0 & 10 \\
\hline$(3,4,4)$ & MSC & 0,18 & 0,91 & 0,20 & 0,89 & 0,20 & 0,20 & 0,89 & 3,0 & 10 \\
\hline
\end{tabular}


Fortsetzung Tab. 20

C18:1, gemahlene Achänen

\begin{tabular}{|c|c|c|c|c|c|c|c|c|c|c|}
\hline Abl. & SK & SEC & $\mathrm{R}^{2}$ & SECV & $1-V R$ & SEP & SEPC & $\mathrm{RSQ}$ & RPD & Terme \\
\hline$(0,0,1)$ & keine & 0,93 & 0,82 & 0,97 & 0,80 & 0,94 & 0,94 & 0,81 & 2,3 & 16 \\
\hline$(0,0,1)$ & Detrend & 0,79 & 0,87 & 0,85 & 0,85 & 0,81 & 0,81 & 0,86 & 2,7 & 16 \\
\hline$(0,0,1)$ & SNV & 0,97 & 0,80 & 1,02 & 0,78 & 0,92 & 0,93 & 0,82 & 2,4 & 15 \\
\hline$(0,0,1)$ & SNVD & 0,83 & 0,85 & 0,89 & 0,83 & 0,79 & 0,80 & 0,87 & 2,8 & 16 \\
\hline$(0,0,1)$ & MSC & 0,90 & 0,83 & 0,93 & 0,82 & 0,90 & 0,90 & 0,83 & 2,4 & 16 \\
\hline$(1,2,2)$ & keine & 0,49 & 0,95 & 0,53 & 0,94 & 0,47 & 0,47 & 0,95 & 4,6 & 16 \\
\hline$(1,2,2)$ & Detrend & 0,50 & 0,95 & 0,53 & 0,94 & 0,51 & 0,51 & 0,95 & 4,3 & 16 \\
\hline$(1,2,2)$ & SNV & 0,44 & 0,96 & 0,50 & 0,95 & 0,41 & 0,42 & 0,97 & 5,3 & 16 \\
\hline$(1,2,2)$ & SNVD & 0,45 & 0,96 & 0,49 & 0,95 & 0,41 & 0,41 & 0,97 & 5,4 & 16 \\
\hline$(1,2,2)$ & MSC & 0,45 & 0,96 & 0,49 & 0,95 & 0,43 & 0,43 & 0,96 & 5,1 & 16 \\
\hline$(1,4,4)$ & keine & 0,48 & 0,95 & 0,51 & 0,94 & 0,42 & 0,42 & 0,96 & 5,2 & 16 \\
\hline$(1,4,4)$ & Detrend & 0,48 & 0,95 & 0,50 & 0,95 & 0,45 & 0,45 & 0,96 & 4,9 & 16 \\
\hline$(1,4,4)$ & SNV & 0,44 & 0,96 & 0,47 & 0,95 & 0,38 & 0,38 & 0,97 & 5,8 & 16 \\
\hline$(1,4,4)$ & SNVD & 0,44 & 0,96 & 0,46 & 0,95 & 0,37 & 0,37 & 0,97 & 5,9 & 16 \\
\hline$(1,4,4)$ & MSC & 0,44 & 0,96 & 0,46 & 0,95 & 0,37 & 0,38 & 0,97 & 5,8 & 16 \\
\hline$(1,10,5)$ & keine & 0,56 & 0,93 & 0,60 & 0,92 & 0,53 & 0,53 & 0,94 & 4,1 & 16 \\
\hline$(1,10,5)$ & Detrend & 0,59 & 0,93 & 0,61 & 0,92 & 0,57 & 0,58 & 0,93 & 3,8 & 16 \\
\hline$(1,10,5)$ & SNV & 0,55 & 0,94 & 0,58 & 0,93 & 0,52 & 0,52 & 0,94 & 4,2 & 16 \\
\hline$(1,10,5)$ & SNVD & 0,55 & 0,93 & 0,58 & 0,93 & 0,53 & 0,53 & 0,94 & 4,1 & 16 \\
\hline$(1,10,5)$ & MSC & 0,55 & 0,94 & 0,57 & 0,93 & 0,51 & 0,51 & 0,95 & 4,3 & 16 \\
\hline$(2,4,4)$ & keine & 0,40 & 0,97 & 0,46 & 0,96 & 0,43 & 0,43 & 0 & 5,1 & 15 \\
\hline$(2,4,4)$ & Detrend & 0,40 & 0,97 & 0,46 & 0,96 & 0,43 & 0,43 & 0,96 & 5,0 & 15 \\
\hline$(2,4,4)$ & SNV & 0,35 & 0,97 & 0,40 & 0,97 & 0,36 & 0,36 & 0,97 & 6,0 & 15 \\
\hline$(2,4,4)$ & SNVD & 0,35 & 0,97 & 0,40 & 0,97 & 0,36 & 0,36 & 0,97 & 6,0 & 15 \\
\hline$(2,4,4)$ & MSC & 0,35 & 0,97 & 0,40 & 0,97 & 0,36 & 0,36 & 0,97 & 6,1 & 15 \\
\hline$(2,10,5)$ & keine & 0,49 & 0,95 & 0,51 & 0,94 & 0,50 & 0,50 & 0,95 & 4,4 & 15 \\
\hline$(2,10,5)$ & Detren & 0,49 & 0,95 & 0,52 & 0,94 & 0,50 & 0,50 & 0,95 & 4,4 & 15 \\
\hline$(2,10,5)$ & SNV & 0,46 & 0,95 & 0,49 & 0,95 & 0,44 & 0,44 & 0,96 & 4,9 & 16 \\
\hline$(2,10,5)$ & SNVD & 0,47 & 0,95 & 0,50 & 0,95 & 0,45 & 0,45 & 0,96 & 4,9 & 16 \\
\hline$(2,10,5)$ & MSC & 0,47 & 0,95 & 0,49 & 0,95 & 0,45 & 0,45 & 0,96 & 4,9 & 16 \\
\hline$(2,20,10)$ & keine & 0,76 & 0,88 & 0,81 & 0,86 & 0,73 & 0,73 & 0,89 & 3,0 & 16 \\
\hline$(2,20,10)$ & Detrend & 0,74 & 0,88 & 0,80 & 0,86 & 0,71 & 0,71 & 0,90 & 3,1 & 16 \\
\hline$(2,20,10)$ & SNV & 0,76 & 0,88 & 0,82 & 0,86 & 0,71 & 0,72 & 0,90 & 3,1 & 16 \\
\hline$(2,20,10)$ & SNVD & 0,77 & 0,87 & 0,81 & 0,86 & 0,72 & 0,73 & 0,89 & 3,0 & 16 \\
\hline$(2,20,10)$ & MSC & 0,77 & 0,87 & 0,81 & 0,86 & 0,72 & 0,72 & 0,89 & 3,0 & 16 \\
\hline$(3,4,4)$ & keine & 0,39 & 0,97 & 0,46 & 0,96 & 0,46 & 0,46 & 0,96 & 4,8 & 15 \\
\hline$(3,4,4)$ & Detrend & 0,39 & 0,97 & 0,46 & 0,96 & 0,46 & 0,46 & 0,96 & 4,8 & 15 \\
\hline$(3,4,4)$ & SNV & 0,36 & 0,97 & 0,41 & 0,96 & 0,40 & 0,40 & 0,97 & 5,5 & 14 \\
\hline$(3,4,4)$ & SNVD & 0,36 & 0,97 & 0,41 & 0,96 & 0,40 & 0,40 & 0,97 & 5,5 & 14 \\
\hline$(3,4,4)$ & MSC & 0,36 & 0,97 & 0,41 & 0,96 & 0,40 & 0,40 & 0,97 & 5,4 & 14 \\
\hline
\end{tabular}


Fortsetzung Tab. 20

C18:1, intakte Achänen

\begin{tabular}{|c|c|c|c|c|c|c|c|c|c|c|}
\hline Abl. & SK & SEC & $\mathrm{R}^{2}$ & SECV & $1-\mathrm{VR}$ & SEP & SEPC & RSQ & RPD & Terme \\
\hline$(0,0,1)$ & keine & 0,92 & 0,78 & 0,96 & 0,76 & 0,94 & 0,94 & 0,77 & 2,1 & 14 \\
\hline$(0,0,1)$ & Detrend & 0,88 & 0,80 & 0,92 & 0,78 & 0,87 & 0,87 & 0,80 & 2,3 & 15 \\
\hline$(0,0,1)$ & SNV & 0,92 & 0,78 & 0,94 & 0,77 & 0,87 & 0,88 & 0,80 & 2,3 & 14 \\
\hline$(0,0,1)$ & SNVD & 0,89 & 0,80 & 0,93 & 0,78 & 0,88 & 0,89 & 0,80 & 2,2 & 15 \\
\hline$(0,0,1)$ & MSC & 0,90 & 0,79 & 0,93 & 0,77 & 0,91 & 0,91 & 0,79 & 2,2 & 15 \\
\hline$(1,2,2)$ & keine & 0,84 & 0,82 & 0,89 & 0,80 & 0,85 & 0,85 & 0,81 & 2,3 & 12 \\
\hline$(1,2,2)$ & Detrend & 0,84 & 0,82 & 0,88 & 0,80 & 0,84 & 0,84 & 0,82 & 2,3 & 12 \\
\hline$(1,2,2)$ & SNV & 0,83 & 0,82 & 0,88 & 0,80 & 0,82 & 0,82 & 0,83 & 2,4 & 12 \\
\hline$(1,2,2)$ & SNVD & 0,83 & 0,82 & 0,88 & 0,80 & 0,81 & 0,81 & 0,83 & 2,4 & 12 \\
\hline$(1,2,2)$ & MSC & 0,82 & 0,83 & 0,87 & 0,80 & 0,80 & 0,80 & 0,84 & 2,5 & 13 \\
\hline$(1,4,4)$ & keine & 0,82 & 0,82 & 0,86 & 0,81 & 0,81 & 0,81 & 0,83 & 2,4 & 14 \\
\hline$(1,4,4)$ & Detrend & 0,83 & 0,82 & 0,88 & 0,80 & 0,82 & 0,82 & 0,83 & 2,4 & 13 \\
\hline$(1,4,4)$ & SNV & 0,82 & 0,83 & 0,86 & 0,81 & 0,78 & 0,78 & 0,84 & 2,5 & 13 \\
\hline$(1,4,4)$ & SN & 0,82 & 0,82 & 0,87 & 0,80 & 0,79 & 0,80 & 0,84 & 2,5 & 3 \\
\hline$(1,4,4)$ & MSC & 0,82 & 0,82 & 0,87 & 0,81 & 0,79 & 0,79 & 0,84 & 2,5 & 13 \\
\hline$(1,10,5)$ & keine & 0,83 & 0,82 & 0,87 & 0,80 & 0,81 & 0,82 & 0,83 & 2,4 & 14 \\
\hline$(1,10,5)$ & Detrend & 0,83 & 0,82 & 0,88 & 0,80 & 0,81 & 0,81 & 0,83 & 2,4 & 14 \\
\hline$(1,10,5)$ & SNV & 0,83 & 0,82 & 0,87 & 0,80 & 0,78 & 0,78 & 0,84 & 2,5 & 13 \\
\hline$(1,10,5)$ & SNVD & 0,83 & 0,82 & 0,87 & 0,80 & 0,80 & 0,80 & 0,84 & 2,5 & 13 \\
\hline$(1,10,5)$ & MSC & 0,83 & 0,82 & 0,87 & 0,80 & 0,79 & 0,79 & 0,84 & 2,5 & 13 \\
\hline$(2,4,4)$ & kei & 0,81 & 0,83 & 0,86 & 0,81 & 0,85 & 0,86 & 0,81 & 2,3 & 9 \\
\hline$(2,4,4)$ & Detren & 0,81 & 0,83 & 0,86 & 0,81 & 0,85 & 0,85 & 0,81 & 2,3 & 9 \\
\hline$(2,4,4)$ & SNV & 0,80 & 0,83 & 0,86 & 0,81 & 0,82 & 0,82 & 0,83 & 2,4 & 10 \\
\hline$(2,4,4)$ & SNVD & 0,80 & 0,83 & 0,86 & 0,81 & 0,81 & 0,82 & 0,83 & 2,4 & 10 \\
\hline$(2,4,4)$ & MSC & 0,81 & 0,83 & 0,87 & 0,81 & 0,82 & 0,82 & 0,83 & 2,4 & 10 \\
\hline$(2,10,5)$ & keine & 0,81 & 0,83 & 0,86 & 0,81 & 0,82 & 0,82 & 0,83 & 2,4 & 12 \\
\hline$(2,10,5)$ & Detren & 0,81 & 0,83 & 0,86 & 0,81 & 0,82 & 0,82 & 0,83 & 2,4 & 12 \\
\hline$(2,10,5)$ & SNV & 0,81 & 0,83 & 0,85 & 0,81 & 0,79 & 0,79 & 0,84 & 2,5 & 12 \\
\hline$(2,10,5)$ & SNVD & 0,81 & 0,83 & 0,85 & 0,81 & 0,79 & 0,80 & 0,84 & 2,5 & 12 \\
\hline$(2,10,5)$ & MSC & 0,81 & 0,83 & 0,86 & 0,81 & 0,79 & 0,80 & 0,84 & 2,5 & 12 \\
\hline$(2,20,10)$ & keine & 0,87 & 0,80 & 0,92 & 0,78 & 0,85 & 0,85 & 0,81 & 2,3 & 12 \\
\hline$(2,20,10)$ & Detrend & 0,87 & 0,80 & 0,91 & 0,78 & 0,86 & 0,86 & 0,81 & 2,3 & 13 \\
\hline$(2,20,10)$ & SNV & 0,87 & 0,80 & 0,91 & 0,79 & 0,83 & 0,84 & 0,82 & 2,4 & 11 \\
\hline$(2,20,10)$ & SNVD & 0,86 & 0,81 & 0,90 & 0,79 & 0,83 & 0,84 & 0,82 & 2,4 & 12 \\
\hline$(2,20,10)$ & MSC & 0,86 & 0,81 & 0,90 & 0,79 & 0,82 & 0,83 & 0,83 & 2,4 & 12 \\
\hline$(3,4,4)$ & keine & 0,77 & 0,85 & 0,88 & 0,80 & 0,84 & 0,84 & 0,82 & 2,3 & 12 \\
\hline$(3,4,4)$ & Detrend & 0,77 & 0,85 & 0,88 & 0,80 & 0,84 & 0,84 & 0,82 & 2,3 & 12 \\
\hline$(3,4,4)$ & SNV & 0,77 & 0,85 & 0,88 & 0,80 & 0,83 & 0,84 & 0,82 & 2,4 & 12 \\
\hline$(3,4,4)$ & SNVD & 0,77 & 0,85 & 0,88 & 0,80 & 0,83 & 0,84 & 0,82 & 2,4 & 12 \\
\hline$(3,4,4)$ & MSC & 0,78 & 0,84 & 0,88 & 0,80 & 0,83 & 0,83 & 0,83 & 2,4 & 11 \\
\hline
\end{tabular}


Fortsetzung Tab. 20

C18:2, gemahlene Achänen

\begin{tabular}{|c|c|c|c|c|c|c|c|c|c|c|}
\hline Abl. & SK & SEC & $\mathrm{R}^{2}$ & SECV & 1-VR & SEP & SEPC & $\mathrm{RSQ}$ & RPD & Terme \\
\hline$(0,0,1)$ & keine & 0,58 & 0,84 & 0,60 & 0,82 & 0,55 & 0,55 & 0,87 & 2,8 & 16 \\
\hline$(0,0,1)$ & Detrend & 0,45 & 0,90 & 0,50 & 0,88 & 0,44 & 0,44 & 0,92 & 3,5 & 16 \\
\hline$(0,0,1)$ & SNV & 0,60 & 0,82 & 0,65 & 0,80 & 0,60 & 0,60 & 0,85 & 2,6 & 16 \\
\hline$(0,0,1)$ & SNVD & 0,50 & 0,88 & 0,52 & 0,87 & 0,47 & 0,47 & 0,91 & 3,2 & 16 \\
\hline$(0,0,1)$ & MSC & 0,58 & 0,83 & 0,62 & 0,81 & 0,57 & 0,58 & 0,86 & 2,7 & 16 \\
\hline$(1,2,2)$ & keine & 0,30 & 0,96 & 0,33 & 0,95 & 0,30 & 0,29 & 0,96 & 5,2 & 16 \\
\hline$(1,2,2)$ & Detrend & 0,29 & 0,96 & 0,32 & 0,95 & 0,29 & 0,29 & 0,97 & 5,3 & 16 \\
\hline$(1,2,2)$ & SNV & 0,27 & 0,96 & 0,30 & 0,95 & 0,27 & 0,27 & 0,97 & 5,7 & 16 \\
\hline$(1,2,2)$ & SNVD & 0,28 & 0,96 & 0,32 & 0,95 & 0,28 & 0,28 & 0,97 & 5,6 & 16 \\
\hline$(1,2,2)$ & MSC & 0,28 & 0,96 & 0,30 & 0,96 & 0,27 & 0,27 & 0,97 & 5,7 & 16 \\
\hline$(1,4,4)$ & keine & 0,30 & 0,96 & 0,33 & 0,95 & 0,27 & 0,27 & 0,97 & 5,6 & 16 \\
\hline$(1,4,4)$ & Detrend & 0,27 & 0,96 & 0,32 & 0,95 & 0,25 & 0,25 & 0,97 & 6,2 & 16 \\
\hline$(1,4,4)$ & SNV & 0,26 & 0,97 & 0,29 & 0,96 & 0,24 & 0,24 & 0,98 & 6,5 & 16 \\
\hline$(1,4,4)$ & SNVD & 0,28 & 0,96 & 0,30 & 0,96 & 0,25 & 0,25 & 0,97 & 6,1 & 16 \\
\hline$(1,4,4)$ & MSC & 0,27 & 0,96 & 0,29 & 0,96 & 0,24 & 0,24 & 0,98 & 6,3 & 16 \\
\hline$(1,10,5)$ & keine & 0,39 & 0,93 & 0,40 & 0,92 & 0,37 & 0,37 & 0,94 & 4,2 & 16 \\
\hline$(1,10,5)$ & Detrend & 0,36 & 0,94 & 0,39 & 0,93 & 0,35 & 0,35 & 0,95 & 4,4 & 16 \\
\hline$(1,10,5)$ & SNV & 0,34 & 0,94 & 0,35 & 0,94 & 0,33 & 0,33 & 0,95 & 4,6 & 16 \\
\hline$(1,10,5)$ & SNVD & 0,33 & 0,95 & 0,35 & 0,94 & 0,33 & 0,33 & 0,95 & 4,7 & 16 \\
\hline$(1,10,5)$ & MSC & 0,34 & 0,94 & 0,35 & 0,94 & 0,33 & 0,33 & 0,95 & 4,6 & 16 \\
\hline$(2,4,4)$ & keine & 0,24 & 0,97 & 0,28 & 0,96 & 0,26 & 0,26 & 0,97 & 5,9 & 16 \\
\hline$(2,4,4)$ & Detrer & 0,24 & 0,97 & 0,28 & 0,96 & 0,25 & 0,25 & 0,97 & 6,0 & 16 \\
\hline$(2,4,4)$ & SNV & 0,21 & 0,98 & 0,25 & 0,97 & 0,23 & 0,23 & 0,98 & 6,6 & 15 \\
\hline$(2,4,4)$ & SNVD & 0,21 & 0,98 & 0,25 & 0,97 & 0,23 & 0,23 & 0,98 & 6,6 & 15 \\
\hline$(2,4,4)$ & MSC & 0,21 & 0,98 & 0,24 & 0,97 & 0,23 & 0,23 & 0,98 & 6,7 & 16 \\
\hline$(2,10,5)$ & keine & 0,29 & 0,96 & 0,31 & 0,95 & 0,29 & 0,29 & 0,96 & 5,2 & 16 \\
\hline$(2,10,5)$ & Detrend & 0,30 & 0,96 & 0,31 & 0,95 & 0,30 & 0,29 & 0,96 & 5,2 & 16 \\
\hline$(2,10,5)$ & SNV & 0,28 & 0,96 & 0,30 & 0,96 & 0,26 & 0,26 & 0,97 & 5,8 & 16 \\
\hline$(2,10,5)$ & SNVD & 0,28 & 0,96 & 0,30 & 0,96 & 0,26 & 0,26 & 0,97 & 5,9 & 16 \\
\hline$(2,10,5)$ & MSC & 0,28 & 0,96 & 0,30 & 0,96 & 0,27 & 0,27 & 0,97 & 5,7 & 15 \\
\hline$(2,20,10)$ & keine & 0,49 & 0,88 & 0,52 & 0,87 & 0,44 & 0,44 & 0,92 & 3,4 & 16 \\
\hline$(2,20,10)$ & Detrend & 0,49 & 0,88 & 0,52 & 0,87 & 0,45 & 0,45 & 0,92 & 3,4 & 16 \\
\hline$(2,20,10)$ & SNV & 0,49 & 0,88 & 0,52 & 0,87 & 0,43 & 0,43 & 0,92 & 3,5 & 16 \\
\hline$(2,20,10)$ & SNVD & 0,49 & 0,88 & 0,52 & 0,87 & 0,44 & 0,44 & 0,92 & 3,5 & 16 \\
\hline$(2,20,10)$ & MSC & 0,49 & 0,88 & 0,52 & 0,87 & 0,44 & 0,44 & 0,92 & 3,5 & 16 \\
\hline$(3,4,4)$ & keine & 0,26 & 0,97 & 0,30 & 0,96 & 0,31 & 0,31 & 0,96 & 4,9 & 14 \\
\hline$(3,4,4)$ & Detrend & 0,26 & 0,97 & 0,30 & 0,96 & 0,31 & 0,31 & 0,96 & 4,9 & 14 \\
\hline$(3,4,4)$ & SNV & 0,22 & 0,98 & 0,25 & 0,97 & 0,23 & 0,23 & 0,98 & 6,6 & 14 \\
\hline$(3,4,4)$ & SNVD & 0,22 & 0,98 & 0,25 & 0,97 & 0,23 & 0,23 & 0,98 & 6,6 & 14 \\
\hline$(3,4,4)$ & MSC & 0,22 & 0,98 & 0,25 & 0,97 & 0,24 & 0,24 & 0,98 & 6,5 & 14 \\
\hline
\end{tabular}


Fortsetzung Tab. 20

C18:2, intakte Achänen

\begin{tabular}{|c|c|c|c|c|c|c|c|c|c|c|}
\hline Abl. & SK & SEC & $\mathrm{R}^{2}$ & SECV & $1-V R$ & SEP & SEPC & RSQ & RPD & Terme \\
\hline$(0,0,1)$ & keine & 0,70 & 0,67 & 0,72 & 0,64 & 0,70 & 0,70 & 0,68 & 1,8 & 14 \\
\hline$(0,0,1)$ & Detrend & 0,69 & 0,68 & 0,71 & 0,66 & 0,69 & 0,69 & 0,69 & 1,8 & 13 \\
\hline$(0,0,1)$ & SNV & 0,69 & 0,67 & 0,71 & 0,66 & 0,69 & 0,69 & 0,69 & 1,8 & 14 \\
\hline$(0,0,1)$ & SNVD & 0,68 & 0,69 & 0,69 & 0,67 & 0,68 & 0,68 & 0,70 & 1,8 & 14 \\
\hline$(0,0,1)$ & MSC & 0,68 & 0,68 & 0,70 & 0,66 & 0,66 & 0,66 & 0,72 & 1,9 & 14 \\
\hline$(1,2,2)$ & keine & 0,63 & 0,73 & 0,66 & 0,70 & 0,60 & 0,60 & 0,77 & 2,1 & 12 \\
\hline$(1,2,2)$ & Detrend & 0,63 & 0,72 & 0,67 & 0,69 & 0,61 & 0,61 & 0,76 & 2,0 & 12 \\
\hline$(1,2,2)$ & SNV & 0,62 & 0,73 & 0,66 & 0,71 & 0,58 & 0,58 & 0,78 & 2,1 & 12 \\
\hline$(1,2,2)$ & SNVD & 0,63 & 0,72 & 0,66 & 0,70 & 0,60 & 0,60 & 0,77 & 2,1 & 11 \\
\hline$(1,2,2)$ & MSC & 0,62 & 0,74 & 0,66 & 0,71 & 0,57 & 0,58 & 0,79 & 2,2 & 12 \\
\hline$(1,4,4)$ & keine & 0,64 & 0,72 & 0,66 & 0,70 & 0,59 & 0,60 & 0,77 & 2,1 & 12 \\
\hline$(1,4,4)$ & Detrend & 0,63 & 0,73 & 0,66 & 0,70 & 0,59 & 0,59 & 0,77 & 2,1 & 13 \\
\hline$(1,4,4)$ & SNV & 0,62 & 0,74 & 0,65 & 0,71 & 0,56 & 0,56 & 0,80 & 2,2 & 13 \\
\hline$(1,4,4)$ & SN & 0,63 & 0,73 & 0,66 & 0,70 & 0,58 & 0,58 & 0,79 & 2,2 & 2 \\
\hline$(1,4,4)$ & MSC & 0,63 & 0,73 & 0,66 & 0,71 & 0,57 & 0,57 & 0,79 & 2,2 & 12 \\
\hline$(1,10,5)$ & keine & 0,64 & 0,72 & 0,67 & 0,69 & 0,61 & 0,61 & 0,76 & 2,0 & 12 \\
\hline$(1,10,5)$ & Detrend & 0,64 & 0,72 & 0,67 & 0,69 & 0,59 & 0,60 & 0,77 & 2,1 & 13 \\
\hline$(1,10,5)$ & SNV & 0,64 & 0,72 & 0,66 & 0,70 & 0,59 & 0,59 & 0,78 & 2,1 & 12 \\
\hline$(1,10,5)$ & SNVD & 0,64 & 0,72 & 0,66 & 0,70 & 0,59 & 0,59 & 0,78 & 2,1 & 12 \\
\hline$(1,10,5)$ & MSC & 0,63 & 0,72 & 0,66 & 0,70 & 0,57 & 0,58 & 0,79 & 2,2 & 12 \\
\hline$(2,4,4)$ & keine & 0,63 & 0,73 & 0,66 & 0,70 & 0,63 & 0,64 & 0,74 & 2,0 & 8 \\
\hline$(2,4,4)$ & Detren & 0,63 & 0,73 & 0,66 & 0,70 & 0,63 & 0,64 & 0,74 & 2,0 & 8 \\
\hline$(2,4,4)$ & SNV & 0,63 & 0,73 & 0,67 & 0,69 & 0,63 & 0,63 & 0,74 & 2,0 & 8 \\
\hline$(2,4,4)$ & SNVD & 0,63 & 0,73 & 0,67 & 0,69 & 0,63 & 0,63 & 0,74 & 2,0 & 8 \\
\hline$(2,4,4)$ & MSC & 0,63 & 0,73 & 0,67 & 0,69 & 0,62 & 0,62 & 0,75 & 2,0 & 8 \\
\hline$(2,10,5)$ & keine & 0,63 & 0,72 & 0,66 & 0,70 & 0,60 & 0,60 & 0,77 & 2,1 & 10 \\
\hline$(2,10,5)$ & Detre & 0,64 & 0,72 & 0,66 & 0,70 & 0,60 & 0,60 & 0,77 & 2,1 & 10 \\
\hline$(2,10,5)$ & SNV & 0,63 & 0,73 & 0,66 & 0,70 & 0,59 & 0,59 & 0,77 & 2,1 & 10 \\
\hline$(2,10,5)$ & SNVD & 0,63 & 0,73 & 0,66 & 0,70 & 0,59 & 0,59 & 0,77 & 2,1 & 10 \\
\hline$(2,10,5)$ & MSC & 0,62 & 0,73 & 0,66 & 0,70 & 0,59 & 0,59 & 0,78 & 2,1 & 11 \\
\hline$(2,20,10)$ & keine & 0,66 & 0,70 & 0,69 & 0,67 & 0,63 & 0,63 & 0,74 & 2,0 & 11 \\
\hline$(2,20,10)$ & Detrend & 0,66 & 0,70 & 0,69 & 0,67 & 0,63 & 0,63 & 0,74 & 2,0 & 11 \\
\hline$(2,20,10)$ & SNV & 0,66 & 0,70 & 0,69 & 0,68 & 0,61 & 0,61 & 0,76 & 2,0 & 11 \\
\hline$(2,20,10)$ & SNVD & 0,66 & 0,70 & 0,69 & 0,68 & 0,62 & 0,62 & 0,75 & 2,0 & 10 \\
\hline$(2,20,10)$ & MSC & 0,66 & 0,70 & 0,68 & 0,68 & 0,62 & 0,62 & 0,75 & 2,0 & 10 \\
\hline$(3,4,4)$ & keine & 0,65 & 0,71 & 0,69 & 0,67 & 0,65 & 0,65 & 0,72 & 1,9 & 7 \\
\hline$(3,4,4)$ & Detrend & 0,65 & 0,71 & 0,69 & 0,67 & 0,65 & 0,65 & 0,72 & 1,9 & 7 \\
\hline$(3,4,4)$ & SNV & 0,63 & 0,73 & 0,68 & 0,68 & 0,65 & 0,65 & 0,73 & 1,9 & 7 \\
\hline$(3,4,4)$ & SNVD & 0,63 & 0,73 & 0,68 & 0,68 & 0,65 & 0,65 & 0,73 & 1,9 & 7 \\
\hline$(3,4,4)$ & MSC & 0,63 & 0,73 & 0,68 & 0,68 & 0,64 & 0,64 & 0,73 & 1,9 & 7 \\
\hline
\end{tabular}


Tab. 21 Ergebnisse der Kalibration, Kreuzvalidation und Validation bei Verwendung verschiedener Ableitungen (DT) und Streulichtkorrekturen (SK) für die Parameter ÖI $\mathrm{LT}_{\mathrm{LT}}$, C18:1 $\mathrm{LT}_{\mathrm{LT}}$, Protein $_{\text {GES }}$ sowie 18:1 $1_{\text {GES }}$ in gemahlenen bzW. intakten Achänen

Öl ${ }_{L T}$, gemahlene Achänen

\begin{tabular}{|c|c|c|c|c|c|c|c|c|c|c|}
\hline Abl. & SK & SEC & $R^{2}$ & SECV & 1-VR & SEP & SEPC & $\mathrm{RSQ}$ & RPD & Terme \\
\hline$(0,0,1)$ & Detrend & 0,76 & 0,90 & 0,78 & 0,90 & 0,77 & 0,77 & 0,90 & 3,1 & 13 \\
\hline$(0,0,1)$ & MSC & 0,73 & 0,91 & 0,75 & 0,90 & 0,70 & 0,71 & 0,92 & 3,4 & 15 \\
\hline$(0,0,1)$ & keine & 0,76 & 0,90 & 0,79 & 0,89 & 0,76 & 0,77 & 0,90 & 3,2 & 14 \\
\hline$(0,0,1)$ & SNVD & 0,73 & 0,91 & 0,75 & 0,90 & 0,70 & 0,70 & 0,92 & 3,4 & 15 \\
\hline$(0,0,1)$ & SNV & 0,77 & 0,90 & 0,78 & 0,90 & 0,75 & 0,75 & 0,91 & 3,2 & 13 \\
\hline$(1,2,2)$ & Detrend & 0,71 & 0,91 & 0,76 & 0,90 & 0,73 & 0,73 & 0,91 & 3,3 & 12 \\
\hline$(1,2,2)$ & MSC & 0,71 & 0,91 & 0,75 & 0,91 & 0,70 & 0,70 & 0,92 & 3,5 & 12 \\
\hline$(1,2,2)$ & keine & 0,73 & 0,91 & 0,76 & 0,90 & 0,75 & 0,75 & 0,90 & 3,2 & 12 \\
\hline$(1,2,2)$ & SNVD & 0,70 & 0,92 & 0,75 & 0,90 & 0,71 & 0,71 & 0,91 & 3,4 & 12 \\
\hline$(1,2,2)$ & SNV & 0,72 & 0,91 & 0,75 & 0,90 & 0,72 & 0,72 & 0,91 & 3,4 & 11 \\
\hline$(1,4,4)$ & Detrend & 0,71 & 0,91 & 0,74 & 0,91 & 0,71 & 0,71 & 0,92 & 3,4 & 13 \\
\hline$(1,4,4)$ & MSC & 0,70 & 0,92 & 0,73 & 0,91 & 0,68 & 0,68 & 0,92 & 3,5 & 13 \\
\hline$(1,4,4)$ & keine & 0,72 & 0,91 & 0,75 & 0,90 & 0,72 & 0,72 & 0,91 & 3,4 & 13 \\
\hline$(1,4,4)$ & SNVD & 0,69 & 0,92 & 0,73 & 0,91 & 0,68 & 0,68 & 0,92 & 3,6 & 14 \\
\hline$(1,4,4)$ & SNV & 0,70 & 0,92 & 0,73 & 0,91 & 0,68 & 0,69 & 0,92 & 3,5 & 13 \\
\hline$(1,10,5)$ & Detrend & 0,72 & 0,91 & 0,75 & 0,91 & 0,72 & 0,72 & 0,91 & 3,4 & 13 \\
\hline$(1,10,5)$ & MSC & 0,70 & 0,92 & 0,73 & 0,91 & 0,68 & 0,68 & 0,92 & 3,6 & 14 \\
\hline$(1,10,5)$ & keine & 0,73 & 0,91 & 0,75 & 0,90 & 0,72 & 0,73 & 0,91 & 3,3 & 13 \\
\hline$(1,10,5)$ & SNVD & 0,70 & 0,92 & 0,73 & 0,91 & 0,69 & 0,69 & 0,92 & 3,5 & 14 \\
\hline$(1,10,5)$ & SNV & 0,70 & 0,92 & 0,73 & 0,91 & 0,67 & 0,68 & 0,92 & 3,6 & 14 \\
\hline$(2,4,4)$ & Detren & 0,73 & 0,91 & 0,79 & 0,89 & 0,74 & 0,74 & 0,91 & 3,3 & 10 \\
\hline$(2,4,4)$ & MSC & 0,71 & 0,91 & 0,77 & 0,90 & 0,71 & 0,71 & 0,91 & 3,4 & 11 \\
\hline$(2,4,4)$ & keine & 0,73 & 0,91 & 0,79 & 0,89 & 0,73 & 0,74 & 0,91 & 3,3 & 10 \\
\hline$(2,4,4)$ & SNVD & 0,71 & 0,91 & 0,77 & 0,90 & 0,71 & 0,71 & 0,91 & 3,4 & 11 \\
\hline$(2,4,4)$ & SNV & 0,71 & 0,91 & 0,77 & 0,90 & 0,71 & 0,71 & 0,91 & 3,4 & 11 \\
\hline$(2,10,5)$ & Detrend & 0,71 & 0,91 & 0,75 & 0,90 & 0,70 & 0,70 & 0,92 & 3,5 & 13 \\
\hline$(2,10,5)$ & MSC & 0,70 & 0,92 & 0,74 & 0,91 & 0,70 & 0,70 & 0,92 & 3,5 & 13 \\
\hline$(2,10,5)$ & keine & 0,71 & 0,91 & 0,75 & 0,90 & 0,70 & 0,70 & 0,92 & 3,5 & 13 \\
\hline$(2,10,5)$ & SNVD & 0,70 & 0,92 & 0,74 & 0,91 & 0,70 & 0,70 & 0,92 & 3,5 & 13 \\
\hline$(2,10,5)$ & SNV & 0,70 & 0,92 & 0,74 & 0,91 & 0,70 & 0,70 & 0,92 & 3,5 & 13 \\
\hline$(2,20,10)$ & Detrend & 0,74 & 0,91 & 0,77 & 0,90 & 0,73 & 0,74 & 0,91 & 3,3 & 13 \\
\hline$(2,20,10)$ & MSC & 0,71 & 0,91 & 0,74 & 0,91 & 0,71 & 0,71 & 0,91 & 3,4 & 14 \\
\hline$(2,20,10)$ & keine & 0,73 & 0,91 & 0,76 & 0,90 & 0,73 & 0,74 & 0,91 & 3,3 & 13 \\
\hline$(2,20,10)$ & SNVD & 0,72 & 0,91 & 0,75 & 0,91 & 0,71 & 0,72 & 0,91 & 3,4 & 13 \\
\hline$(2,20,10)$ & SNV & 0,71 & 0,91 & 0,74 & 0,91 & 0,70 & 0,71 & 0,92 & 3,4 & 14 \\
\hline$(3,4,4)$ & Detrenc & 0,73 & 0,91 & 0,81 & 0,89 & 0,76 & 0,76 & 0,90 & 3,2 & 11 \\
\hline$(3,4,4)$ & MSC & 0,70 & 0,92 & 0,79 & 0,89 & 0,71 & 0,72 & 0,91 & 3,4 & 13 \\
\hline$(3,4,4)$ & keine & 0,73 & 0,91 & 0,81 & 0,89 & 0,76 & 0,76 & 0,90 & 3,2 & 11 \\
\hline$(3,4,4)$ & SNVD & 0,70 & 0,92 & 0,79 & 0,89 & 0,72 & 0,72 & 0,91 & 3,4 & 13 \\
\hline$(3,4,4)$ & SNV & 0,70 & 0,92 & 0,79 & 0,89 & 0,72 & 0,72 & 0,91 & 3,4 & 13 \\
\hline
\end{tabular}


Fortsetzung Tab. 21

Öl ${ }_{L T}$, intakte Achänen

\begin{tabular}{|c|c|c|c|c|c|c|c|c|c|c|}
\hline Abl. & SK & SEC & $\mathrm{R}^{2}$ & SECV & $1-V R$ & SEP & SEPC & $\mathrm{RSQ}$ & RPD & Terme \\
\hline$(0,0,1)$ & Detrend & 1,03 & 0,81 & 1,07 & 0,79 & 1,06 & 1,06 & 0,79 & 2,2 & 16 \\
\hline$(0,0,1)$ & MSC & 1,07 & 0,79 & 1,11 & 0,78 & 1,11 & 1,11 & 0,77 & 2,1 & 16 \\
\hline$(0,0,1)$ & keine & 1,09 & 0,78 & 1,11 & 0,78 & 1,10 & 1,09 & 0,78 & 2,1 & 16 \\
\hline$(0,0,1)$ & SNVD & 1,02 & 0,81 & 1,06 & 0,80 & 1,00 & 1,00 & 0,82 & 2,3 & 16 \\
\hline$(0,0,1)$ & SNV & 1,14 & 0,76 & 1,14 & 0,76 & 1,18 & 1,18 & 0,75 & 2,0 & 16 \\
\hline$(1,2,2)$ & Detrend & 0,93 & 0,84 & 0,97 & 0,83 & 0,96 & 0,96 & 0,83 & 2,4 & 15 \\
\hline$(1,2,2)$ & MSC & 0,97 & 0,83 & 1,00 & 0,82 & 1,01 & 1,01 & 0,81 & 2,3 & 14 \\
\hline$(1,2,2)$ & keine & 0,94 & 0,84 & 0,99 & 0,82 & 0,97 & 0,97 & 0,83 & 2,4 & 15 \\
\hline$(1,2,2)$ & SNVD & 0,96 & 0,83 & 1,00 & 0,82 & 1,01 & 1,01 & 0,81 & 2,3 & 14 \\
\hline$(1,2,2)$ & SNV & 0,95 & 0,84 & 0,99 & 0,82 & 0,99 & 0,99 & 0,82 & 2,4 & 15 \\
\hline$(1,4,4)$ & Detrend & 0,93 & 0,84 & 0,96 & 0,83 & 0,95 & 0,95 & 0,84 & 2,5 & 15 \\
\hline$(1,4,4)$ & MSC & 0,97 & 0,83 & 0,99 & 0,82 & 1,01 & 1,01 & 0,81 & 2,3 & 14 \\
\hline$(1,4,4)$ & keine & 0,94 & 0,84 & 0,98 & 0,83 & 0,98 & 0,98 & 0,82 & 2,4 & 15 \\
\hline$(1,4,4)$ & SNVD & 0,95 & 0,84 & 0,98 & 0,83 & 0,99 & 0,99 & 0,82 & 2,4 & 15 \\
\hline$(1,4,4)$ & SNV & 0,95 & 0,84 & 0,98 & 0,83 & 0,99 & 0,99 & 0,82 & 2,3 & 15 \\
\hline$(1,10,5)$ & Detrend & 0,95 & 0,84 & 0,98 & 0,83 & 0,96 & 0,96 & 0,83 & 2,4 & 15 \\
\hline$(1,10,5)$ & MSC & 0,98 & 0,83 & 1,01 & 0,81 & 1,02 & 1,03 & 0,81 & 2,3 & 15 \\
\hline$(1,10,5)$ & keine & 0,99 & 0,82 & 1,01 & 0,81 & 0,99 & 0,99 & 0,82 & 2,4 & 14 \\
\hline$(1,10$ & SNVD & 0,97 & 0,83 & 1,00 & 0,82 & 1,01 & 1,01 & 0,81 & 2,3 & 15 \\
\hline$(1,10,5)$ & SNV & 0,98 & 0,83 & 1,00 & 0,82 & 1,02 & 1,02 & 0,81 & 2,3 & 15 \\
\hline$(2,4,4)$ & Detrend & 0,92 & 0,85 & 0,97 & 0,83 & 1,01 & 1,02 & 0,81 & 2,3 & 11 \\
\hline$(2,4,4)$ & MSC & 0,93 & 0,84 & 0,99 & 0,82 & 0,99 & 1,00 & 0,82 & 2,3 & 12 \\
\hline$(2,4,4)$ & keine & 0,92 & 0,85 & 0,97 & 0,83 & 1,02 & 1,02 & 0,81 & 2,3 & 11 \\
\hline$(2,4,4)$ & SNVD & 0,92 & 0,85 & 0,98 & 0,82 & 0,98 & 0,98 & 0,82 & 2,4 & 12 \\
\hline$(2,4,4)$ & SNV & 0,92 & 0,85 & 0,98 & 0,82 & 0,98 & 0,98 & 0,82 & 2,4 & 12 \\
\hline$(2,10,5)$ & Detrer & 0,93 & 0,85 & 0,96 & 0,83 & 0,99 & 1,00 & 0,82 & 2,3 & 13 \\
\hline$(2,10,5)$ & MSC & 0,93 & 0,84 & 0,96 & 0,83 & 0,97 & 0,97 & 0,83 & 2,4 & 14 \\
\hline$(2,10,5)$ & keine & 0,92 & 0,85 & 0,96 & 0,83 & 0,99 & 0,99 & 0,82 & 2,4 & 13 \\
\hline$(2,10,5)$ & SNVD & 0,93 & 0,84 & 0,96 & 0,83 & 0,98 & 0,99 & 0,82 & 2,4 & 14 \\
\hline$(2,10,5)$ & SNV & 0,93 & 0,84 & 0,96 & 0,83 & 0,98 & 0,98 & 0,82 & 2,4 & 14 \\
\hline$(2,20,10)$ & Detrend & 1,00 & 0,82 & 1,02 & 0,81 & 1,04 & 1,04 & 0,80 & 2,2 & 14 \\
\hline$(2,20,10)$ & MSC & 1,01 & 0,81 & 1,04 & 0,80 & 1,02 & 1,02 & 0,81 & 2,3 & 13 \\
\hline$(2,20,10)$ & keine & 1,01 & 0,81 & 1,03 & 0,81 & 1,04 & 1,04 & 0,80 & 2,2 & 13 \\
\hline$(2,20,10)$ & SNVD & 1,01 & 0,81 & 1,04 & 0,81 & 1,02 & 1,02 & 0,81 & 2,3 & 13 \\
\hline$(2,20,10)$ & SNV & 1,01 & 0,82 & 1,04 & 0,80 & 1,01 & 1,01 & 0,81 & 2,3 & 13 \\
\hline$(3,4,4)$ & Detrend & 0,93 & 0,84 & 1,02 & 0,81 & 1,02 & 1,02 & 0,81 & 2,3 & 12 \\
\hline$(3,4,4)$ & MSC & 0,94 & 0,84 & 1,03 & 0,81 & 1,01 & 1,02 & 0,81 & 2,3 & 12 \\
\hline$(3,4,4)$ & keine & 0,93 & 0,84 & 1,02 & 0,81 & 1,02 & 1,02 & 0,81 & 2,3 & 12 \\
\hline$(3,4,4)$ & SNVD & 0,93 & 0,84 & 1,03 & 0,81 & 1,04 & 1,04 & 0,80 & 2,2 & 12 \\
\hline$(3,4,4)$ & SNV & 0,93 & 0,84 & 1,03 & 0,81 & 1,04 & 1,04 & 0,80 & 2,2 & 12 \\
\hline
\end{tabular}


Fortsetzung Tab. 21

C181 LT, gemahlene Achänen

\begin{tabular}{|c|c|c|c|c|c|c|c|c|c|c|}
\hline Abl. & SK & SEC & $\mathrm{R}^{2}$ & SECV & 1-VR & SEP & SEPC & $\mathrm{RSQ}$ & RPD & Terme \\
\hline$(0,0,1)$ & Detrend & 0,73 & 0,88 & 0,82 & 0,85 & 0,76 & 0,76 & 0,88 & 2,8 & 16 \\
\hline$(0,0,1)$ & MSC & 0,85 & 0,84 & 0,92 & 0,81 & 0,90 & 0,91 & 0,82 & 2,4 & 16 \\
\hline$(0,0,1)$ & keine & 0,92 & 0,81 & 0,97 & 0,79 & 0,95 & 0,95 & 0,81 & 2,3 & 16 \\
\hline$(0,0,1)$ & SNVD & 0,76 & 0,87 & 0,80 & 0,86 & 0,76 & 0,76 & 0,87 & 2,8 & 16 \\
\hline$(0,0,1)$ & SNV & 0,87 & 0,83 & 0,91 & 0,82 & 0,89 & 0,90 & 0,83 & 2,4 & 16 \\
\hline$(1,2,2)$ & Detrend & 0,48 & 0,95 & 0,51 & 0,94 & 0,52 & 0,52 & 0,94 & 4,1 & 16 \\
\hline$(1,2,2)$ & MSC & 0,44 & 0,96 & 0,48 & 0,95 & 0,44 & 0,44 & 0,96 & 4,9 & 16 \\
\hline$(1,2,2)$ & keine & 0,46 & 0,95 & 0,51 & 0,94 & 0,49 & 0,49 & 0,95 & 4,4 & 16 \\
\hline$(1,2,2)$ & SNVD & 0,44 & 0,96 & 0,49 & 0,95 & 0,44 & 0,44 & 0,96 & 4,9 & 16 \\
\hline$(1,2,2)$ & SNV & 0,44 & 0,96 & 0,49 & 0,95 & 0,44 & 0,44 & 0,96 & 4,9 & 16 \\
\hline$(1,4,4)$ & Detrend & 0,46 & 0,95 & 0,49 & 0,95 & 0,42 & 0,42 & 0,96 & 5,1 & 16 \\
\hline$(1,4,4)$ & MSC & 0,42 & 0,96 & 0,46 & 0,95 & 0,37 & 0,37 & 0,97 & 5,8 & 16 \\
\hline$(1,4,4)$ & keine & 0,46 & 0,95 & 0,48 & 0,95 & 0,41 & 0,41 & 0,96 & 5,2 & 16 \\
\hline$(1,4,4)$ & SNVD & 0,41 & 0,96 & 0,46 & 0,95 & 0,37 & 0,37 & 0,97 & 5,8 & 16 \\
\hline$(1,4,4)$ & SNV & 0,42 & 0,96 & 0,46 & 0,95 & 0,37 & 0,37 & 0,97 & 5,8 & 16 \\
\hline$(1,10,5)$ & Detren & 0,53 & 0,94 & 0,57 & 0,93 & 0,52 & 0,52 & 0,94 & 4,1 & 16 \\
\hline$(1,10$ & MSC & 0,52 & 0,94 & 0,56 & 0,93 & 0,50 & 0,50 & 0,95 & 4,3 & 16 \\
\hline$(1,10,5)$ & keine & 0,55 & 0,93 & 0,57 & 0,93 & 0,54 & 0,54 & 0,94 & 4,0 & 16 \\
\hline$(1,10$ & SNVD & 0,50 & 0,95 & 0,55 & 0,93 & 0,49 & 0,49 & 0,95 & 4,4 & 16 \\
\hline$(1,10,5)$ & SNV & 0,52 & 0,94 & 0,55 & 0,93 & 0,51 & 0,51 & 0,94 & 4,2 & 16 \\
\hline$(2,4,4)$ & Detrend & 0,38 & 0,97 & 0,45 & 0,96 & 0,41 & 0,41 & 0,96 & 5,2 & 15 \\
\hline$(2,4,4)$ & MSC & 0,33 & 0,98 & 0,39 & 0,97 & 0,36 & 0,36 & 0,97 & 5,9 & 15 \\
\hline$(2,4,4)$ & keine & 0,38 & 0,97 & 0,45 & 0,96 & 0,41 & 0,41 & 0,96 & 5,3 & 15 \\
\hline$(2,4,4)$ & SNVD & 0,33 & 0,98 & 0,39 & 0,97 & 0,37 & 0,37 & 0,97 & 5,8 & 15 \\
\hline$(2,4,4)$ & SNV & 0,33 & 0,98 & 0,39 & 0,97 & 0,37 & 0,36 & 0,97 & 5,9 & 15 \\
\hline$(2,10,5)$ & Detrend & 0,49 & 0,95 & 0,52 & 0,94 & 0,48 & 0,47 & 0,95 & 4,5 & 15 \\
\hline$(2,10,5)$ & MSC & 0,44 & 0,96 & 0,47 & 0,95 & 0,39 & 0,39 & 0,97 & 5,5 & 16 \\
\hline$(2,10,5)$ & keine & 0,49 & 0,95 & 0,52 & 0,94 & 0,48 & 0,47 & 0,95 & 4,5 & 15 \\
\hline$(2,10,5)$ & SNVD & 0,44 & 0,96 & 0,47 & 0,95 & 0,39 & 0,39 & 0,97 & 5,5 & 16 \\
\hline$(2,10,5)$ & SNV & 0,44 & 0,96 & 0,47 & 0,95 & 0,39 & 0,38 & 0,97 & 5,6 & 16 \\
\hline$(2,20,10)$ & Detrend & 0,73 & 0,88 & 0,77 & 0,87 & 0,74 & 0,73 & 0,88 & 2,9 & 16 \\
\hline$(2,20,10)$ & MSC & 0,73 & 0,88 & 0,76 & 0,87 & 0,68 & 0,67 & 0,90 & 3,1 & 16 \\
\hline$(2,20,10)$ & keine & 0,73 & 0,88 & 0,77 & 0,87 & 0,72 & 0,72 & 0,89 & 3,0 & 16 \\
\hline$(2,20,10)$ & SNVD & 0,73 & 0,88 & 0,76 & 0,87 & 0,69 & 0,69 & 0,90 & 3,1 & 16 \\
\hline$(2,20,10)$ & SNV & 0,72 & 0,89 & 0,75 & 0,87 & 0,66 & 0,66 & 0,91 & 3,3 & 16 \\
\hline$(3,4,4)$ & Detrend & 0,39 & 0,97 & 0,46 & 0,95 & 0,45 & 0,45 & 0,96 & 4,7 & 14 \\
\hline$(3,4,4)$ & MSC & 0,34 & 0,97 & 0,40 & 0,96 & 0,38 & 0,38 & 0,97 & 5,7 & 15 \\
\hline$(3,4,4)$ & keine & 0,39 & 0,97 & 0,46 & 0,95 & 0,45 & 0,45 & 0,96 & 4,7 & 14 \\
\hline$(3,4,4)$ & SNVD & 0,34 & 0,97 & 0,40 & 0,96 & 0,37 & 0,37 & 0,97 & 5,8 & 15 \\
\hline$(3,4,4)$ & SNV & 0,34 & 0,97 & 0,40 & 0,96 & 0,37 & 0,37 & 0,97 & 5,8 & 15 \\
\hline
\end{tabular}


Fortsetzung Tab. 21

C18:1 $1_{\mathrm{LT}}$, intakte Achänen

\begin{tabular}{|c|c|c|c|c|c|c|c|c|c|c|}
\hline Abl. & SK & SEC & $R^{2}$ & SECV & $1-V R$ & SEP & SEPC & $\mathrm{RSQ}$ & RPD & Terme \\
\hline$(0,0,1)$ & Detrend & 0,90 & 0,77 & 0,95 & 0,75 & 0,88 & 0,89 & 0,79 & 2,2 & 15 \\
\hline$(0,0,1)$ & MSC & 0,95 & 0,75 & 0,99 & 0,73 & 0,89 & 0,89 & 0,79 & 2,2 & 13 \\
\hline$(0,0,1)$ & keine & 0,91 & 0,77 & 0,96 & 0,75 & 0,88 & 0,88 & 0,79 & 2,2 & 15 \\
\hline$(0,0,1)$ & SNVD & 0,91 & 0,77 & 0,96 & 0,74 & 0,87 & 0,87 & 0,80 & 2,2 & 15 \\
\hline$(0,0,1)$ & SNV & 0,93 & 0,76 & 0,98 & 0,73 & 0,88 & 0,88 & 0,79 & 2,2 & 15 \\
\hline$(1,2,2)$ & Detrend & 0,86 & 0,79 & 0,90 & 0,78 & 0,83 & 0,83 & 0,82 & 2,3 & 11 \\
\hline$(1,2,2)$ & MSC & 0,84 & 0,80 & 0,89 & 0,78 & 0,78 & 0,78 & 0,84 & 2,5 & 12 \\
\hline$(1,2,2)$ & keine & 0,82 & 0,81 & 0,89 & 0,78 & 0,78 & 0,78 & 0,84 & 2,5 & 13 \\
\hline$(1,2,2)$ & SNVD & 0,85 & 0,80 & 0,90 & 0,78 & 0,80 & 0,81 & 0,83 & 2,4 & 11 \\
\hline$(1,2,2)$ & SNV & 0,84 & 0,80 & 0,89 & 0,78 & 0,78 & 0,78 & 0,84 & 2,5 & 11 \\
\hline$(1,4,4)$ & Detrend & 0,82 & 0,81 & 0,88 & 0,79 & 0,79 & 0,79 & 0,83 & 2,4 & 14 \\
\hline$(1,4,4)$ & MSC & 0,84 & 0,80 & 0,89 & 0,78 & 0,79 & 0,79 & 0,83 & 2,4 & 12 \\
\hline$(1,4,4)$ & keine & 0,83 & 0,81 & 0,88 & 0,79 & 0,78 & 0,78 & 0,84 & 2,5 & 14 \\
\hline$(1,4,4)$ & SNVD & 0,83 & 0,81 & 0,88 & 0,79 & 0,76 & 0,76 & 0,85 & 2,5 & 13 \\
\hline$(1,4,4)$ & SNV & 0,84 & 0,81 & 0,88 & 0,78 & 0,77 & 0,77 & 0,84 & 2,5 & 12 \\
\hline$(1,10,5)$ & Detren & 0,85 & 0,80 & 0,89 & 0,78 & 0,79 & 0,79 & 0,84 & 2,4 & 13 \\
\hline$(1,10,5)$ & MSC & 0,85 & 0,80 & 0,90 & 0,78 & 0,80 & 0,80 & 0,83 & 2,4 & 12 \\
\hline$(1,10,5)$ & keine & 0,85 & 0,80 & 0,89 & 0,78 & 0,77 & 0,77 & 0,84 & 2,5 & 13 \\
\hline$(1,10,5)$ & SNVD & 0,84 & 0,80 & 0,89 & 0,78 & 0,76 & 0,76 & 0,85 & 2,5 & 13 \\
\hline$(1,10,5)$ & SNV & 0,85 & 0,80 & 0,89 & 0,78 & 0,79 & 0,79 & 0,83 & 2,4 & 12 \\
\hline$(2,4,4)$ & Detren & 0,83 & 0,81 & 0,88 & 0,78 & 0,85 & 0,85 & 0,81 & 2,3 & 8 \\
\hline$(2,4,4)$ & MSC & 0,83 & 0,81 & 0,88 & 0,79 & 0,83 & 0,83 & 0,82 & 2,3 & 9 \\
\hline$(2,4,4)$ & keine & 0,83 & 0,81 & 0,89 & 0,78 & 0,85 & 0,85 & 0,81 & 2,3 & 8 \\
\hline$(2,4,4)$ & SNVD & 0,84 & 0,80 & 0,89 & 0,78 & 0,86 & 0,86 & 0,80 & 2,2 & 8 \\
\hline$(2,4,4)$ & SNV & 0,82 & 0,81 & 0,88 & 0,78 & 0,83 & 0,83 & 0,82 & 2,3 & 9 \\
\hline$(2,10,5)$ & Detrer & 0,84 & 0,80 & 0,88 & 0,78 & 0,79 & 0,79 & 0,84 & 2,4 & 10 \\
\hline$(2,10$ & MSC & 0,82 & 0,82 & 0,87 & 0,79 & 0,78 & 0,78 & 0,84 & 2,5 & 12 \\
\hline$(2,10,5)$ & keine & 0,83 & 0,81 & 0,88 & 0,78 & 0,80 & 0,81 & 0,83 & 2,4 & 11 \\
\hline$(2,10,5)$ & SNVD & 0,82 & 0,81 & 0,87 & 0,79 & 0,78 & 0,78 & 0,84 & 2,5 & 11 \\
\hline$(2,10,5)$ & SNV & 0,82 & 0,81 & 0,87 & 0,79 & 0,78 & 0,78 & 0,84 & 2,5 & 11 \\
\hline$(2,20,10)$ & Detrer & 0,86 & 0,79 & 0,91 & 0,77 & 0,80 & 0,80 & 0,83 & 2,4 & 14 \\
\hline$(2,20,10)$ & MSC & 0,87 & 0,79 & 0,92 & 0,76 & 0,80 & 0,80 & 0,83 & 2,4 & 13 \\
\hline$(2,20,10)$ & keine & 0,87 & 0,79 & 0,92 & 0,76 & 0,81 & 0,81 & 0,83 & 2,4 & 13 \\
\hline$(2,20,10)$ & SNVD & 0,87 & 0,79 & 0,92 & 0,76 & 0,80 & 0,81 & 0,83 & 2,4 & 12 \\
\hline$(2,20,10)$ & SNV & 0,87 & 0,79 & 0,93 & 0,76 & 0,80 & 0,81 & 0,83 & 2,4 & 12 \\
\hline$(3,4,4)$ & Detrend & 0,76 & 0,84 & 0,89 & 0,78 & 0,81 & 0,81 & 0,82 & 2,4 & 13 \\
\hline$(3,4,4)$ & MSC & 0,79 & 0,82 & 0,90 & 0,77 & 0,83 & 0,83 & 0,82 & 2,3 & 11 \\
\hline$(3,4,4)$ & keine & 0,76 & 0,84 & 0,89 & 0,78 & 0,81 & 0,81 & 0,82 & 2,4 & 13 \\
\hline$(3,4,4)$ & SNVD & 0,79 & 0,83 & 0,90 & 0,78 & 0,83 & 0,82 & 0,82 & 2,3 & 11 \\
\hline$(3,4,4)$ & SNV & 0,79 & 0,83 & 0,90 & 0,78 & 0,83 & 0,82 & 0,82 & 2,3 & 11 \\
\hline
\end{tabular}


Fortsetzung Tab. 21

Protein $_{\mathrm{GES}}$, gemahlene Achänen

\begin{tabular}{|c|c|c|c|c|c|c|c|c|c|c|}
\hline Abl. & SK & SEC & $\mathrm{R}^{2}$ & SECV & 1-VR & SEP & SEPC & $\mathrm{RSQ}$ & RPD & Terme \\
\hline$(0,0,1)$ & Detrend & 0,71 & 0,95 & 0,73 & 0,95 & 0,82 & 0,82 & 0,94 & 4,0 & 14 \\
\hline$(0,0,1)$ & MSC & 0,69 & 0,95 & 0,71 & 0,95 & 0,76 & 0,76 & 0,95 & 4,3 & 15 \\
\hline$(0,0,1)$ & keine & 0,70 & 0,95 & 0,72 & 0,95 & 0,79 & 0,78 & 0,94 & 4,2 & 14 \\
\hline$(0,0,1)$ & SNVD & 0,69 & 0,96 & 0,70 & 0,95 & 0,74 & 0,74 & 0,95 & 4,5 & 14 \\
\hline$(0,0,1)$ & SNV & 0,69 & 0,95 & 0,71 & 0,95 & 0,75 & 0,76 & 0,95 & 4,4 & 14 \\
\hline$(1,2,2)$ & Detrend & 0,67 & 0,96 & 0,70 & 0,95 & 0,82 & 0,82 & 0,94 & 4,0 & 12 \\
\hline$(1,2,2)$ & MSC & 0,63 & 0,96 & 0,66 & 0,96 & 0,68 & 0,68 & 0,96 & 4,8 & 13 \\
\hline$(1,2,2)$ & keine & 0,65 & 0,96 & 0,69 & 0,95 & 0,77 & 0,77 & 0,95 & 4,3 & 14 \\
\hline$(1,2,2)$ & SNVD & 0,62 & 0,96 & 0,66 & 0,96 & 0,66 & 0,66 & 0,96 & 5,0 & 14 \\
\hline$(1,2,2)$ & SNV & 0,63 & 0,96 & 0,66 & 0,96 & 0,68 & 0,67 & 0,96 & 4,9 & 13 \\
\hline$(1,4,4)$ & Detrend & 0,66 & 0,96 & 0,69 & 0,95 & 0,80 & 0,80 & 0,94 & 4,1 & 14 \\
\hline$(1,4,4)$ & MSC & 0,63 & 0,96 & 0,66 & 0,96 & 0,68 & 0,68 & 0,96 & 4,9 & 14 \\
\hline$(1,4,4)$ & keine & 0,67 & 0,96 & 0,70 & 0,95 & 0,79 & 0,78 & 0,94 & 4,2 & 13 \\
\hline$(1,4,4)$ & SNVD & 0,62 & 0,96 & 0,66 & 0,96 & 0,67 & 0,67 & 0,96 & 4,9 & 14 \\
\hline$(1,4,4)$ & SNV & 0,63 & 0,96 & 0,66 & 0,96 & 0,69 & 0,69 & 0,96 & 4,7 & 13 \\
\hline$(1,10,5)$ & Detrend & 0,69 & 0,96 & 0,72 & 0,95 & 0,81 & 0,81 & 0,94 & 4,0 & 13 \\
\hline$(1,10,5)$ & MSC & 0,65 & 0,96 & 0,68 & 0,96 & 0,70 & 0,70 & 0,96 & 4,7 & 14 \\
\hline$(1,10,5)$ & keine & 0,68 & 0,96 & 0,71 & 0,95 & 0,80 & 0,80 & 0,94 & 4,1 & 12 \\
\hline$(1,10,5)$ & SNVD & 0,64 & 0,96 & 0,67 & 0,96 & 0,69 & 0,69 & 0,96 & 4,8 & 15 \\
\hline$(1,10,5)$ & SNV & 0,65 & 0,96 & 0,68 & 0,96 & 0,70 & 0,70 & 0,96 & 4,7 & 14 \\
\hline$(2,4,4)$ & Detrend & 0,65 & 0,96 & 0,69 & 0,95 & 0,77 & 0,77 & 0,95 & 4,2 & 10 \\
\hline$(2,4,4)$ & MSC & 0,61 & 0,97 & 0,65 & 0,96 & 0,69 & 0,69 & 0,96 & 4,8 & 11 \\
\hline$(2,4,4)$ & keine & 0,65 & 0,96 & 0,69 & 0,95 & 0,77 & 0,77 & 0,95 & 4,2 & 10 \\
\hline$(2,4,4)$ & SNVD & 0,61 & 0,97 & 0,65 & 0,96 & 0,70 & 0,70 & 0,96 & 4,7 & 11 \\
\hline$(2,4,4)$ & SNV & 0,61 & 0,97 & 0,65 & 0,96 & 0,69 & 0,70 & 0,96 & 4,7 & 11 \\
\hline$(2,10,5)$ & Detrend & 0,67 & 0,96 & 0,71 & 0,95 & 0,83 & 0,83 & 0,94 & 4,0 & 13 \\
\hline$(2,10,5)$ & MSC & 0,61 & 0,96 & 0,65 & 0,96 & 0,71 & 0,71 & 0,95 & 4,7 & 14 \\
\hline$(2,10,5)$ & keine & 0,67 & 0,96 & 0,71 & 0,95 & 0,83 & 0,82 & 0,94 & 4,0 & 13 \\
\hline$(2,10,5)$ & SNVD & 0,61 & 0,97 & 0,64 & 0,96 & 0,71 & 0,71 & 0,95 & 4,6 & 14 \\
\hline$(2,10,5)$ & SNV & 0,61 & 0,97 & 0,64 & 0,96 & 0,71 & 0,71 & 0,95 & 4,6 & 14 \\
\hline$(2,20,10)$ & Detrend & 0,70 & 0,95 & 0,74 & 0,95 & 0,84 & 0,84 & 0,94 & 3,9 & 13 \\
\hline$(2,20,10)$ & MSC & 0,67 & 0,96 & 0,69 & 0,95 & 0,74 & 0,75 & 0,95 & 4,4 & 13 \\
\hline$(2,20,10)$ & keine & 0,70 & 0,95 & 0,73 & 0,95 & 0,84 & 0,84 & 0,94 & 3,9 & 13 \\
\hline$(2,20,10)$ & SNVD & 0,68 & 0,96 & 0,70 & 0,95 & 0,74 & 0,74 & 0,95 & 4,4 & 12 \\
\hline$(2,20,10)$ & SNV & 0,67 & 0,96 & 0,69 & 0,95 & 0,74 & 0,74 & 0,95 & 4,4 & 13 \\
\hline$(3,4,4)$ & Detrend & 0,64 & 0,96 & 0,70 & 0,95 & 0,76 & 0,75 & 0,95 & 4,3 & 10 \\
\hline$(3,4,4)$ & MSC & 0,57 & 0,97 & 0,65 & 0,96 & 0,65 & 0,64 & 0,96 & 5,1 & 13 \\
\hline$(3,4,4)$ & keine & 0,64 & 0,96 & 0,70 & 0,95 & 0,76 & 0,75 & 0,95 & 4,3 & 10 \\
\hline$(3,4,4)$ & SNVD & 0,57 & 0,97 & 0,65 & 0,96 & 0,64 & 0,64 & 0,96 & 5,1 & 13 \\
\hline$(3,4,4)$ & SNV & 0,57 & 0,97 & 0,65 & 0,96 & 0,64 & 0,64 & 0,96 & 5,1 & 13 \\
\hline
\end{tabular}


Fortsetzung Tab. 21

Protein $_{\mathrm{GES}}$, intakte Achänen

\begin{tabular}{|c|c|c|c|c|c|c|c|c|c|c|}
\hline Abl. & SK & SEC & $\mathrm{R}^{2}$ & SECV & $1-V R$ & SEP & SEPC & $\mathrm{RSQ}$ & RPD & Terme \\
\hline$(0,0,1)$ & Detrend & 0,92 & 0,84 & 0,95 & 0,83 & 0,99 & 1,00 & 0,80 & 2,3 & 15 \\
\hline$(0,0,1)$ & MSC & 0,93 & 0,84 & 0,95 & 0,83 & 1,02 & 1,02 & 0,79 & 2,2 & 16 \\
\hline$(0,0,1)$ & keine & 0,94 & 0,83 & 0,96 & 0,83 & 1,01 & 1,02 & 0,80 & 2,2 & 16 \\
\hline$(0,0,1)$ & SNVD & 0,91 & 0,84 & 0,93 & 0,83 & 1,00 & 1,00 & 0,80 & 2,2 & 15 \\
\hline$(0,0,1)$ & SNV & 0,96 & 0,82 & 0,97 & 0,82 & 1,04 & 1,05 & 0,78 & 2,2 & 15 \\
\hline$(1,2,2)$ & Detrend & 0,79 & 0,88 & 0,86 & 0,86 & 0,87 & 0,87 & 0,85 & 2,6 & 15 \\
\hline$(1,2,2)$ & MSC & 0,77 & 0,89 & 0,83 & 0,87 & 0,86 & 0,86 & 0,85 & 2,6 & 15 \\
\hline$(1,2,2)$ & keine & 0,79 & 0,88 & 0,86 & 0,86 & 0,87 & 0,87 & 0,85 & 2,6 & 15 \\
\hline$(1,2,2)$ & SNVD & 0,77 & 0,89 & 0,83 & 0,87 & 0,86 & 0,86 & 0,85 & 2,6 & 15 \\
\hline$(1,2,2)$ & SNV & 0,81 & 0,88 & 0,86 & 0,86 & 0,89 & 0,89 & 0,84 & 2,5 & 14 \\
\hline$(1,4,4)$ & Detrend & 0,79 & 0,88 & 0,85 & 0,86 & 0,87 & 0,87 & 0,85 & 2,6 & 15 \\
\hline$(1,4,4)$ & MSC & 0,76 & 0,89 & 0,82 & 0,87 & 0,85 & 0,85 & 0,86 & 2,6 & 15 \\
\hline$(1,4,4)$ & keine & 0,79 & 0,88 & 0,85 & 0,86 & 0,85 & 0,86 & 0,85 & 2,6 & 15 \\
\hline$(1,4,4)$ & SNVD & 0,77 & 0,89 & 0,82 & 0,87 & 0,86 & 0,86 & 0,85 & 2,6 & 15 \\
\hline$(1,4,4)$ & SNV & 0,78 & 0,88 & 0,84 & 0,87 & 0,88 & 0,89 & 0,84 & 2,5 & 15 \\
\hline$(1,10,5)$ & Detrer & 0,83 & 0,87 & 0,88 & 0,85 & 0,93 & 0,93 & 0,83 & 2,4 & 14 \\
\hline$(1,10,5)$ & MSC & 0,81 & 0,88 & 0,84 & 0,87 & 0,90 & 0,90 & 0,84 & 2,5 & 15 \\
\hline$(1,10,5)$ & keine & 0,79 & 0,88 & 0,84 & 0,87 & 0,85 & 0,86 & 0,85 & 2,6 & 16 \\
\hline$(1,10,5)$ & SNVD & 0,79 & 0,88 & 0,83 & 0,87 & 0,89 & 0,89 & 0,84 & 2,5 & 15 \\
\hline$(1,10,5)$ & SNV & 0,81 & 0,88 & 0,86 & 0,86 & 0,91 & 0,92 & 0,83 & 2,5 & 15 \\
\hline$(2,4,4)$ & Detren & 0,73 & 0,90 & 0,82 & 0,87 & 0,82 & 0,83 & 0,87 & 2,7 & 13 \\
\hline$(2,4,4)$ & MSC & 0,74 & 0,90 & 0,81 & 0,87 & 0,80 & 0,81 & 0,87 & 2,8 & 12 \\
\hline$(2,4,4)$ & keine & 0,73 & 0,90 & 0,82 & 0,87 & 0,82 & 0,83 & 0,86 & 2,7 & 13 \\
\hline$(2,4,4)$ & SNVD & 0,73 & 0,90 & 0,82 & 0,87 & 0,79 & 0,80 & 0,88 & 2,8 & 12 \\
\hline$(2,4,4)$ & SNV & 0,73 & 0,90 & 0,82 & 0,87 & 0,79 & 0,80 & 0,87 & 2,8 & 12 \\
\hline$(2,10,5)$ & Detren & 0,74 & 0,89 & 0,80 & 0,88 & 0,82 & 0,82 & 0,87 & 2,7 & 14 \\
\hline$(2,10,5)$ & MSC & 0,75 & 0,89 & 0,80 & 0,88 & 0,82 & 0,82 & 0,87 & 2,7 & 13 \\
\hline$(2,10,5)$ & keine & 0,74 & 0,89 & 0,80 & 0,88 & 0,82 & 0,82 & 0,87 & 2,7 & 14 \\
\hline$(2,10,5)$ & SNVD & 0,74 & 0,90 & 0,79 & 0,88 & 0,82 & 0,82 & 0,87 & 2,7 & 13 \\
\hline$(2,10,5)$ & SNV & 0,74 & 0,90 & 0,80 & 0,88 & 0,82 & 0,82 & 0,87 & 2,7 & 13 \\
\hline$(2,20,10)$ & Detrend & 0,85 & 0,86 & 0,88 & 0,85 & 0,96 & 0,96 & 0,82 & 2,3 & 14 \\
\hline$(2,20,10)$ & MSC & 0,85 & 0,86 & 0,89 & 0,85 & 0,95 & 0,95 & 0,82 & 2,4 & 13 \\
\hline$(2,20,10)$ & keine & 0,84 & 0,87 & 0,88 & 0,85 & 0,96 & 0,97 & 0,81 & 2,3 & 14 \\
\hline$(2,20,10)$ & SNVD & 0,83 & 0,87 & 0,86 & 0,86 & 0,93 & 0,93 & 0,83 & 2,4 & 14 \\
\hline$(2,20,10)$ & SNV & 0,83 & 0,87 & 0,86 & 0,86 & 0,93 & 0,94 & 0,83 & 2,4 & 14 \\
\hline$(3,4,4)$ & Detrend & 0,79 & 0,88 & 0,88 & 0,85 & 0,86 & 0,87 & 0,85 & 2,6 & 10 \\
\hline$(3,4,4)$ & MSC & 0,79 & 0,88 & 0,88 & 0,85 & 0,84 & 0,84 & 0,86 & 2,7 & 10 \\
\hline$(3,4,4)$ & keine & 0,79 & 0,88 & 0,88 & 0,85 & 0,86 & 0,87 & 0,85 & 2,6 & 10 \\
\hline$(3,4,4)$ & SNVD & 0,79 & 0,88 & 0,88 & 0,85 & 0,86 & 0,86 & 0,86 & 2,6 & 10 \\
\hline$(3,4,4)$ & SNV & 0,79 & 0,88 & 0,88 & 0,85 & 0,86 & 0,86 & 0,86 & 2,6 & 10 \\
\hline
\end{tabular}


Fortsetzung Tab. 21

C181 $\mathrm{GES}$, gemahlene Achänen

\begin{tabular}{|c|c|c|c|c|c|c|c|c|c|c|}
\hline Abl. & SK & SEC & $\mathrm{R}^{2}$ & SECV & 1-VR & SEP & SEPC & $\mathrm{RSQ}$ & RPD & Terme \\
\hline$(0,0,1)$ & Detrend & 2,70 & 0,99 & 2,85 & 0,99 & 2,49 & 2,50 & 0,99 & 9,9 & 16 \\
\hline$(0,0,1)$ & MSC & 1,69 & 1,00 & 1,74 & 1,00 & 1,46 & 1,46 & 1,00 & 17,0 & 16 \\
\hline$(0,0,1)$ & keine & 2,80 & 0,99 & 2,88 & 0,99 & 2,77 & 2,77 & 0,99 & 8,9 & 16 \\
\hline$(0,0,1)$ & SNVD & 1,53 & 1,00 & 1,64 & 1,00 & 1,37 & 1,38 & 1,00 & 18,0 & 16 \\
\hline$(0,0,1)$ & SNV & 1,73 & 1,00 & 1,78 & 0,99 & 1,45 & 1,45 & 1,00 & 17,0 & 16 \\
\hline$(1,2,2)$ & Detrend & 2,19 & 0,99 & 2,36 & 0,99 & 2,24 & 2,25 & 0,99 & 11,0 & 15 \\
\hline$(1,2,2)$ & MSC & 1,03 & 1,00 & 1,15 & 1,00 & 1,00 & 1,00 & 1,00 & 24,8 & 16 \\
\hline$(1,2,2)$ & keine & 2,16 & 0,99 & 2,31 & 0,99 & 2,40 & 2,40 & 0,99 & 10,3 & 15 \\
\hline$(1,2,2)$ & SNVD & 1,11 & 1,00 & 1,19 & 1,00 & 1,07 & 1,07 & 1,00 & 23,2 & 15 \\
\hline$(1,2,2)$ & SNV & 1,04 & 1,00 & 1,14 & 1,00 & 1,01 & 1,01 & 1,00 & 24,6 & 16 \\
\hline$(1,4,4)$ & Detren & 2,12 & 0,99 & 2,26 & 0,99 & 2,25 & 2,25 & 0,99 & 11,0 & 16 \\
\hline$(1,4,4)$ & MSC & 1,08 & 1,00 & 1,16 & 1,00 & 1,01 & 1,02 & 1,00 & 24,4 & 16 \\
\hline$(1,4,4)$ & keine & 2,06 & 0,99 & 2,24 & 0,99 & 2,40 & 2,40 & 0,99 & 10,3 & 16 \\
\hline$(1,4,4)$ & SNVD & 1,12 & 1,00 & 1,17 & 1,00 & 1,07 & 1,07 & 1,00 & 23,2 & 15 \\
\hline$(1,4,4)$ & SNV & 1,11 & 1,00 & 1,18 & 1,00 & 1,03 & 1,03 & 1,00 & 24,1 & 15 \\
\hline$(1,10,5)$ & Detren & 2,32 & 0,99 & 2,45 & 0,99 & 2,41 & 2,41 & 0,99 & 10,3 & 15 \\
\hline$(1,10$ & MSC & 1,23 & 1,00 & 1,29 & 1,00 & 1,11 & 1,12 & 1,00 & 22,2 & 15 \\
\hline$(1,10,5)$ & keine & 2,25 & 0,99 & 2,37 & 0,99 & 2,46 & 2,46 & 0,99 & 10,0 & 16 \\
\hline$(1,10$ & SNVD & 1,24 & 1,00 & 1,27 & 1,00 & 1,16 & 1,17 & 1,00 & 21,2 & 15 \\
\hline$(1,10,5)$ & SNV & 1,21 & 1,00 & 1,27 & 1,00 & 1,10 & 1,10 & 1,00 & 22,5 & 15 \\
\hline$(2,4,4)$ & Detren & 2,03 & 0,99 & 2,26 & 0,99 & 2,25 & 2,25 & 0,99 & 11,0 & 14 \\
\hline$(2,4,4)$ & MSC & 0,93 & 1,00 & 1,05 & 1,00 & 0,89 & 0,89 & 1,00 & 27,7 & 15 \\
\hline$(2,4,4)$ & keine & 2,01 & 0,99 & 2,25 & 0,99 & 2,18 & 2,19 & 0,99 & 11,3 & 14 \\
\hline$(2,4,4)$ & SNVD & 0,92 & 1,00 & 1,03 & 1,00 & 0,89 & 0,90 & 1,00 & 27,6 & 15 \\
\hline$(2,4,4)$ & SNV & 0,92 & 1,00 & 1,02 & 1,00 & 0,89 & 0,89 & 1,00 & 27,7 & 15 \\
\hline$(2,10,5)$ & Detrend & 2,13 & 0,99 & 2,34 & 0,99 & 2,32 & 2,32 & 0,99 & 10,7 & 16 \\
\hline$(2,10,5)$ & MSC & 1,06 & 1,00 & 1,15 & 1,00 & 0,98 & 0,98 & 1,00 & 25,1 & 16 \\
\hline$(2,10,5)$ & keine & 2,19 & 0,99 & 2,40 & 0,99 & 2,39 & 2,40 & 0,99 & 10,3 & 15 \\
\hline$(2,10,5)$ & SNVD & 1,05 & 1,00 & 1,14 & 1,00 & 0,99 & 0,99 & 1,00 & 25,0 & 16 \\
\hline$(2,10,5)$ & SNV & 1,05 & 1,00 & 1,14 & 1,00 & 1,00 & 1,00 & 1,00 & 24,8 & 16 \\
\hline$(2,20,10)$ & Detrend & 2,66 & 0,99 & 2,86 & 0,99 & 2,64 & 2,65 & 0,99 & 9,3 & 16 \\
\hline$(2,20,10)$ & MSC & 1,52 & 1,00 & 1,61 & 1,00 & 1,37 & 1,38 & 1,00 & 18,0 & 16 \\
\hline$(2,20,10)$ & keine & 2,76 & 0,99 & 2,89 & 0,99 & 2,71 & 2,71 & 0,99 & 9,1 & 15 \\
\hline$(2,20,10)$ & SNVD & 1,53 & 1,00 & 1,62 & 1,00 & 1,39 & 1,40 & 1,00 & 17,7 & 16 \\
\hline$(2,20,10)$ & SNV & 1,52 & 1,00 & 1,61 & 1,00 & 1,39 & 1,39 & 1,00 & 17,8 & 16 \\
\hline$(3,4,4)$ & Detrend & 1,90 & 0,99 & 2,20 & 0,99 & 2,03 & 2,03 & 0,99 & 12,1 & 14 \\
\hline$(3,4,4)$ & MSC & 0,96 & 1,00 & 1,08 & 1,00 & 0,93 & 0,93 & 1,00 & 26,7 & 14 \\
\hline$(3,4,4)$ & keine & 1,90 & 0,99 & 2,20 & 0,99 & 2,03 & 2,03 & 0,99 & 12,1 & 14 \\
\hline$(3,4,4)$ & SNVD & 0,95 & 1,00 & 1,07 & 1,00 & 0,93 & 0,93 & 1,00 & 26,5 & 14 \\
\hline$(3,4,4)$ & SNV & 0,95 & 1,00 & 1,07 & 1,00 & 0,93 & 0,93 & 1,00 & 26,5 & 14 \\
\hline
\end{tabular}


Fortsetzung Tab. 21

C18:1 $1_{\mathrm{GES}}$, intakte Achänen

\begin{tabular}{|c|c|c|c|c|c|c|c|c|c|c|}
\hline Abl. & SK & SEC & $\mathrm{R}^{2}$ & SECV & 1-VR & SEP & SEPC & $\mathrm{RSQ}$ & RPD & Terme \\
\hline$(0,0,1)$ & Detrend & 4,18 & 0,91 & 4,45 & 0,90 & 4,29 & 4,29 & 0,91 & 3,3 & 16 \\
\hline$(0,0,1)$ & MSC & 4,50 & 0,90 & 4,81 & 0,88 & 4,36 & 4,35 & 0,90 & 3,2 & 16 \\
\hline$(0,0,1)$ & keine & 4,54 & 0,90 & 4,59 & 0,89 & 4,64 & 4,65 & 0,89 & 3,0 & 16 \\
\hline$(0,0,1)$ & SNVD & 4,54 & 0,90 & 4,48 & 0,90 & 4,60 & 4,59 & 0,89 & 3,1 & 16 \\
\hline$(0,0,1)$ & SNV & 5,04 & 0,87 & 5,16 & 0,87 & 5,16 & 5,17 & 0,86 & 2,7 & 16 \\
\hline$(1,2,2)$ & Detrend & 2,93 & 0,96 & 3,19 & 0,95 & 3,12 & 3,13 & 0,95 & 4,5 & 16 \\
\hline$(1,2,2)$ & MSC & 3,36 & 0,94 & 3,53 & 0,94 & 3,54 & 3,55 & 0,94 & 4,0 & 15 \\
\hline$(1,2,2)$ & keine & 3,11 & 0,95 & 3,25 & 0,95 & 3,14 & 3,15 & 0,95 & 4,5 & 15 \\
\hline$(1,2,2)$ & SNVD & 3,02 & 0,95 & 3,28 & 0,95 & 3,22 & 3,23 & 0,95 & 4,4 & 16 \\
\hline$(1,2,2)$ & SNV & 3,28 & 0,95 & 3,52 & 0,94 & 3,43 & 3,45 & 0,94 & 4,1 & 15 \\
\hline$(1,4,4)$ & Detrend & 2,95 & 0,96 & 3,18 & 0,95 & 3,11 & 3,12 & 0,95 & 4,5 & 16 \\
\hline$(1,4,4)$ & MSC & 3,40 & 0,94 & 3,54 & 0,94 & 3,56 & 3,57 & 0,94 & 3,9 & 15 \\
\hline$(1,4,4)$ & keine & 2,92 & 0,96 & 3,19 & 0,95 & 2,95 & 2,96 & 0,96 & 4,8 & 16 \\
\hline$(1,4,4)$ & SNVD & 3,07 & 0,95 & 3,29 & 0,95 & 3,20 & 3,21 & 0,95 & 4,4 & 16 \\
\hline$(1,4,4)$ & SNV & 3,32 & 0,94 & 3,50 & 0,94 & 3,41 & 3,42 & 0,94 & 4,1 & 15 \\
\hline$(1,10,5)$ & Detrend & 3,36 & 0,94 & 3,55 & 0,94 & 3,47 & 3,49 & 0,94 & 4,0 & 15 \\
\hline$(1,10,5)$ & MSC & 3,70 & 0,93 & 3,88 & 0,92 & 3,84 & 3,85 & 0,93 & 3,6 & 15 \\
\hline$(1,10,5)$ & keine & 3,36 & 0,94 & 3,55 & 0,94 & 3,42 & 3,43 & 0,94 & 4,1 & 15 \\
\hline$(1,10,5)$ & SNVD & 3,53 & 0,94 & 3,75 & 0,93 & 3,75 & 3,76 & 0,93 & 3,7 & 15 \\
\hline$(1,10,5)$ & SNV & 3,69 & 0,93 & 3,86 & 0,92 & 3,78 & 3,79 & 0,93 & 3,7 & 15 \\
\hline$(2,4,4)$ & Detren & 2,50 & 0,97 & 2,79 & 0,96 & 2,78 & 2,79 & 0,96 & 5,0 & 14 \\
\hline$(2,4,4)$ & MSC & 2,64 & 0,96 & 2,92 & 0,96 & 2,96 & 2,96 & 0,96 & 4,7 & 14 \\
\hline$(2,4,4)$ & keine & 2,49 & 0,97 & 2,78 & 0,96 & 2,77 & 2,78 & 0,96 & 5,1 & 14 \\
\hline$(2,4,4)$ & SNVD & 2,59 & 0,97 & 2,86 & 0,96 & 2,90 & 2,91 & 0,96 & 4,8 & 14 \\
\hline$(2,4,4)$ & SNV & 2,59 & 0,97 & 2,87 & 0,96 & 2,90 & 2,90 & 0,96 & 4,8 & 14 \\
\hline$(2,10,5)$ & Detrer & 3,02 & 0,95 & 3,26 & 0,95 & 3,27 & 3,28 & 0,95 & 4,3 & 14 \\
\hline$(2,10,5)$ & MSC & 3,19 & 0,95 & 3,48 & 0,94 & 3,63 & 3,64 & 0,93 & 3,9 & 15 \\
\hline$(2,10,5)$ & keine & 3,02 & 0,95 & 3,26 & 0,95 & 3,30 & 3,31 & 0,95 & 4,3 & 14 \\
\hline$(2,10,5)$ & SNVD & 3,13 & 0,95 & 3,48 & 0,94 & 3,50 & 3,51 & 0,94 & 4,0 & 15 \\
\hline$(2,10,5)$ & SNV & 3,14 & 0,95 & 3,49 & 0,94 & 3,55 & 3,55 & 0,94 & 4,0 & 15 \\
\hline$(2,20,10)$ & Detrer & 3,83 & 0,93 & 3,99 & 0,92 & 4,18 & 4,18 & 0,91 & 3,4 & 15 \\
\hline$(2,20,10)$ & MSC & 4,04 & 0,92 & 4,17 & 0,91 & 4,30 & 4,30 & 0,91 & 3,3 & 15 \\
\hline$(2,20,10)$ & keine & 3,83 & 0,93 & 4,01 & 0,92 & 4,23 & 4,23 & 0,91 & 3,3 & 14 \\
\hline$(2,20,10)$ & SNVD & 4,00 & 0,92 & 4,17 & 0,91 & 4,22 & 4,21 & 0,91 & 3,3 & 14 \\
\hline$(2,20,10)$ & SNV & 4,01 & 0,92 & 4,17 & 0,91 & 4,24 & 4,24 & 0,91 & 3,3 & 14 \\
\hline$(3,4,4)$ & Detrend & 2,66 & 0,96 & 3,06 & 0,95 & 2,84 & 2,85 & 0,96 & 4,9 & 13 \\
\hline$(3,4,4)$ & MSC & 2,70 & 0,96 & 3,06 & 0,95 & 3,06 & 3,07 & 0,95 & 4,6 & 14 \\
\hline$(3,4,4)$ & keine & 2,66 & 0,96 & 3,06 & 0,95 & 2,84 & 2,85 & 0,96 & 4,9 & 13 \\
\hline$(3,4,4)$ & SNVD & 2,67 & 0,96 & 3,05 & 0,95 & 2,96 & 2,97 & 0,96 & 4,7 & 14 \\
\hline$(3,4,4)$ & SNV & 2,67 & 0,96 & 3,05 & 0,95 & 2,96 & 2,97 & 0,96 & 4,7 & 14 \\
\hline
\end{tabular}


Tab. 20: Ergebnisse der Rangvarianzanalyse nach Friedman und multiple Vergleiche nach Wilcoxon und Wilcox zum Einfluss verschiedener Datenvorbehandlungen

Feuchte, gemahlene Achänen

Ableitungen

Friedman-Test: $\quad \mathrm{Chi}^{2}=32,8 \quad \mathrm{P}=0,000$

\begin{tabular}{l|lllllll} 
Wilcoxon-Wilcox & $(2,4,4)$ & $(2,10,5)$ & $(1,10,5)$ & $(2,20,10)$ & $(1,2,2)$ & $(3,4,4)$ & $(0,0,1)$
\end{tabular}

\begin{tabular}{ll|lllllll} 
& & $R 2=36$ & $R 3=32$ & $R 4=23,5$ & $R 5=18,5$ & $R 6=18$ & $R 7=10$ & $R 8=5$ \\
\hline$(1,4,4)$ & $R 1=37$ & n.s. & n.s. & n.s. & n.s. & n.s. & $*$ & $*$ \\
$(2,4,4)$ & R2=36 & & n.s. & n.s. & n.s. & n.s. & $*$ & $* *$
\end{tabular}

$(2,10,5) \quad R 3=32$

n.s.

n.s. n.s.

n.s.

$(1,10,5) \quad R 4=23,5$

n.s. n.s. n.s. n.s.

$(2,20,10) \quad R 5=18,5$

n.s. n.s. n.s.

$(1,2,2) \quad \mathrm{R} 6=18$

n.s. n.s.

$(3,4,4) \quad R 7=10$

n.s.

Streulichtkorrekturen

Friedman-Test: $\quad \mathrm{Chi}^{2}=\quad 9,8 \quad \mathrm{P}=0,045$

Wilcoxon-Wilcox $\quad$ SNVD MSC Detrend keine

\begin{tabular}{ll|llll} 
& & $R 2=30$ & $R 3=24,5$ & $R 4=21,5$ & $R 5=13,5$ \\
\hline SNV & $R 1=30,5$ & n.s. & n.s. & n.s. & n.s.
\end{tabular}

SNVD R2 $=30 \quad$ n.s. n.s. n.s.

MSC R3=24,5 n.s. n.s.

Detrend R4=21,5 n.s.

Feuchte, intakte Achänen

Ableitungen

Friedman-Test: $\quad \mathrm{Chi}^{2}=27,4 \quad \mathrm{P}=0,000$

Wilcoxon-Wilcox $\quad \begin{array}{lllllll}(1,4,4) & (3,4,4) & (1,10,5) & (2,4,4) & (2,10,5) & (2,20,10) & (0,0,1)\end{array}$

\begin{tabular}{ll|lllllll} 
& & $R 2=32$ & $R 3=29,5$ & $R 4=26$ & $R 5=19$ & $R 6=19$ & $R 7=8,5$ & $R 8=8$ \\
\hline$(1,2,2)$ & $R 1=38$ & n.s. & n.s. & n.s. & n.s. & n.s. & $* *$ & $* *$ \\
$(1,4,4)$ & R2=32 & & n.s. & n.s. & n.s. & n.s. & $*$ & $*$
\end{tabular}

$(3,4,4) \quad R 3=29,5$

n.s.

n.s.

n.s. n.s. n.s. n.s.

$(1,10,5) \quad R 4=26$

n.s.

n.s. n.s. n.s.

$(2,4,4) \quad R 5=19$

n.s.

n.s. n.s.

$(2,10,5) \quad R 6=19$

n.s. n.s.

$(2,20,10) \quad R 7=8,5$

n.s.

Streulichtkorrekturen

\begin{tabular}{|c|c|c|c|c|c|}
\hline \multirow{2}{*}{\multicolumn{2}{|c|}{$\begin{array}{l}\text { Friedman-Test: } \\
\text { Wilcoxon-Wilcox }\end{array}$}} & \multirow{2}{*}{$\begin{array}{l}\quad \mathrm{Chi}^{2}= \\
\text { keine } \\
\text { R2=31 }\end{array}$} & 21,4 & $P=$ & \multirow{2}{*}{$\begin{array}{l}\quad 0,000 \\
\text { MSC } \\
\text { R5 }=12,5\end{array}$} \\
\hline & & & SNVD & SNV & \\
\hline Detrend & $R 1=37,5$ & n.s. & n.s. & n.s. & ** \\
\hline keine & $\mathrm{R} 2=31$ & & n.s. & n.s. & 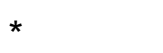 \\
\hline SNVD & $\mathrm{R} 3=23$ & & & n.s. & n.s. \\
\hline SNV & $R 4=16$ & & & & n.s. \\
\hline
\end{tabular}


Fortsetzung Tab. 20

FFA, gemahlene Achänen

Ableitungen

Friedman-Test:

$\mathrm{Chi}^{2}=\quad 33,8 \quad \mathrm{P}=0,000$

Wilcoxon-Wilcox $(3,4,4) \quad(1,4,4) \quad(1,2,2)$ $(1,10,5) \quad(2,20,10) \quad(0,0,1)$

\begin{tabular}{lllllllll} 
& & $R 2=37$ & $R 3=28$ & $R 4=27$ & $R 5=18$ & $R 6=17$ & $R 7=10$ & $R 8=5$ \\
\hline$(2,10,5)$ & $R 1=38$ & n.s. & n.s. & n.s. & n.s. & n.s. & $* *$ & $* *$ \\
$(2,4,4)$ & R2=37 & & n.s. & n.s. & n.s. & n.s. & $*$ & $* *$
\end{tabular}

$(3,4,4) \quad R 3=28$

n.s.

n.s.

n.s.

n.s.

n.s.

$(1,4,4) \quad \mathrm{R} 4=27$

n.s.

n.s.

n.s.

n.s.

$(1,2,2) \quad \mathrm{R} 5=18$

n.s.

n.s.

n.s.

$(1,10,5) \quad R 6=17$

n.s. n.s.

$(2,20,10) \quad R 7=10$

n.s.

Streulichtkorrekturen

\begin{tabular}{|c|c|c|c|c|c|}
\hline \multirow{2}{*}{\multicolumn{2}{|c|}{$\begin{array}{l}\text { Friedman-Test: } \\
\text { Wilcoxon-Wilcox }\end{array}$}} & \multirow{2}{*}{$\begin{array}{l}\quad \mathrm{Chi}^{2}= \\
\text { SNVD } \\
\text { R2=25,5 }\end{array}$} & 2,3 & $P=$ & \multirow{2}{*}{$\begin{array}{r}0,681 \\
\text { Detrend } \\
\mathrm{R} 5=18,5\end{array}$} \\
\hline & & & keine & MSC & \\
\hline SNV & $R 1=27,5$ & n.s. & n.s. & n.s. & n.s. \\
\hline SNVD & $R 2=25,5$ & & n.s. & n.s. & n.s. \\
\hline keine & $R 3=25$ & & & n.s. & n.s. \\
\hline MSC & $R 4=23,5$ & & & & n.s. \\
\hline
\end{tabular}

FFA, intakte Achänen

Ableitungen

\begin{tabular}{|c|c|c|c|c|c|c|c|c|}
\hline \multicolumn{2}{|c|}{$\begin{array}{l}\text { Friedman-Test: } \\
\text { Wilcoxon-Wilcox }\end{array}$} & $\begin{array}{l}\text { Chi }^{2}= \\
(1,4,4) \\
\text { R2 }=31,5\end{array}$ & $\begin{array}{r}25,6 \\
(1,10,5) \\
\text { R3=31,5 }\end{array}$ & $\begin{array}{r}P= \\
(1,2,2) \\
R 4=31\end{array}$ & $\begin{array}{r}0,001 \\
(2,10,5) \\
R 5=16,5\end{array}$ & $\begin{array}{l}(2,4,4) \\
R 6=14,5\end{array}$ & $\begin{array}{l}(3,4,4) \\
R 7=13\end{array}$ & $\begin{array}{l}(0,0,1) \\
R 8=8\end{array}$ \\
\hline$(2,20,10)$ & R1=34 & n.s. & n.s. & n.s. & n.s. & n.s. & n.s. & * \\
\hline$(1,4,4)$ & $\mathrm{R} 2=31,5$ & & n.s. & n.s. & n.s. & n.s. & n.s. & * \\
\hline$(1,10,5)$ & $\mathrm{R} 3=31,5$ & & & n.s. & n.s. & n.s. & n.s. & * \\
\hline$(1,2,2)$ & $\mathrm{R} 4=31$ & & & & n.s. & n.s. & n.s. & n.s. \\
\hline$(2,10,5)$ & $R 5=16,5$ & & & & & n.s. & n.s. & n.s. \\
\hline$(2,4,4)$ & $R 6=14,5$ & & & & & & n.s. & n.s. \\
\hline$(3,4,4)$ & $R 7=13$ & & & & & & & n.s. \\
\hline
\end{tabular}

Streulichtkorrekturen

\begin{tabular}{|c|c|c|c|c|c|}
\hline \multirow{2}{*}{\multicolumn{2}{|c|}{$\begin{array}{l}\text { Friedman-Test: } \\
\text { Wilcoxon-Wilcox }\end{array}$}} & \multirow{2}{*}{$\begin{array}{l}\mathrm{Chi}^{2}= \\
\mathrm{MSC} \\
\mathrm{R} 2=33\end{array}$} & \multirow{2}{*}{$\begin{array}{l}20,9 \\
\text { SNVD } \\
\text { R3=27 }\end{array}$} & $P=$ & \multirow{2}{*}{$\begin{array}{l}\quad 0,000 \\
\text { Detrend } \\
\mathrm{R} 5=11,5\end{array}$} \\
\hline & & & & keine & \\
\hline SNV & $\mathrm{R} 1=33,5$ & n.s. & n.s. & n.s. & $* *$ \\
\hline MSC & $\mathrm{R} 2=33$ & & n.s. & * & $* *$ \\
\hline SNVD & $\mathrm{R} 3=27$ & & & n.s. & n.s. \\
\hline keine & $\mathrm{R} 4=15$ & & & & n.s. \\
\hline
\end{tabular}


Fortsetzung Tab. 20

Öl, gemahlene Achänen

\begin{tabular}{|c|c|c|c|c|c|c|c|c|}
\hline \multicolumn{2}{|c|}{$\begin{array}{l}\text { Ableitungen } \\
\text { Friedman-Test: } \\
\text { Wilcoxon-Wilcox }\end{array}$} & $\begin{array}{r}\text { Chi }^{2}= \\
(2,20,10)\end{array}$ & $\begin{array}{r}28,9 \\
(1,4,4)\end{array}$ & $\begin{array}{r}\mathrm{P}= \\
(2,10,5)\end{array}$ & $\begin{array}{l}0,000 \\
(1,2,2)\end{array}$ & $(2,4,4)$ & $(0,0,1)$ & $(3,4,4)$ \\
\hline$(1,10,5)$ & & & & & & & & \\
\hline$(2,20,10)$ & $R 2=32$ & & 11.0. & $n c$ & $n c$ & $n c$ & $n c$ & * \\
\hline$(1,4,4)$ & $R 3=31$ & & & n.s. & n.s. & n.s. & n.s. & * \\
\hline$(2,10,5)$ & $R 4=30$ & & & & n.s. & n.s. & n.s. & * \\
\hline$(1,2,2)$ & $R 5=16,5$ & & & & & n.s. & n.s. & n.s. \\
\hline$(2,4,4)$ & $R 6=16$ & & & & & & n.s. & n.s. \\
\hline$(0,0,1)$ & $R 7=13,5$ & & & & & & & n.s. \\
\hline
\end{tabular}

Streulichtkorrekturen

\begin{tabular}{ll|llll}
\multicolumn{2}{l}{ Friedman-Test: } & \multicolumn{2}{c}{$\mathrm{Chi}^{2}=$} & 24,9 & \multicolumn{2}{c}{$\begin{array}{l}0,000 \\
\text { Wilcoxon-Wilcox }\end{array}$} & SNV & SNVD & Detrend & keine \\
& & R2=32 & R3=29 & R4=12 & R5=12 \\
\hline MSC & R1=35 & n.s. & n.s. & n.s. & $* *$ \\
SNV & R2=32 & & n.s. & $*$ & $*$ \\
SNVD & R3=29 & & & n.s. & n.s. \\
Detrend & R4=12 & & & & n.s.
\end{tabular}

Öl, intakte Achänen

Ableitungen

\begin{tabular}{|c|c|c|c|c|c|c|c|c|}
\hline \multicolumn{2}{|c|}{$\begin{array}{l}\text { Friedman-Test: } \\
\text { Wilcoxon-Wilcox }\end{array}$} & $\begin{array}{l}\quad \text { Chi }^{2}= \\
(2,4,4) \\
\text { R2 }=34,5\end{array}$ & $\begin{array}{r}30,7 \\
(1,4,4) \\
\text { R3 }=29,5\end{array}$ & $\begin{array}{l}P= \\
(2,10,5) \\
R 4=25\end{array}$ & $\begin{array}{l}0,000 \\
(1,2,2) \\
R 5=22\end{array}$ & $\begin{array}{l}(1,10,5) \\
R 6=14\end{array}$ & $\begin{array}{l}(2,20,10) \\
R 7=11,5\end{array}$ & $\begin{array}{l}(0,0,1) \\
R 8=5,5\end{array}$ \\
\hline$(3,4,4)$ & $R 1=38$ & n.s. & n.s. & n.s. & n.s. & * & * & ** \\
\hline$(2,4,4)$ & $\mathrm{R} 2=34,5$ & & n.s. & n.s. & n.s. & n.s. & n.s. & $* *$ \\
\hline$(1,4,4)$ & $\mathrm{R} 3=29,5$ & & & n.s. & n.s. & n.s. & n.s. & * \\
\hline$(2,10,5)$ & $R 4=25$ & & & & n.s. & n.s. & n.s. & n.s. \\
\hline$(1,2,2)$ & $\mathrm{R} 5=22$ & & & & & n.s. & n.s. & n.s. \\
\hline$(1,10,5)$ & $R 6=14$ & & & & & & n.s. & n.s. \\
\hline$(2,20,10)$ & $\mathrm{R} 7=11,5$ & & & & & & & n.s. \\
\hline
\end{tabular}

Streulichtkorrekturen

\begin{tabular}{|c|c|c|c|c|c|}
\hline \multirow{2}{*}{\multicolumn{2}{|c|}{$\begin{array}{l}\text { Friedman-Test: } \\
\text { Wilcoxon-Wilcox }\end{array}$}} & \multirow{2}{*}{$\begin{array}{c}\text { Chi }^{2}= \\
\text { Detrend } \\
\text { R2=30,5 }\end{array}$} & 8,4 & & \multirow{3}{*}{$\begin{array}{l}\quad 0,077 \\
\text { keine } \\
\text { R5=18 }\end{array}$} \\
\hline & & & MSC & SN & \\
\hline & & & & & \\
\hline & 1,5 & n.s. & n.s. & n.s. & n.s. \\
\hline etrend & $\mathrm{R} 2=30,5$ & & n.s. & n.s. & n.s. \\
\hline SC & $R 3=21$ & & & n.s. & n.s. \\
\hline SNV & $R 4=19$ & & & & \\
\hline
\end{tabular}


Fortsetzung Tab. 20

Protein, gemahlene Achänen

Ableitungen

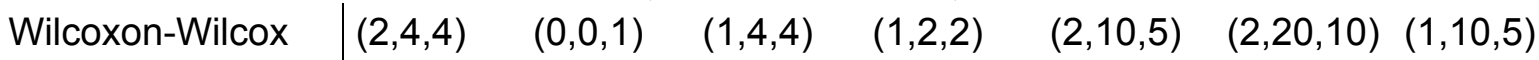

\begin{tabular}{ll|lllllll} 
& & $R 2=36,5$ & $R 3=24$ & $R 4=24$ & $R 5=18,5$ & $R 6=18,5$ & $R 7=12$ & $R 8=8$ \\
\hline$(3,4,4)$ & $R 1=38,5$ & n.s. & n.s. & n.s. & n.s. & n.s. & $*$ & $*$ \\
& & & R2 & & & $*$
\end{tabular}

$(2,4,4) \quad$ R2 $=36,5$ n.s. n.s. n.s. n.s. * *

$(0,0,1) \quad R 3=24$

n.s. n.s. n.s. n.s. n.s.

$(1,4,4) \quad \mathrm{R} 4=24$

n.s. n.s. n.s. n.s.

$(1,2,2) \quad R 5=18,5$

$(2,10,5) \quad R 6=18,5$

n.s. n.s. n.s.

$(2,20,10) \quad R 7=12$

n.s. n.s.

Streulichtkorrekturen

\begin{tabular}{|c|c|c|c|c|c|}
\hline \multirow{2}{*}{\multicolumn{2}{|c|}{$\begin{array}{l}\text { Friedman-Test: } \\
\text { Wilcoxon-Wilcox }\end{array}$}} & \multirow{3}{*}{$\begin{array}{l}\quad \mathrm{Chi}^{2}= \\
\text { SNV } \\
\text { R2=31,5 }\end{array}$} & \multirow{3}{*}{$\begin{array}{l}26,5 \\
\text { MSC } \\
\text { R3=27,5 }\end{array}$} & \multirow{3}{*}{$\begin{array}{r}P= \\
\text { Detrend } \\
R 4=13,5\end{array}$} & \multirow{3}{*}{$\begin{array}{l}\quad 0,000 \\
\text { keine } \\
\text { R4=10,5 }\end{array}$} \\
\hline & & & & & \\
\hline DIV & & & & & \\
\hline SIVVD & $R T=31$ & n.s. & n.s. & n.s. & $\pi x$ \\
\hline SNV & $R 2=31,5$ & & n.s. & & ** \\
\hline MSC & $\mathrm{R} 3=27,5$ & & & n.s. & n.s. \\
\hline Detrend & $R 4=13,5$ & & & & n.s. \\
\hline
\end{tabular}

Protein, intakte Achänen

Ableitungen

\begin{tabular}{l|llllllll} 
Friedman-Test: & \multicolumn{2}{c}{$\mathrm{Chi}^{2}=$} & 34,2 & $\mathrm{P}=$ & 0,000 & \\
\multicolumn{2}{l}{ Wilcoxon-Wilcox } & $(2,10,5)$ & $(3,4,4)$ & $(1,4,4)$ & $(1,2,2)$ & $(1,10,5)$ & $(2,20,10)$ & $(0,0,1)$ \\
& & R2=37,5 & R3=30 & R4=23 & R5=22 & R6=15 & R7=10 & R8=5 \\
\hline$(2,4,4)$ & R1=37,5 & n.s. & n.s. & n.s. & n.s. & n.s. & $* *$ & $* *$ \\
$(2,10,5)$ & R2=37,5 & & n.s. & n.s. & n.s. & n.s. & $* *$ & $* *$ \\
$(3,4,4)$ & R3=30 & & & n.s. & n.s. & n.s. & n.s. & $*$ \\
$(1,4,4)$ & R4=23 & & & & n.s. & n.s. & n.s. & n.s. \\
$(1,2,2)$ & R5=22 & & & & & n.s. & n.s. & n.s. \\
$(1,10,5)$ & R6=15 & & & & & & n.s. & n.s. \\
$(2,20,10)$ & $R 7=10$ & & & & & & & n.s.
\end{tabular}

Streulichtkorrekturen

\begin{tabular}{|c|c|c|c|c|c|}
\hline \multirow{2}{*}{\multicolumn{2}{|c|}{$\begin{array}{l}\text { Friedman-Test: } \\
\text { Wilcoxon-Wilcox }\end{array}$}} & \multirow{3}{*}{$\begin{array}{l}\quad \mathrm{Chi}^{2}= \\
\text { keine } \\
\text { R2=29,5 }\end{array}$} & 6,9 & $P=$ & \multirow{3}{*}{$\begin{array}{l}\quad 0,141 \\
\text { MSC } \\
\text { R5 }=16,5\end{array}$} \\
\hline & & & SNVD & SNV & \\
\hline & & & & & \\
\hline & $\mathrm{R} 1=29,5$ & n.s. & n.s. & n.s. & n.s. \\
\hline in & $R 2=29,5$ & & n.s. & n.s. & n.s. \\
\hline VVD & $R 3=25$ & & & n.s. & n.s. \\
\hline NV & $R 4=19.5$ & & & & n.s. \\
\hline
\end{tabular}


Fortsetzung Tab. 20

C16:0, gemahlene Achänen

Ableitungen

Friedman-Test

$\mathrm{Chi}^{2}=$

$31,7 \quad P=\quad 0,000$

Wilcoxon-Wilcox

$$
\begin{array}{|lllllll}
(2,10,5) & (1,2,2) \quad(1,10,5) & (2,4,4) \quad(2,20,10) & (3,4,4) \quad(0,0,1)
\end{array}
$$

$\begin{array}{lllllll}\mathrm{R} 2=36,5 & \mathrm{R} 3=31 & \mathrm{R} 4=23,5 & \mathrm{R} 5=22,5 & \mathrm{R} 6=13 & \mathrm{R} 7=9,5 & \mathrm{R} 8=7,5 \\ & & * & * & * *\end{array}$

\begin{tabular}{ll|l} 
& $(1,4,4) \quad \mathrm{R} 1=36,5$ & n.s.
\end{tabular}

$(2,10,5) \quad \mathrm{R} 2=36,5$

n.s.

n.s.

n.s.

$(1,2,2) \quad \mathrm{R} 3=31$

n.s.

n.s.

n.s.

n.s.

n.s.

n.s.

$(1,10,5) \quad R 4=23,5$

n.s.

n.s.

n.s.

n.s.

$(2,4,4) \quad \mathrm{R} 5=22,5$

n.s.

n.s.

n.s.

$(2,20,10) \quad R 6=13$

n.s. n.s.

$(3,4,4) \quad R 7=9,5$

n.s.

Streulichtkorrekturen

\begin{tabular}{|c|c|c|c|c|c|}
\hline \multirow{2}{*}{\multicolumn{2}{|c|}{$\begin{array}{l}\text { Friedman-Test: } \\
\text { Wilcoxon-Wilcox }\end{array}$}} & \multirow{2}{*}{$\begin{array}{l}\quad \mathrm{Chi}^{2}= \\
\text { SNV } \\
\text { R2=31,5 }\end{array}$} & 25,2 & $P=$ & \multirow{2}{*}{$\begin{array}{l}0,000 \\
\text { keine } \\
\text { R5 }=11\end{array}$} \\
\hline & & & MSC & Detrend & \\
\hline SNVD & $\mathrm{R} 1=35,5$ & n.s. & n.s. & n.s. & ** \\
\hline SNV & $\mathrm{R} 2=31,5$ & & n.s. & * & * \\
\hline MSC & $R 3=29$ & & & n.s. & * \\
\hline Detrend & $R 4=13$ & & & & n.s. \\
\hline
\end{tabular}

C16:0, intakte Achänen

Ableitungen

\begin{tabular}{|c|c|c|c|c|c|c|c|c|}
\hline \multicolumn{2}{|c|}{$\begin{array}{l}\text { Friedman-Test: } \\
\text { Wilcoxon-Wilcox }\end{array}$} & $\begin{array}{l}\text { Chi }^{2}= \\
(3,4,4) \\
\text { R2 }=33,5\end{array}$ & $\begin{array}{l}30,3 \\
(1,4,4) \\
R 3=26\end{array}$ & $\begin{array}{r}P= \\
(2,10,5) \\
R 4=23,5\end{array}$ & $\begin{array}{l}0,000 \\
(1,2,2) \\
R 5=21\end{array}$ & $\begin{array}{l}(1,10,5) \\
R 6=21\end{array}$ & $\begin{array}{l}(2,20,10) \\
R 7=10\end{array}$ & $\begin{array}{l}(0,0,1) \\
\mathrm{R} 8=5\end{array}$ \\
\hline$(2,4,4)$ & $\mathrm{R} 1=40$ & n.s. & n.s. & n.s. & n.s. & n.s. & ** & ** \\
\hline$(3,4,4)$ & $\mathrm{R} 2=33,5$ & & n.s. & n.s. & n.s. & n.s. & * & $* *$ \\
\hline$(1,4,4)$ & $R 3=26$ & & & n.s. & n.s. & n.s. & n.s. & n.s. \\
\hline$(2,10,5)$ & $\mathrm{R} 4=23,5$ & & & & n.s. & n.s. & n.s. & n.s. \\
\hline$(1,2,2)$ & $\mathrm{R} 5=21$ & & & & & n.s. & n.s. & n.s. \\
\hline$(1,10,5)$ & $R 6=21$ & & & & & & n.s. & n.s. \\
\hline$(2,20,10)$ & $R 7=10$ & & & & & & & n.s. \\
\hline
\end{tabular}

Streulichtkorrekturen

\begin{tabular}{|c|c|c|c|c|c|}
\hline \multirow{2}{*}{\multicolumn{2}{|c|}{$\begin{array}{l}\text { Friedman-Test: } \\
\text { Wilcoxon-Wilcox }\end{array}$}} & \multirow{2}{*}{$\begin{array}{l}\quad \mathrm{Chi}^{2}= \\
\text { keine } \\
\mathrm{R} 2=29\end{array}$} & \multirow{2}{*}{$\begin{array}{l}9,4 \\
\text { SNVD } \\
\text { R3=28,5 }\end{array}$} & $P=$ & \multirow{2}{*}{$\begin{array}{l}\quad 0,051 \\
M S C \\
R 5=16\end{array}$} \\
\hline & & & & SI & \\
\hline & $\mathrm{R} 1=$ & $\mathrm{ns}$ & $\mathrm{ns}$ & $n c$ & $n c$ \\
\hline ene & $\mathrm{R} 2=29$ & & n.s. & n.s. & n.s. \\
\hline 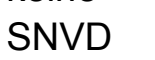 & $R 3=28,5$ & & & n.s. & n.s. \\
\hline NV & $\mathrm{R} 4=17$ & & & & \\
\hline
\end{tabular}


Fortsetzung Tab. 20

C18:0, gemahlene Achänen

Ableitungen

Wilcoxon-Wilcox

$\mathrm{Chi}^{2}=\quad 34,7 \quad \mathrm{P}=\quad 0,000$

\begin{tabular}{ll|lllllll} 
Wilcoxon-Wilcox & $(1,4,4)$ & $(2,10,5)$ & $(3,4,4)$ & $(1,2,2)$ & $(1,10,5)$ & $(2,20,10)$ & $(0,0,1)$ \\
& & R2=35 & R3=30 & R4=25 & R5=19 & R6=16 & R7=10 & R8=5 \\
\hline$(2,4,4)$ & R1=40 & n.s. & n.s. & n.s. & n.s. & $*$ & $* *$ & $* *$ \\
$(1,4,4)$ & R2=35 & & n.s. & n.s. & n.s. & n.s. & $*$ & $*$ \\
$(2,10,5)$ & R3=30 & & & n.s. & n.s. & n.s. & n.s. & $*$
\end{tabular}

$(3,4,4) \quad \mathrm{R} 4=25$

n.s.

n.s. n.s. n.s.

$(1,2,2) \quad \mathrm{R} 5=19$

n.s. n.s. n.s.

$(1,10,5) \quad R 6=16$

n.s. n.s.

$(2,20,10) \quad R 7=10$

n.s.

Streulichtkorrekturen

\begin{tabular}{|c|c|c|c|c|c|}
\hline \multirow{2}{*}{\multicolumn{2}{|c|}{$\begin{array}{l}\text { Friedman-Test: } \\
\text { Wilcoxon-Wilcox }\end{array}$}} & \multirow{2}{*}{$\begin{array}{l}\quad \text { Chi }^{2}= \\
\text { SNVD } \\
\text { R2=31 }\end{array}$} & \multirow{2}{*}{$\begin{array}{l}\quad 14,1 \\
\text { SNV } \\
\text { R3=26 }\end{array}$} & \multirow{2}{*}{$\begin{array}{r}P= \\
\text { Detrend } \\
\mathrm{R} 4=16,5\end{array}$} & \multirow{2}{*}{$\begin{array}{l}\quad 0,007 \\
\text { keine } \\
\mathrm{R} 5=14\end{array}$} \\
\hline & & & & & \\
\hline ISC & $\mathrm{R} 1=32,5$ & n.s. & & & * \\
\hline 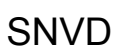 & $\mathrm{R} 2=31$ & & n.s. & & n.s. \\
\hline IV & $R 3=26$ & & & n.s. & n.s. \\
\hline etre & $R 4=16.5$ & & & & \\
\hline
\end{tabular}

C18:0, intakte Achänen

Ableitungen

Friedman-Test: $\quad \mathrm{Chi}^{2}=\quad 30,4 \quad \mathrm{P}=0,000$

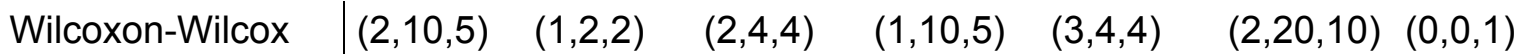

\begin{tabular}{ll|lllllll} 
& & $R 2=35$ & $R 3=30,5$ & $R 4=24,5$ & $R 5=19$ & $R 6=19$ & $R 7=8,5$ & $R 8=6,5$ \\
\hline$(1,4,4)$ & $R 1=37$ & n.s. & n.s. & n.s. & n.s. & n.s. & $*$ & ${ }^{* *}$ \\
$(2,10,5)$ & R2=35 & & n.s. & n.s. & n.s. & n.s. & $*$ & $* *$ \\
$(1,2,2)$ & R3=30,5 & & & n.s. & n.s. & n.s. & n.s. & $*$ \\
$(2,4,4)$ & R4=24,5 & & & & n.s. & n.s. & n.s. & n.s.
\end{tabular}

$(1,10,5) \quad R 5=19$

n.s. n.s. n.s.

$(3,4,4) \quad \mathrm{R} 6=19$

n.s. n.s.

$(2,20,10) \quad R 7=8,5$

n.s.

Streulichtkorrekturen

\begin{tabular}{|c|c|c|c|c|c|}
\hline \multirow{2}{*}{\multicolumn{2}{|c|}{$\begin{array}{l}\text { Friedman-Test: } \\
\text { Wilcoxon-Wilcox }\end{array}$}} & $\mathrm{Chi}^{2}=$ & 2,2 & $P=$ & \multirow{2}{*}{$\begin{array}{l}\quad 0,704 \\
\text { Detrend } \\
\mathrm{R} 5=20\end{array}$} \\
\hline & & SNV & SNVD & keine & \\
\hline $\mathrm{SC}$ & $\mathrm{R} 1=27,5$ & n.s. & n.s. & n.s. & n.s. \\
\hline VV & $\mathrm{R} 2=27$ & & n.s. & n.s. & n.s. \\
\hline VVD & $\mathrm{R} 3=24$ & & & n.s. & n.s. \\
\hline & $R 4=21$, & & & & \\
\hline
\end{tabular}


Fortsetzung Tab. 20

C18:1, gemahlene Achänen

Ableitungen

Friedman-Test:

Wilcoxon-Wilcox

$$
\mathrm{Chi}^{2}=\quad 34,5 \quad \mathrm{P}=0,000
$$

\begin{tabular}{ll|lllllll}
\multicolumn{2}{l}{ Wilcoxon-Wilcox } & $(1,4,4)$ & $(3,4,4)$ & $(1,2,2)$ & $(2,10,5)$ & $(1,10,5)$ & $(2,20,10)$ & $(0,0,1)$ \\
& & R2=36 & R3=30 & R4=24 & R5=21 & R6=15 & R7=10 & R8=5 \\
\hline$(2,4,4)$ & R1=39 & n.s. & n.s. & n.s. & n.s. & $*$ & $* *$ & $* *$ \\
$(1,4,4)$ & R2=36 & & n.s. & n.s. & n.s. & n.s. & $*$ & $*$ \\
$(3,4,4)$ & R3=30 & & & n.s. & n.s. & n.s. & n.s. & $*$
\end{tabular}

$(1,2,2) \quad R 4=24$

n.s.

n.s. n.s. n.s.

$(2,10,5) \quad R 5=21$

n.s. n.s. n.s.

$(1,10,5) \quad R 6=15$

n.s. n.s.

$(2,20,10) \quad R 7=10$

n.s.

Streulichtkorrekturen

\begin{tabular}{|c|c|c|c|c|c|}
\hline \multirow{2}{*}{\multicolumn{2}{|c|}{$\begin{array}{l}\text { Friedman-Test: } \\
\text { Wilcoxon-Wilcox }\end{array}$}} & \multirow{2}{*}{$\begin{array}{l}\quad \mathrm{Chi}^{2}= \\
\mathrm{MSC} \\
\mathrm{R} 2=30\end{array}$} & 14,3 & $\mathrm{P}=$ & \multirow{2}{*}{$\begin{array}{l}\quad 0,006 \\
\text { keine } \\
\mathrm{R} 5=14\end{array}$} \\
\hline & & & SNV & Detrend & \\
\hline SNVD & $\mathrm{R} 1=30,5$ & n.s. & n.s. & n.s. & n.s. \\
\hline MSC & $\mathrm{R} 2=30$ & & n.s. & n.s. & n.s. \\
\hline SNV & $R 3=30$ & & & n.s. & n.s. \\
\hline Detrend & $R 4=15,5$ & & & & n.s. \\
\hline
\end{tabular}

C18:1, intakte Achänen

Ableitungen

\begin{tabular}{|c|c|c|c|c|c|c|c|c|}
\hline \multicolumn{2}{|c|}{$\begin{array}{l}\text { Friedman-Test: } \\
\text { Wilcoxon-Wilcox }\end{array}$} & $\begin{array}{c}\text { Chi }^{2}= \\
(1,10,5) \\
\text { R2 }=36,5\end{array}$ & $\begin{array}{r}31,4 \\
(2,10,5) \\
\text { R3=31,5 }\end{array}$ & $\begin{array}{r}P \\
(1,2,2) \\
R 4=23\end{array}$ & $\begin{array}{l}0,000 \\
(2,4,4) \\
R 5=18\end{array}$ & $\begin{array}{l}(3,4,4) \\
R 6=15\end{array}$ & $\begin{array}{l}(2,20,10) \\
R 7=14\end{array}$ & $\begin{array}{l}(0,0,1) \\
R 8=5\end{array}$ \\
\hline$(1,4,4)$ & $\mathrm{R} 1=37$ & n.s. & n.s. & n.s. & n.s. & n.s. & n.s. & $* *$ \\
\hline$(1,10,5)$ & $\mathrm{R} 2=36,5$ & & n.s. & n.s. & n.s. & n.s. & n.s. & $* *$ \\
\hline$(2,10,5)$ & $\mathrm{R} 3=31,5$ & & & n.s. & n.s. & n.s. & n.s. & * \\
\hline$(1,2,2)$ & $R 4=23$ & & & & n.s. & n.s. & n.s. & n.s. \\
\hline$(2,4,4)$ & $R 5=18$ & & & & & n.s. & n.s. & n.s. \\
\hline$(3,4,4)$ & $R 6=15$ & & & & & & n.s. & n.s. \\
\hline$(2,20,10)$ & $R 7=14$ & & & & & & & n.s. \\
\hline
\end{tabular}

Streulichtkorrekturen

\begin{tabular}{|c|c|c|c|c|c|}
\hline \multirow{2}{*}{\multicolumn{2}{|c|}{$\begin{array}{l}\text { Friedman-Test: } \\
\text { Wilcoxon-Wilcox }\end{array}$}} & $\mathrm{Chi}^{2}=$ & 19,5 & $P=$ & \multirow{2}{*}{$\begin{array}{l}\quad 0,001 \\
\text { keine } \\
\text { R5=10,5 }\end{array}$} \\
\hline & & MSC & SNVD & Detrend & \\
\hline $\mathrm{JV}$ & R1: & $\mathrm{ns}$ & $n s$ & ns & $* *$ \\
\hline 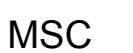 & $\mathrm{R} 2=31$ & & n.s. & n.s. & * \\
\hline VVD & $\mathrm{R} 3=29,5$ & & & n.s. & * \\
\hline tre & $R 4=16$ & & & & \\
\hline
\end{tabular}


Fortsetzung Tab. 20

C18:2, gemahlene Achänen

Ableitungen

Friedman-Test

$\mathrm{Chi}^{2}=\quad 31,6 \quad \mathrm{P}=0,000$

Wilcoxon-Wilcox

$(1,4,4)$

$(3,4,4) \quad(2,10,5) \quad(1,2,2)$

$(1,10,5)$

$(2,20,10) \quad(0,0,1)$

\begin{tabular}{ll|l} 
& R2 \\
\hline$(2,4,4)$ & R1=39 & n.s.
\end{tabular} $\mathrm{R} 2=33$

$(1,4,4) \quad \mathrm{R} 2=33$

n.s.

$\mathrm{R} 4=26$

n.s.

* $6=15$

$\mathrm{R} 7=9$

$\mathrm{R} 8=6$

$(3,4,4) \quad \mathrm{R} 3=29$

n.s.

n.s.

n.s.

n.s.

n.s.

n.s.

n.s.

*

$(2,10,5) \quad \mathrm{R} 4=26$

n.s.

n.s.

n.s.

n.s.

$(1,2,2) \quad R 5=23$

n.s.

n.s.

$(1,10,5) \quad R 6=15$

n.s.

n.s.

$(2,20,10) \quad R 7=9$

n.s.

Streulichtkorrekturen

\begin{tabular}{|c|c|c|c|c|c|}
\hline \multirow{2}{*}{\multicolumn{2}{|c|}{$\begin{array}{l}\text { Friedman-Test: } \\
\text { Wilcoxon-Wilcox }\end{array}$}} & \multirow{3}{*}{$\begin{array}{l}\text { Chi }^{2}= \\
\text { SNVD } \\
\text { R2=30 }\end{array}$} & \multirow{2}{*}{$\begin{array}{l}14,4 \\
\text { MSC } \\
\text { R3=28,5 }\end{array}$} & \multirow{2}{*}{$\begin{array}{r}P= \\
\text { Detrend } \\
\mathrm{R} 4=17,5\end{array}$} & \multirow{2}{*}{$\begin{array}{l}\quad 0,006 \\
\text { keine } \\
\mathrm{R} 5=12,5\end{array}$} \\
\hline & & & & & \\
\hline SNV & $R 1=31,5$ & & n.s. & n.s. & * \\
\hline SNVD & $\mathrm{R} 2=30$ & & n.s. & n.s. & * \\
\hline MSC & $\mathrm{R} 3=28,5$ & & & n.s. & n.s. \\
\hline Detrend & $\mathrm{R} 4=17,5$ & & & & n.s. \\
\hline
\end{tabular}

C18:2, intakte Achänen

Ableitungen

\begin{tabular}{|c|c|c|c|c|c|c|c|c|}
\hline \multicolumn{2}{|c|}{$\begin{array}{l}\text { Friedman-Test: } \\
\text { Wilcoxon-Wilcox }\end{array}$} & $\begin{array}{c}\text { Chi' }^{2}= \\
(1,10,5) \\
\text { R2 }=31,5\end{array}$ & $\begin{array}{l}33,4 \\
(1,2,2) \\
\text { R3 }=30,5\end{array}$ & $\begin{array}{l}P= \\
(2,10,5) \\
R 4=28\end{array}$ & $\begin{array}{r}0,000 \\
(2,20,10) \\
R 5=19,5\end{array}$ & $\begin{array}{l}(2,4,4) \\
R 6=15,5\end{array}$ & $\begin{array}{l}(3,4,4) \\
R 7=10\end{array}$ & $\begin{array}{l}(0,0,1) \\
R 8=5\end{array}$ \\
\hline$(1,4,4)$ & $\mathrm{R} 1=40$ & n.s. & n.s. & n.s. & n.s. & * & ** & ** \\
\hline$(1,10,5)$ & $\mathrm{R} 2=31,5$ & & n.s. & n.s. & n.s. & n.s. & n.s. & * \\
\hline$(1,2,2)$ & $\mathrm{R} 3=30,5$ & & & n.s. & n.s. & n.s. & n.s. & * \\
\hline$(2,10,5)$ & $R 4=28$ & & & & n.s. & n.s. & n.s. & n.s. \\
\hline$(2,20,10)$ & $R 5=19,5$ & & & & & n.s. & n.s. & n.s. \\
\hline$(2,4,4)$ & $R 6=15,5$ & & & & & & n.s. & n.s. \\
\hline$(3,4,4)$ & $R 7=10$ & & & & & & & n.s. \\
\hline
\end{tabular}

Streulichtkorrekturen

\begin{tabular}{|c|c|c|c|c|c|}
\hline \multirow{2}{*}{\multicolumn{2}{|c|}{$\begin{array}{l}\text { Friedman-Test: } \\
\text { Wilcoxon-Wilcox }\end{array}$}} & \multirow{2}{*}{$\begin{array}{l}\quad \mathrm{Chi}^{2}= \\
\text { SNV } \\
\text { R2=30,5 }\end{array}$} & \multirow{2}{*}{$\begin{array}{l}\quad 26,1 \\
\text { SNVD } \\
\text { R3=28,5 }\end{array}$} & \multirow{2}{*}{$\begin{array}{l}P= \\
\text { Detrend } \\
\mathrm{R} 4=13\end{array}$} & \multirow{2}{*}{$\begin{array}{l}\quad 0,000 \\
\text { keine } \\
\text { R5=11 }\end{array}$} \\
\hline & & & & & \\
\hline SC & $\mathrm{R} 1$ & n.s. & n.s. & ns. & $* *$ \\
\hline & $\mathrm{R} 2=30,5$ & & & * & 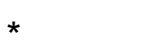 \\
\hline JVD & $\mathrm{R} 3=28,5$ & & & n.s. & * \\
\hline & & & & & \\
\hline
\end{tabular}




\section{Lebenslauf}

Persönliche Daten

Name:

Christian Rainer Moschner

geboren:

09 Juli 1975 in Braunschweig

Familienstand: verheiratet

Email:

info@cmoschner.de

\section{Ausbildung}

1997 - 1999

Chemie- und Pharmazieschule BBS 22, Hannover

Ausbildung zum Chemisch-Technischen Assistenten mit Schwerpunkt Umweltanalytik

\section{Studium}

$1999-2003$

Fachhochschule Hannover, Fachbereich Bioverfahrenstechnik Studiengang: Technologie Nachwachsender Rohstoffe Abschluss: Diplom-Ingenieur (FH)

Aug. - Sep. 2001 Praktikum an der Ege-Universität in Izmir, Türkei Institut für Landtechnik

Okt. - Dez. $2001 \quad$ Praktikum an der Justus-Liebig-Universität Gießen Institut für Pflanzenbau und Pflanzenzüchtung I

Feb. - Aug. 2003 Praktikum an der Bundesforschungsanstalt für Landwirtschaft in Braunschweig zur Anfertigung der Diplomarbeit Institut Pflanzenbau und Grünlandwirtschaft

\section{Berufstätigkeit}

seit 2003

Forschungstätigkeit als Wissenschaftlicher Mitarbeiter an der Fakultät II - Maschinenbau und Bioverfahrenstechnik der Fachhochschule Hannover 


\section{Danksagung}

Mein herzlicher Dank gilt Frau Prof. Dr. Bettina Biskupek-Korell, die diese Arbeit fachlich und mit großem Engagement betreut hat. Ihre stete Diskussionsbereitschaft sowie die Unterstützung bei der Anfertigung der vorliegenden Dissertationsschrift haben mir sehr geholfen.

Herrn Prof. Dr. Heiko C. Becker möchte ich meinen besonderen Dank für Betreuung dieser Arbeit sowie für die Übernahme des Referats aussprechen.

Ebenso danke ich Prof. Dr. Elke Pawelzik für die freundliche Übernahme des Koreferats.

Herrn Dr. Christian Paul sowie Herrn Dr. Gerhard Rühl sei für die stets gute Zusammenarbeit sowie Unterstützung gedankt.

Auch Herrn Prof. Dr. Eberhard Wüst möchte ich für seine vielfältige Hilfe und seinen scharfen "chemometrischen Blick“ herzlich danken.

Herrn Dr. Peter Tillmann danke ich für die zahlreichen Beantwortung meiner Fragen.

Frau Dipl.-Ing. Hélène Gibaud möchte ich herzlich für Ihre große Hilfe während der Erstellung dieser Arbeit danken.

Allen Mitarbeiterinnen und Mitarbeitern der Abteilung Bioverfahrenstechnik der Fakultät II der Fachhochschule Hannover $(\mathrm{FHH})$ sowie des Instituts für Pflanzenbau und Grünlandwirtschaft der Bundesforschungsanstalt für Landwirtschaft (FAL) in Braunschweig danke ich für die Unterstützung sowie für das stets angenehme Arbeitsklima.

Diese Arbeit wurde im Rahmen des Verbundprojektes „Ertrags- und Qualitätssicherung von HO-Sonnenblumen in Deutschland" durch die Fachagentur Nachwachsender Rohstoffe e.V. (FNR) finanziert. 